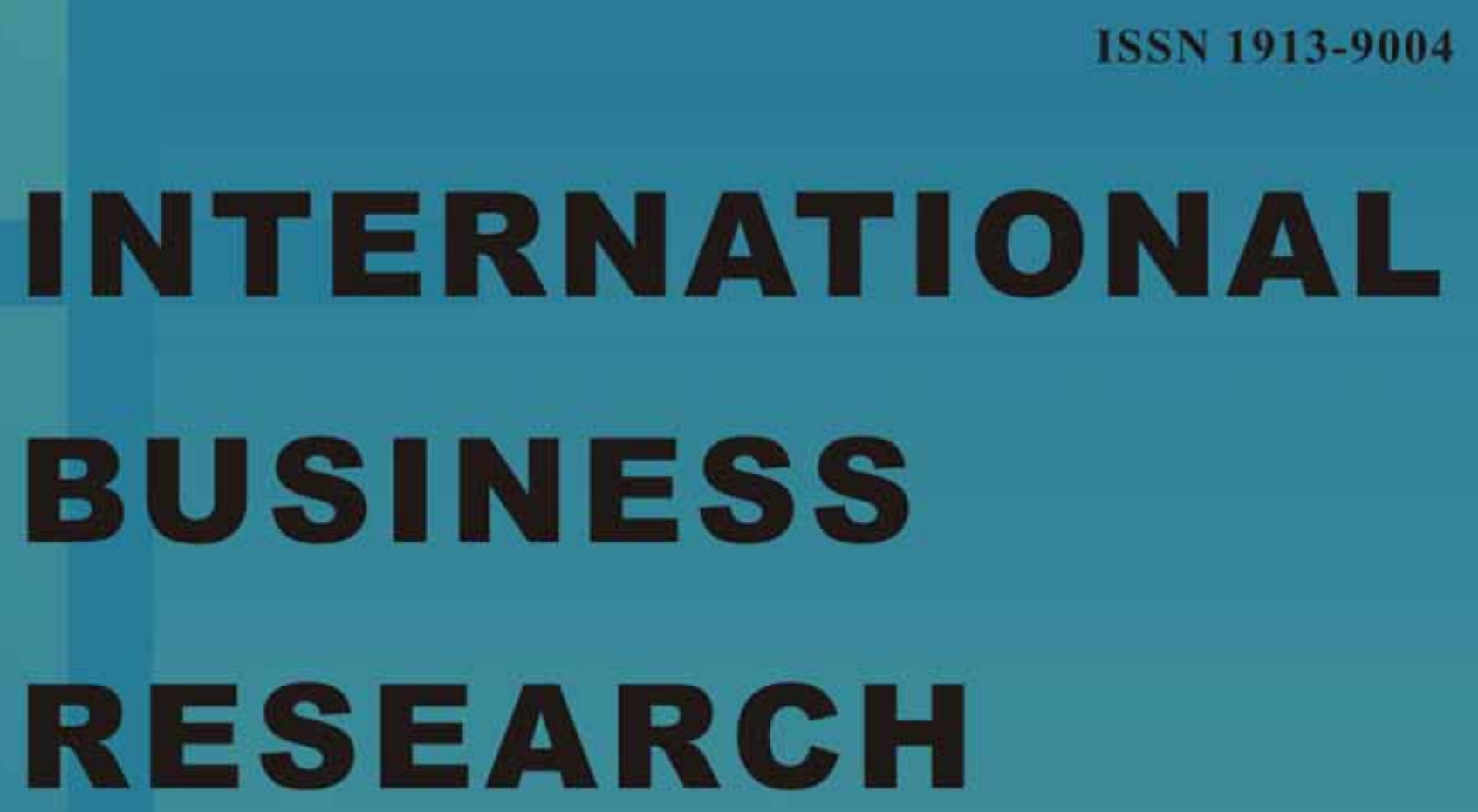

Vol. 1, No. 3

July 2008

CCSE

Canadian Center of Science and Education 


\section{Contents}

How Do the Internal Variables of the Sport Konsumer Affect the Marketing of Sports Events; Case Study

Triathlon in the UK

Ian Arnott

Causes and Sources of Waste in the Printing Industry in Ghana: A Study of Printing Houses in the Cities of

Accra and Kumasi

Ashford C. Chea

The Cultivation of Enterprise Accountants in the Era of Knowledge Economy

Wenjun Chen \& Yehua Yue

A Survey Research of Contemporary Management Development Practices In Malaysian Corporations

Kian Aun Law

The Study of the Use of FDI to Enhance the Product Competitiveness of Integrated Circuits and

Micro-electronic Components

Xiangyang Zhang \& Wei Liu

Airborne Hyperspectral Imagery for Agricultural Businesses in Malaysia

Hj. Kamaruzaman Jusoff \& Hj. Malek Hj. Mohd Yusoff

A Study on the Business Innovation and the Management Mode of Business Cooperation between Banks

and Trust

Xiaoyu $\mathrm{Li}$

Examining the Determinants and Outcomes of Superior Downward Influence Tactics: The Mediating

Impact of Role Ambiguity and Subordinates' Competence Level

Kim Lian Lee \& Abdul Latif Hj. Salleh

The Scheme of Rizhao City Brand

Qingjun $W u$

Foreign Direct Investment and Manufacturing Growth: The Malaysian Experience

$V$ G R Chandran \& Gopi Krishnan

Effect of Technical Barriers to Trade on Chinese Textile Product Trade

Ningchuan Jiang

The Interest Prohibition and Financial Performance of Islamic Banks: Indonesian Evidence

Ari Kuncara Widagdo \& Siti Rochmah Ika

Research on Evolving of Green Products' Attribute for Manufacturing Industry

Xin Wen, Jian Xu \& Qingshan Zhang

Webs of Culture: Applying Intercultural Communication Theory to Understand Distributed

Decision-Making Processes

Norhayati Zakaria \& Derrick Cogburn

A Study on the Development Strategy of China's Clothing Industry at the After-Quota Age

Jing $X u$

Factors that Influence the Survival of Women-Owned Small Business Start-Ups in the City of Tema, Ghana Ashford C. Chea 


\section{Contents}

Research on the Exit Routes of Chinese Private Equity Funds

Jingjing Yang \& Lesha Zhang

The Influences on the Frequency with Which Product Costs Are Used in Decision Making

John A. Brierley

An Analysis on Selection Efficiency of Japanese Internal Supervision System

Benxu Zou \& Guoyin Shang

Service Quality and Student Satisfaction: A Case Study at Private Higher Education Institutions

Hishamuddin Fitri Abu Hasan, Azleen Ilias, Rahida Abd Rahman \& Mohd Zulkeflee Abd Razak

Mature Cluster's Risk Evaluation

176

Fei Gao, Kai Li \& Yaning Li 


\title{
How Do the Internal Variables of the Sport Konsumer Affect the Marketing of ports Events; Case Study Triathlon in the UK
}

\author{
Ian Arnott \\ Teesside Business School, University of Teesside, Middlesbrough, Tees Valley, TS1 3BA, UK \\ Tel: 44-164-234-2809Ｅ-mail: i.arnott@tees.ac.uk
}

\begin{abstract}
Triathlons and their events are in a new era in the consumption of sport. Because of this increased funding more professionals are needed to understand what attracts sports consumers to what is seen as a gruelling but enjoyable multi sports event.

For affective marketing and event management, practioners need to understand more and more what decisions are made when the sports consumer makes a choice for a particular sports event.

This study is focused at the National Governing Body for the sport of Triathlon in the United Kingdom and also the Regional/ local event managers and marketers. Drawing upon marketing and consumer behaviour literature, the primary aim of this research was to investigate from the consumer perspective how their internal variables during the decision making process of consumer behaviour affects the selection of sports event, namely triathlon. To establish this information, data was drawn upon previous participants of a triathlon event, then a further investigation into what decisions were made from triathlon consumer's perspective when selecting an event.
\end{abstract}

A self administered piloted questionnaire was done in January (2005) with twelve active local triathletes. A further 60 were then posted and electronically mailed to previous participants of a Triathlon event 2005 at the end of January (2005). The consumer's abilities ranged from the recreational participant through to the elite athlete and the questionnaire contained eighteen questions incorporating a variety of ordinal and nominal questions as well as likert scale questions. The questionnaires were both returned electronically and by post.

The response rate was fairly high at $92 \%(\mathrm{n}=55)$, respondents represented the sample frame representing a cross section of gender, age and abilities. The quantitative data was analysed via SPSS 13.0 which is a statistical package. This revealed a variety of statistical results of approximately twenty with statistical findings $(\mathrm{P}<0.05)$. ). Event selection was made from athletes' experiences from internal factors of what they held in memory to what they wished to achieve in the sport. Interestingly enough, all the respondents came from one of the three disciplines in the sport.

Keywords: Lifestyle, Performance, Motivation

\section{Introduction to Sports Marketing}

Marketing is an area in which sports practioners are seeking help. A number of sport organisations are struggling to produce a profit (Howard \& Compton, 1995) in a highly competitive marketplace, and many are seeking to improve marketing efforts to strengthen their organisation (Mullin, Hardy, \& Sutton, 1993). Therefore to understand how an individual makes a decision to participate in sport or exercise is critical to sport marketers who want to make customer-oriented marketing plans (Kang 2002). In particular, how applicable are the many theoretical decision making process models to a consumer's choice in the field of sport (McGhee, Yoon \& Cardemas 2003)? Asseal (1992) paralleled this largely theoretical involvement with a consumer's belief systems, decision making process, brand loyalty, and product identification. Specifically, it is argued that a consumer who indicates high levels of involvement is more likely to become more loyal and resist buying another product brand than a consumer with low levels of involvement. By studying groups of consumers who are loyal to a product or activity, marketers may become more informed as to how to market their product. So there is a need for more continued research in this area of marketing. If sport marketing ideally consists of activities designed to meet the wants and needs of the sports consumer, then historically the industry has been guilty of what Levitt (1960) called "marketing myopia" or a lack of foresight in marketing ventures. Although some organisations have shifted their perspectives, marketing myopia is reported still to be a widespread affliction in many industry segments (Mullins, Sutton \& Hardy, 2000).

Given the unique characteristics of marketing myopia, what are the factors that should be considered in making the decisions about packaging, promoting, and delivering sport and sports events? Who will be attracted to a sport or in particular sport events and how will the packaging, promoting and delivering of the events influence the consumer's 
experience and perceptions, now and in the future? How does the sports marketer understand the decision making process of the sports consumer and their choices within the participation in sport and more specifically between sports events?

\subsection{Sports Events}

Although a great deal of attention has been given to events in general, and to some impacts of sports events, little research is being directed in the supply/demand system as a whole and therefore many specific issues are being ignored (Getz, 1998). More importantly sports events with multi disciplines which have a variety of elements such as triathlon.

The sport of triathlon is still in its infancy and is evolving slowly although the demand to host events has risen considerably over the last five years (Lole, 2004). The market place is now very competitive and to survive, a more professional approach is urgently required to understand and meet the needs of the increasing discerning triathlon consumer. Triathlon has grown in number which is demonstrated in table 1, this growth accounts now to approximately three triathlons a week. With the scale of triathlons growing, how will the triathlete make decision to choose one event over another? And is this purely down to sport beginning to play a significant role in today's society?

\subsubsection{Statement of the problem}

Though it transcends that sport plays an increasingly important role in society, there are still many areas of sports management that are under researched (Chelladurai, 1994). As stated by Mahony and Pitts (1998), sport marketing is still a young and developing discipline and it is helpful to determine the direction with in this field. One such area that appears to be vital to the practitioner in a competitive triathlon event market place, and there is also a need for a better understanding of consumer behaviour with in this subject area. Only when the event organiser appreciate the needs and decision making processes of the triathlon consumer can he/she determine a sustainable competitive advantage and improve in his/her marketing communications in the attraction of people to their event.

\subsection{A Further understanding of the term events through literature}

Shone \& Parry (2001) described that special events are the phenomenon arising from those non routine occasions which have sport, leisure, cultural, personal or organisational objectives they are set apart from the normal activity of daily life, whose purpose is to enlighten, celebrate, entertain or challenge the experience of a group of people (Shone \& Parry 2001). Goldblatt (1990) goes onto suggest, "a special event recognises a unique moment in time with ceremony and ritual to satisfy specific needs". Though this definition clearly works for events like weddings, parades, and so on, but it works less well for activities like sport events etc. Getz (1997), refers to experience which participants have, he states:

To the customer a special event is an opportunity for a sport, leisure, social cultural experience outside the normal range of choices or beyond experience.

Despite this definition being cited in many key event management texts (Goldblatt, 1990, Getz, 1997, Shone \& Parry 2001), it appears to have one fundamental weakness, namely that it focuses upon the subjective nature of 'special' but barely defines the nature of 'an event' (Emery, 1997). In addressing this issue, Shone \& Parry (2001) characterise into four categorise shown in figure 1 based on concepts of having leisure, cultural, personal or organisational objectives.

It is crucial to bear in mind when considering this categorisation that there are frequent overlaps, therefore to categories an event even by analysing its objectives. There must be reasons for the organiser's origins, and motives for running the event (Shone \& Parry 2001). In addressing this issue. Welsh-Heron and Stevens (1990) propose that the main distinguishing characteristics is the component of time. Specifically referring to tourism, they suggest that visitor attractions are predominantly permanent features whereas events are of a temporary nature (Emery 1997). Torkildsen (1999) similarly draws the attention to events carrying opportunities to capture the imagination of sellers and buyers. They can be a means of promoting or raising the profile of a sport like triathlon or an event to also encourage participation in a sport like triathlon. However it could be argued, how can we classify a triathlon event? Within consumption is it a whole product or a service?

\subsection{Sports Events as Service}

Sports Events have become a vital component of the marketing mix (Getz, 1998; Gibson, 1998). As a sports event, the main product is therefore service orientated with the distinguishing features of intangibility and tangibility (Palmer 1994). Why sport is considered a service (Shilbury, Quick \& Westerbeck, 1998). A common theme of authors writing on sport marketing (Mullin et al. 1993; Mullin) has been their agreement on how unique characteristics of sports events as a product requiring marketing personnel to adopt different strategies from those traditionally exposed (Shilbury, Quick \& Westerbeck, 1998). Although many of these writings are void of specific references to services marketing discussions pertaining to these unique characteristics align sport events to the attributes of a service. In summary the characteristics distinguishing goods from a service in Table 2. However, as the final sports event (a service), it is a composite of those interrelated tangible elements. He elaborates, by arguing that there are two types of consumers, the immediate (spectators, participants and volunteers) and the secondary consumer (auxiliary users of the sport). A great deal of 
satisfaction is therefore gained directly from the event environment, in a person or via the media, their high levels of satisfaction from the feeling of event ownership (Emery, 1997). Though begins to give use direction on the term event and more importantly establishing the links to being a product or service, it could be argued has does this encapsulate the sport of triathlon? Or more importantly a triathlon event.

\subsection{Triathlon a Sporting Event}

The key case study that this research is centred on is the sport of triathlon with its specific nature being a triathlon event. This is an emerging sport, but what are its origins? In 1971, there was a jogging crazy era in America. To differentiate between running events there was a move to add a different perspective to sport by incorporating a friendly but multi disciplined competition, in California, USA (Shannon 1999). But it was not until a group of physical instructors from the services ran an event for a bet in Hawaii that triathlon really started. The first race comprised of a 2.4 mile swim, a 112 mile bike ride followed by a marathon. All these distances were based on existing events on the island. Thus the first Ironman as it has become known was born (Budgett 2000).

Though a sport like triathlon is fairly technical, especially as it compromises of three different disciplines how can it be organised? In some cases it is a question from an event organiser's point of view to understand what attracts the triathlon consumer to that particular event (Lole, 2003). It is essential that event managers need to understand who the potential customers might be and who the current customers are in the triathlon as all of the consumer are fairly diverse and are all motivated differently (Darlymple \& Parsons, 1990).

The sport of triathlon has now been growing in popularity in many parts of the world. For example, in Australia the number of triathletes registered with the national association (Triathlon Australia) has grown from under 5,000 at the beginning of 1992 to over 8,000 by the middle of 1993 (Martin, Chang, Lester \& Johnson, 1995). Although astonishing growth cannot be expected to continue indefinitely, it is reasonably clear that triathlons (and other similar multisports events) are here to stay. However, even today, relatively little is known about why some people are predisposed to engage in triathlon whereas others are not (Moss, 2004). Several attempts were made to form a world governing body for triathlon (ETU 1999). Finally in 1989 the International Triathlon Union (ITU) was formed, initially with 29 member countries. In that year, the first official world championships were held. In 1991 triathlon was given Olympic recognition, with the event being included in the Olympic programme for the year 2000 (Springman 1998).

So how should marketers segment the triathlon population and identify individuals with high a probability of engaging in the sport? (Shoham, 2000). Lawson (2004) suggests that a sport like triathlon has very few events around and there is need for more people to run these events. Questions could be asked about the sport of triathlon, is it because there is a lack of knowledge in this field? Are there enough athletes participating in the sport? In the United Kingdom the sport has grown over the last four years as shown in Table 3.

Within the scope of this study it must be defined exactly what or who is the triathlon consumer? As the sport of triathlon is purely based on an individual's own performance, what defines a participant?

Mullins, Hardy \& Sutton 2000 attempt to do this in the role of marketing, they give an example of this where 18 million soccer participants in 1996 who played once a year as seen in table 4. This is a fairly typical use of the term participant, but it has obvious limitations. It can be helpful in tackling long term interest, but it has little to do with marketing of events in sport. These statistics provide a very limited snapshot - one year's rate of change. Their real importance lies in their more precise approach to defining participation. Casual or careless use of definitions will severely limit the utility of statistics (Larson, 1995). Therefore it is essential that marketers must consider more than one measure when writing or reading the sport consumer (Thav, 1995). A step forward in the right direction maybe profiling the triathlon consumer by their demographics which then may give some idea of the implications involved both in marketing and delivery of a sports event.

\subsection{Demographic Implication on Sports Events}

As a marketer it is essential to understand the unique and physical components of the types of consumers that are attracted to an event, especially those who consume international events to the characteristic types of those who take part in local events. Demographic information segmentation can be useful as it tends to rely on stereotypical images of groups of people who are linked through gender, age etc. Segmenting based on demographic characteristics would be like trying to plan a party for a variety of consumers (Parks, Quaterman 2002). They then go onto define demographic segmentation:

"Dividing the market into groups based on demographic variables such as age, sex, family size, income, occupation, education, religion and ethnicity".

It attempts to chronicle what consumers are, in terms of observable attributes primarily concerned with nose counts. The importance of demographic studies in the field of sport cannot be over estimated. One critical argument could be is to ask why should we waste such efforts and resources? Most business practitioners feel that effective marketing is a 
prerequisite for achieving event objectives (Fullerton \& Dodge, 1995). Brooks, (1990), feels that demographic studies are crucial to sport marketing in identifying consumers who are most likely to use certain types of products or services. Further more, Mile and Mcdonald (1999) suggest that success in sport marketing requires an understanding on what factors influence sport consumption during this stage.

Marketers are aware that sports' marketing is now becoming a major business and in 1987, sport in the United States' was the 23rd largest industry, totalling $\$ 50.2$ billion a year (Sandomir, 1988). Organisations selling a sport product are, of course, in the business of trying to attract a large audience/consumer base (Horface, College, Burman \& Dewilbe, 1992) subsequently to increase their profit margins and become a major industry as was highlighted by Horface et al, (1992). But what other areas with in sports consumption patterns must be considered? The sports industry, though clearly a large, what are the other key factors about this area of specialism must be understood. Athlete's or participants? What considerations must be taken into account there?

Other factors could be based on a particular event falling into place with the athlete's training program. This is where the preparation for achieving an athlete's lifetime competitive goal of Olympics or World title, etc. commences with the earliest experience of sport and is brought to fruition sometime during the athlete's performance years in his/her chosen sport (Dick 1997). So in the case of the athlete, it is essential that both training and event participation are well organised. This means that their training and peak performances are balanced (Ackland 1999), However this is then influenced by motivational influences and also the individuals personality.

\subsection{Personality Traits in Sport Events}

One key area in sports events that lacks research is the personality characteristics of the people who consume sport. However even today, relatively little is known about why some people are predisposed to engage in sports events where others are not (Shoham, 2000). How should marketers segment the general population of engaging in sport event consumption by their personality? This issue has been relatively understudied for the exceptions on risky sports (Arnould and Price 1993; Celsi, 1992; Celsi, Rose \& Kahle, (1998). Briefly, risky sports differ from many leisure activities which entail low levels, of risk. Schiffman and Kanuk, (2000), categories this, where they discuss about personality reflecting individual differences. Nevertheless, many individuals may be similar in terms of single personality characteristics, but not in terms of others (Shoham, 2000). Consumers tend to buy into events that closely match their own personality or that strengthen an area they feel deficient in (Hawkins, Best and Convey, 1995). In some cases some sports consumers perceive self images or perceptions of self in the sport or event, they are closely linked with (Schiffman and Kanuk, 2000). Personality in the individuals who buy into sports/events whose image corresponds to their own self images in essence; consumers seek to depict themselves physically in their event/sport (Karande, Zinkham \& Baord, 1997). Kang (2002), further goes onto support this in the decision making process for participant consumption, where a certain product/service cues (event/sport type) with images it activates self image and beliefs (Sirgy, 1982). It is important that the sport/event fit the consumer's personality types and vice versa. Shilbury, Quick and Sutton (1998) identified that a basic understanding of personality types ensures that a wide range of consumers as possible are being catered for. However, Brassington and Pettitt (2000) link purchasing and personality patterns from personality to their individual traits as a person, but subsequently at best tenuous, suggesting that this is not a reliable source for marketers to act on. Kassarjian (1971) probably best summed up the situation in a review of a previous study that showed a strong relationship between personality and purchasing, the majority showed at best a weak relationship. Lancaster \& Reynolds (2002) question this is, as they liken it to self-concept and that purchase decisions are likely to reflect their personality, and marketers must consider this when making marketing appealing. Because personality links with motivation in social psychology then a further study is needed into what drives them to make a choices.

\subsubsection{Motivation of the consumer in choice of events}

Motivation is the mixture of wants, needs and is driven within the individual to seek gratification through the acquisition of an object (Rice 1997). Marketers continually ask what ultimately promotes the consumer to purchase their products (Mullins, Hardy \& Sutton 1993). Within sports events the opinions can be varied and inconsistent. Clearly consumer motivations are complex, and marketers must work vigorously to uncover them. It is clear that a greater understanding is required. The former Mets (American Football) marketing president, Michael Aronin, put it, "As an industry, we haven't had a good understanding of what motivates people to make a purchase" (Moore, 1987). According to motivation theory, environmental stimuli may activate the drive to satisfy an underlying need. Theorists like Abraham Maslow, Henry Murray and David McCelland have elaborate models of the way physiological, psychological, and social needs influence behaviour (Korman 1974). Of their categories of motives, several seem to reoccur in sport literature. McCelland argues that many needs are not as universal as Maslow proposes. He believes that some needs are socially acquired and picks out specifically the need for achievement with in the scope of a persons lifestyle (Rice 1997). 


\subsubsection{Lifestyle Impact on Sports Consumption}

William Lazer (1963) who is given credit for introducing the lifestyle concept suggests that lifestyle is defined as a person or a family's distinctive characteristics mode or manner of living. Marketers tend to determine lifestyle by activities, interests and opinions (Plummer 1974). He then attempts to conceptualise and the application of lifestyle segmentation to it being drawn upon their perceptions and opinions. Plummer (1974) being the early exponents of lifestyle segmentation, breaks it down into four categories looking more expansively than his model he goes onto discuss each one individually in its application:

- Activities: Includes all the things people do in the course of their lives. It therefore covers work, shopping, holidays and social life. Within that, the marketer will be interested in people's hobbies and their preferred forms of entertainment, as well as sports interests, club memberships and their activities with the community.

- Interests refer to what is important to the consumer where their priorities lie. It may include the things that are very close to them, such as family, home and work, or their interest in sports participation and choice of events.

- Opinions comes very close to the individual's inner most thoughts by probing attitudes and feelings about such things as themselves, social and cultural issues and politics. Opinion may also be sought about other influences on society, such as education, economics and business. Closer to home for the marketer, this category also investigates products and individual's view of the needs and wants that are likely to Change (Brassington and Pettitt 2000).

It could be argued that Plummer's view on opinions is guided through sport? He goes onto segment their interest on achievement, culture and stage in the life cycle, but not all consumers fit into this category. Lifestyle segmentation is an altogether more difficult area to define, as it involves intangible variables such as beliefs, attitudes and opinions of the potential sports consumer (Brassington and Pettitt 2000). What ever the case may be participation with in sport is ever increasing not just in triathlon but also other sports as well to suit people's lifestyles.

This can be a great leveller, as performance is related to ability rather than a participant's financial means of social standing (Barnard 1998). Marketers however created another status hierarchy through the increasing emphasis on the labels and brand of sports clothing and equipment. Whether the sport is golf, cycling, sailing or tennis and that image statements are seen as a functional benefit. This phenomenon is not only in clothing and equipment. Elids Faberge launched a new range of body care products, Physio Sport, which aimed to attract worldwide sales of $£ 300$ million within two years. The target is 'serious' sports people of either sex or the range covers personal freshness, washing, hair washing and chafed skin. This was launched at the London Triathlon of that same year and therefore there was a brand association to a particular sport.

Within certain sports such as triathlon to have the correct sports equipment is essential, so does this mean that the sport is only accessible to people who can afford it? Is it affluent households who constitute an especially attractive target segment because its consumer who has incomes that provides them with a disproportionately larger share of all discretionary income (Schiffman \& Kanuk, 2000)? The extras allow them to consume other areas of triathlon.

For almost 25 years Mendelshonn Media Research has conducted an annual study of the affluent market. While it consists of only $21 \%$ of all households, this upscale market segments consumes sport other than that of non-affluent households (Mendelshon, 1998). The average household purchases up to three other affluent segments (Figure 2a) furthermore, affluent consumers in sports participation, of the three segments of affluent consumers (Figure 2b). The results reveal that the most affluent are more likely than members of the other two consumers to participate in a sample Observations from research (Quick, 1995, 1994) with psychographic dimensions suggests less than 5\% of sports events participants travel to another venue (restaurant, bar or hotel) after sports. Furthermore, the TV is a major source of event information for sports consumers. (Shilbury, Qucik \& Westerbeck, 1998). However this is highlighted by Brooks (1994) where the sports product itself is a composite of these interrelated tangible and intangible elements. He elaborates, by arguing that there are two types of sports consumers, the immediate (spectators, participants and volunteers) and second consumer (auxiliary users of the sport). Therefore psychographics can be more important than demographics in the consumer decision making process. However they are often more difficult to quantify, and they are also based on values. Values play a big part in a person consuming sport, because this combines all of the individual internal influences of personality, motivation, and lifestyle. A clearer understanding of the individual's value of sport should be considered.

\subsubsection{Principle Values in sport}

Values were originally defined in psychology (Florenthal, 2000). Spranger (1928) developed a value system based on personality characteristics, which is a confirmed system that generalised men. In general the values are based on the combined personal impact of the intersection of individuals (Grunet \& Schemon, 1990). Therefore the individual's value system (Figure 3) represents personality characteristics as well as self actualisation, self fulfilment and cultural 
influences on the basis of social norms within sport (Flortenthal, 2000). Previous research has identified characteristic sensations on seeking (Zukerman, 1974), personal state of mind-arousal seeking (Apter, 1982) that drive individuals to search for sports events/activities. The value systems should represent this need for participation in a sports event. Many have argued that this system is another dimension of selection in sports events. Mullins, Hardy \& Sutton (2002) referred to this as a state of mind segmentation where the consumer is divided by personality traits, lifestyle characteristics such as attitudes, interests and opinions. The most noteworthy approach to state of mind segmentation was developed by the Stamford Research Institute (SRI), called the values and lifestyles (VALS) typology. It assumes that attitudes, opinions, desires and other psychological collectively govern behaviour (Mullins, Hardy \& Sutton, 2000). Although one study of exercise showed a relationship between VALS categories and exercise "inner directed" people exercised at twice the rate of "outer directed" people.

Although internal influences play a major role in the decision making process of a person's consumption of sport and sports events, there is still further research required in this area and there is no conclusive evidence to support this. Outside the internal influences there are external variables that can sway a person's choice, namely thoughts that make up the marketing mix. This area is fairly well researched in the consumption of products, e.g. running shoes etc. But very little is known about the consumption of sports events.

Based on these definitions, it has been identified that the constructs could be classified as benefits in the professional sports industry; participant identification, peer group acceptance, escapeism, nostalgia, and pride in place. Identification with an event or organisation is one more widely constructed in literature (Sutton, Milne, \& Cimperman, 1997; Mael \& Ashforoth, 1992; Branscombe \& Wann, 1991; Wann \& Brandscomber, 1990; Cialidini, Borden, Thorne, Walker, Freeman \& Sloan, 1976). Cialidini et al first offered the notion of basking in reflected glory, by observing individuals that publicise their association with successful sports events, here it is conceptualised that identification components of the pride in place of the brand association framework (Gladden \& Funk, 2002). That is, identification with a particular event fulfils a sports consumer's needs to affiliate with something successful or desirable and thus in one form of brand association, This further supports ideas that for a successful relationship in marketing it involves the core service the marketing mix and the other 'P' (Promotion, Place \& Price), where a customer relationship can be built. The core service must be in the long term in nature and allow service augmentation and customisation (Gonroos, 1990). The sports product must provide the opportunity for such customisation. Many have argued that sport is an ideal medium for personalisation. "The service" can be tailored to satisfy very narrow individual needs. This might explain the proliferation of the new innovative sports that are tailored for unique needs (Milne, Sutton, \& McDonald, 1996). Mullin (1985) identified this by expressing that sport marketing holds special characteristics. In examining these characteristics he noted:

Almost every element of marketing requires significantly different approaches when the product being is sport. Predictably, the critical differences lie in the unique Aspects of the sport product/service, and the unusual market conditions facing sport Marketers.

The characteristics noted by Mullin are summarised in Table 5, with supporting examples.

It is clear that all aspect of the marketing mix play an integral part in the consumer decision process when they are making choices. It is essential however that all areas are taken into account and further study needs to be clarified. Those each one of the elements plays an essential role with in influencing the consumer on their choice of triathlon events, what and who is the event participant? It was established earlier who was the triathlete but how can it be established?

Kurtzman and Zauhar (1998) were among the first in North America to include the examination of the sports event participant. They divided the sports participant into four distinct classifications or concepts; organised structure or team sports, sport spectator, heritage sport enthusiast, and individual sport participant. The last category consists of individual sports participants who are primarily competing against themselves. They are self-motivated intrinsically. Some would argue that they would fit into Walter's (1978) model of consumer rationalisation in figure 4

The traditional focus is based on the economic man, but it is deficient for two reasons. It fails to recognise the difference between the reason for a decision or action and the decision itself. The second, economic man concept rationally implies that physical and emotional motives are two different things (Walters, 1978). In fact the two cannot be separated practically on people. While this is valid an important methodology for eliminating models against the sports participant, it may prove problematic. For many sports events promotions to operationalise and incorporate into marketing strategies it does not take into account all the variables in the way that it affect a person's decisions in choosing events.

Shilbury, Quick and Westerbeck (1998) attempt to apply an approach as shown Figure 5. As a person is influenced by a number of different elements, the person specific factors, which are similar to those that Kollat, Engel and Blackwell (1990) identified in their model of consumer behaviour, e.g. that psychological influences and social forces all play a 
part in constructing the context from which the decision to purchase is made.

While Jackson, Reeves, and Collins (1998) examined this area further, little is known about triathletes and their specific behaviour/decision making in choosing events. As a result, marketers especially in the field of triathlon have little or no understanding.

\subsection{Participant Decision Making Involvement}

Involvement is a means of understanding a person's consumer behaviour and decision-making processes (Assael, 1992), enduring by nature, therefore different from simple participation. The involvement in decision making construct has roots in consumer behaviour and marketing (Bechling, 1999); Bech, Larson \& Nielson, 1999; Broderick \& Mueller, 1999; Donovan \& Jalleh, 1999; Assael, 1992).

In marketing, it is important to understand how to use involvement in decision making as a theoretical construct for understanding the decision making cycle of the sports consumer (Mcghee, Yoon, \& Cardenas, 2003). Consumers with higher levels of involvement take longer to make a decision than those sports consumer with lower levels of involvement (Assael, 1992, 1987; Maheswaren \& Meyers-Levy, 1990). Those with high levels of involvement actively search for information in the decision process (Figure 6). Rice's (1997) decision making model is based on being faced with a choice during the initial information search, what value is attached to the outcome? In sport that can be very subjective to the motivation and the personality of the athlete. The second is the perception of the probability of satisfaction; yet again this is very subjective with regards to why the athlete is taking part in this particular event. Do something to change it through a purchase. The individuality of each person is greatly complex, consumer decision making especially in sport is difficult to encapsulate.

\section{Research Methodology}

In summary, 60 triathletes from a local 2005 Triathlon were invited to provide retrospective data on the choice in the selection of participating in the Triathlon event and some previous events they have taken part in. This sample constituted triathletes ranging in abilities from a complete novice; intermediary athlete (participated in more than three triathlons and advanced athletes competing in under 65 minutes for a sprint event (400m swim, $20 \mathrm{~K}$ bike race, $5 \mathrm{k}$ run). Of these 60 participants $10 \%$ six were selected for the qualitative analysis in the form of interviewing to gain an understanding of their decisions in the choice of triathlon events. The athletes that were chosen for his part of the analysis were a combination of participants through to the elite athlete. The reason for this was so that the results would not be biased towards one particular level of athlete. By using a variety of abilities and ages ranging from $20-60$ would allow the researcher to gain a mixture of views from triathletes in their selection of events. Also there was a cross section of males and females (3/3) which allowed responses from an equal segmentation from the triathlon community

\subsection{Questionnaire Design}

Most of the previous competitors were from the North East of England, and the furthest coming from North Yorkshire. A mailed questionnaire was deemed the most appropriate research tool (Laborvitz \& Hagedporn, 1976). The passed participants who had email addresses were also contacted electronically as this was deemed a good idea for a quick response (Emery, 2004). Using this form of contact allowed respondents to be contacted interactively, this allowed more than one person to be surveyed simultaneously (Irwin, Sutton \& Gladden, 1998).

For comparative purposes the questions were structured to aid event managers/marketers in the decision purposes. Categorisations within questions were, where appropriate based, on some previous research in this area (Emery, 1997). For example "reasons for choosing an event in the Liker scale, were based on consumer behaviour research done by, Dimanche \& Havitz (1999).

A more in-depth analysis of the third aim in the identification, why triathletes make decision about the choices of events was conducted, with some of the information that has already collected by the some of the aspects of the questionnaire. The selection was conducted by taking $10 \%$ of the total cohort from the questionnaire, e.g. 6 respondents. By taking this approach it would ensure a more qualitative way of research. The selection of the respondents was made by those respondents who completed the questionnaires and returned them in the first instant.

\subsection{Respondent Overview}

Although all questionnaires were returned and the data was collected, the sample type was very limited with regards to the demographic types of people, e.g. predominantly male and very few females to get a gender differences in the sport as shown in table 6 .

The respondent rate for males was $67 \%$ and females $33 \%$, subsequently this was further supported with the numeric representing males being 1.0, the most reoccurring number to appearing as the mode.

Using a cross tabulation, previous performance can be further compared with the level of athlete. Figure 7 illustrates that using Kruskal-Wallis Test, that there is no significant findings with a $\mathrm{P}$ value $=0.05$, the results prove this with an 
assumed significance level of $t=0.729$ meaning that the level of significance in the relationship of the two variables grouped is $t=>0.679$. It is very evident that $72.7 \%$ of the total population that there is a peak and that the novice and participant sees this as a great importance (7.0, very important) to them, but for the intermediate and elite athlete there is not, which explains the further $27.3 \%$.

There were further cross tabulations with level of athlete and race distance, place, atmosphere and experience, cost and promotion and awareness but there were significant findings from using a Kruskal-Wallis Test which is demonstrated in Table 7.

The only statistical finding that was close to the $\mathrm{P}$ value $=0.05$ ( $95 \%$ relationship) with this type of statistical test was one factor:

- An athlete's choice based on the level of competition $(t=8.870 ; \mathrm{p}>0.05$ by 0.026$)$ this suggest that the elite and intermediate athletes (20.9\%) are selecting their events based on this which is a small percentage. This is further demonstrated in table 20.

Figure 8 provides an insight from the population being researched and it has a value of $22 \%($ mean $=4.58)$ of $\mathrm{N}=12$ that feel it is fairly important in the selection of one event over another, and a further $27 \%(\mathrm{~N}=15)$ with a range of 5.0 (1.0 not important and 7.0 very important) The values from $5.0-7.0=54.5 \%$ demonstrates that the cost of the event will possibly assist them in making a decision. Using the Kruskal-Wallis test, there were no significant relationship found between age and cost $(t=0.388 ; \mathrm{P}>0.05)$.

\section{Research Analysis Findings}

The research intended to look at how the internal influences of person will affect their decision making on sports event? Namely the construct for this was the sport of triathlon. What can be clearly seen taking a snap shot at demographics as it would be useful just to briefly acknowledge this that the sport is predominantly is engaged by males (table 6). It would be then fare to say is this a true reflection on the sport internationally?

So one of the questions raised is that do women feel that this is a male sport more so than a female? If this is the case then this would bias any decision in choosing a sport/sports event because of their perceptions. This is further supported by in a major triathlon event (more than 1,000 consumers) the split from males and females is very high (Casey, 2003), (See Table 8)

Table 8 demonstrates that disparities in gender participating in triathlon is fairly extreme, ranging from $75 / 25$ in the male sprint event to and 82/18 split in the Olympic distance event. The overall gender difference equating to an 80/20 split at this one event. Nationally the current number of memberships affiliated to the British Triathlon, the sports National Governing body is a total of 6842.5300 males and 1542 females with 78/22 split in gender (Moss, 2004). Presently the sport recognises that they must do something about this to attract and encourage more females into the sport, and hope to do so by the employment of the development officers in all the UK regions and the establishment of more event managers (Brook, 2004).

The job of event managers and development officers is to break down the social issues surrounding triathlon for women participating in the sport.

\subsection{Performance}

The abilities ranged from the complete beginner/participant with $16 \%$ (Figure 7) through to the elite athlete $25 \%$ with only $>9 \%$ difference between the numbers of higher levelled athletes to those who wish to participate in their first event. Such findings all relate purely to participant numbers and can be principally explained to the event nature, with triathlon events possessing very different profiles from other events (Emery, 1997).

It has also been identified (Table 7) that a number of respondents feel that the type of event is important in relation to their training calendar. Most athletes will select an event with regards to its time of year so fits into their training calendar. Though this is a valid piece of information and it should be noted, this tended to be a reason why the elite athlete was more. The athlete is more selective about a course based on their previous performance because it allows them to gauge their level of fitness at that point of the season (Maw, 2005), this will then help the athlete make a decision on which events they wish to participate in or not. As the management of the training calendar is just as important as participating in a event as it has to fit into an athletes training. Though performance is a linked to a consumer's lifestyle and is partially related to beliefs, a more thorough understanding needs to be provided and there is more research required in this field.

\subsection{Internal Influences}

A demographic trend related to income is leisure time (Hofacre \& Burman, 1992), both men and women have more leisure time now than they had in 1965.

Lifestyle refers to how people spend their time participating in a wide range of activities, such as consumption patterns 
etc (Assael, 1998). Therefore triathlon consumption is linked to the patterns in their lives. Many triathletes today come from professional backgrounds and are maturer athletes and some are students with very little income. Stanford Research Institute (2002) has found that some people in the higher levels of the VALS (Values and Lifestyles Survey) are in the age of 45 years of age, married, highly educated with high incomes and holding professional jobs, which in the sport of triathlon are the consumers who participate and are more likely to choose a triathlon event. Generally, it is assumed that values and personality influence activity participation and purchasing consumption behaviours (Standford Research Institute, 2002, Todd \& Lawson, 2001, Assael, 1998; Zins, 1998, Weinstein 1994) because in most cases a sport like triathlon can be very expensive. Armstrong (2004) further supports this assumption by stating:

A sport like triathlon can be very expensive unless you have a modest income and as the equipment is very expensive. It tends to encourage more affluent older people than those who can actually afford.

Lifestyle relates to the economic level at which people live, how they spend their money, and how they allocate their time (Anderson \& Golden, 1984). What is apparent is that triathletes do commit a lot of time to their training and it is seen as a major part of their life, irrespective of their income. Chelladurai (1997) further goes onto support this and elaborates that the total athletic experience involves training periods that are disproportionably longer than the performance periods in sports events. He further then goes to say, "given that athletes spend an inordinate amount of time in very agnostic prior to a event(s), their reactions to the experiences during these training periods become equally, if not more important. However there were no significant findings to relate lifestyle, personality and values to the quantitative and qualtatitive analysis and sport has become recognised as a major aspect of lifestyle activities and it is assumed that lifestyle will always, in the current climate, affect sport consumption (Todd \& Lawson 2001; Zins, 1998; Rex, 1991).

\subsubsection{Motives}

Motives can be clearly linked to performance, why a person participates. Armstrong (2005), Riall (2005) felt that this was an important factor to them when choosing a triathlon event. This can be clearly linked to the level at which they participate. Figure 7 demonstrates that some athletes select events based on previous performance as a sense of motivation, but not all athletes at different levels choose to do so. Only $46 \%$ of people felt that this was important and a motivational factor when choosing an event. While motives have been shown to be associated with event identification (Trail, Fink \& Anderson, 2003, Funk et al, 2002, Wann, Royalty \& Rochelle, 2002; James, 2001; Brewer, \& Royalty, 1999; Wann, 1995), the relationship among specific motives to events is minimal. However, indirect evidence exists to suggest this might not be the case, (Funk et al, 2002; Funk, Mahony, Nazakawa, \& Hirakawa, 2001), and the combination of direct and indirect evidence supports this in one of their models (Figure 9).

Funk, Mahony, Nakazawa, \& Hikrawa (2001) model represents the separation of motives into a variety variables and the triathlete event consumers in same cases fit into this categorisation. One group, the overreaching variable, consist of the motives of social support and escape. A second variable consist solely of vicarious achievement motive. The third latent variable is the athlete's motives and consist of the aesthetic, drama/ eutress, acquisition of knowledge, and appreciation of physical drive motives. The vicarious achievement motive is directly related to latent variable termed sports event identification. This latent construct is represented by the five points of attachment; place, season, perception, persuasion and price. The athlete's motive is directly related to a latent variable labelled sport identification that consists of a two point attachment construct; type and level of sport (Funk et al 2001). In this model, sports event identification and sport identification are related. Separation of the motives of trathletes has not been proposed before now. However, Sloan (1989) suggested that sports spectators and participants react differently to winning and losing, contingent on the specific motivational theory. However there is no supporting evidence to prove this in the form of trathletes and their selection of events. However Mcghee, Yoon and Cardenas (2003) challenge Sloan's (1989) theory as they feel that consumer behaviour research indicate that triathletes with high levels of motivation form strong loyalties with events. This indicates that attracted athletes with high levels of motivation are more likely to return to an event than the attracted triathletes with medium levels of motivation.

Consumer behaviour research into triathlon events is very limited; if at all it has been attempted. Linking theorist models to a very diverse and driven consumer with a wide range of both internal and external influences, in their attraction to a sport and sports event needs more attention. While models of sport consumption tend to fragment consumer behaviours and can dilute the strategic value for sports marketers, they also capture important distinctions. Lewis' (2001) contrast of symbolic fans is a good example as is the distinction Hunt, Bristol and Bashaw (2000) make between functional and dysfunctional sports participants.

Though the key influencers are not linked to the triathlon consumer there is some partial evidence linking to their motives on why they are participating in a triathlon in figure 7 and also table 7 . These could then be said to be the key internal variables that motivate the triathlete. Though this is useful information it does not take account that larger fitness community as a whole. Therefore it is essential that sports marketers do a wider research on what other multi event individuals, and kept fit see as the key variables that internally motivate them to participate in sport like triathlon. 


\section{References}

Ackland, J. (1999). Principles of training; Complete Guide to Endurance Training, A. \& C. Black, London. pg8-9.

Anderson, W. T. \& Golden, L. (1984). Lifestyle and Psychograohics: A critical review and recommendation. In Kinnear., T (1999). Advances in Consumer Research $6^{\text {th }}$ ed Ann Arbor, pp 405-411.

Apter, M. J. (1982). The experience of Motivation London, Academic Press.

Armstong, S. (2004). Female Participant in the Triathlon. Informal Interview conducted December 2004.

Arnould, E. J. \& Prcie, L. L (1993). River magic extraordinary experience and the extended service counter; Journal of Consumer Research, 20, pg 24-45.

Assael, H. (1992). Consumer behaviour and marketing action (4th Ed) Boston, MA: PWS-KETN Publishing.

Barnard, P. (1998). " Class Wars in the Great Outdoors The Times, 24 January pg 49.

Bech-larsen, T. \& Nielsen, N. (1999). A comparison of five elicitation techniques for elicitation of attributes of low involvement products Journal of Economic Psychology 20(3) 315-341.

Bechling, D. (1999). Measuring Involvement Perceptual Motor Skills, 88, (1) 55-64.

Bloch, P., Sherrell, D. \& Ridgeway, N. (1986). Consumer search; An extended Framework Journal of Consumer Research, 13, 119-126.

Branscombe, N. R. \& Wann, D. L. (1991). The positive social and slef concept consequences of sport identification. Journal of sport and social issues, 15, 115-127.

Brassington, F. \& Petitt, S. (2000). Segmenting Markets Principles of Marketing, Prentice Hall, 187-191.

Brassington, S. \& Pettitt, S. (2000). Services and Non Profit Marketing Principles of Marketing, $2^{\text {nd }}$, Prentice hall, pg 955.

Broderick, A. \& Mueller, R. (1999). A theoretical and empirical exegesis of the consumer involvement construct; The psychology of the food shopper Journal of Marketing Theory and Practice, 7 (4), $97-108$

Brookes, C. M. (1990). Sponsorship : Athletic Business, pp 59-62.

Brooks, C. M. (1994). Sports Marketing Competitive Business Strategies for Sports. Prentice Hall.

Casey, L. (2003). The London Triathlon Statistical Breakdown SBS Marketing Annual Report.

Celsi, R. L (1992). Transcendent benefits of high risk sports. In sherry, J.F, J \& J B Strenthal (ed) Advances in consumer research. (19), pg 636-641.

Celsi, R. L., Rose, R. L. \& Kahle, T. W. (1993). An exploration of high risk leisure consumption through sky diving Journal of Consumer Research, 20, 1-23.

Chelludurai, P. (1994). S ort Management: Defining the Field p European Journal of Sport Management 1, 7-21.

Cialdini, R. B., Borden, R. J., Thorne, R. J., Walker, M. R., Freeman, S. \& Sloann, L.r. (1976). Basking in Reflected glory; Three event studies Journal of Personality and Social Psychology, 34, 366-375.

Dick, F. (1997). Variations in per iodisation; Sport Training Principles, $3^{\text {rd }}$ ed, A \& C Black, London, pg $302-303$.

Dimanche, F. \& Havtiz, M. (1999). Leisure involvement revisited: Drive properties and paradoxes Journal of Leisure research, 3 (2) 122-149.

Donovan, R., \& Jalleh, G (1999). Positively versus negatively framed product attributes The influence of involvement Psychology of marketing, 16 (7) 613-630.

Emery, P. (1997). The Management of Major Events Durham University 1997.

European Triathlon Union (1999). Direction for the sport of triathlon.

Florenthal, B. (2000). Value differences between risky sports participants and non participants Sport Marketing Quarterly 1 (9) pg 26-27.

Fullerton, S. \& Dodge, H. R (1995). An Application of Market Segmentation in a Sport Marketing Area. Sport Marketing Quarterly 4 (3) pg 43.

Funk, D. \& James, J. (2002). The psychological continuum model: A conceptual framework for understanding an individuals psychological commitment to sport Sport Management Review, 4 (2), 119- 159.

Funk, D. C, Mahony, D. F. \& Havitz, M. E (2003) Sports Consumer Behaviour: Assessment and Direction. Sports Marketing Quarterly 12 (4), pg 200-205.

Funk, D. C., Mahony, D. F., Nakazawa, M. \& Hirkawa, S. (2001). Development of the Sport Interest Inventory (SII): 
Implications for measuring Unique Consumer Motives at team Sporting Events. international Journal of Sport Marketing \& Sponsorship, 3 291-316.

Getz, D. (1997). Event Management and Event Tourism New York: Cognizant Communication Corp.

Getz, D. (1998). Trends Strategies, and Issues in Sport Event Tourism Sport Marketing Quarterly, 7 (2) 8-13.

Gibson, H. (1998). Sport Tourism; A critical analysis of research Sport Management Research, 1, 45-76.

Gladden, J. M. \& Funk, D. C (2002). Developing an Understanding of Brand Association in Sport. Empirical Evidence from Consumer of Professional Sport; Journal of Sport management, 16, 54-81.

Goldblatt, J. J. (1990). Special Events: The Art Science of Celebration New York: Van Nostrand Reinhold, p4.

Grunert, S. C \& Schernon, G. (1990). Consumer values in West Germany underlying dimensions and cross cultural comparison with North America Journal of Business, 20, 97-107.

Hawkins, D. I., Best, R. J. \& Coney, K. A. (1996). Consumer Behaviour. Implications of Marketing Strategy.

Horface, S. \& Burman, T. K. (1992). Demographic changes in the US into the Twenty-First Century: Their Impact on Sport Marketing: Sport Marketing Quarterly, (1) 1, pg 31-35

Howard, D. R. \& Crompton, J. L. (1995). Financing Sport Morgantown, W.V. Fitness Information Technology.

Hunt. K., Bristol, T. \& Bashaw, R. (2000). A conceptual approach to classifying sports fans. Journal of Services Marketing 13 (6) 439-452.

Irwin, L., Sutton, W. A. \& Gladden, J. (1998). Tools of the trade: Practical research for events, teams and venues. Sport Marketing Quarterly 7 (2), pg 45.

Kang, J. H. (2002). A Structural Model of Image Based and Utilarian Decision-Making Process for Participant Sport Consumption; Journal of Sport Management 16, 173-189.

Karande, K., Zinkhan, G. M. \& Baird, A. (1997). Brand personality and Self Concept: A replication and extension; AMA Conference pg 165-171.

Kassrijian, H. H. (1971). Personality and consumer behaviour: A review of marketing research, 8 (nov), pp 409-418, In Brassington, F \& Pettitt, S (2000) Consumer Behaviour Principles of marketing, $2^{\text {nd }}$ ed, Prentice Hall pg 108.

Korman, A. (1974). The psychology of Motivation. Englewood Cliffs, N.J Prentice Hall; Runyon, K (1977) Consumer Behaviour and the practise of Marketing. (Columbus, OH;C.E Merrill.

Labovitz, C. \& Hagedon, R. (1976). Introduction to Social research, $2^{\text {nd }}$ ed, Mcgraw Hill. In Emery, P (1997) Management of Major Events Durham MBA.

Lancaster, G. \& Reynolds, P. (2003). Buyer Behaviour, Marketing, Palgrave \& Macmillan, pg 50-83.

Larson, J. (1997). The fans Sport Business daily, 98), pg 42-50.

Lawson, J. (2004). Executive Board Member British triathlon Association; Triathlon Events 2004 Informal face to face discussion, January, $19^{\text {th }} 9.30 \mathrm{am}$.

Lazer, W. (1963). The lifestyle concepts and Marketing; Toward Scientific marketing American Marketing Assoc, pp $130-131$.

Lewis, M. (2001). Franchise relocation and fan allegiance. Journal of Sport and Social Issues, 25 (1), 6-19.

Lole, I. (2004). National Participation Manager, informal telephone interview, February 2004.

Mael, F. \& Ashforth, B. E. (1992). Alumni and their Alma mater; A partial test of the reformulated model of organisational identification. Journal of Organisational Behaviour, 13,103-123.

Maheswaren, D. \& Meyer-Levy, J (1990). Influence of message framing and involvement Journal of Marketing Research, 27, 362-367.

Mahony, D. F. \& Pitts. (1998). Research Outlets in Sport Marketing: The Need for Increased Specialisation: Journal of Sport Management, Human Kinetics (12), pg 259-265.

Manly, L. (1993). Sport Marketing draws a crowd: The magazine for marketing management, p.19.

Martin, G. S. J., Chang, M. B. A., Lester, W. \& Johnson. (1995). Segmenting the Triathlon Association Memebership Market: An Australian Example. Sport Marketing Quarterly 4 (4) 25-28.

Maw, G. (2005). Performance Director British Triathlon. Telephone Interview conducted October, 2005.

Mcghee, N. G., Yoon, Y. \& Gardensas, D. (2003). Involvement and Travel of Recreational Runners in North Carolina Journal of Sport Management, 17, 305-324. 
Milne, G. R \& Mcdonald, M. A. (1999). Sport Marketing: Managing the exchange process. Sudbury.pp169.

Moore, M. E. (1987). The Relationship of situational attributes and management . The style to the success of marketing, intercollegiate football programs. Unpublished doctoral dissertation, University of Pittsburgh.

Moss, M. (2004). Informal Interview conducted at the BTA Headquarters Loughborough National Participation Administrator December 19th.

Mullin, B. J., Hardy, S. \& Sutton, W. A. (1993). Sports Marketing Champaign IL, Human Kinetics.

Mullin, B. J., Hardy, S. \& Sutton. W. (2000). Perspectives in Sports Consumer behaviour, Sports Marketing Human Kinetics, p676-777.

Mullin, B. J., Hardy, S. \& Sutton. W. A. (1998). Perspectives in Sports Consumer Behaviour, Sports Marketing Human Kinetics, p676-777.

Palmer, A. (1994). Principles of Service Marketing Mcgraw Hall.

Parks, B. J., Zanger, B. K. \& Quaterman, J. (1998). Sport Management an Overview. Contemporary Sports Management; Human Kinetics, pg 8-9.

Plummer, J. T. (1974). " The concept and application of lifestyle segmentation Journal of Marketing, 138, pp33-37.

Quick, S. (1994). Fan Survey reports to IMG (Australian Motorcycle Grand Prix) Unpublished technical report.

Riall, J. (2004). Participant in the triathlon. Informal interview conducted December 2004.

Rice.,C. (1997). Predicting and influencing consumer behaviour: Consumer Behaviour (2n ed) Butterworth \& heinman, pg210-211.

Sandomir, R. (1992). (188) Get in the position for the older market American Demographics

Schiffman, L. G. \& Kanuk, L. L. (2000). Personality and consumer behaviour; Consumer behaviour 7th ed, Prentice Hall, New Jersey.

Schiffman, L. G. \& Kanuk, L. L. (2000). Personality and consumer behaviour. Consumer behaviour 7th ed, Prentice Hall, New Jersey.

Shilbury, D., Quick, S. \& Westerbeck, H. (1998). The Sport Product Strategic Sport Marketing, Allen \& Unwin, pg 88-89.

Shoham, A. (2000). Predicting Future Sport Consumption; The impact of perceived benefits Sports Marketing Quarterly. 1 (9), pg 9.

Shone, A. \& Parry, B. (2001). An introduction to events Successful event management, Continuum, London, pg 4-5.

Spranger, E. (1928). Types of men, the psychology and ethics of personality; In Florenthal, B (2000). Value differences between risky sports participants and non participants, Sport Marketing Quarterly, pg 27.

Springman, S. (1998). Executive Board member British Triathlon. Presidents address to the future direction of triathlon.

Stanford Research Institute. (2002). Value and Lifestyle Survey (VALS 2).

Sutton, W. A., Mcdonald, M. A., Milne, G. R. \& Cimperman,, J. (1997). Creating and fostering fan identification in profession sports Sport marketing Quarterly, 6(1) 15-22.

Thav, R. (1995). The change sin magazine research. American demographics, pg 12-13.

Todd, S. \& Lawson, R. (2001). Lifestyle Segmentation and Museum / gallery visiting behaviour. International Journal of Non-Profit and Voluntary Sector Marketing, 6, 269-277.

Torklidsen, G. (1999). Organisation of Major Events Leisure and Recreation Management, 4th Ed, Spon Press.

Trail, G. T., Fink, J. S. \& Anderson, D. F. (2003). Sport Spectator Consumption Behaviour Sports Marketing Quarterly, 12 (1) pg 8-9.

Walsh-Heron, J. \& Stevens, T. (1990). The Management of Visitor Attractions \& Events Prentice Hall.

Walters, G. C. (1978). The Nature of the Consumer. Consumer Behaviour, Theory and Practice, $3^{\text {rd }}$ ed. R. Irwin.

Wann, d. L. \& Branscombe, N. r. (1990). Die hard and fair-weather fans; Effects of identification on BIRGing and CORGing tendencies. Journal of Sport and Social issues, 14 (2), 103-117.

Weinstein, A. (1994). Market segmentation: Using demographics, psychographics, and other niche marketing techniques to predict consumer behaviour $2^{\text {nd }}$ ed New York: Mcgraw-Hill.

Zins, A. H. (1998). Leisure Traveller Choice of Theme Hotels Using Psychographics. Journal of Travel research, 36, $3-15$. 
Zuckerman, M. (1974). The Sensation Seeking Motive. In Macher, B. A. (1999). Progress in experiential personality research. New York; Academic Press.

Table 1. Events Sanctioned by the British Triathlon Association (Lole 2004)

\begin{tabular}{|l|l|l|l|l|l|}
\hline Event Type & 2000 & 2001 & 2002 & 2003 & 2004 \\
\hline Triathlon & 98 & 110 & 143 & 151 & 192 \\
\hline Duathlon & 60 & 66 & 76 & 74 & 81 \\
\hline Aquathlon & 37 & 47 & 50 & 49 & 58 \\
\hline Other Events & 2 & 3 & 5 & 5 & 8 \\
\hline
\end{tabular}

Table 2. Characteristics distinguishing goods from a service (Shilbury, Quick \& Westerbeck, 1998)

\begin{tabular}{|l|l|}
\hline \multirow{5}{*}{ Intangibility } & $\begin{array}{l}\text { Service cannot be seen, tasted or smelled before they are bought. Services are } \\
\text { performances rather than objects. For example, is it possible to describe what } \\
\text { product benefits people take home with them after participating in a sports event? Or } \\
\text { the benefits derived from watching a Triathlon event? There is no tangible take home } \\
\text { product in this example. }\end{array}$ \\
\hline Inseparability & $\begin{array}{l}\text { Services are simultaneously produced and consumed. The product cannot be present } \\
\text { during production. For example attending a sporting contest or visiting a } \\
\text { physiotherapist. You need to attend. }\end{array}$ \\
\hline Heterogeneity & $\begin{array}{l}\text { Services are potentially variable in their performance, employees can come into } \\
\text { contact with the consumer; therefore, consistency becomes an issue. Few sporting } \\
\text { events and experiences are the same one week to the next, and the consistency of } \\
\text { service delivery by people working at such an event can also vary. }\end{array}$ \\
\hline Perishability & $\begin{array}{l}\text { Services cannot be stored. Hotel rooms not occupied, airline seat not sold or tickets } \\
\text { to a sporting event not sold cannot be reclaimed. Simply, it is lost revenue and } \\
\text { indicates the importance of understanding that services are time dependent. }\end{array}$ \\
\hline
\end{tabular}

Table 3. Individual Memberships and Club Memberships 2001-2004 (adapted from Moss, 2004)

\begin{tabular}{|l|l|l|l|l|}
\hline & 2001 & 2002 & 2003 & 2004 \\
\hline $\begin{array}{l}\text { Individual } \\
\text { Members } \\
\text { Affiliated }\end{array}$ & 4164 & 4967 & 5939 & 6400 \\
\hline $\begin{array}{l}\text { Club } \\
\text { Memberships }\end{array}$ & 234 & 214 & 246 & 260 \\
\hline
\end{tabular}


Table 4. Soccer participation, 1995 - 1996 (Mullins Hardy \& Sutton, 2000)

\begin{tabular}{|l|l|l|l|}
\hline Category & $\begin{array}{l}1995 \\
\text { In millions }\end{array}$ & $\begin{array}{l}1996 \\
\text { In millions }\end{array}$ & $\begin{array}{l}\text { increase } \\
1995-1996\end{array}$ \\
\hline Total Participants & 16.8 & 18.1 & 7.7 \\
\hline Male & 9.5 & 10.9 & 14.7 \\
\hline female & 7.3 & 7.2 & -1.3 \\
\hline Under 18 & 13.3 & 13.4 & 0.7 \\
\hline 18 and Over & 3.5 & 4.7 & 34.2 \\
\hline Frequent 25 or more days per year & 7.3 & 7.7 & 5.4 \\
\hline Core ; 52 or more days per year & 3.2 & 3.2 & 0.0 \\
\hline Afionadoa: Soccer is favourite activity & 3.7 & 4 & 8.1 \\
\hline
\end{tabular}

Table 5. Gender

\begin{tabular}{|l|l|l|l|l|l|l|l|}
\hline & $\mathrm{N}$ & Numeric & Valid \% & Mode & Mean & Median & $\begin{array}{l}\text { Std } \\
\text { dev }\end{array}$ \\
\hline Male & 37 & 1.0 & 67.3 & 1.0 & 1.327 & 1.000 & .4735 \\
\cline { 1 - 6 } Female & 18 & 2.0 & 32.7 & & & \\
\cline { 1 - 5 } Total & 55 & \multicolumn{7}{|l}{}
\end{tabular}

Table 6. Kruskal Wallis Test: Level of Athlete

\begin{tabular}{|c|c|c|c|c|c|c|c|c|c|}
\hline & course & $\begin{array}{c}\text { level of } \\
\text { competition }\end{array}$ & $\begin{array}{c}\text { Race } \\
\text { distance }\end{array}$ & $\begin{array}{c}\text { Location/Training } \\
\text { place }\end{array}$ & $\begin{array}{c}\text { Pre \& post } \\
\text { calendar } \\
\text { event } \\
\text { management }\end{array}$ & $\begin{array}{c}\text { Experience } \\
\& \\
\text { Atmosphere }\end{array}$ & Cost & $\begin{array}{c}\text { Promotion } \\
\text { and } \\
\text { awareness }\end{array}$ \\
\hline Chi-Square & 3.835 & 6.870 & 4.130 & .496 & 5.599 & 2.364 & 4.535 & 1.777 & 1.045 \\
\hline Df & 3 & 3 & 3 & 3 & 3 & 3 & 3 & 3 & 3 \\
\hline Asymp. Sig. & .280 & .076 & .248 & .920 & .133 & .500 & .209 & .620 & .790 \\
\hline
\end{tabular}

Table 7. Gender differences of participants entering the London Triathlon in 2003 per event (Casey, 2003)

\begin{tabular}{|c|c|c|c|c|c|}
\hline & $\begin{array}{c}\text { Junior } \\
\text { Event } \\
\text { (Under 16) }\end{array}$ & $\begin{array}{c}\text { Super Sprint } \\
(400 \mathrm{~m} \text { swim, 10k } \\
\text { bike, 2 K run) }\end{array}$ & $\begin{array}{c}\text { Sprint Event } \\
(750 \mathrm{~m} \text { swim, } \\
20 \mathrm{k} \mathrm{bike,} \mathrm{k} \\
\text { run })\end{array}$ & $\begin{array}{c}\text { Elite Olympic } \\
\text { Event } \\
(1500 \mathrm{~m} \text { swim, 40k } \\
\text { bike, 10 k run })\end{array}$ & $\begin{array}{c}\text { Olympic distance } \\
\text { event all age groups } \\
(1500 \mathrm{~m} \text { swim, } 40 \mathrm{k} \\
\text { bike, 10 k run })\end{array}$ \\
\hline Male & 20 & 151 & 931 & 59 & 1513 \\
\hline Female & 8 & 31 & 310 & 20 & 328 \\
\hline Total & 28 & 182 & 1241 & 79 & 1841 \\
\hline
\end{tabular}




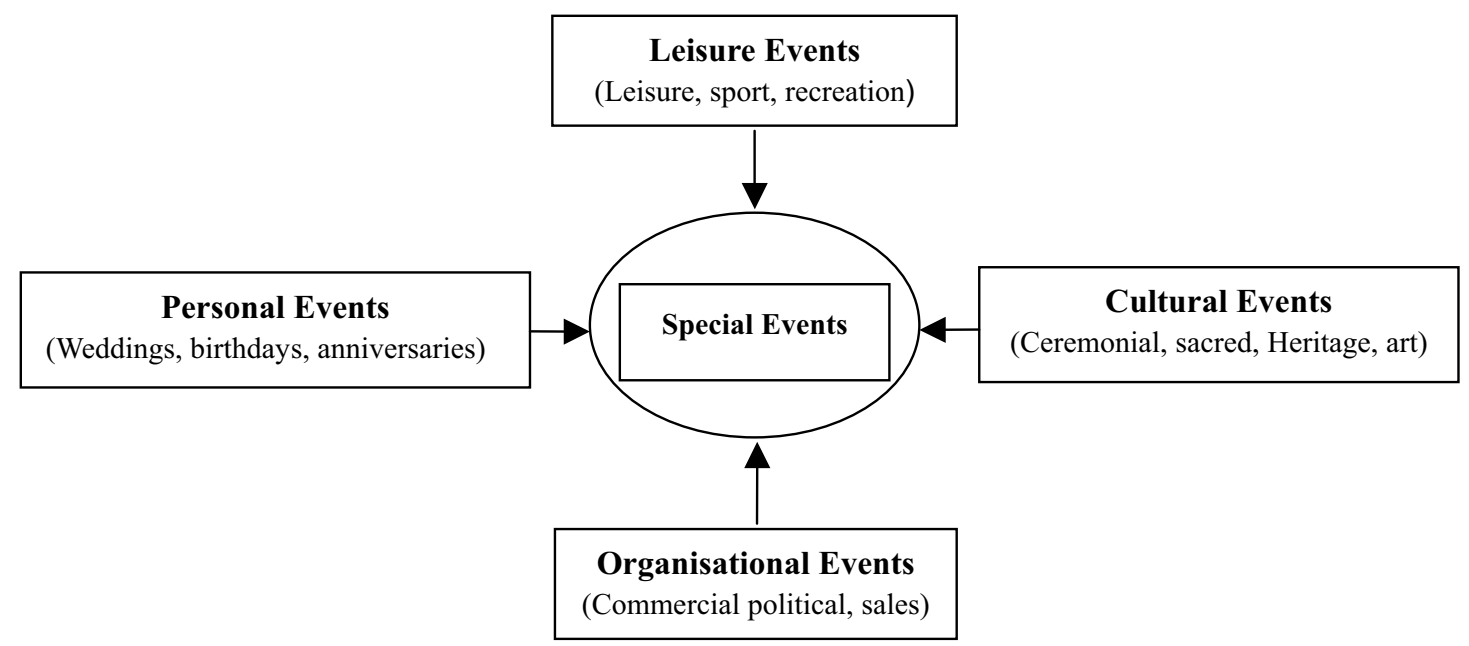

Figure 1. Suggested Categorisation of Special Events (Shone \& Parry 2001)

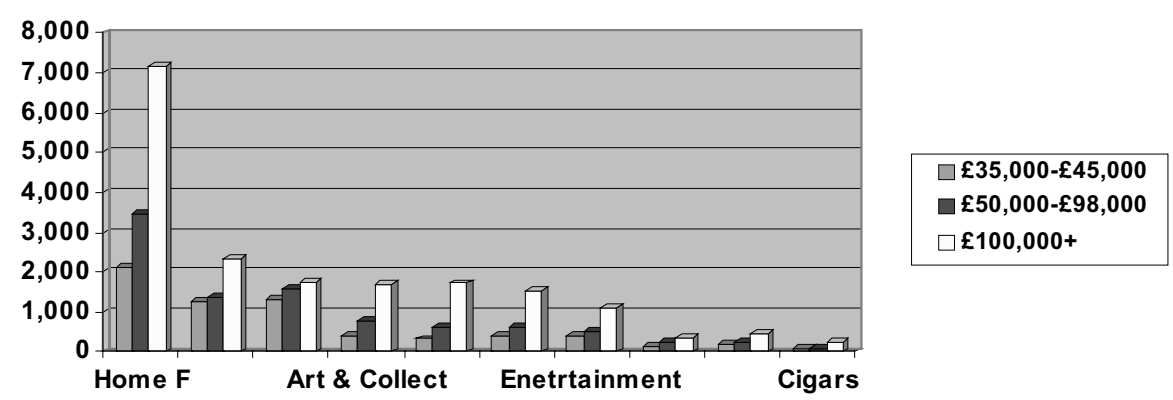

Figure 2a. Three segments of affluent Consumers Average Household Expenditures (Among Purchasing households) (Source: Mendelssohn Affluent Survey 1998) 


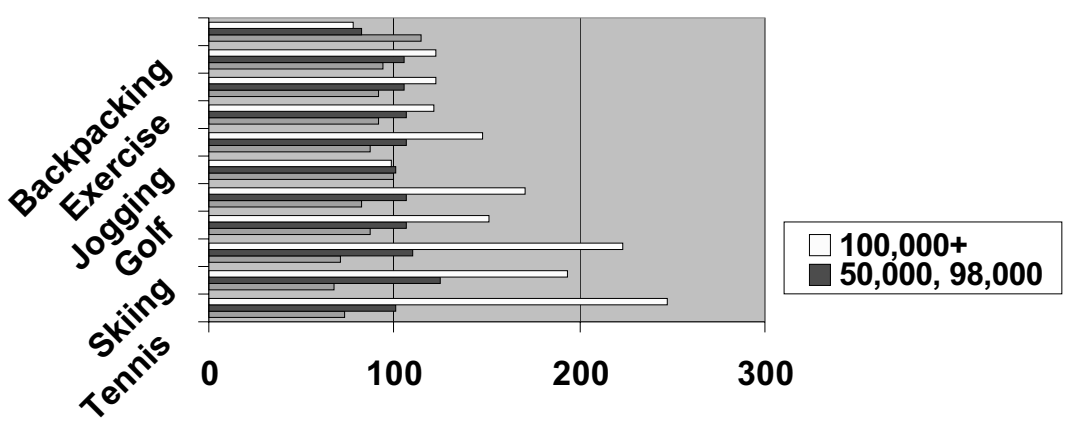

Figure 2b. Affluent Consumers Participation in Selected Sports

(Number of days in past year indexed to each three income segment)

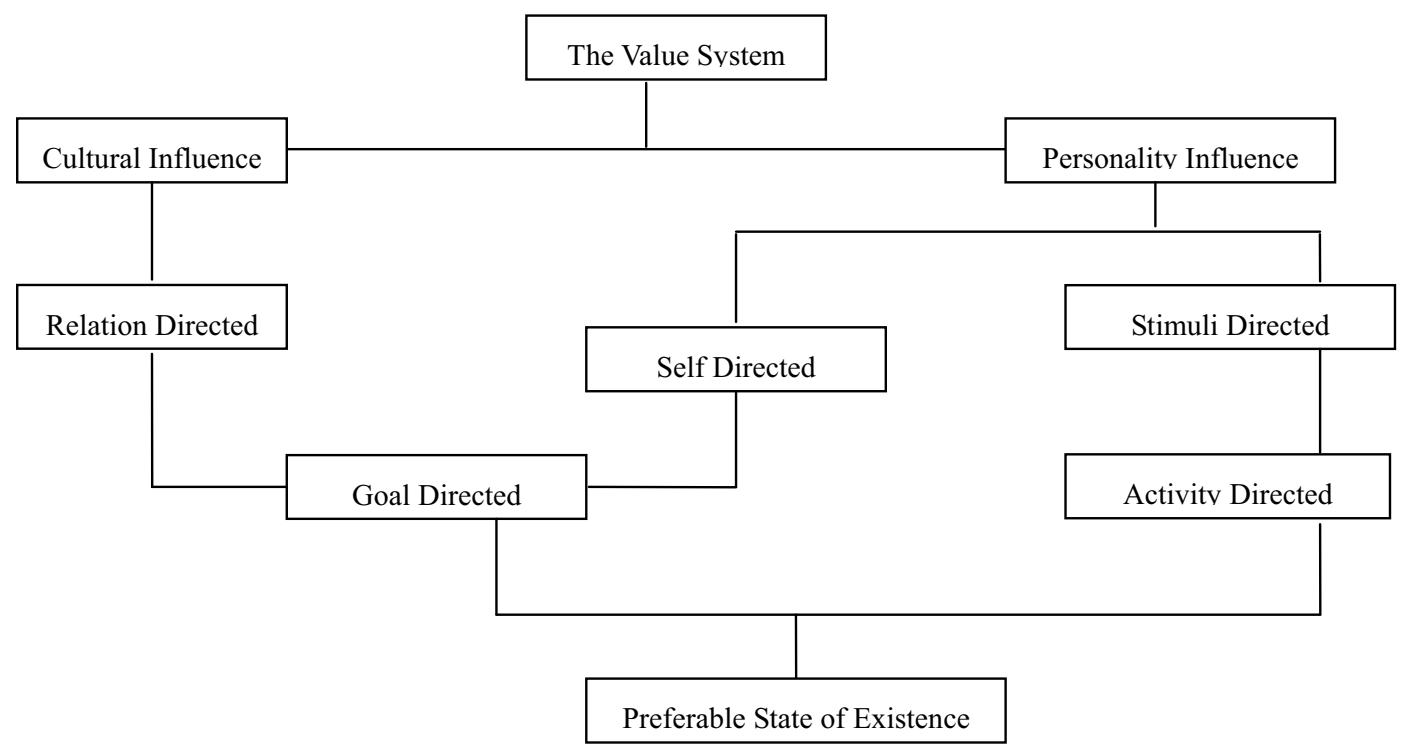

Figure 3. The Value Structure: A conceptual Model (Florenthal, 2000) 


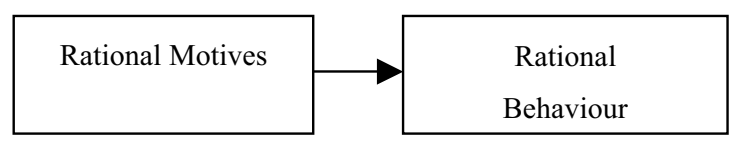

1. Traditional Explanation

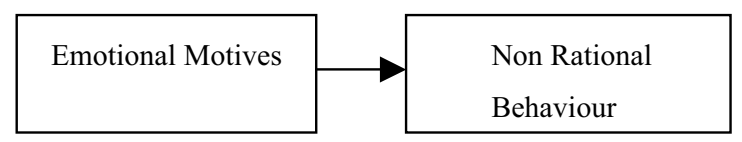

2. Contemporary Explanation
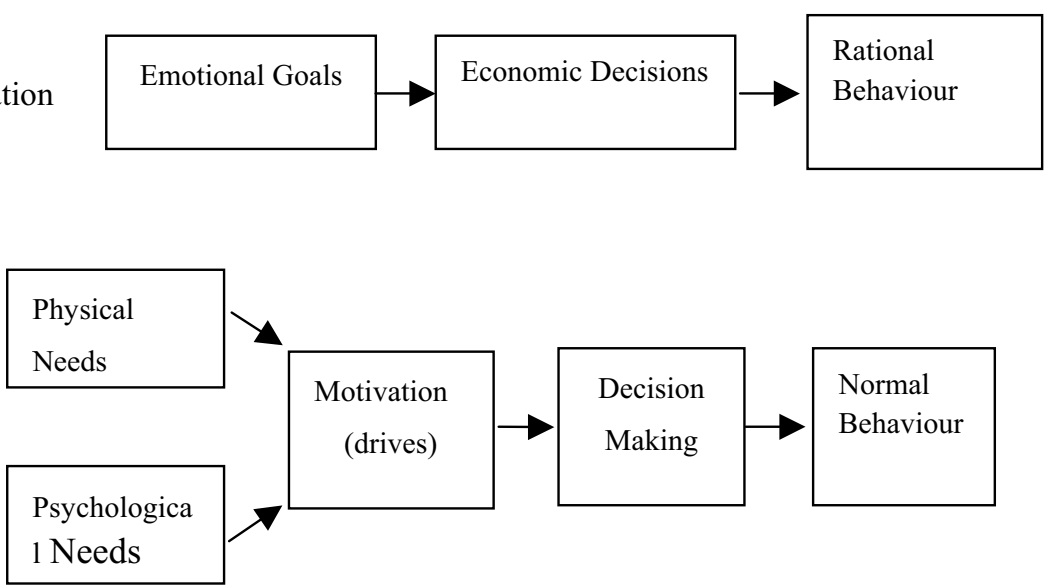

Figure 4. Concepts of Consumer Rationality (Adapted from Walters, 1978)

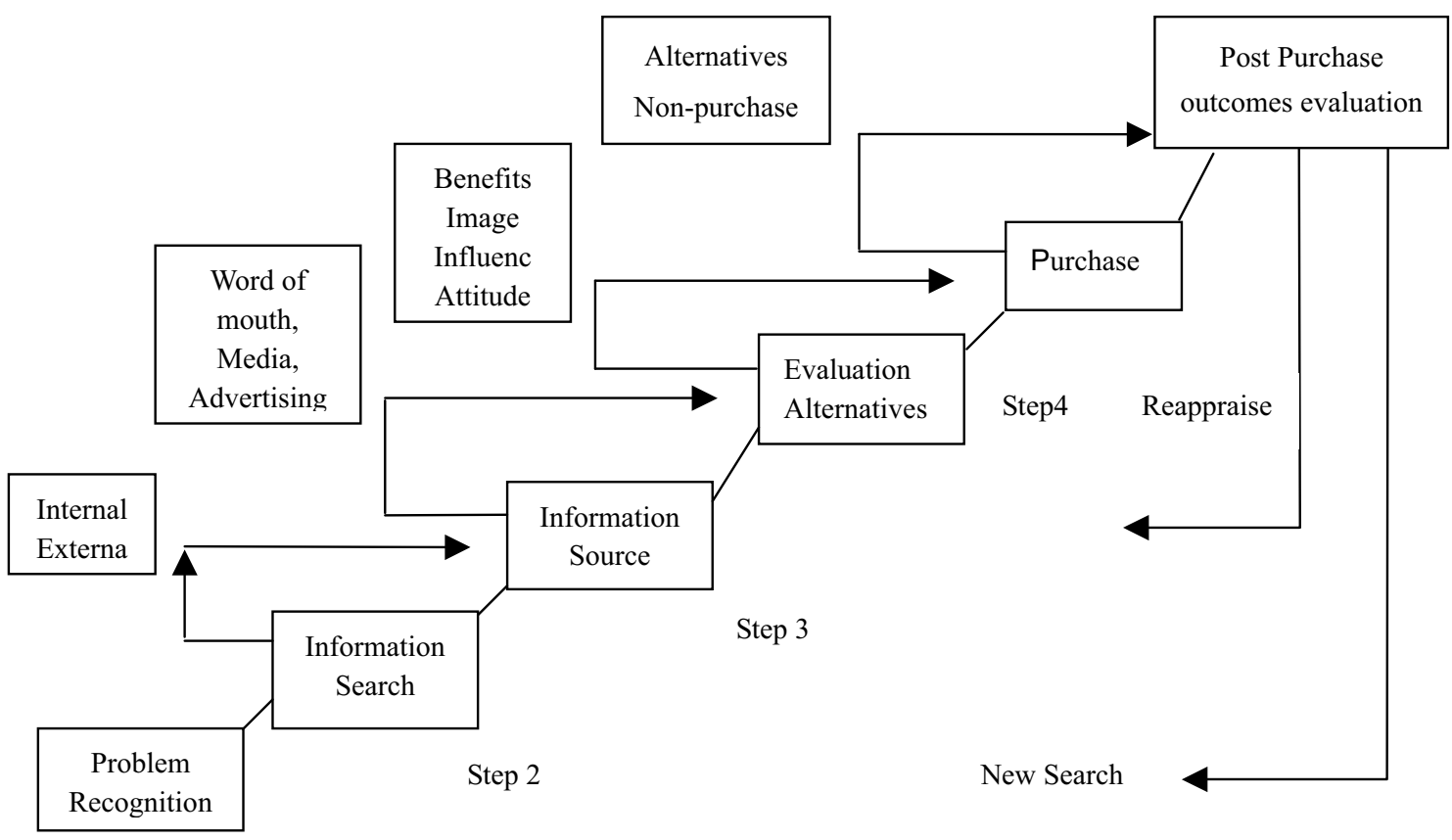

Step 1

Figure 5. The Consumer Making Decision Making Process

(Shilbury, Quick \& Westerbeck, 1998) 


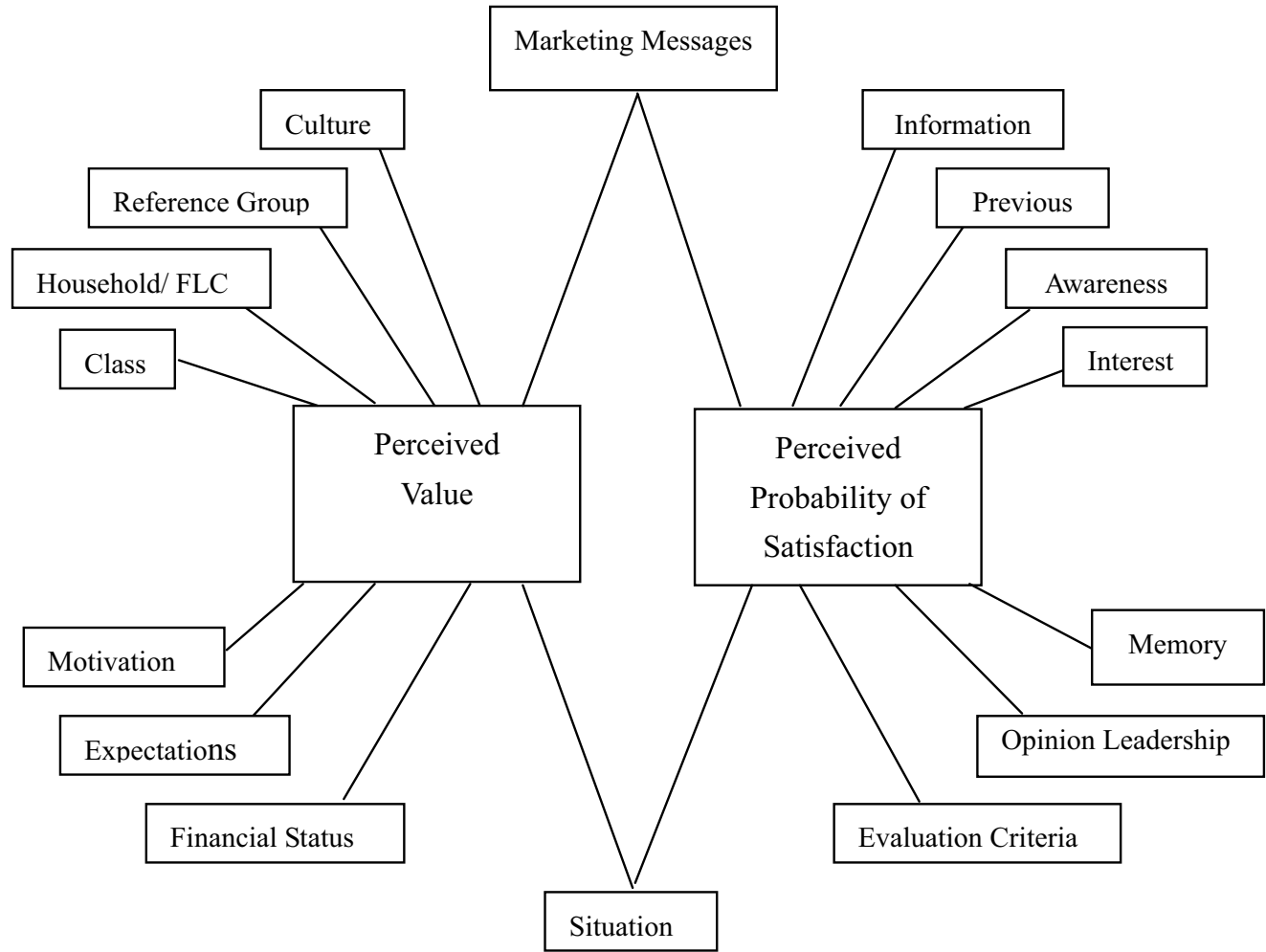

Figure 6. Perceived value/perceived probability of satisfaction model of consumer decision making.

(Adapted from Rice, 1997)

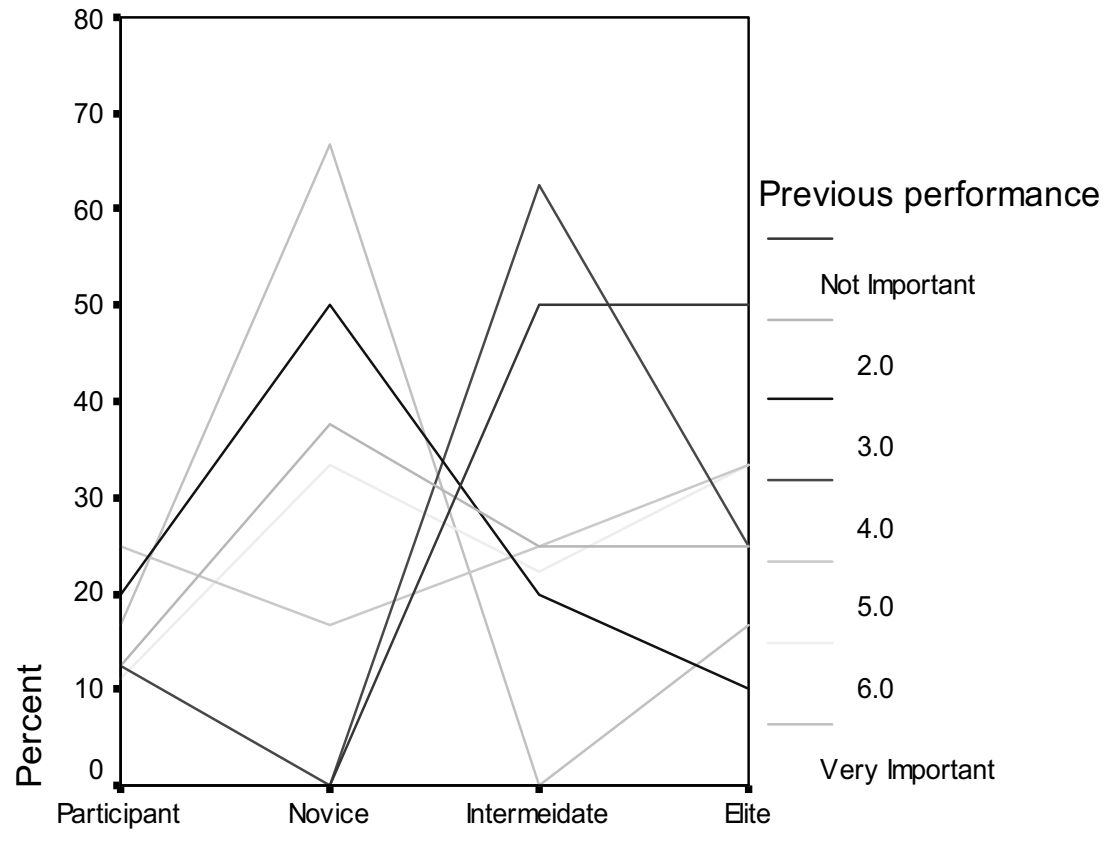

Level of athlete

Figure 7. Level of Athlete's choice based on their previous performance 


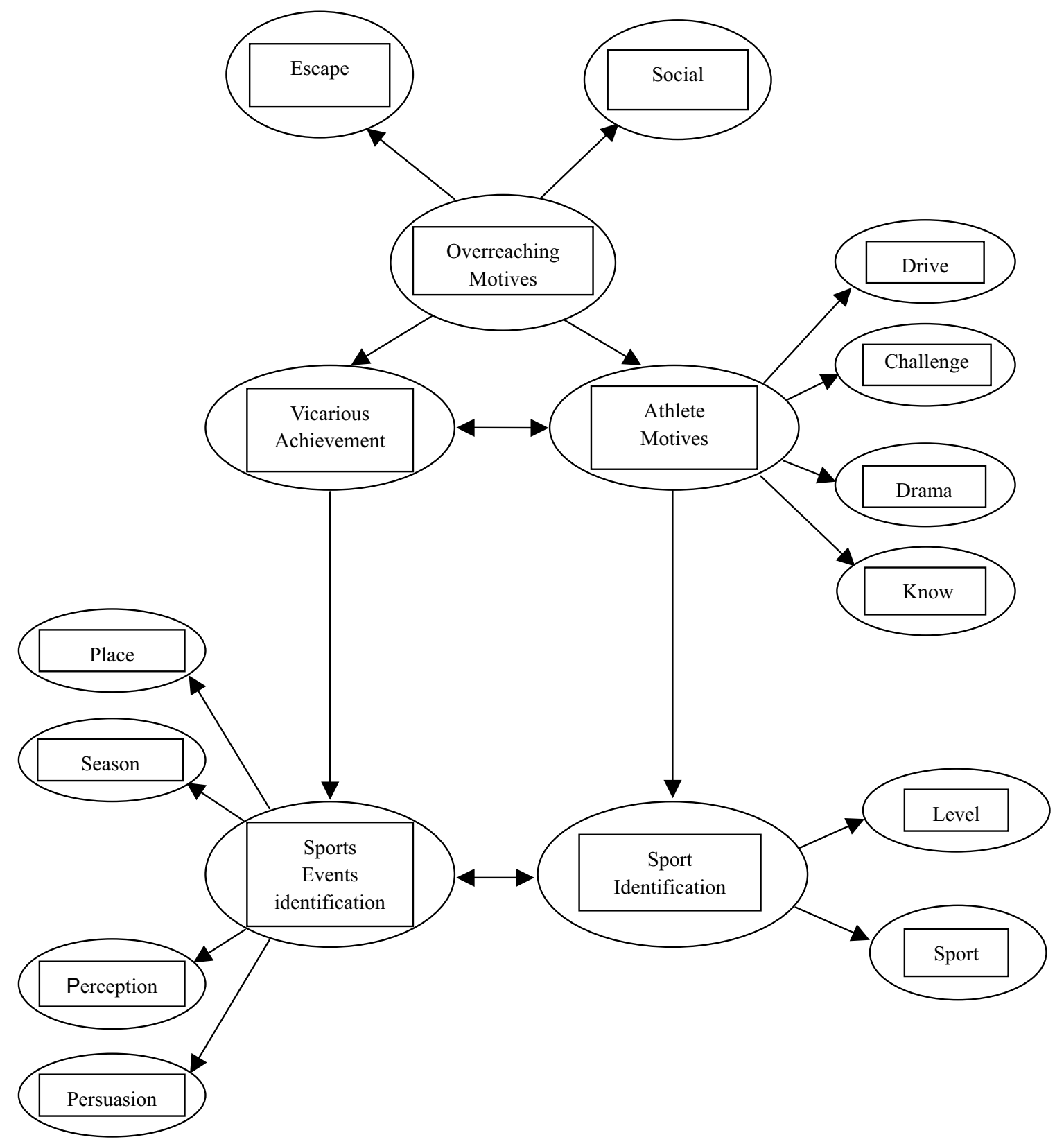

Figure 8. Sports Consumer Behaviour Motives Model

(Funk, Mahony, Nazakawa \& Hirkawa 2001) 


\title{
Causes and Sources of Waste in the Printing Industry in Ghana: A Study of Printing Houses in the Cities of Accra and Kumasi
}

\author{
Ashford C. Chea \\ School of Business, Stillman College \\ $19258^{\text {th }}$ Ave. $\# 12 \mathrm{H}$ \\ Tuscaloosa, AL 35401, U.S.A \\ Tel: 1-205-366-8829 E-mail: achea@ix.netcom.com
}

\begin{abstract}
This study was undertaken in the summer of 2006 to identify the causes of waste in the printing houses in two major cities in Ghana, namely, Accra and Kumasi. The scope of the study was limited to printing houses operating in the above cities only. The relevant literature on offset lithographic printing, the categories and causes of waste, and its effects on the environment were reviewed. The method used in gathering data for the study consisted of questionnaires that were sent out to fifty-five printing houses in Accra and Kumasi. Forty-seven printing houses responded to the questionnaires. The data were thoroughly analyzed and, where necessary, presented in tables. Finally, findings are discussed, implications outlined, recommendations and areas of future research proposed, and conclusion drawn.
\end{abstract}

Keywords: Ghana, Industry, Printing, Houses, Waste, Environment

\section{Introduction}

The problem of spoilage and waste control in the printing industry in Ghana cannot be overemphasized. It had been discussed in workshops and seminars. Observation showed that waste created in printing houses in the cities of Accra and Kumasi was enormous-a lot of papers, inks, darkroom chemicals, films, and plates. The practice has become a normal trend for the employees and management of these printing houses, without realizing the effect waste poses on the customers, the company, the environment, and the Ghanaian society as a whole. The quantity of waste created affects the production cost, and its disposal poses a threat to the environment. In Ghana, the disposal of printing waste doesn't cost printing houses financially. Even though there are laws governing the proper disposal of waste, these laws are not enforced. Since there are no stringent penalties for improper disposal of waste and spoilage, printing houses dispose of their waste anyway - in gutters, in dumpsters, in rivers, and on the land. This study was taken during the summer of 2006 to investigate the causes of excessive waste/spoilage generated in printing houses in the cities of Accra and Kumasi in Ghana.

\section{Objective and Scope of the Study}

The objective of this study was to identify the causes and sources of waste in the printing houses in the Ghanaian cities of Accra and Kumasi. The scope of this study was limited to the causes and reduction of spoilage and waste in the printing industry in Ghana. The study involved forty-seven (47) printing houses in the cities of Accra and Kumasi. It primarily focused on the causes of spoilage of materials such as papers, ink, plates, and chemicals. The research question was: What material is the greatest contributor to waste generated in printing firms in the cities of Accra and Kumasi?

\section{Literature Review}

Waste is defined as something lying unproductive, inhabited, or desolate. Generally all waste appears in three forms, namely: solid waste, wastewater (liquid waste), and air emission (Appiah, 2002). Waste reduction which is vital to the growth and development of printing houses in Ghana cannot be overemphasized. In order to run a printing house as economically and efficiently as possible, one should reduce all types of wastes including hazardous wastes, solid wastes, and air and water emissions. Waste generation is inevitable in printing industry. All the printing processes, namely, offset lithographic printing, gravure printing, flexography/letterpress, and screen printing use materials and chemicals that generate waste. When the waste generated causes financial loss to a company and poses a threat to the environment-air, water, and land, then it becomes a problem to society at large. This study reviews literature on waste generation and reduction in offset lithographic printing. 


\subsection{The Printing Industry}

The printing industry uses various printing technologies for printing books, magazine, newspapers, business documents, catalogs, form, etc. These technologies include lithography, rotogravure, flexography, screen, letter-press, and digital technologies including inkjet and electro-photography. The use of these technologies depends on the required quality of the print, number of impressions to be printed, availability of required resources, cost of the equipment, consumables cost per unit, need to use variable content, and other factor (Romano, 2004).

\subsubsection{Overview of Offset Lithographic Printing}

Offset lithographic printing is the predominant process used in printing today. In the United States, it is currently the most prevalent printing technology. According to an estimate by A.F. Lewis \& Co., a market research firm specializing in the graphic arts industry, there are over 53,000 establishments employing the printing process, and approximately 49,000 of these use lithographic presses. Lithographic printing is likely to remain a viable technology for the long term for static, long run jobs either as a standalone technology or as a component of hybrid production (Romano, 2003). Digital color printing is poised to grow significantly over the next five years with the primary growth driver being cost reduction (Dalessandro, 2001). In Ghana, a survey of forty-seven (47) presses in the cities of Accra and Kumasi conducted by the author of this study shows that all of the printing houses use lithographic presses. The success of the lithographic printing is due to the ability of the process to produce high quality text and illustrations cheaply and effectively in short, medium, and high volume production runs.

Lithography is used for a wide range of items from letterheads to books and magazines. Some other applications of the lithographic printing process include advertising, envelops, labels and tags, stationery, greeting cards, and packaging. However, the ascendancy of the lithographic process may soon be challenged by both improvements in flexography and relatively new plate-less technologies, which make up the fastest growing sector of the printing industry in both developing and developed countries (Hird, 1991).

\subsubsection{Types of Lithography}

The lithographic printing is divided into three separate sub-processes: sheet fed offset, heat set web offset, and non-heat set web offset. Sheetfed presses refer to presses designed to print a single sheet of paper at a time. They are built to pick up individual sheets of paper from a feed table. Sheets are delivered equally, one at a time down a feedboard to the printing unit (Appiah, 2002). Sheetfed presses constitute the majority of presses in offset lithographic printing. The web offset presses are so named because of their use of rolls of paper which are continuously fed into the press. Only a few of lithographers use the web offset process. In heatset web offset printing, inks are dried using a recirculating hot air system. This type of printing is very useful for high-volume, high-speed production runs (up to 40,000) impressions per hour); however, the ink drying process involved may result in volatile organic compound (VOC) emissions that must be controlled. In contrast, non-heatset web offset process often uses inks that do not require assisted drying. Each of these sub-processes has some distinct environmental and human health impact (Romano, 2003).

\subsubsection{Classification of Waste}

It is important to note that waste do differ from process to process and the methods of reducing waste in one printing process do not necessarily apply to other printing processes. There are three major waste streams found in the printing industry. They include: (a) solid waste - in general printing environment solid waste could consist of the following: empty containers, used film packages, outdated materials, damaged plates, developed films, dated materials, test production, bad printing or spoilage, damaged product, and scrap papers (b) water waste - water waste from printing operations may contain lubricating oils, waste ink, clean-up solvents, photographic chemicals, acids, alkaline, and plate coatings, as well as metals such as silver, iron, chromium, copper, and barium and (c) air emissions - printing operations produce volatile organic compound emissions from the use of cleaning solvents and inks, as well as alcohol and other wetting agents used in lithographic printing. Larger plants can be the source of sulfur dioxide emissions (Lewis, 1982). Finishing operations may include final trimming, die cutting, folding, collating, binding, laminating, embossing, and assembling operations. Binding methods include stitching (stapling), gluing, and mechanical binding. The primary waste are binding and laminating chemicals and scrap papers (Banerjee, 2001).

\subsubsection{Waste and the Environment}

An awareness of environmental, health, and safety issues plays an important role in the identification of printing technologies. Lithographic printers may not be familiar with available government-supported environmental information programs, and may rely primarily on vendors, suppliers, customers and trade association for such information (Rothenberg, Toribio, and Becker, 2002).

Printing operations use materials that may adversely affect air, water, and land resources: certain chemicals involved in printing volatilize, which contributes to air emissions from the facility and to smog formation; other chemicals may be discharged to drains and impact freshwater or marine ecosystem; and solid waste contribute to the existing local and 
regional disposal problems. There is a growing concern in Ghana about industrial waste and pollution, health and safety hazards to industrial workers, public health problems due to adverse environmental changes and the misapplication of hazardous chemicals. Atmospheric pollution associated with Ghana's industrialization activities result mainly from combustion processes. These pollutants tend to be in the form of particulate matter, smog, odor, and nuisance gases. These emissions contain varying amounts of gases such as nitrogen, hydrocarbons, and carbon. Apart from the health problems caused by these gases, they also contribute to the problem of acid rain. In recent years, hydrocarbons have been identified as substances contributing to the global ozone depletion problem (Tilley, 1999).

In the printing industry inks such as web offset heatset and non-heatset inks contain hydrocarbons in their formulation. The improper disposal of fixer, for instance, can be very harmful to the environment. The disposal of fixer is a big problem for the environment (Appiah, 2002).

\section{Method}

The method used in carrying out the study includes both primary and secondary sources of information gathering. Books, articles, and relevant documents were reviewed to help carry out this study. Structured questionnaires were used as instruments to solicit vital data. Questionnaires were used due to the large number of printing houses and time constraint. The questionnaires were distributed to fifty-five (55) printing houses in Accra and Kumasi.

\subsection{Sampling}

In the researcher's attempt to conduct an effective study, a population which was made up of all printing houses in Accra and Kumasi was considered. The sample size was made up of forty-seven (47) printing houses. The sample frame was chosen with the random sampling method with each printing house having not less than five employees. There are about 92 registered printing houses in Accra and Kumasi. Out of the 55 questionnaires distributed, an impressive number of 47 were retrieved. The responses were compiled, analyzed, and presented on tables. Comparisons and deductions were made and implications were drawn from the responses.

\subsection{Data Analysis}

Spoilage/wastage in a printing house cannot be done eliminated, but can readily be controlled. There are many causes of spoilage/wastage in a printing house. The data gathered will help find out from the printing houses selected, the causes of spoilage/wastage in the presses; their ways of disposal; the effects of spoilage/waste on a company and the environment. This section groups the data collected into three sub headings. These include (1) grouping the printing houses in the sample (2) causes of paper spoilage/wastage and (3) causes of film and darkroom chemicals wastage/spoilage.

The questions used in collecting the data are stated and the responses are presented in tables. Deductions, inferences, explanations, and implications are then used to analyze the responses.

\subsubsection{Grouping of Responses}

The researcher's concern was to know the categories of printing houses studied. Three questions were asked to help gather responses for the stated intention. These questions are (a) how many workers are in the company? (b) what departments do you have? and (c) what equipment, materials, and chemicals do you use? Most of the respondents refused to write the number of machines and equipment they had; for this reason, the responses from the number of employees were used as the criteria for grouping the printing houses into three groups, A, B, and C. From the responses, companies with employees numbering 61-100 and above were grouped as A. Employees numbering 21-60 were grouped as B, and employees numbering 5-20 were grouped as $\mathrm{C}$. The number of employees available in a printing house and the quantity of goods produced determined the level of waste created. From the data gathered, the level of waste created by group A is expected to be higher compared to that of group B because they have more machines and workers, and they produce more. Group B is also expected to produce a higher amount of waste/spoilage compared to that of group C. Group C is expected to produce less waste/spoilage with regard to the number of machines, and workers and the quantity of production as compared to that of groups A and B. The responses are presented in the tables 1 and 2 .

\subsubsection{Causes of Paper Wastage/Spoilage: Machines}

The working condition of the machines in the printing house is as vital as the expertise of the machine operator. All the parts of the machine are supposed to work properly if quality of work is to be achieved. The feeder board, grippers, cylinders, rollers, delivery board etc., must be in place and functioning properly to avoid the malfunctioning or the total break down of the machines during production. This calls for the regular maintenance of the machines to keep them in good condition which will help in the reduction of waste in the printing house. In view of this, the researcher asked the following question: Do you have a maintenance schedule for your machines? The answer options to the question were Yes and No. $89 \%$ of the respondents have a maintenance schedule program. $11 \%$ do not have a maintenance schedule program. It could also be that, even though they do not have a schedule for maintaining their machines, they may have 
their own way of ensuring that their machines are in good condition for work. In a bid to know if the maintenance schedule was implemented by the printing houses under study, the researcher asked accordingly. From the data, $9 \%$ had a weekly maintenance schedule program, $42 \%$ had a monthly maintenance schedule program, $28 \%$ carry out a yearly maintenance schedule program, and $21 \%$ did not choose any of the options but had their own reasons such as (a) the machines are checked daily and will therefore not need a total maintenance section (b) the machines are not faulty and so if they are tempered within the verge of maintenance, they may develop problems and (c) they may even breakdown totally due to the constant removing of screws and bolts. The responses are presented table 3 .

It is encouraging to know that some sort of maintenance is carried out on the machines of the printing houses in one way or the other. How often the schedule of the machine is carried out may depend on the efficiency or the working condition of the machine. When machines break down due to poor maintenance, production time is wasted. And when a part of the machine is faulty, papers and other materials are wasted.

\subsubsection{Spoilage Allowance (Overs) Added To Paper}

Printing on the press demands that extra sheets be added to the actual number of sheets needed for the job. This is termed as overs or spoilage allowance. Overs are added to ensure that the correct number of copies a job demands is attained. On the average, the overs on a full color job should not exceed $15 \%$, and that of a single color job should not exceed $10 \%$. If overs for a full color job and single color job exceed their average percentages, it will cause waste. The objective of the researcher was to know the percentage of overs used by the respondents. This was to verify if the respondents use the right number of overs during a press run. The data show that the average percentage of overs added to a full color job should be more than that of a single color (black and white) job. Since more sheets are needed when printing full color. The responses are presented in tables 4 and 5 .

\subsubsection{Waste Control Policy}

A waste control policy is a guiding framework within which an organization controls its waste. This policy entails the dos and don'ts that will help reduce waste in a printing house. All printing houses should have a waste management policy that will help them reduce the amount of waste produced and then monitor its disposal. To achieve this, all the workers must be aware of the policy and know their various roles in implementing it. The researcher's aim was to know if there is any printing house that does have a waste control policy. Therefore, the following question was posed: Do you have rules that govern the controlling of waste? The answer options for this question were Yes and No. $72 \%$ answered yes to the question and $28 \%$ answered no, meaning measures have not been put in place to help check waste. This means that they are likely to generate a lot of waste in their daily activities in the printing house. It could also happen that some of the printing houses have the policy, but the workers do not know about it.

Policies must be implemented to prove their existence and to solve the problems for which they were made. Having a policy alone is not good enough. It has to be implemented at a uniform level in the printing house to achieve the aim for which it was initiated. For this reason, the researcher wanted to know if the respondents implemented their policies. The answer options to this question were Yes and No. $47 \%$ of the respondents answered yes to the question, while $53 \%$ responded no to the question. It can be deduced that $25 \%$ of the respondents have rules to control waste in their printing houses but do not implement them, leaving $47 \%$ who have a policy and at the same time implement it.

\subsubsection{Quality Control}

The researcher wanted to know if the quality control unit of the various printing houses inspects the jobs as they go through the various stages in the production process. From the responses, $79 \%$ of the sample frame has a quality control unit while $8 \%$ does not have any quality control unit or system in their printing houses. $13 \%$ did not choose any of the options but gave their reasons as: There were no departments in the printing house responsible for quality control, and every individual employee who works in the printing house from pre-press, press to finishing is trained to know about quality control which they apply in the working process. This implies that a higher percentage of the respondents have quality control/assurance units, which is a good sign. $13 \%$ do not have a quality control unit, but rather, every individual employee in each section is trained for that duty. This means that they may not need a structured quality control department or unit. The quality control unit in the printing house helps to avoid the generation of waste during production.

\subsubsection{Materials with High Rate of Spoilage}

The researcher wanted to find out the most wasted material in the press. The data reveal that paper records the highest percentage of spoilage/waste. Some respondents specified that newsprint is most wasted. Ink is considered to be the second most wasted material according to $11 \%$ of the respondents. Films, darkroom chemicals, and plates made up $8 \%$ of the respondents. The fact cannot be disputed that paper is the most wasted material in the printing house. The results of this question are presented in the table 6. 


\subsubsection{Paper Storage}

Printing houses normally buy their papers in bulk and keep them in storerooms for production. Papers must be stored in a proper storeroom. That is, a well-ventilated room with cabinets, good roofs without leakage, and good windows and doors. If paper is not well-stored, it can create a lot of problems for the printer. (Dimensional problems such as humidity, crumpling of the paper, color change of paper are examples). With paper, proper storage will avoid damage from temperature, humidity, and spills as well as physical damage. On this note, the researcher's focus was to know if printers encounter difficulties printing with stored papers. The responses gathered revealed that $32 \%$ encounter some difficulties when printing with stored papers, but $62 \%$ do not encounter difficulties in printing with stored papers. $6 \%$ did not choose any option. The $62 \%$ of the respondents that do not encounter problems when printing is quite encouraging. This is because if difficulties are not encountered, then waste is avoided. $32 \%$ of the respondents encounter difficulties when using stored papers because their papers are not properly stored.

\subsubsection{Temperature}

Paper is delivered in sealed packs; the temperature of the pack or the storeroom can be different. If a paper with a different temperature is exposed to the press room atmosphere, it will change the temperature of the air surrounding the stack and alter the surrounding humidity. If the relative humidity surrounding the stack is higher than the moisture content of the paper the edges of the stack will absorb moisture until it reaches the level of equilibrium. This can cause the paper to curl or have wavy edges.

If the relative humidity surrounding the stack is lower than the moisture content of the stack, the edges will release moisture into the atmosphere producing tight edged papers. Printing with wavy edge or tight edge paper generates a lot of waste. In view of this, the researcher asked the following question: Is the temperature in the pressroom the same as that of the storeroom? The answer options for the question were: Always, Never, or Sometimes. The data collected show that $34 \%$ of the respondents said their pressroom temperature is always the same as the storeroom temperature. $32 \%$ said the temperature is never the same. $26 \%$ said the temperature is sometimes the same, and $8 \%$ gave no response. Those who responded that their pressroom temperature is always the same as the storeroom will not have problems when printing with stored papers. It would not even be necessary to condition the papers before printing. Those who said it is never the same are likely to generate a lot of waste when printing with stored papers if they do not condition the papers. The $26 \%$ who said the temperature is sometimes the same are likely to generate waste as well if they do not condition their paper before printing on it. This is because a change in temperature can occur at anytime. To avoid wasting paper, it has to be conditioned all the time.

\subsubsection{Paper Conditioning}

This is a term given to the process of allowing paper to adjust to the temperature or the humidity of a given area. The greatest enemy of paper in the press is temperature. Changes in humidity cause changes in the paper's properties. The physical properties of paper are affected by moisture to some extent. The one that concerns printing houses most is dimensional stability, which relates to changes in size and shape of the paper. Sheets that have wavy edges and tight edges are difficult to feed through the gripper system which can cause papers to crease on the press and destroy the blanket. The problems mentioned above accounts much of the waste in the printing house. The only way this can be reduced is for printers to condition paper before it is used. In view of this, the researcher wanted to find out if the respondents condition the paper before using it, and therefore asked the following question: Are sheets of paper conditioned before use? The answer options were Always, Never, and Sometimes. The responses to this question reveal that $21 \%$ of the subjects always condition their papers before using them. $17 \%$ never condition their paper before using it. $53 \%$ sometimes condition their paper before using it, and $9 \%$ did not respond. The $21 \%$ who always condition their paper before printing are engaged in a very good practice, which will help them in reducing paper waste to the minimum. It is obvious the $53 \%$ are not ignorant of the practice. They sometimes ignore the practice due to pressure on the press floor, which forces them to print within a very short notice, without conditioning the papers. The $17 \%$ who never condition their papers may have the temperature in both the pressroom and the storeroom being the same. Therefore it becomes unnecessary to condition paper.

It is a bad practice to print on sheets of paper without conditioning them. This is because it can lead to the generation of a lot of waste. Conditioning the paper is also very important. Some printers allow just a short time for paper to condition when it is brought to the press. The standard time limit for a paper to condition is 24 hours.

If the temperature in the pressroom and the storeroom are almost the same, the papers can adjust in just a short time. Therefore, it is always advisable to allow at least one hour for paper conditioning before safe printing. If paper is conditioned for less than an hour, it is likely to have dimension stability like tight edges, wavy edges or poor feeding. This causes a lot of paper spoilage during printing. Some other problems that cause paper spoilage are as follows: (a) bad weather conditions and (b) discolored paper. 


\subsubsection{Causes of Plate Waste/Spoilage}

The research revealed that $8 \%$ of printing plates were processed in house, whereas $11 \%$ were done outside. The concern of the researcher, however, was to establish the various complications that are associated with plate processing, and that are likely to cause waste or spoilage. To this end, the respondents were asked to state complications in plate usage. The data show that $30 \%$ of the respondents encountered the problem of over exposure, $26 \%$ had the problem of under exposure, and $28 \%$ encountered problems due to weak chemicals. $16 \%$ did not choose any of the options. In addition to the options chosen, some respondents added other problems that can cause plate wastage/spoilage. These include (a) expired plates sold out to printer (b) poor stripping (c) outdated or expired plates (d) improper application of chemicals (e) unstable electricity current, and (f) faulty plate making machine. The data presented imply that printers develop one problem or the other when developing plates. Under exposure occurs when the light source for plate burning is not strong enough or when the required time for developing the plate is not reached. Images on this plate cannot be made sharp for printing and must be discarded. $30 \%$ also faced the problem of over exposure. When plates are over exposed, the images get distorted and the plate cannot be used in printing. Nothing can be done to reverse this effect and the plates therefore go to waste. After plates have been exposed, they are developed with chemicals. The chemicals are negative and positive plate developers. If these chemicals are not strong enough to remove all the coatings on the plate to make the image sharp the plate will not be suitable for use. This causes the plates to go to waste.

\subsubsection{Plate Storage}

If plates are not well stored, they may get destroyed at any time, because they are very sensitive to light, water, and scratches. The researcher's aim was to find out the causes of plate wastage/spoilage during storage and if plates are reused or discarded after production. For this reason, the researcher asked the following question: Are plates stored and reused? The answer options were Yes and No. The data show that $72 \%$ of the respondents said they store their plates and reuse them, and $11 \%$ do not store their plates. $17 \%$ did not choose any option. The information implies that $72 \%$ store their plates with preservatives and use them again when needed. Some printers encounter problems when using stored plates. The preservatives sometimes get stuck to the plates and will not come off. $11 \%$ do not store their plates at all. They make new ones whenever they need to do a re-print. This happens especially with newspaper and magazine printers. This practice costs a company a lot of money since it will have to make a new plate for every re-print. The old plates go to waste. The data gathered are presented in Table 7.

The researcher wanted to know why stored plates sometimes go waste. He therefore asked the following question: "Do stored plates go to waste?" If yes, what amounts to the waste? The following options were given: (a) Poor storage (b) Outlive their number of impressions and (c) Others. The responses show that $19 \%$ said plates go waste due to poor storage. $32 \%$ also admitted that plates outlive their number of impressions, and $28 \%$ gave their own reasons why plates go to waste in their printing houses: These include, for example, a publisher seeking a re-printing of a previously printed work, and changes such as changes in pages and dates are to be made. Other instances involve bad storage conditions and temperature, and the use of too much deleting fluid on the plates. When plates are stored in a damp place, oxygen will act on the plate causing the plates to rust. Plates are made to only withstand a certain number of impressions after which they become unsuitable for reuse. When a plate outlives its number of impressions, it becomes unsuitable for reuse. The responses to this question are presented in the table 8 .

\subsubsection{Disposal of Waste by Printing Houses and Its Effect on the Environment}

Wastes created in the printing house must be disposed of. The disposal methods can cause a serious threat to the environment and human life. It is the social responsibility of the company to make its surrounding community a pollution-free environment. The researcher wanted to know how the wastes created by the printing houses were disposed of. In view of this, the question below was asked. How are the following waste materials disposed of: paper, ink, plate, films/darkroom chemicals? The results show that $67 \%$ of the sample frame burn their waste papers. $21 \%$ sell them to paper-making companies, $10 \%$ dump them in the dumpster, and $2 \%$ did not choose any of the options. $39 \%$ of the respondents pour their ink waste into the drains. $36 \%$ keep them in containers for reuse, and $20 \%$ burn their ink waste. $79 \%$ of the respondents sell their waste plates to the local aluminum pot makers. $11 \%$ use them for items such as calendar, while $6 \%$ throw them away. $74 \%$ of the respondents burn their waste films, while $26 \%$ throw them away. The responses also show that $67 \%$ pour their waste darkroom chemicals into the drains. $23 \%$ pour them away anywhere outside the printing house, and $10 \%$ did not choose any option. The statistics presented above shows that most of the methods used by the printing houses in disposing of the waste generated are not environmentally friendly.

\section{Summary of Findings}

The following findings were derived from this study. The study revealed that a good number of the printing houses had maintenance schedule programs and just a small number of them did not have them, but they had other ways of making certain that their machines are in good condition for use. It is established that a high percentage of the respondents had a waste control policy, but some of them did not implement it. The research again revealed that a 
large number of the respondents have a quality control unit. Others do not have a structured department/section assigned for checking quality but have trained all their employees in the area. There were some who did not have a unit for quality control at all.

It is established in this study that paper is the most wasted material in the printing houses followed by ink, plate, films, darkroom and chemicals. It is also established that many printing houses do not encounter difficulties in printing with stored papers. Just a few printing houses face problems when printing with stored papers because they do not carry out paper conditioning practices, or they go about it in the wrong way. It was discovered that a large percentage of the respondents admitted the temperature of their storeroom is the same as the pressroom.

Another finding was that the plates are stored with preservatives and reused.

A majority of the respondents process their plate in-house. Some printing houses do not store their plates and reuse them, but make new ones when needed. Storage of unused or new plates does not cause very much waste compared to already processed plates because workers pay more attention to the proper storage of new plates. It was discovered that a majority of the printing houses determine the quantity of ink needed for a job by estimates. Others also determine the ink needed by experience. Finally the research unveiled the fact that the methods of disposal adopted by printing houses studied were not environmentally friendly. In terms of the limitation of the study, the researcher couldn't cover a wider area in the population due to the lack of time.

\section{Recommendations and Managerial Implications}

Companies can use a variety of ways to reduce the amount of waste they generate while increasing their operational efficiency. Best management practices (BMPs) create the most cost-effective way to decrease the amount of waste generated from operations. BMPs require building an employee commitment and interest in waste prevention, as well as managerial support, to encourage participation in waste prevention programs. This includes a careful control of raw materials, practical scheduling, and job management. Other potential hazardous waste reduction techniques for printing houses require good housekeeping. Good housekeeping measures can greatly decrease the amount of waste that a firm generates. For example, a good housekeeping and maintenance program can help to ensure that all machinery and processes are working well with no leaking valves and tanks. Similarly, to reduce excess waste production, printing houses should: (a) Make sure container lids are tight fitting whenever they are not in use to prevent loss of chemical through evaporation or spoilage. Keeping lids on containers also prevents contamination with water, dirt, or other materials (b) Use spigots and pumps when dispensing new materials and funnels when transferring waste to storage containers to reduce the possibility of spills (c) Store products in locations that will preserve their shelf life. For instance, solvents should be kept in locations protected from extreme temperatures (d) Never mix different types of waste together. Mixing wastes may make recycling impossible or make waste disposal more expensive and (e) keep printing houses clean and orderly to prevent accidents and spills.

Several implications for managers were drawn from this study. First, managers need to train their employees in the proper operation of printing equipments to minimize waste created through misuse, and ensure that all employees are aware of and are familiar with company waste reduction programs, policies, and objectives. Second, managers need to set up an employee waste reduction committee. Third, they need to order and manage materials to minimize inventory going out of date and becoming a waste. Fourth, management should implement a first-in first-out inventory policy for materials with a limited shelf life. Fifth, managers should inspect all materials received and off-specification or damaged materials should be returned immediately to vendors. Sixth, they should store ink according to manufacturer instructions to prevent skinning and drying, and ink should be kept in locations that will preserve its shelf life. Finally, managers should centralize responsibility for storing and distributing solvents.

This study also has an implication for the literature on waste management in the printing industry, particularly regarding the adoption of waste management practices such as best management practices and good housekeeping standards. This study likewise contributes to previous research on waste management in the printing industry in Ghana. Prior research had used an in-depth qualitative case study to explore the effectiveness of a firm's waste management approach. In this current study, the researcher took a different approach by using a larger sample of printing houses and a quantitative approach to assess and analyze the causes and sources of waste in printing houses in Ghana.

\section{Areas for Future Research}

An important task for future research would be to further examine the relationship between different forms of waste and their impact on the environment. Future research might also continue to explore the alternative waste management strategies and their effects on printing houses' operating costs and profitability. Another promising avenue for further study would be to expand the study of waste generation in printing houses to include firms in other cities in Ghana.

\section{Conclusion}

Waste in the printing houses, as stated earlier, can be controlled but cannot be totally eliminated. Refusing to control 
the waste generated in a printing house means that production costs will rise, customers will drift, the company's profit will reduce drastically, and the environment will be polluted. The findings of this research reveal that a lot of waste is being created in printing houses, some of which can be prevented or reduced if workers make a conscious effort to manage printing waste

\section{References}

Appiah, I. K. (2002). Printing techniques. Kumasi, Ghana: Kwame Nkrumah. University of Science \& Technology Publishing.

Banerjee, S. B. (2001). Managerial perceptions of corporate environmentalism: Interpretations from industry and strategic implications for organizations. Journal of Management Studies, 38, 489-513.

Dalessandro, W. (2001). Critical issues in strategic corporate environmental management. Arlington, MA: Business and the Environment, Cutter Information Corp.

Hird, K. F. (1991). Offset Lithographic Technology. Tinley Park, Ill: Goodheart-Willcox Company, Inc.

Lewis, P. V. (1982). Managing Human Relations. Boston, MA: Kent Publishing Company.

Romano, F. (2003). The state of printing in the United States. Electronic Publishing, 27:12.

Romano, F. (2004). An investigation into printing industry trends (PICRM-2004-01). Rochester, NY: Rochester Institute of Technology, Printing Industry Center.

Rothenberg, S., Toribia, R. \& Becker, M. (2002). Environmental management in lithographic printing (PICRM-2002-07). Rochester, NY: Rochester Institute of Technology, Printing Industry Center.

Tilley, F. (1999). The gap between the environmental attitude and the environmental behavior of small firms. Business Strategy and the Environment, 8, 238-248.

Table 1. The Number of Employees in the Printing Houses

\begin{tabular}{|c|c|c|}
\hline Number of Employees & Number of Respondents & Percentage \\
\hline $5-10$ & 17 & $36 \%$ \\
$11-20$ & 7 & $15 \%$ \\
$21-40$ & 10 & $21 \%$ \\
$41-60$ & 6 & $13 \%$ \\
$61-100$ & 3 & $6 \%$ \\
101 and above & 4 & $9 \%$ \\
\hline Total & 47 & $100 \%$ \\
\hline
\end{tabular}

Table 2. The Number of Printing Houses in Each Group

\begin{tabular}{|c|c|c|}
\hline Groups & Number & Percentage \\
\hline A & 7 & $15 \%$ \\
B & 16 & $34 \%$ \\
C & 24 & $51 \%$ \\
\hline Total & 47 & $100 \%$ \\
\hline
\end{tabular}


Table 3. Implementation of the Maintenance Schedule

\begin{tabular}{|c|c|c|}
\hline Options & Number of Respondents & Percentage \\
\hline Weekly & 4 & $9 \%$ \\
Monthly & 20 & $42 \%$ \\
Yearly & 13 & $28 \%$ \\
Others & 10 & $21 \%$ \\
\hline Total & 47 & $100 \%$ \\
\hline
\end{tabular}

Table 4. Percentage of Overs on Full Color Jobs

\begin{tabular}{|c|c|c|}
\hline Range Of Overs & Respondents & Percentage \\
\hline $1-5$ & 14 & $30 \%$ \\
$6-10$ & 16 & $34 \%$ \\
$11-15$ & 6 & $13 \%$ \\
$16-20$ & 4 & $8 \%$ \\
Others & 7 & $15 \%$ \\
\hline Total & 47 & $100 \%$ \\
\hline
\end{tabular}

Table 5. Percentage of Overs on Single Color Job

\begin{tabular}{|c|c|c|}
\hline Range of Overs & Respondents & Percentage \\
\hline $1-5$ & 30 & $64 \%$ \\
$6-10$ & 8 & $17 \%$ \\
$11-15$ & 0 & $0 \%$ \\
$16-20$ & 0 & $0 \%$ \\
None & 9 & $19 \%$ \\
\hline Total & 47 & $100 \%$ \\
\hline
\end{tabular}

Table 6. Materials with High Rate of Spoilage

\begin{tabular}{|c|c|c|}
\hline Option & Respondent & Percentage \\
\hline Paper & 35 & $75 \%$ \\
Plate & 3 & $6 \%$ \\
Ink & 5 & $11 \%$ \\
Films and darkroom \\
chemicals
\end{tabular}


Table 7. Reusing Stored Plates

\begin{tabular}{|c|c|c|}
\hline Options & Respondents & Percentage \\
\hline Yes & 31 & $72 \%$ \\
No & 5 & $11 \%$ \\
None & 8 & $17 \%$ \\
\hline Total & 47 & $100 \%$ \\
\hline
\end{tabular}

Table 8. Causes of Plate Spoilage/Wastage

\begin{tabular}{|c|c|c|}
\hline Options & Respondents & Percentage \\
\hline Poor storage & 9 & $19 \%$ \\
$\begin{array}{c}\text { Outlive the number of } \\
\text { impressions } \\
\text { Others }\end{array}$ & 15 & $32 \%$ \\
None & 13 & $28 \%$ \\
\hline Total & 10 & $21 \%$ \\
\hline
\end{tabular}




\title{
The Cultivation of Enterprise Accountants in the
}

\section{Era of Knowledge Economy}

\author{
Wenjun Chen \\ Ginlin College, Nanjing Normal University \\ Room 4-9-101 Jin Xin Garden, 68 Qing Liang Meng Street, Nanjing 210046, China \\ Tel: 86-137-7077-6770Ｅ-mail: chenwenjun1106@163.com
}

Yehua Yue

Ginlin College, Nanjing Normal University, Nanjing 210046, China

Tel: 86-138-5229-7206 E-mail: yueyehua1118@163.com

\begin{abstract}
Knowledge economy, as well as circular economy, has been the trend of the economic development of the world since the $21^{\text {st }}$ century. The development of knowledge economy requires people to strengthen their ability of replacing material resources with intellectual resources, realizing that participants in the economic activities are better educated. With knowledge economy coming, the society is eager for the high-quality people. No doubt, enterprise accountants are one of the different kinds of talents. But we may wonder what an accountant should have to meet the high requirements of knowledge economy. Consequently, this paper which combines the theory with the practice of enterprise accountants, deeply analyzes the problem of accountants' cultivation by an all-round and developing viewpoint from four aspects that is morality, consciousness, talent, and scholarship. It aims at making it possible for accountants to promote their cultivation to proper the accounting cause in the era of knowledge economy.
\end{abstract}

Keywords: The era of knowledge economy, Enterprise accountants, Cultivation

The talented, in the era of knowledge economy, are the precious treasure over currency fund and natural resources. Obviously, enterprise accountants are included. In this age, it is of greatly realistic significance to have an in-depth research on the cultivation of enterprise accountants. So the paper is planned to analyze the problem from four aspects that is mortality, consciousness, talent, and scholarship of enterprise accountants. There is a necessity to point out that compared to the cultivation of other talents, that of enterprise accountants has its own character. Besides, with our accession to the era of knowledge economy, accountants' cultivation is inevitably affected by the age.

\section{Morality is the fundamental cultivation of enterprise accountants.}

The accountant-held morality mainly refers to the cultivation such as political ideology, career ethics, etc. The cultivation of political ideology contains two factors: one is the cultivation on the world outlook, views of life, and values of accountants; another is accountants' ability to carry out the Party's policy initiatively.

In comparison with other work, accounting is a job of distinct characters of politics and ideology. It requires enterprise accountants to firmly hold a concept of serving users of accounting information and the socialist, and to put the social effectiveness of their jobs first. This principle should still be followed though the era of knowledge economy has come. To meet the requirements, enterprise accountants should learn the Marxism-Leninism, Mao Tse-tung Thought, Deng Xiaoping Theory and the concept of scientific development earnestly while working, continuously promote the cultivation on the world outlook, views of life, and values, and attempt to be socialist accountants with career ethics. Mortality is the behavior standard and rule in people's common life. Similarly, accountants' career ethics, which morally require accountants to get along with people and deal with things by proper attitudes and emotional thoughts to accomplish their work effectively, are the behavior standard and rule of enterprise accounting industry. Accounting is a particular work, as accountants have much connection with leaders, other employees, even the society at large, which indispensably exists the relation between reputation and benefits. Hence, it is necessary for an enterprise accountant to build a noble view of career ethics, have a strong feeling of social responsibilities and calling, and attempt to learn to deal with various social ties, especially those are related to the reputation and benefits. However, there is scarce possibility to promote the cultivation of career ethics within a few minutes. Consequently, enterprise accountants should persist in moral cultivation while working, and regularize their career behaviors by the principle of socialist morality to 
acquire better accomplishment.

\section{Good consciousness is the intellectual cultivation of enterprise accountants.}

Good consciousness which means insights and courage, is the cultivation that enterprise accountants have remarkable consciousness in advance, scientific anticipation and resolutely determination. "Only is good consciousness first under heaven", say the ancient. This reflects that the ancient have realized the importance of good consciousness to talents. While good consciousness is more important to enterprise accountants, as a result of the particularity of enterprise accounting. As to this aspect, some scholar has point out that researchers on accounting theory badly need talent, learners of accounting knowledge need scholarship, and accounting operators need good consciousness.

Advanced consciousness is a kind of foresight and sagacity, in essence of innovative ideology, which keeps ahead of others' thoughts. But it is necessary for accountants to have the ability of scientific anticipation to accomplish advanced consciousness. Scientific anticipation of enterprise accountants, from a macro-view, is an accurate prediction on the information, such as political and social thoughts of our time, the developing trend of social and accounting science. Besides, it requires accountants not only to know the present need of accounting information users, but also the need of the society in near future. While from a micro-view, enterprise accountants are expected to predict the future demand and feedback of users of accounting information.

\section{Talent is the capable cultivation of enterprise accountants.}

Talent, namely intellect and capability, is the ability of knowing and transforming the world. In the term of enterprise accountants, talent mainly indicates their working ability including basic skills and innovative abilities. Basic working skills, such as communication with accounting information users, the ability of providing various kinds of service and management, and so forth, are the prerequisite and base for enterprise accountants to accomplish their work. Innovative abilities which are determined by the character of accounting and the requirements of the age of cyber-economy, chiefly refer to accountants' abilities to supply services of creative significance. Enterprise accounting, an intellectual labor of innovation in essence, not only requires accountants to have the basic working skills, but also the abilities of continuous innovation, that is, only the accountants with high innovative abilities can competent the enterprise accounting. With the era of knowledge economy coming, our government is accelerating to build a state innovative system, and requires continuous innovation in all walks of life. No doubt, is it more important for enterprise accountants to innovate, as enterprise accounting is a creative work. Given this point, new requirements to the innovative abilities of enterprise accountants have appeared. Whether enterprise accountants has the potential of innovation, and put the innovative spirit into practice is the key for enterprise accountants to adapt to the new situation and competent their work.

\section{Scholarship is the knowledge cultivation of enterprise accountants.}

Scholarship is the knowledge that enterprise accountants should have. The knowledge cultivation of enterprise accountants, with distinct career character compared to that of talents of other careers, not only consists of solid specialized knowledge, but also the profound. This is determined by the character of enterprise accounting, and is the knowledge base for enterprise accountants to acquire the professional accomplishment.

Enterprise accounting, as a work with outstanding character of speciality and science, requires accountants to have solid specialized knowledge which involves two parts: one is the specialized knowledge of over one subject, another is of accounting. The reason is that enterprise accounting is going forward in the social and cultural environment where multi-subjects are interactive and infiltrative, and edge disciplines and new subjects spring up continuously, facing the increasingly abundant science and culture fruit of human beings. Therefore, it requires enterprise accountants to have profound knowledge, including all the culture knowledge conductive to enterprise accounting and the better abilities of writing and computer operating.

Obviously, it is of particular importance for enterprise accountants to persist in learning earnestly, and accumulate knowledge during a long time, in order to become talents with solid specialized and profound knowledge.

All in all, the connotation of enterprise accountants' cultivation is of great abundance, mainly including four aspects, that is, morality, consciousness, talent and scholarship. The four aspects, an organic whole, can not be divided, as they're mutual promotion and checks. Morality ranks the first among these four aspects, which is the political orientation and soul of enterprise accountants and the basic aspect of enterprise accountants' cultivation. Motivated by morality, consciousness, talent and scholarship, which are the intelligent aspects of the cultivation, and the intelligent conditions of the success of enterprise accountants. Furthermore, consciousness is based on talent and scholarship, and talent and scholarship are guided by consciousness. Consequently, we must research the cultivation of enterprise accountants by an all-round viewpoint. Not only do we research their morality which is the basic factor of the cultivation, but also the intelligence, namely consciousness, talent and scholarship. At the same time, we should use a developing viewpoint to research this problem, as the cultivation of enterprise accountants is a dynamic organic whole, changing and developing with the same pace of the society. 


\section{References}

Accounting Department of Ministry of Finance. (2006). Explanation of enterprise accounting standard. Beijing: The People's Publishing Agency.

Li, min. \& Li, Jiayi, (2006). Application guide of enterprise finance general standard. Shanghai: The Publishing Agency of Shanghai Finance and Economics University.

Ministry of Finance, (2006). Enterprise accounting standard. Beijing: The Economy and Science Publishing Agency. 


\title{
A Survey Research of Contemporary Management Development
}

\section{Practices In Malaysian Corporations}

\author{
Kian Aun Law \\ Faculty of Management and IT, UCSI, UCSI Heights, Kuala Lumpur, Malaysia \\ Tel: 60-3-9101-8880 E-mail: kalaw@ucsi.edu.my
}

\begin{abstract}
This survey was designed and developed to assess key issues related to management development practices in Malaysian corporations especially on needs assessment, programme selection, programme evaluation, and future directions and trends. The survey research instrument is a questionnaire that was distributed to 189 selected Malaysian corporations listed on the Main Board of the Bursa Malaysia or formerly known as Kuala Lumpur Stock Exchange (KLSE). These corporations represent a cross-section of local industries and was selected through stratified random sampling. The 16-percent or 31 responses were collated and the data analyzed and interpreted using descriptive statistics. The major findings suggest that despite being aware of the importance of MD practices to achieve productivity and enhance corporate performance, most Malaysian corporations are unsure how to practise MD. They seldom implement value-added MD programmes to improve managerial productivity and enhance managerial performance achievements. The main reason given is cost-effective considerations vis-à-vis actual bottom-line results. Specifically, the majority of the respondents articulated their concern over several areas such as the lack of needs assessment, indiscriminate programme selection, non-standardized programme evaluation and vague ideas about future directions and trends in MD activities. On the whole, the survey research suggests that there is a need for Malaysian corporations to redress the prevailing weaknesses so that any concrete management development initiative undertaken can produce the desired results and productivity outcomes including bottom-line achievements.
\end{abstract}

Keywords: Management development, Needs assessment, Programme selection, Programme evaluation

\section{Introduction}

Asian nations are aware of the critical impact of management development (MD) on organizational effectiveness and competitiveness (Jain, 1987) and as a result, MD is seen as an integral component of the corporate strategy and overall development of organizations (Heng, 1987). More recently, Bontis, Chua and Richardson (2000) argued that there exists a positive relationship between $\mathrm{MD}$ and business performance, in this regard, the discussion is receiving increased attention. Despite recognising the importance of MD to corporate effectiveness, very little research about MD has been conducted (Abdullah, 1994; Hamid, 1985). The purpose of this study is to survey selected corporations from the KLSE Main Board in Malaysia to understand the practices and trends in MD and to examine these issues by industry type.

Over the past 20 over years, the pace of development of the Malaysian economy has been considerably rapid. Throughout the 1970's, the economy grew at an average annual rate of 7.8 per cent (Malaysian Second Outline Perspective Plan, 1990). Strong growth in both public and private investment during this period stimulated domestic demand and contributed to a consistent rise in income and employment. The effect of global economic recession in the early 1980's and the severe worsening of Malaysia's external trade performance led to a general slow-down in growth. The second half of the 1980's saw the economy coming out of the recession and recording GDP growth rates of 6.7 per cent per annum.

During the same period, substantial structural transformation in the composition of output, employment as well as exports occurred. The manufacturing and services sectors respectively contributed 2.1 per cent and 3 per cent out of 6.7 per cent GDP growth per year during the period 1970-90 (Malaysian Second Outline Perspective Plan, 1991). Despite the performance of the manufacturing and services sectors over the past two decades, it is widely believed that these two sectors are significant in terms of their contribution to economic development, there is a lack of MD and training in the industries to support the national industrialization drive (Report of the Cabinet Committee on Training, 1991; Bontis, Chua \& Richardson, 2000).

Most Malaysian manufacturing and services industries are still using tangible assets such as buildings and equipment as an organizational performance measurement. The knowledge-based business environment that Malaysia and many other countries are currently developing requires a new model of MD which encompasses intangible assets such as MD 
practices that could help in establishing organizational competitiveness.

Very little research about MD has been conducted in Southeast Asian countries and none of the research has focused on what Malaysian organizations are currently doing in this field (Hamid, 1985; Hashim, Wafa \& Sulaiman, 2003). In the West, a substantial portion of MD research has focused on training techniques (Hughey \& Mussnug, 1997; Kaplan, Drath \& Kofodimos, 1987; Vinten, 2000) and assessment of different approaches (Burke \& Day, 1986; Garavan et al., 1995). However, very little research has focused on what organizations are currently doing in these areas including trends and issues (Saari et. al., 1988).

The purpose of this research is to survey current MD practices adopted by large Malaysian corporations in the manufacturing as well as services and trading sectors and to examine current MD issues and future trends. Specifically, the investigation focuses on topics such as training needs assessment, programmes selection, programme evaluation and future trends. The crucial role of MD in developing organizations has yet to be carefully examined in the Malaysian context. It is partly for this reason that this study was formulated to investigate contemporary MD practices of Malaysian corporations. It is hoped that the research findings would be able to throw some light on the emerging role and current MD practices in the Malaysian corporate sector.

More significantly, it is useful to know and understand the MD practices of the manufacturing and services sectors as it will provide insight into the overall picture of MD practices, particularly in the aspects of needs assessment, programme selection, programme evaluation and future trends. This information serving as a pedogogycal tool, would be useful to the management of organizations in Malaysia to improve their understanding of the importance and implementation of various aspects of MD practices.

Hence, to achieve the purpose and objectives of this study, an attempt is made to provide answers to the following research questions:

(1) What are the general MD practices of manufacturing, services and trading industries in Malaysia?

(2) Is there any relationship between MD practices and types of industries?

(3) What are the main perceived benefits when selecting MD approaches in manufacturing and services sectors in Malaysia?

(4) What are the trends and future directions of MD practices in the manufacturing and services sectors in Malaysia?

\section{Literature Review}

According to Taylor (1984), in order for corporate management to face the future challenges, their organizational success will require an all-out effort in every field of business management. He suggested that organizational development, especially $\mathrm{MD}$, will have to play a more important role in a well-coordinated programme of organizational changes. MD practices need to be interlinked with corporate policies and strategies in order to ensure organizational effectiveness.

Taylor (1984) also emphasized that it is imperative to develop managers for strategic thinking and action. This emphasis on the emerging role of MD is in line with current developments in the field of human resource management.

In the local context, a survey conducted by Hamid (1985) reported that 60.4 per cent of employer-respondents from Malaysian companies acknowledged the importance of MD programmes. The respondents attributed the objectives of their MD programmes to efforts in improving job skills, productivity and efficiency as well as preparing for management succession. However, the findings were limited to the various types of company such as the sole proprietor, partnership, private and public limited companies and does not differentiate between manufacturing and services industries in terms of their MD practices.

The need for MD in the corporate sector is crucial. As Malaysia is basically an open economy, the corporate sector, especially investment in the manufacturing sector, is expected to grow at more than 65 per cent annually (Malaysian Second Outline Perspective Plan, 1991). It is in this economically promising scenario that there emerges the future role of MD in enhancing and sustaining corporate viability, profitability and excellence.

Roos et al. (1997) argued that managers develop organizational competence through education and development. Intellectual agility enables managers to think of innovative solutions to problems and issues. Similarly, Hudson (1993) and Bontis (1998) regarded MD as the basis for building corporate human capital and capability.

Apart from stressing MD as the key strategic mechanism for developing organizational and managerial competency and capability, Doyle (1994) stressed the importance of effective MD in terms of systematic needs assessment. He observed that MD needs analysis has been traditionally conducted in a piecemeal approach. This view is affirmed by Mumford (1993) who pointed out that needs analysis should be consistently reviewed and modified in response to changing situational contexts.

In their study on MD programme selection, Burgoyne and Stuart (1991) contended that MD programme selection is 
viewed by practitioners simply as a way to choose a programme that matches its organizational objective and specific required content. Margerison (1991) found that MD programme selection had become a dynamic process and learner oriented rather than a static, product and instructor dominated. The studies illustrate the crucial need to examine the transfer of knowledge and behaviour of a MD programme to organizational work settings. In this context, Hogarth (1980), in his study on the effectiveness of MD on organizational performance identified six critical factors that affect the transfer of learning to the work place. They are (1) the support of the work environment; (2) the job itself; (3) organizational policy; (4) top management involvement and commitment; (5) organizational structure; and (6) economic situations.

In his study of programme evaluation, Mole (1996) advocated that evaluation should adopt a holistic perspective to the extent that how much of MD fits with the organizational needs and context. Smith (1993) affirmed that MD programme evaluation should integrate both internal and external organizational factors in order to be realigned with their learning, adaptation and renewal. In this regard, Brinkerhoff (1987) has proposed a six process model for evaluation purposes, namely, (1) evaluation of needs and objectives; (2) evaluation of design; (3) evaluation of operation; (4) evaluation of learning; (5) evaluation of usage and endurance of learning; and (6) evaluation of pay-off. Finally, Brinkerhoff's model assured a dynamic and interactive design by highlighting the multiple effects of MD and the recycling process of programme evaluation.

As there are many sources which have extensively reviewed the MD literature, the focus of this paper will be to examine the MD practices of large companies representing both the manufacturing and services industries in Malaysia.

\section{Methodology}

Given the important role KLSE Main Board listed companies play in the country's development, it was decided that the five major sectors, namely manufacturing, trading and services, construction and properties, finance and plantations be included in this study. As small companies might not practice MD, they were excluded from the research (Hamid, 1985). This study used a self-administered mailed-questionnaire that was sent to 189 out of 570 KLSE Main Board listed companies across industry types. Stratified random sampling was used to select the sample. Responses were obtained from 31 out of 189 companies giving a response rate of 16 per cent. These are responses with complete information indicated from the questionnaire. Partial or incomplete responses were rejected and not taken into consideration for the analysis. The respondents consisted of 15 manufacturing companies, 8 trading and services, 4 construction and properties, 2 financial and 2 plantation companies. Due to the small number of non-manufacturing and services respondents (i.e. construction and properties, financial and plantations), it was decided that services, construction and properties, financial and plantations companies be grouped together. Hence, the manufacturing companies will be referred to as $\mathrm{M}$; trading and services, construction and properties, financial and plantations organizations will be referred to as S\&T (services \& trading).

The questionnaire consisted of 35 itemized questions. It contained four main parts that measured training needs assessment, programmes selection, programmes evaluation and future trends. The questions were fundamentally based on the study by Saari, Johnson, MacLaughlin and Zimmerle (1988) and had been adapted to suit the objectives and goals of this survey research.

The survey by Saari et al. (1988) focused on the practices and trends of 611 small to large US organizations having at least 1,000 employees in the field of MD. The study examined topics such as needs assessment, MD approaches, reasons for selecting MD programmes, evaluation of the programme and programme content based on the following programme: university residential, executive MBA, short-course and company-specific. The research found that only $27 \%$ of the organizations conducted needs assessment. Multiple MD approaches, especially on-the-job training was reported to be widely used. Programme content and manager's needs were the primary factors when selecting MD programmes. The majority of organizations do not evaluate programmes and most organizations cited strategic planning and managing people as the most important programme content which needs more attention in the future.

The questionnaire used in this survey focuses on four major MD approaches, namely, the university residential programme, executive MBA, short course and company specific programme type. The questionnaire was to be completed by a person responsible for human resource especially in matters regarding management development practices. Respondents were encouraged to ask questions about the purpose of the survey through the telephone in order to ensure that the meanings of the questions were clear and fully understood.

The survey was based on questions with response categories or structured questions which need definite answers such as yes or no and other open ended categories or unstructured questions which allow free expression of respondents' opinions. Descriptive statistics, mainly, percentages were used to reflect the contemporary situation of management development practices of industry-type and their approaches to management development. A high percentage of response suggest a high degree of agreement with the statements of the questionnaire. 


\section{Limitation of the Study}

This research is based solely on survey methodology. Although the survey was based on a randomly stratified sample across industry type, their overall response on MD practices may not necessarily be representative of other Malaysian organizations, for example, companies listed in the Second Board of KLSE and other small and medium size enterprises. In short, as the research is only confined to larger organizations (companies with 500 or more employees and a minimum paid-up capital of RM60 millions), the findings cannot be generalized to represent the experiences of small and medium size companies (organizations with lesser than 500 employees and lower than minimum paid-up capital of RM60 millions). However, the information and data obtained from the study can be useful as a source of reference for studies in similar industry sectors in developing countries.

The low response rate of $16 \%$ is a limitation that can only compound the biases of the research findings which are confined to only, the M and the S\&T industries. A reason of low response rate could be because of the extensive questionnaire that requires a long time to answer that deter from more participation. However, a way to eliminate this bias is to include cross sectional sampling that covers more than just two-sector survey, such as involving samples of small, medium and large corporations across industry types in Malaysia, with better and more attractive questionnaire instruments.

This research mainly relies on observations, opinions and information provided by the respondents. In ascertaining the presence of MD, particularly the phases of needs assessment, programme selection and evaluation, there was no cost-benefit analysis made. This is because the data was analyzed without relating it to investment justification and rationale on MD practices. According to Garavan et al. (1995), MD should be presented as an activity that is able to fulfill a functional performance rationale with direct improvement on corporate benefits. The investment justification of MD will be made explicit considering the cost and benefits factors. Future research should remedy this limitation by addressing the issue in additional perspective.

When examining issues related to MD, it is suggested that future research should include SMEs (Small and Medium Size Enterprises) in order to create a more MD findings to Malaysian corporations in general. Thus, a large scale of survey should be conducted to include carefully selected samples of SMEs in order to understand the practices and trends in MD in Malaysian corporations.

In addition, it is also appropriate to conduct the similar research in the duration of every 5 years. This is suggested with the purpose to provide the most contemporary findings of MD in Malaysians corporations as current state of MD practices matters in terms of reflecting the mindsets of most organizational leadership.

Future research can also focus on governmental administrative development (besides private sector) by focusing the similar research merely on governmental organizations. As government is a focal point in business activities in Malaysia, it seems appropriate to have such research conducted to address the relevant developmental problems and issues in order to improve administrative effectiveness and efficiency.

\section{Result and Discussion}

This discussion is divided into four main parts namely, needs assessment, selection of programme, programme evaluation and future direction and trends.

\subsection{Needs Assessment}

The result shows that 83.8 per cent of the M and S\&T firms have a management training and development policy. This figure as indicated in Table 1 suggests that firms do recognize the importance of MD policy as part of corporate activity. M firms appeared to have instituted MD policy slightly more than S\&T. About 87 per cent of M firms and 81 per cent of S\&T firms have a policy that requires managers to participate in formal MD programmes. The reason both industries recognize the importance of MD policy could be because it is vital in attracting, retaining and developing competent management personnel.

The findings suggest that firms may recognize the importance of MD and consider it as important as corporate priority other than profit achievement. As a policy is a statement of intention of the organizations to practice $\mathrm{MD}$, it suggests that the corporations could have benefited at one time or another from MD practice.

Despite recognizing the importance of MD policy, the survey result shows that 90.4 per cent of all firms do not have needs analysis when it comes to MD practices. A total of 93.4 percent of M firms and 87.5 percent of S\&T firms have no specific documented procedures or practices for determining developmental needs of their managerial people. See Table 2. These results are relatively high when compared to the USA where more than two-thirds of the largest companies conduct systematic needs assessment procedures (Saari et al, 1988).

In other words, there is still no existence of a systematic or structured MD needs assessment approach and procedure. The main reason behind the findings may be related to the absence of professional knowledge in MD planning and the failure and reluctance to allocate funds for MD in Malaysia due to limited knowledge in MD. 
The findings also suggest that it could be possible that new managers have yet to benefit from existing MD programmes. Some are also unaware that their companies have not conducted needs analysis and have yet to internalize the policy through the implementation of recommendations and translate it into practical terms for the organization.

Being a public listed organization, the respondent organizations could have conducted needs analysis for their MD programme. But the issue is more of a financial one rather than a human resource one as the public listed corporations are always being pressured to perform financially. The corporations may not be able to understand the relationship between the MD programmes and company performance.

In addition, there could be existing MD programmes which are taken for granted and perhaps, these MD programmes need to be overhauled in order to produce better financial and human resource results.

The comparison of these results provides an important insight that: while both M and S\&T firms may be committed to MD through policies, they either disregard or fail to see the significance of integrating MD into their organizational strategic planning process. In other words, the corporations fail to recognize the strategic value of MD and are not well versed in establishing and implementing MD practices. It is suggested that there is a need for Malaysian corporations to change the perception of MD and learn to understand the strategic role of MD within their own organizations.

Table 3 shows that the companies have indicated their reliance on several sources of information which are based when considering needs of management training and development. The main sources are direct supervisors ( 93 per cent for $\mathrm{M}$ firms and 81 percent for S\&T firms) and performance appraisal results ( 80 per cent for M firms and 75 per cent for S\&T firms). 75 per cent of S\&T firms use changes in work as a method while 73 per cent of M firms rely on the attendees themselves as sources of training and development needs. Other types of sources used by these companies are promotion decisions and previous programme results. Manpower planning, is the least important source of information with 40 per cent of $\mathrm{M}$ firms and 37 per cent of S\&T firms using this method.

This study found that the reliance of companies on direct supervisors and performance appraisal results as sources of information is consistent with corporate management practices of developing economies. Ong (1987) suggested that coaching and supervising should be linked to performance appraisal reviews and results as these two are the synergistical elements of a performance management system.

It is suggested that as needs assessment determines the gap between the current and desired performance (Kaufmann \& English, 1979), the absence of systematic and structured needs assessment will be a severe drawback to Malaysian organizations' MD efforts. Thus, the knowledge of needs assessment and analysis may help to reduce MD cost by placing the right candidates in the right programmes.

\subsection{Selection of Programmes}

Table 4 shows the frequency of MD approaches for M and the S\&T firms in percentages. It is worth nothing that M and S\&T firms mainly rely on short-course and company-specific. A total of 80 per cent of M firms and 81 per cent of S\&T firms chose short-course, while 73 per cent of $M$ firms and 75 per cent of S\&T firms selected company-specific programmes. Most Malaysian companies adopt the least formal MD approaches when compared to the more formal programmes. This is evident from the fact that only 26 per cent of $M$ firms and 31 per cent of S\&T firms used university residential and 33 per cent of $M$ firms and 37 per cent of S\&T firms chose executive MBA when considering their management development approaches. Whether a corporation employs MD approaches depends on the industry with both M's firms and S\&T firms are most likely to have short-course and company-specific programme (73-81\% across industry type) and less likely on residential university and Executive MBA (26-37\% across industry type). Hence, it seemed that selection of MD approaches is dependent on the industry, in other words, the tendency of M firms and S\&T firms when selecting the MD approaches are towards short-course and company-specific rather than the university residential and executive MBA.

However, the results seem to be contrary to the findings of Saari et al. (1988) which showed that formal educational programmes were the most popular among US organizations. Thus, it is suggested that formal developmental programmes which has proven very popular and useful in the West, is rarely used in Malaysia. This could be because of the shortage of the formal developmental programmes.

Malaysian M and S\&T companies reported different reasons when selecting their MD approaches. Table 5 shows that the primary reasons indicated by $\mathrm{M}$ firms were to broaden the individual's perspective (54-80\% across approaches), a chance to interact with other executives (41-80\% across approaches), to obtain state-of-the-art knowledge and skills (45-75\% across approaches) and obtain general management education (45-80\% across approaches).

The least indicated reason when considering developmental approaches was reward to the executives $(20-36 \%$ across approaches). This was also found in Saari et al.'s (1988) study. Another less important reason indicated was to prepare individuals for their next job (25-41\% across approaches) 
It is worth noting that $\mathrm{M}$ firms reported that obtaining job-specific knowledge and skills was the primary reason when selecting short-course and company-specific developmental approaches. In this regard, short-course was indicated at 83 per cent and company-specific was indicated at 90 per cent. University residential and executive MBA was only indicated at 25 per cent and 20 per cent respectively. It is thus suggested that most Malaysian M companies opted for practical job related developmental activities rather than the formal MD programme.

This research also observed that $M$ firms perceived that University residential and Executive MBA benefited most in terms of broadening the manager's perspective, providing a chance to interact with others and obtaining general management education. The percentages recorded were at $75 \%$ for University residential and $80 \%$ for Executive MBA for all three reasons. Another primary reason considered when selecting formal educational programmes was to obtain state-of-the-art knowledge and skills for their participants respectively at $75 \%$ for Universilty residential and $60 \%$ for Executive MBA.

As for the S\&T firms (Table 6), their primary reasons for sending their managers to University residential and Executive MBA were to broaden their managers' perspectives and obtain state-of-the-art knowledge and skills. The percentages recorded at $80 \%$ and $83 \%$ respectively is relatively higher than $\mathrm{M}$ firms. When considering short-course and company-specific programme, the primary reasons were to obtain job-specific knowledge and skills, both at $84 \%$ and $83 \%$ respectively. This finding may reflect that the service and manufacturing sectors in Malaysia both put a similar emphasis on primary reasons when selecting the developmental approaches.

The perceived benefits when selecting MD approaches are shown in Table 7 (M firms) and Table 8 (S\&T firms). The most important reasons indicated are program content (75-92\% across approaches), the needs of participants (75-91\% across approaches) and the effectiveness of the program (75-92\% across approaches). There are major differences across approaches regarding the importance of program length (20-84\% across approaches) and the program fees (25-83\% across approaches). These five reasons are indicated as the most important factors when selecting and deciding on these developmental approaches. These results, in general, confirm with the findings of Saari et al. (1988)

\subsection{Programme Evaluation}

This research also shows that 93 per cent of $M$ firms and 87 per cent of S\&T firms have no systematic follow-up procedures for evaluating the effectiveness of MD programmes. When asked about the approach the organization uses to brief participants prior to attending the management development program, 86 per cent of $\mathrm{M}$ and $81 \%$ of S\&T firms reported that participants are not generally briefed before attending the programme. It is worth noting that 80 per cent of $M$ firms and 75 per cent of S\&T firms have no feedback from the participants regarding their assessment of the programmes attended.

This suggests that Malaysian companies generally lack organizational skills in evaluating MD programme effectiveness. These results concur with the study by Trapnell (1984) stating that effective evaluation should be multi-dimensional, aiming for improvement both in program design and effect. In another words, the evaluation should adequately assess its context, input, process, product and the final impact of the programme.

\section{Future Directions and Trends}

When asked about the company's use of current MD approaches in the next five years, 75 per cent of M and 81 per cent of S\&T firms expect an increase use. Table 9 and Table 10 show the main reasons both sectors gave for the increased usage of current MD approaches. They are the need to update managers on changing concepts/skills (75-83\% across approaches for $\mathrm{M}$ firms and 60-69\% across approaches for S\&T firms), new corporate emphasis on MD (50-75\% across approaches for $\mathrm{M}$ firms and $80-84 \%$ across approaches for S\&T firms). However, S\&T firms also reported more managers in their companies as a main reason for the increased use of MD approaches (40-75\% across approaches).

When asked about management development content areas and specific topics that need additional emphasis in the next five years, for M's firms users of University residential and Executive MBA, the most frequently indicated topics are strategic planning (77\%), managing human asset (66\%) and decision making (55\%). As for the short-course and company-specific programs, the emphasis is more on management and communication skills (65\%) and IT knowledge $(43 \%)$.

Finally, this research also observed that for S\&T firms, the topics that needed more emphasis for formal programs are strategic planning (54\%) and managing change (63\%). As for short-courses and company-specific programs, the emphasis is on job skills (52\%) and computers technology (40\%). These results are consistent with Mintzberg's (1980) management theory which indicate that formal education and development shape the knowledge of an individual (i.e. strategic planning, managing human assets and decision making) to develop conceptual skills whereas short-courses and tailored programs train organizational technical skills such as practical job skills and computer application knowledge.

\section{Conclusion \& Implications}

In conclusion, it appears that although Malaysian companies are conducting some aspects of MD, these efforts are still 
remained weak and deficient particularly in terms of needs assessment, programme selection and programme evaluation. With increased awareness of industrial competitiveness, inadequeate needs assessment, programme selection and programme evaluation will make organizations vulnerable to pressures of competition. Both manufacturing and services sectors are very reactive to the overall process of organizational MD at upgrading the Malaysian managerial skills and capabilities.

Even though the findings suggest that M and S\&T firms do have some awareness of the importance of MD practices, there is still much can be done to upgrade the knowledge of the entire MD process. If current attitudes among the Malaysian firms towards MD prevail, it could result in a gradual decline in overall organizational competitiveness as developing executives and managers is perceived as a key to organizational success and performance (Lees, 1992).

Thus, despite the difficulties that originate from negative attitude or lack of information about MD, adequate planning, implementation and follow-up of MD efforts of Malaysian companies could be established through consistent policy or initiative and implementation of MD programmes. It is suggested that systematic needs assessment, proper programme selection and effective programme evaluation should be practiced by the firms.

Proactive programme evaluation should focus on practical results and transference of knowledge and skill to the workplace. Kirkpatrick (1979), Vinten (2000) and Dikken and Hoeksema (2001), Mahieu and Stuart (2001), Kirkbride (2003) and Longenecker and Neubert (2003) argued that the most practical programme evaluation approach concentrated on effects of the application of learned concepts and information on the company. It is suggested that MD practices should be linked with other corporate activities (e.g. reengineering, organizational learning and knowledge management) to provide a clear perspective to organizations and managers about the practicality and application of learned knowledge and skills.

The findings of this study shed light on contemporary MD practices in Malaysia; the issues raised may be of value to both academics and practitioners in other developing countries. Deficient needs assessment, programme selection and programme evaluation need to be remedied. However, the increased use of MD approaches indicate a growing commitment among Malaysian firms to MD and suggest that companies are starting to concentrate on areas of MD practices.

\section{References}

Abdullah, W. A. (1994). Transnational corporations and human resource development. Personnel Review, vol.23, no.5, pp.50-69.

Bontis, N. (1998). Intellectual Capital: An exploratory study that develops measures and models. Management Decision, vol.36, no.2, pp.63-76.

Bontis, N., Chua, W. \& Richardson, S. (2000). Intellectual capital and business performance in Malaysia industries. Journal of Intellectual Capital, vol.1, no.1, pp.85-100.

Brinkerhoff, R. O. (1987). Achieving Results from Training, Jossey-Bass, London.

Burgoyne, J. G. \& Stuart, R. (1991). Teaching and Learning Methods in Management Development. Personnel Review, vol.20, no.3, pp.27-33.

Burke, M. J. \& Day, R. R. (1986) A cumulative study of the effectiveness of managerial training. Journal of Applied Psychology, vol.71, pp.232-45.

Dikken, L. S. \& Hoeksema, L. H. (2001). The palette of management development. Journal of Management Development, vol.20, no.2, pp.168-179.

Doyle, M. (1994). Organizational transformation and renewal: A case for reframing management development. Personnel Review, vol.24, no.6, pp.6-18.

Gavaran, T. N., Costine, P. \& Heraty, N. (1995). The emergence of strategic human resource development. Journal of European Industrial Training, vol.19, no.10, pp.4-10.

Government of Malaysia. (1991). Report of the Cabinet Committee on Training: Training for Industrial Development, EPU/Ministry of Education, Rita/National Printing Department, Kuala Lumpur.

Government of Malaysia. (1991). The Second Outline Perspective Plan, 1990-2000, National Printing Department, Kuala Lumpur.

Hamid, A. A. (1985). Management Education in Malaysia. Journal of the Malaysian Institute of Management, vol.8, no.1, pp.77-94.

Hashim, M. K., Wafa, S. A. \& Sulaiman, M. (2003). Strategic management in Malaysian SME's: An empirical assessment. Malaysian Management Review, vol.38, no.2, pp.28-38.

Heng, M. (1987). Developing Managers for Leadership: The New Imperative in J.H. Tan and P.S. You (Eds), 
Developing Managers in Asia, John Wesley, Singapore, pp.39-46.

Hogarth, R. (1980). Judgement and Choice, New York, John Wiley \& Sons.

Hudson, W. (1993). Intellectual Capital: How to Build it, Enhance it, Use it, John Wiley, New York, NY.

Hughey, A. W. \& Mussnug, K. J. (1997). Designing effective employees training programmes. Training for Quality, vol.5, no.2, pp.52-57.

Hussey, D. (1985). Implementing Corporate Strategy:Using Management Education and Training. Long Range Planning, vol.18, no.5, pp.28-37.

Jain, S. K. (1987). Management Education to the End of this Century: The Asian Scene in J.H. Tan and P.S. You (Eds), Developing Managers in Asia, John Wesley, Singapore, pp.11-26.

Kaplan, R. E., Drath, W. H. \& Kofodimos, J.R. (1987). High hurdles: The challenge of executive self-development. The Academy of Management Executive, vol.1, pp.81-92.

Kaufmann, R. and English, F. (1979). Needs Assessment: Concept and Application. Educational Technology, Englewood Cliffs, NJ.

Kirkbride, P. S. (2003). Management development: in search of a new role?. Journal of Management Development, vol.22, no.2, pp.171-180.

Kirkpatrick, D. L. (1979). Techniques for evaluating training programs. Training and Development Journal, vol.33, pp.78-92.

Lees, S. (1992). Ten faces of management development. Journal of Management Development, vol.23, no.2, pp.89-105.

Longenecker, C. O. \& Neubert, M. (2003). The management development needs of front-line managers: voices from the field. Career Development International, vol.8, no.4, pp.210-218.

Mahieu, C. \& Stuart, S. (2001). Management development in Royal Dutch/Shell. Journal of Management Development, vol.20, no.2, pp.121-130.

Margerison, C. (1991). Making management development work, McGraw-Hill, Maidenhead.

Mintzberg, H. (1980). The Nature of Managerial Work, Prentice Hall, Englewood Cliffs, NJ.

Mole, G. (1996). The management training in industry in the UK. Human Resources Management Journal, vol.6, no.1, pp.19-26.

Mumford, A. (1993). Management Development: Strategies for Action, IPD, London.

Ong, T. W. (1987). Designing and Implementing Successful Management Training and Development Programmes in J.H.Tan and P.S.You (Eds), Developing Managers in Asia, John Wesley, Singapore, pp. 77-83.

Roos, G., Roos, J., Edvinsson, L. \& Dragonetti, N. C. (1991). Intellectual Capital-Navigating in the New Business Landscape, NYU Press, New York.

Saari, L. M, Johnson, T. R., MacLaughlin, S. D. \& Zimmerle, D. M. (1988). A survey of management training and education practices in US companies. Personnel Psychology, vol.41, pp.731-43.

Smith, A. (1993). Evaluation and effectiveness. Journal of Management Development, vol.12, no.1, pp.20-33.

Taylor, B. \& Lippitt, G. (1984). Management Development and Training Handbook, McGraw-Hill, New York.

Trapnell, G. (1984). Putting the Evaluation Puzzle Together. Training and Development Journal, pp.90-92.

Vinten, G. (2000). Training in small-and-medium-sized enterprises. Industrial and Commercial Training, vol.32, no.1, pp.9-14. 
Table 1. Industry Type and Management Development Policy

\begin{tabular}{|c|c|c|c|}
\hline $\begin{array}{l}\text { Does your company have a policy that requires managers to participate in formal management } \\
\text { development programmes? }\end{array}$ & No & Yes & Total \\
\hline & $2(13.4)^{\mathrm{a}}$ & $13(86.6)^{\mathrm{a}}$ & 48.4 \\
\hline M & 6.5 & 41.9 & 16 \\
\hline S \& T & $3(18.7)^{\mathrm{a}}$ & $13(81.3)^{\mathrm{a}}$ & 51.6 \\
Percentage & 9.7 & 41.9 & 31 \\
\hline Total & 5 & 26 & 100 \\
\hline Percentage & 16.2 & 83.8 & 26 \\
\hline
\end{tabular}

Note: ${ }^{a}$ numbers in parentheses are the percentages of the total which the numbers represent.

$\mathrm{M}=$ Manufacturing firms

$\mathrm{S} \& \mathrm{~T}=$ Services $\&$ trading firms

Table 2. Industry Type and Needs Analysis

\begin{tabular}{|c|c|c|c|}
\hline \multicolumn{2}{|c|}{$\begin{array}{l}\text { Does your company have documented procedures or practices for determining the management } \\
\text { development needs for managers (i.e., for conducting a needs analysis?) }\end{array}$} \\
\hline & No & Yes & 15 \\
\hline M & $14(93.4)^{\mathrm{a}}$ & $1(6.6)^{\mathrm{a}}$ & 48.4 \\
Percentage & 45.2 & 3.2 & 16 \\
\hline S \& T & $14(87.5)^{\mathrm{a}}$ & $2(12.5)^{\mathrm{a}}$ & 51.6 \\
Percentage & 45.2 & 6.4 & 31 \\
Total & 28 & 3 & 100 \\
\hline Percentage & 90.4 & 9.6 & 2 \\
\hline
\end{tabular}

Note: ${ }^{\mathrm{a}}$ numbers in parentheses are the percentages of the total which the numbers represent.

$\mathrm{M}=$ Manufacturing firms

$\mathrm{S} \& \mathrm{~T}=$ Services $\&$ trading firms

Table 3. Sources of information about management development needs as indicated by M and S\&T firms

\begin{tabular}{|l|c|c|}
\hline \multicolumn{1}{|c|}{ Source } & M (\%) & S\&T(\%) \\
\hline Supervisors & 93 & 81 \\
Change requirement & 66 & 75 \\
Trainees themselves & 73 & 62 \\
Performance appraisal results & 80 & 75 \\
Promotion decisions & 46 & 68 \\
Previous programmes result & 66 & 68 \\
Manpower planning & 40 & 37 \\
\hline
\end{tabular}

Note:

$\mathrm{M}=$ Manufacturing firms

$\mathrm{S} \& \mathrm{~T}=$ Services $\&$ Trading firms 
Table 4. Most prominent management development approaches in M and S\&T firms

\begin{tabular}{|l|c|c|}
\hline \multicolumn{1}{|c|}{ Approaches } & M (\%) & S\&T(\%) \\
\hline University Residential & 26 & 31 \\
Executive MBA & 33 & 37 \\
Short-course & 80 & 81 \\
Company-specific & 73 & 75 \\
\hline
\end{tabular}

Note: $\mathrm{M}=$ Manufacturing firms

$\mathrm{S} \& \mathrm{~T}=$ Services $\&$ Trading firms

$\mathrm{n}=31$

Table 5. Perceived benefit indicated as primary importance when selecting management development approaches by $\mathrm{M}$ firms

\begin{tabular}{|c|c|c|c|c|}
\hline Reasons & $\begin{array}{c}\text { University } \\
\text { Residential } \\
(\%)\end{array}$ & $\begin{array}{c}\text { Executive } \\
\text { MBA } \\
(\%)\end{array}$ & $\begin{array}{c}\text { Short- } \\
\text { Course } \\
(\%)\end{array}$ & $\begin{array}{c}\text { Company- } \\
\text { Specific } \\
(\%)\end{array}$ \\
\hline $\begin{array}{l}\text { Broaden the individual's } \\
\text { perspective }\end{array}$ & 75 & 80 & 58 & 54 \\
\hline $\begin{array}{l}\text { Chance to interact with } \\
\text { other executives }\end{array}$ & 75 & 80 & 41 & 45 \\
\hline $\begin{array}{l}\text { Obtain job-specific } \\
\text { knowledge / skills }\end{array}$ & 25 & 20 & 83 & 90 \\
\hline $\begin{array}{l}\text { Obtain state of the art } \\
\text { knowledge / skills }\end{array}$ & 75 & 60 & 50 & 45 \\
\hline $\begin{array}{l}\text { Reward to the } \\
\text { executives }\end{array}$ & 25 & 20 & 33 & 36 \\
\hline $\begin{array}{l}\text { Prepare individual for } \\
\text { next job }\end{array}$ & 25 & 40 & 41 & 36 \\
\hline $\begin{array}{l}\text { Obtain general management } \\
\text { education }\end{array}$ & 75 & 80 & 50 & 45 \\
\hline $\begin{array}{l}\text { Cost-effective relative to } \\
\text { other programs }\end{array}$ & - & - & 41 & 54 \\
\hline Obtain quality instruction & - & - & 33 & 45 \\
\hline
\end{tabular}


Table 6. Perceived benefit indicated as primary importance when selecting management development approaches by S\&T firms

\begin{tabular}{|c|c|c|c|c|}
\hline Reasons & $\begin{array}{l}\text { University } \\
\text { Residential } \\
(\%)\end{array}$ & $\begin{array}{c}\text { Executive } \\
\text { MBA } \\
(\%)\end{array}$ & $\begin{array}{c}\text { Short- } \\
\text { Course } \\
(\%)\end{array}$ & $\begin{array}{l}\text { Company- } \\
\text { Specific } \\
(\%)\end{array}$ \\
\hline $\begin{array}{l}\text { Broaden the individual's } \\
\text { perspective }\end{array}$ & 80 & 83 & 61 & 58 \\
\hline $\begin{array}{l}\text { Chance to interact with } \\
\text { other executives }\end{array}$ & 60 & 66 & 38 & 41 \\
\hline $\begin{array}{l}\text { Obtain job-specific } \\
\text { knowledge / skills }\end{array}$ & 20 & 16 & 84 & 83 \\
\hline $\begin{array}{l}\text { Obtain state of the art } \\
\text { knowledge / skills }\end{array}$ & 80 & 83 & 46 & 50 \\
\hline $\begin{array}{l}\text { Reward to the } \\
\text { executives }\end{array}$ & 20 & 16 & 30 & 33 \\
\hline $\begin{array}{l}\text { Prepare individual for } \\
\text { next job }\end{array}$ & - & - & 23 & 25 \\
\hline $\begin{array}{l}\text { Obtain general management } \\
\text { education }\end{array}$ & 40 & 66 & 38 & 50 \\
\hline $\begin{array}{l}\text { Cost-effective relative to } \\
\text { other programs }\end{array}$ & - & 16 & 46 & 41 \\
\hline Obtain quality instruction & 20 & - & 30 & 33 \\
\hline
\end{tabular}

Table 7. Perceived benefits when selecting management development approaches by $\mathrm{M}$ firms

\begin{tabular}{|l|c|c|c|c|}
\hline \multirow{2}{*}{ Reasons } & \multicolumn{4}{|c|}{ Approaches } \\
\cline { 2 - 5 } & $\begin{array}{c}\text { University } \\
\text { residential } \\
(\%)\end{array}$ & $\begin{array}{c}\text { Executive } \\
\text { MBA } \\
(\%)\end{array}$ & $\begin{array}{c}\text { Short- } \\
\text { course } \\
(\%)\end{array}$ & $\begin{array}{c}\text { Company- } \\
\text { specific } \\
(\%)\end{array}$ \\
\hline Program content & 75 & 80 & 91 & 90 \\
\hline Program fees & 25 & 20 & 66 & 72 \\
\hline Program length & 25 & 20 & 75 & 81 \\
\hline $\begin{array}{l}\text { Other participants/companies } \\
\text { enrolled }\end{array}$ & 25 & 20 & 33 & 36 \\
\hline Needs of participants & 75 & 80 & 91 & 90 \\
\hline Regional convenience & 50 & 40 & 58 & 63 \\
\hline Program effectiveness & 75 & 80 & 91 & 90 \\
\hline Reputation of program & 75 & 80 & 66 & 81 \\
\hline $\begin{array}{l}\text { Reputation of organization/ } \\
\text { university }\end{array}$ & 50 & 40 & 50 & 54 \\
\hline
\end{tabular}


Table 8. Perceived benefits when selecting management development approaches by S\&T firms

\begin{tabular}{|l|c|c|c|c|}
\hline \multirow{2}{*}{ Reasons } & \multicolumn{4}{|c|}{ Approaches } \\
\cline { 2 - 5 } & $\begin{array}{c}\text { University } \\
\text { residential } \\
(\%)\end{array}$ & $\begin{array}{c}\text { Executive } \\
\text { MBA } \\
(\%)\end{array}$ & $\begin{array}{c}\text { Short- } \\
\text { course } \\
(\%)\end{array}$ & $\begin{array}{c}\text { Company- } \\
\text { specific } \\
(\%)\end{array}$ \\
\hline Program content & 80 & 83 & 92 & 91 \\
\hline Program fees & 40 & 50 & 76 & 83 \\
\hline Program length & 20 & 33 & 84 & 75 \\
\hline $\begin{array}{l}\text { Other participants/companies } \\
\text { enrolled }\end{array}$ & 20 & 50 & 23 & 25 \\
\hline Needs of participants & 80 & 83 & 84 & 91 \\
\hline Regional convenience & 40 & 50 & 46 & 33 \\
\hline Program effectiveness & 80 & 83 & 92 & 91 \\
\hline Reputation of program & 60 & 66 & 53 & 58 \\
\hline $\begin{array}{l}\text { Reputation of organization/ } \\
\text { university }\end{array}$ & 40 & 50 & 46 & 50 \\
\hline
\end{tabular}

Table 9. Major reasons given by M firms for increased management development by approaches in the next five years

\begin{tabular}{|l|c|c|c|c|}
\hline \multirow{2}{*}{ Reasons } & \multicolumn{4}{|c|}{ Approaches } \\
\cline { 2 - 5 } & $\begin{array}{c}\text { University } \\
\text { residential } \\
(\%)\end{array}$ & $\begin{array}{c}\text { Executive } \\
\text { MBA } \\
(\%)\end{array}$ & $\begin{array}{c}\text { Short- } \\
\text { course } \\
(\%)\end{array}$ & $\begin{array}{c}\text { Company- } \\
\text { specific } \\
(\%)\end{array}$ \\
\hline $\begin{array}{l}\text { More managers in } \\
\text { our company }\end{array}$ & 25 & 40 & 41 & 45 \\
\hline Program quality improving & 25 & 20 & 25 & 27 \\
\hline $\begin{array}{l}\text { Need to update managers } \\
\text { on changing concepts / skills }\end{array}$ & 75 & 80 & 83 & 72 \\
\hline $\begin{array}{l}\text { New corporate emphasis or } \\
\text { management development }\end{array}$ & 50 & 60 & 75 & 27 \\
\hline $\begin{array}{l}\text { Program becoming more } \\
\text { cost-effective }\end{array}$ & 0 & 0 & 16 & 2 \\
\hline
\end{tabular}


Table 10. Major reasons given by S\&T firms for increased management development by approaches in the next five years

\begin{tabular}{|l|c|c|c|c|}
\hline \multirow{2}{*}{ Reasons } & \multicolumn{4}{|c|}{ Approaches } \\
\cline { 2 - 5 } & $\begin{array}{c}\text { University } \\
\text { residential } \\
(\%)\end{array}$ & $\begin{array}{c}\text { Executive } \\
\text { MBA } \\
(\%)\end{array}$ & $\begin{array}{c}\text { Short- } \\
\text { course } \\
(\%)\end{array}$ & $\begin{array}{c}\text { Company- } \\
\text { specific } \\
(\%)\end{array}$ \\
\hline $\begin{array}{l}\text { More managers in } \\
\text { our company }\end{array}$ & 40 & 50 & 61 & 75 \\
\hline Program quality improving & 20 & 33 & 38 & 41 \\
\hline $\begin{array}{l}\text { Need to update managers } \\
\text { on changing concepts / skills }\end{array}$ & 60 & 66 & 69 & 83 \\
\hline $\begin{array}{l}\text { New corporate emphasis or } \\
\text { management development }\end{array}$ & 80 & 83 & 845 & 33 \\
\hline $\begin{array}{l}\text { Program becoming more } \\
\text { cost-effective }\end{array}$ & 20 & 16 & 18 & \multirow{2}{*}{8} \\
\hline
\end{tabular}




\title{
The Study of the Use of FDI to Enhance the Product Competitiveness of Integrated Circuits and Micro-electronic Components
}

\author{
Xiangyang Zhang \\ School of International Business, Southwestern University of Finance and Econonics \\ 55 Guang Hua Cun Street, Chengdu 610074, China \\ Tel: 86-159-2891-8907Ｅ-mail: andyletter@163.com
}

Wei Liu

School of International Business, Southwestern University of Finance and Econonics

55 Guang Hua Cun Street, Chengdu 610074, China

Tel: 86-135-4085-6027 E-mail: liuweiswufe@163.com

\begin{abstract}
Integrated Circuit (IC) industry as the cornerstone of economic development of information society with great penetration on traditional industries, as well as playing the leading role in traditional industries, has become the focus of the current international competitiveness. What is more, IC has also become an important indicator which measures the modernization and overall national strength of a country or a region. Therefore, the competitiveness of the products of integrated circuits and the products of micro-electronic components has become more social and economic significance. This paper which is on the basis of a model country (U.S.) for the future development goals and a example country (South Korea) for the comparison of current development explore the competitiveness of the status quo of China's integrated circuits and the products of micro-electronic components, and through the development of the advantages of FDI in South Korea, indicate that how to use FDI in order to enhance the competitiveness of space for development of integrated circuits and micro-electronic components in china.
\end{abstract}

Keywords: FDI, Competitiveness of the products, Integrated circuit

At present, the electronic information industry as the core of integrated circuit has over the traditional industries as the representative of car, oil, iron and steel to become the first major industry, which is powerful engines and solid cornerstone that transforming and pulling traditional industries into the digital age. The data of modern economic shows that each $1 \sim 2$ Yuan output of integrated circuits, lead 10 Yuan industrial output in form of electronic and then promote 100 Yuan of GDP growth. Currently, the 65 percent of the economic growth of GDP of developed countries is related to IC. As the focus in today's world economic competition, the integrated circuit which with their own copyright has become the lifeblood of economic development, social progress, the basis for a bargaining chip in international competition and the protection of national security. In the 1990s, the integrated circuits of the electronics industry (HS1992: 85) for the import and export throughout the world, is only second to the nuclear industry (HS1992: 84), and in the year 2000, it has become the top one in the world both in the import and export.

The competitive power of export products is an economic potentiality manifestation of a country, which reflects the competitiveness of a country in products, business, industry at different levels of international competition, involving many factors in the field of external economic cooperation. China is a large trading nation, but not the powerful. The main reason for this is that our export competitiveness is not high enough. Therefore, doing research on electron industry, especially in electronic core product --- the competitive power of the products of integrated circuit and micro electron module (HS1992:8542), has important practical significance as measure the development of China in the future.

\section{Introduction}

The relations of a country's foreign direct investment to this country's foreign trade whether supplementary or substitutes, is a long-term academic question that has not come to a conclusion, and thus, it has also drawn out many discussions about product competitive power of FDI. After the data analysis of Latin American and East Asian countries, Hein (1992) believed that the countries that carried out the successful export promotion policy attracted a lot of FDI, but the expansion of exports was before the growth of FDI in the succession. Zhang and Felmingham (2001) 
also obtained similar conclusions through the research on the relationship between the use of FDI and the exports in China. The findings of these studies were the expansion of exports had attracted the entry of FDI. However, Bayonmi, Lipworth (1995), Muchielli, Chedor (1999) and so on, held the opposite point of view with the above result according to their research conclusions. They thought that the FDI growth caused a country export scale increase, namely FDI growth before, export scale expansion after. They pointed out that FDI carried on the developing country had some advantages the enterprises of host country did not have, such as the international market experience, more perfect international sales network, more advanced technology and management and so on. Therefore FDI may enhance country export competitive power greatly. Ng and Yeats (2003) also had the similar viewpoint. F. Gerard Adams, Byron Gangnes and Yochanan (2006) through the studies on Chinese competitive power pointed out that there is the relationship between FDI and Chinese export competitive power.

Many Chinese scholars have conducted the related research on FDI and the competitive power. Most of them used macroeconomic data making the regression analysis or the relevant analysis on the FDI and exports value, FDI and imports value, FDI and import and export value, which indicated that FDI had the promoter action and the reciprocity to our country's value of exports, the import value and the import and export value. Zhang Shousen (2005) thought that FDI affected our country competitive power through many kinds of ways. Cai Maosen and so on (2005) believed that there was a significant positive correlation between FDI and the development of export trade of our country, what's more, he also argued that FDI had become the important constitution factor and the growth fountainhead of Chinese trade export competitive power. Wang Suqin (2005) had done some research on export competition power of industrial finished products and she thought that our country export products had certain international competitiveness in the domain of labor-intensive form. Shen yajun (2006) did the study on the impact of FDI on export competitiveness of high-tech products and he indicated that the FDI could promote the export competitiveness of high-tech products. From the above we can see that domestic and foreign scholars not only pay more attention on the research of the relationship between FDI and foreign trade, but also attach great importance to research on the overall structure.

We can also see that most empirical research on products competitiveness still stay in FDI and the changes of the structure of goods, and the research that adopted to measure the competitiveness of products is fewer, which mainly study the effect of FDI on the product. So, in this paper, on the basis of previous studies, I will compare Chinese products Competitiveness index of integrated circuits and micro-electronic components with the United States and South Korea respectively, and analyze the impact of FDI inflows on the products competitiveness both in China and South Korea from the model so as to determine whether the introduce of FDI in China can enhanced competitiveness development space of integrated circuits and microelectronic Component product in the future.

2. The export competitiveness of integrated circuits and micro-electronic components: The empirical analysis and comparison of The United States, China and South Korea

\subsection{The popular indicators assessing the competitiveness of export products}

Internationally, it is very popular to use Revealed comparative advantage index, Trade Competition index, and Market Share index these three important indicators to analyze the competitive power of export products of on country.

Stated simply, the revealed comparative advantage of country $j$ in the trade of product $j$ is measured by the item's share in the country's exports relative to its share in world trade. That is, if Ej is the value of a country's exports of product $j$, and Et is the country's total exports, its revealed comparative advantage index is: $\mathrm{RCA}=(\mathrm{Ej} / \mathrm{Et}) /(\mathrm{Wj} / \mathrm{Wt})$. Where the w subscripts refers to world totals. The index RCA has a relatively simple interpretion. Generally speaking, if it takes a value of less than 1 this implies that the country has a revealed comparative disadvantage in the product. Similarly, if the index exceed 2.5 this implies that the country has a strong revealed comparative advantage in the item. And if the value of RCA is between 1 and 2.5, this implies that the country has a relatively strong revealed comparative advantage.

The formula of Trade competitiveness index $(\mathrm{TC})$ is: $\mathrm{TC}=(\mathrm{Ej}-\mathrm{Ij}) /(\mathrm{Ej}+\mathrm{Ij})$.in this formula, Ej is on behalf of one kind of industry exports of a country and $\mathrm{Ij}$ is the imports. TC changes between 1 and -1 . If TC $>0$, it means that this industry is in a dominant position. Oppositely, if TC $<0$, it implies this industry is at a competitive disadvantage. TC $=1$ and TC $=-1$ means that the industry of a country only imports or exports, which is under an extreme condition.

The formula of International market share (MS) is $\mathrm{MS}=\mathrm{Ej} / \mathrm{Wj}$. And in this, $\mathrm{Ej}$ and $\mathrm{Wj}$ are respectively on behalf of the value of goods export of a country and of the world. In addition, the higher the value of MS is, the stronger the international competitiveness of such goods in the country will be.

2.2 The analysis of the products of integrated circuits and micro-electronic components competitiveness of United States, China, and South Korea (HS1992: 8542) (the data is from trade goods database of the United Nations: http://comtrade.un.org/)

The United States is a technical leading country of the products of integrated circuits and micro-electronic components, and at the same time both of its value of RAC and TC show that it has advantages in products; especially, we can see that it is in an extremely competitive position. And we also find that its value of RCA is bound in a relatively stable 
range, and its market share is quite high, but as the time goes by, its market share is declined continually, which mainly due to Japan's development of technique of integrated circuits and micro-electronic components, as well as the rapid growth of being processing large country of integrated circuits and micro-electronic components of South Korea and Taiwan. However, in this regard, these do not affect the leading position of U.S. being the leader of the global integrated circuit and micro-electronic components market in the aspects of research and development (see table 1).

South Korea show significant comparative advantage with the comparison with the USA. From 2001 to 2003 , the global semiconductor industry is at low ebb, which affected South Korea's integrated circuits and micro-Electronic component products significantly, and the exports of South Korea within this period have eased substantially, making the value of TC to be negative. However, with the warming of the semiconductor industry, integrated circuits and micro-electronic items immediately resume the original advantages which it has established as a good foundation. These years, according to MS, we can see that the market share of Korean integrated circuits and micro-electronic components products in international is relatively stable at 7-8 per cent (see table 2 ).

From the RCA and TC index we can see that Chinese integrated circuits and micro-electronic components has been comparative disadvantage products, but as seen from the numerical change, the competitiveness of the products has been increasing, additionally, Market share are also constantly improved (see table 3 ).

2.3 The competitiveness comparison of Chinese integrated circuit and micro-electronic components product with the products of the United States and South Korea

The United States is a "model country" of China, which is the direction of the future development of integrated circuits and micro-electronic components product. Considerable gap of the competitiveness of Chinese integrated circuits and micro-electronic components still exist.

South Korea is the "sample country" of China, which is the example of countries we can follow to improve and learn. Similarly, the competitiveness of Chinese products is far below South Korea; however, the difference is that the various indicators of China are improvement while the indicators of South Korea are in a balanced or weakened. Obviously, the competitiveness power of Chinese integrated circuits and micro-electronic components of the product is lower than South Korea.

\section{The analysis of the affect of FDI on the competitiveness of the integrated circuits and micro-electronic} components

\subsection{The establishment of the model}

Analysis model is established based on the impact of FDI on the exports of the integrated circuits and micro-electronic components: Export $=\mathrm{C}+\mathrm{a}$ FDI. According to the data of export and FDI from 1992 to 2006 (Date source: Statistical Yearbook of Chinese economy and the Korean National Statistical Office), the model is built and the results are obtained as follows with doing regression analysis (figures in brackets is the value of $\mathrm{t}$ statistics):

China: Export $=-6.59 * 10^{9}+0.05 * \mathrm{FDI}$

$$
(-5.4354) \quad(10.4175)
$$

$\mathrm{N}=15 \quad \mathrm{R}^{2}=0.8930 \quad \mathrm{~F}=108.5255$

South Korea: Export $=1.09 * 10^{10}+0.11 * \mathrm{FDI}$

$$
\text { (6.6734) (3.7720) }
$$

$\mathrm{N}=15 \quad \mathrm{R}^{2}=0.8225 \quad \mathrm{~F}=14.2284$

\subsection{Economic significance}

(1) Each dollar of FDI put into China will enhance 5 percent of the export of integrated circuits and micro-electronic components; each dollar of FDI in South Korea will enhance 11 percent of the exports of the integrated circuits and micro-electronic components.

(2) Through the Analysis of the two results, we can see that there is still great space for improvement for the use of FDI in China with the comparison of South Korea, or we can say that the more FDI put into china, the better development the integrated circuits and micro-electronic components products will get.

4. The improvement space of the utilization of FDI on the competitiveness of integrated circuits and micro-electronic components in China

As we can see, each dollar of FDI put into South Korea will enhance 11 percent of the exports of the integrated circuits and micro-electronic components; however, this number in china is just 5, which indicate that there is still a lot of improvement space of the utilization of FDI on the competitiveness of integrated circuits and micro-electronic components. In this aspect, South Korea is a country we can learn. 
In 1980s, the "large-scale integrated circuit project", used the cooperation between laboratories run by private sector and institute of public sector to make South Korea's chip makers playing the main role in the world's electronics manufacturing industry.

After the financial crisis in 1997, South Korea implemented "the plan of three-year economic recovery", established a strategic on high-tech industries, further adjusted to foreign investment policy. Then South Korea became the power country which can attract more FDI than other country, what's more, it also strengthen the competitiveness of FDI on the effectiveness of products.

The South Korean government focuses on the technical development after 2010 and has drawn up a "new areas of research in 21 st century projects". Including the choice of integrated circuits and micro-electronic components, South Korea has selected many of its advantages trip to do research.

In 2000, China promulgated "the policy on encouraging the development of the software industry and integrated circuit industries" (the State Council (2000), the 18th). This creates a favorable policy environment for the development of integrated circuit industry, which has greatly aroused the enthusiasm of all sectors of the community to develop integration Circuit industries. This is two years later than South Korea in terms of policy; therefore China should pay more attention to the effects of the issue when introduce FDI.

In my opinion, I think we should primarily focus on the following two aspects:

(1) China, as a developing country, should pay more attention on the indirect effects of FDI contributing to technological progress, upgrading the industrial structure and improving product competitiveness. Through the use of foreign capital, it can integrate ownership advantages and the host country's comparative advantage organically, prompt foreign investors to strengthen the key link of product in the value chain of investment, and it also can increase exports of products value-added and technology, as well as using multinational companies production and marketing system in the world; what's more, it can continuously improve Chinese participation in the international division of labor, and enhance Chinese international division status.

(2) We need to actively cultivate the true sense of the competitive market structure in foreign investment industrial fields, in order to make foreign-funded enterprises and domestically-funded enterprises within the same "national treatment" conditions to participate in competition, support domestically-funded enterprises which have ability to compete to compete with foreign-funded enterprises. At the same time, in the foreign-found monopoly field, we also should introduce competitive foreign competitors. Through increasing intensity of the competition between domestic and foreign-funded enterprises, it can force foreign-funded enterprises to transfer advanced production technology and Management technology under the pressure of high-level competition. Driven by the motive of lower costs also can speed up the process of localization of production factors. And domestic enterprises can also enjoy more from the technology spillover effects, which can really promote the competitiveness of Chinese products upgrading.

\section{References}

F. Gerard Adams, Byron Gangnes and Yochanan Shachmurove, Why is China so Competitive? Measuring and Explaining China's Competitiveness. World Economy. Feb.2006 pp. 96-120.

http://comtrade.un.org (May, 2008)

Kyoo-HoPark and Keun Lee, Linking the Technological Regime to the Technological Catch-up: Analyzing Korea and China's Taiwan Region Using the US Patent Data, Proceedings of The 2nd Globelics Conference, Beijing: Tsingh University Press, 2004.

Michael Porter. National competitive Advantages. Beijing: Huaxia Press, 2002.

Stefano Bresch,i Franco Malerba and Luigi Orsenigo, Techlogical Regimes and Schumpeterian Patterns of Innovation The Economic Journal, 2000.

Tan, Liwen, Chen Limin, The Empirical Method of International Competitiveness of Chinese Manufacturing Sector---and The Comparison with indicators and Industry Classification of Porte. Chinese industrial economy, 2004.5 pp. 30-37.

Zhang, Huasheng, Xue Lan. The comparative analysis of Chinese knowledge of the manufacturing sector, scale, cost-effective and industrial economy, Chinese industrial economy, 2003.2 pp. 15-22. 
Table 1. Three indexes of U.S. integrated circuits and micro-electronic components

\begin{tabular}{|c|c|c|c|}
\hline \multicolumn{4}{|c|}{$\begin{array}{l}\text { Three indexes of U.S. integrated circuits and micro-electronic } \\
\text { components }\end{array}$} \\
\hline & RCA & $\mathrm{TC}$ & MS \\
\hline 2006 & 1.4668 & 0.0220 & 0.1330 \\
\hline 2005 & 1.5628 & 0.0216 & 0.1401 \\
\hline 2004 & 1.6411 & 0.0237 & 0.1509 \\
\hline 2003 & 1.7891 & 0.0275 & 0.1762 \\
\hline 2002 & 1.6758 & 0.0214 & 0.1851 \\
\hline 2001 & 1.7028 & 0.0182 & 0.2079 \\
\hline 2000 & 1.7081 & 0.0138 & 0.2145 \\
\hline 1999 & 1.7378 & 0.0126 & 0.2201 \\
\hline 1998 & 1.6332 & 0.0060 & 0.2109 \\
\hline 1997 & 1.6808 & 0.0031 & 0.2179 \\
\hline 1996 & 1.8251 & -0.0015 & 0.2275 \\
\hline 1995 & 1.8123 & -0.0078 & 0.2256 \\
\hline 1994 & 1.7762 & -0.0012 & 0.2421 \\
\hline 1993 & 1.6257 & -0.0008 & 0.2668 \\
\hline 1992 & 1.6548 & 0.0012 & 0.3012 \\
\hline
\end{tabular}

Table 2. Three indexes of South Korean integrated circuits and micro-electronic components

\begin{tabular}{|c|c|c|c|}
\hline \multicolumn{1}{|l}{$\begin{array}{l}\text { Three indexes of South Korean integrated circuits and } \\
\text { micro-electronic components }\end{array}$} & TC \\
\hline & RCA & 0.0789 & 0.0736 \\
\hline 2006 & 2.5869 & 0.0718 & 0.0813 \\
\hline 2005 & 2.8845 & 0.0063 & 0.0722 \\
\hline 2004 & 2.5299 & -0.0902 & 0.0650 \\
\hline 2003 & 2.4642 & -0.1049 & 0.0594 \\
\hline 2002 & 2.2942 & -0.0918 & 0.0578 \\
\hline 2001 & 2.3003 & 0.0823 & 0.0793 \\
\hline 2000 & 2.8613 & 0.1304 & 0.0919 \\
\hline 1999 & 3.4977 & 0.2099 & 0.0999 \\
\hline 1998 & 3.9781 & 0.1904 & 0.0989 \\
\hline 1997 & 3.8525 & 0.2392 & 0.0988 \\
\hline 1996 & 3.8065 & 0.3893 & 0.1204 \\
\hline 1995 & 4.5093 & 0.3173 & 0.1040 \\
\hline 1994 & 4.0699 & 0.2164 & 0.0991 \\
\hline 1993 & 3.4114 & 0.1419 & 0.1293 \\
\hline 1992 & 4.1470 & & \\
\hline & & & MS \\
\hline
\end{tabular}


Table 3. Three indexes of Chinese integrated circuits and micro-electronic components

\begin{tabular}{|l|c|c|c|}
\hline \multicolumn{4}{|l}{$\begin{array}{l}\text { Three indexes of Chinese integrated } \\
\text { micro-electronic components }\end{array}$} \\
\hline & RCA & TC & MS \\
\hline 2006 & 0.7312 & -0.6651 & 0.0619 \\
\hline 2005 & 0.6455 & -0.6983 & 0.0488 \\
\hline 2004 & 0.5917 & -0.6922 & 0.0395 \\
\hline 2003 & 0.4641 & -0.7279 & 0.0277 \\
\hline 2002 & 0.4028 & -0.7188 & 0.0209 \\
\hline 2001 & 0.3039 & -0.7323 & 0.0135 \\
\hline 2000 & 0.2905 & -0.6489 & 0.0116 \\
\hline 1999 & 0.2966 & -0.5876 & 0.0106 \\
\hline 1998 & 0.2039 & -0.6183 & 0.0071 \\
\hline 1997 & 0.1657 & -0.5925 & 0.0057 \\
\hline 1996 & 0.1365 & -0.6418 & 0.0041 \\
\hline 1995 & 0.0979 & -0.6901 & 0.0031 \\
\hline 1994 & 0.0511 & -0.8238 & 0.0016 \\
\hline 1993 & 0.0354 & -0.8791 & 0.0011 \\
\hline 1992 & 0.0440 & -0.8424 & 0.0015 \\
\hline & & &
\end{tabular}




\title{
Airborne Hyperspectral Imagery for Agricultural

$$
\text { Businesses in Malaysia }
$$

\author{
Hj. Kamaruzaman Jusoff (Corresponding Author) \\ Yale University \\ Centre for Earth Observation (CEO) \\ Environmental Science Centre \\ 21 Sachem St, New Haven CT 06511, USA
}

Tel: 60-3-8946-7176 E-mail: kamaruz@putra.upm.edu.my

Hj. Malek Hj. Mohd Yusoff, AISP

Universiti Teknologi MARA Perlis

UiTM Arau 02600 Perlis, Malaysia

Tel: 60-4-986-8077 E-mail: malek_uitm@yahoo.com

The research is financed by Aeroscan Precision (M) Sdn Bhd (Sponsoring information)

\begin{abstract}
The Forest Geospatial Information \& Survey Lab in cooperation with Aeroscan Precision (M) Sdn Bhd at Lebuh Silikon, Universiti Putra Malaysia, spent the last four years developing airborne hyperspectral remote sensing and GIS applications, many of which address agriculture, forestry and the environment. This paper wants to make clear from the outset. Despite the lack of significant commercial success for businesses trying to sell airborne hyperspectral remote sensing data and services to agriculture, the only currently available imaging technology being pioneered and developed in UPM, does work. There is no doubt of its benefits to the agriculture industry especially the oil palm plantation giants in saving money, time, increasing yield, enhancing best practices, protecting the environment, and more. Despite that, the company just not made a "real" business of it perhaps due to the market for airborne hyperspectral remote sensing products and services related to agriculture, is still not known to most state and federal departments and agencies on the other. The consumer, for now, is not really in the picture. The commercial side can be broken down into the growers, who produce the food, Farmers Coops that may include growers but also produce food products and food providers. While some states have huge agricultural bases, few have money to invest in airborne hyperspectral remote sensing, which leaves quite a lot of burden on the federal government. The UPM-Aeroscan Precision (M) Sdn Bhd experience launched in 2004, planned to serve the commercial agricultural market by bringing the benefits of airborne hyperspectral remote sensing, also provide a real-time "GIS-ready" made database, and timely crop yield information to the plantation sector and farmer. The vision was simple: the farmer would build his own real-time airborne remote sensing GIS-ready made database documenting fertilizer, watering and planting details in the software (something typically done in a notebook by future high-tech Malaysian graduated farmers) with the use of a crop model to predict the expected yield. The check was to compare that expected outcome to the reality of the airborne hyperspectral remotely sensing images. For that level of detail, the UPM-APSB's AISA very high resolution airborne hyperspectral imagery $(1 \mathrm{~m})$, and in near real-time could only provide the solution for the Malaysian modern generation farmers in the hope that computer technology will reach them. In this paper, what UPM-APSB's AISA airborne hyperspectral remote sensing can bring to agriculture is demonstrated. First off, it can be used to monitor yields, early in the season, and then later. Second, airborne hyperspectral remote sensing can delineate soil zones. A third area of benefit is in field delineation where the boundaries of crops, in support of regulatory procedures could be easily found. The final area is precision agriculture, about best practices, giving a crop just the water, fertilizer, herbicide, etc. it needs to grow to its potential, but no more. The authors feel strongly that precision agriculture could have a significant impact on the Malaysian future environment. If the UPM-APSB's AISA near real-time data can map and provide just enough nitrogen, the impact on the environment is reduced and the plants should still provide their maximum yield. Applying this just enough vision should save the farmer's money on herbicide, water, fertilizer and other such costs.
\end{abstract}


Keywords: Precision agriculture, Remote sensing, Commercial, Oil palm, Sensor

\section{Introduction}

Agriculture is business. It is profitable to those who perceive and practice it as such, and miserable to those who don't. Is that a mere perceptual issue? Malaysians have the perception that agriculture is not a profitable business compared to industrial ventures. This partly explains the poor intakes of students in agricultural programs in universities and of graduates in agric-related jobs. There is some truth to the perception, but a further probe proves the contrary. Facts show that agriculture is indeed big business. The most negotiated topics under the banner of the WTO are agriculture and food. Heading the recent list of Fortune 500 companies in terms of revenue is WalMart, which specializes in retail goods including food and beverages. Other companies involved in consumer goods in the list include Carrefour (France) (ranked $\left.22^{\text {nd }}.\right)$, Metro (Germany) $\left(42^{\text {nd }}.\right)$, Royal Ahold $\left(49^{\text {th }}.\right)$ and Tesco $\left(54^{\text {th }}.\right)$. Eight of the world's largest retail firms are involved in the food business. According to a study by Nielsen (2004), among the top 20 consumer goods that registered the highest growth were soya-based drinks (first), eggs ( $\operatorname{second})$, frozen fruits $\left(6^{\text {th }}.\right)$, salad dressings $\left(7^{\text {th }}\right)$, frozen meat $\left(13^{\text {th }}\right)$ and fresh vegetables $\left(14^{\text {th }}.\right)$. These data show agriculture is a business capable of securing high sales and operating on a global scale. It offers hope and opportunity to local agricultural enterprises. There is no magic in the success of these firms, but the smart strategies of capitalizing on cross-border possibilities and exploiting supply chain management innovations, logistics, computing and biotechnology. Lessons can be learnt from this development. Besides, developing countries as suppliers of raw materials to these companies should be able to secure smart partnerships along the value chain.

Malaysia has its own success stories, with its own global players for primary commodities such as palm oil, rubber and cocoa. The success of these sectors was driven by private estates or agricultural companies that turned the production of these commodities into successful business ventures. The risks and vagaries of agricultural ventures were either internalized or dealt with creatively. Some of the technologies invented were home-grown, such as new planting materials and processing techniques. The success of these private estates is living proof that agriculture can be big business. But the "other" agricultural and food sectors have not been able to match the scale of business of the primary commodity sector. With the current perception that agriculture is a risky and low-return investment, how do we create more "agric-entrepreneurs" or "agribusiness firms"? For sure, entrepreneurs cannot be created overnight. It requires a conducive business environment, education and continuous training, fiscal incentives, credits, technological and infrastructural support, etc. All these strategies have been deliberated in the Government's policy documents. No stone was left unturned. However, agric-entrepreneurs are not entering the economy at the rate expected.

\section{Monitoring agriculture with airborne hyperspectral sensing}

Airborne hypersepctral sensing is the science (and to some extent an art) of acquiring information about the earth's surface without actually being in contact with it. This is done by sensing and recording reflected or emitted energy and processing, analyzing, and applying that information. In remote sensing, information transfer is accomplished by use of electromagnetic radiation (EMR). Electromagnetic radiation is a form of energy that reveals its presence by observable effects it produces when it strikes the matter. It is considered to span the spectrum of wavelengths from $10 \mathrm{~mm}$ to cosmic rays up to $1010 \mathrm{~mm}$, the broadcast wavelengths, which extend from $0.30-15 \mathrm{~mm}$. Figure 1 illustrates an airborne hyperspectral remote sensing process as applied to agricultural monitoring processes where actions can be taken by the farmers at a farm unit level. There are two types of remote sensing, passive e.g. sun radiation, and active e.g. radar. In Malaysia mostly passive remote sensing is used and the Forest Geospatial Information \& Survey Lab (formerly known as Center for Precision Agriculture \& Bioresource Remote Sensing, Institute Bioscience-CPABRS) \& is pioneer of introducing airborne hyperspectral sensing in agriculture. Airborne hyperspectral sensing makes it possible to collect near real-time data on dangerous or inaccessible areas at the desired client or user demand to as high as $0.5 \mathrm{~m}$ spatial resolution (Kamaruzaman, 2007a). Hyperspectral airborne sensors are like having spectrometers in the airspace. They do not obtain images in the same way as you get images from LANDSAT, SPOT or normal optical satellites. Instead what you get is the reflected light in various spectral bands extending beyond the range of the human eye. This combination of spectral bands can for example enable analysis of the different contents of the atmosphere - permitting researchers to correct for atmospheric effects - as well as the mineral contents of soil, bio-chemical constituents like chlorophyll in plants and in water and also biophysical properties such as biomass and leaf area index. There is an opportunity for added information all along the spectral reflectance curve, whereas with conventional images you mostly just interpret what is depicted in the image. Hyperspectral sensors are an improvement on their multispectral counterparts because they use many more spectral bands and so yield more information such as determining the types of leaf fall diseases in rubber plantations (Kamaruzaman and Malek, 2007), and mapping of infrastructures, landuse/cover and rice paddies characteristics (Kamaruzaman, 2006).

(see Figure 1)

Airborne hyperspectral agriculture sensing applications include monitoring deforestation for agriculture conversion, effects of global warming on tropical regions, and agriculture landuse/cover, etc. Airborne hyperspectral sensing also 
replaces costly satellite based sensing and its slow collection on the ground, ensuring in the process that areas or objects are not disturbed (Kamaruzaman, 2007a). When farmers or ranchers observe their fields or pastures to assess their condition without physically touching them, it is remote sensing. Observing the colors of leaves or the overall appearances of plants can determine plant's condition. Remotely sensed images taken from aircraft provide a means to assess field conditions in near real-time without physically touching them from a point of view high above the field. Most remote sensors see the same visible wavelengths of light that are seen by human eye, although in most cases remote sensors can also detect energy from wavelengths that are undetectable to human eye. The remote view of the sensor and it's "ready made GIS" data's ability to store, analyze, and display the sensed data on field maps are what make airborne remote sensing a potentially important tool for agricultural producers (Kamaruzaman, 2007b). Remotely airborne sensed images can be used to identify nutrient, diseases, water deficiency or surplus, weed infestations, insect, wind, herbicide damage, and plant populations. Ranchers use airborne remote sensing to identify prime grazing areas, overgrazed areas or areas of weed infestations. Land institutions use airborne remote sensing data to evaluate the relative values of land by comparing archived images with those of surrounding fields. Airborne remotely sensed images can be used in many applications, for example land use planning and monitoring the condition of forest and agricultural areas. Information from airborne remote sensing can be used as base maps in variable rate applications of fertilizers and pesticides. Information from remotely sensed images allows farmers to treat only affected areas of a field. Problems within a field may be identified remotely before they can be visually identified. Farmers, land care workers and field officers, with their detailed knowledge of the vegetation and soils in their own paddocks or regions, can extract information on productivity from simple displays of the satellite image. Airborne hyperspectral sensing relies on the fact that particular age features of the oil palm landscape such as three, four, 10 or 15 years old, barren areas, and water reflect light differently in different wavelengths that produce a unique spectral signature (Kamaruzaman, 2005a). Grass looks green, for example, because it reflects green light and absorbs other visible wavelengths. This can be seen as a peak in the green band in the reflectance spectrum for green grass above. The spectrum also shows that grass reflects even more strongly in the infrared part of the spectrum. While this can't be detected by human eye, it can be detected by a Near Infrared (NIR) and infrared (IR) sensor. This sensing provides a cost-effective method for mapping and monitoring focused areas, and has the advantage that the spread of diseases such as leaf fall in rubber trees is enhanced by remote monitoring (Kamaruzaman and Malek, 2007).

Archived data can be used to monitor how areas have changed through time. Monitoring information can then be combined with landform information to help predict which areas are at risk from salinity in the future, allowing remedial action to be taken where it is needed the most. This system is also increasingly being used for large-scale environmental monitoring programs. It is able to offer large-scale monitoring relatively cheaply and easily, and can provide a baseline for future monitoring. Remote sensing can provide data on agricultural and forest activities in inaccessible areas, or simply obtain more accurate information than otherwise available. This information can be obtained from airborne hyperspectral images, and interpreted using machine vision techniques to identify different agricultural regions or crop types. The spectral signature from each crop varies according to its characteristics, such as leaf moisture, plant separation and number of leaves per square meter (Kamaruzaman, 2005b).

Airborne hyperspectral sensor systems in aircraft collect image data in various portions of the narrow contiguous electromagnetic (EM) spectrum, and these data contain much information about conditions of agricultural fields. The conditions of interest may include crop health or potential yield, soil conditions, weed infestations, etc. Airborne image data can yield vital information about the variability of these conditions with respect to location, and this kind of information can be used by agricultural producers to optimize their management decisions with respect to location, thus maximizing profit and minimizing environmental effects. Remote sensing offers the possibility of monitoring agricultural resources for rapid and continuous assessment of plant, soil, and water resources (Kamaruzaman, 2004c). This technology has proven a powerful "tool" for assessing the identity, characteristics, and growth potential of most kinds of vegetative matter at several levels (from biomes to individual plants) to bioinformatics (Kamaruzaman, 2004a). Vegetation behavior depends on the nature of the vegetation itself, its interactions with solar radiation and other climate factors, and availability of chemical nutrients and water within the host medium (usually soil, or water in marine environments). A common measure of the status of a given plant, such as a crop used for human consumption, is its potential productivity (one such parameter has units of bushels/acre or tons/hectare, or similar units). Productivity is sensitive to amounts of incoming solar radiation and precipitation (both influence the regional climate), soil chemistry, water retention factors, and plant type.

\section{THE UPM-APSB'S airborne hyperspetral imaging laboratory mission}

The mission of AIRFOR+ is to conduct applied airborne remote sensing research, work with industry and government agencies to develop "real world" precision and site-specific tools for the agriculture and natural resources management. Research conducted by the laboratory ranges from "on-farm" production uses to large-scale agribusiness uses such as regional yield estimations. The laboratory will be staffed with experts in the fields of crop science, agric-forest engineering, extension, agriculture economics, geographic information system and airborne hyperspectral sensing. 
The era of commercial airborne hyperspectral remote sensing for agriculture has finally arrived (Kamaruzaman, 2007a,b). Since the early days of the government run LANDSAT satellite program by The Malaysian Center for Remote Sensing (MACRES), Malaysian remote sensing experts have touted the benefits of remote sensing for crop production management, for eg the use of IKONOS for cabbage market intelligence (Kamaruzaman, 2005). Unfortunately, the technology of these early earth-observing satellites was limited and the sensing system was not validated for agriculture use, perhaps due to the high costs and slow data acquisition issues. Detecting exact locations of potential stresses or nutrient variability within an oil palm plantation field were nearly impossible (Malek et. al., 2007; and Kamaruzaman, 2004b). Quite frequently, the promises of useful applications of remote sensing to commercial agriculture were never kept. To meet these challenges the Forest Geospatial Information \& Survey Lab in Lebuh Silikon is proposing to create the UPM's Laboratory for Airborne Imaging for Tropical Forest and Other Applications (AIRFOR+) as a Faculty of Forestry's Center of Excellence in Universiti Putra Malaysia (UPM), Serdang. The UPM's AIRFOR+ is well positioned to establish itself as a leader in the field of applied airborne hyperspectral agricultural sensing. Many of the components necessary to achieve this goal are resident at UPM and its surrounding community. Many of our nation's top agriculture researchers and extension specialist have appointments with the UPM' specializing in the fields of crop sciences, agricultural engineering, biotechnology, precision farming, and geospatial information systems. Additionally, FGISL/AIRFOR+ is aligning itself with Yale's Tropical Resources Institure and Stanford's Carnegie Airborne Observatory for airborne applications in tropical precision agriculture to collaborate on such projects as calculating and reducing carbon emissions from oil palm plantations, sustainable oil palm management, using dynamic models to monitor agricultural runoff and using data mining and neural network technology to process high spatial and spectral remotely sensed data.

From an industry perspective several major agribusinesses such as FELDA Agricultural Services and TH Group of Plantations have established research plots in Sabah and Riau, Indonesia, respectively. These companies should be viewed as potential industry partners that could benefit from the use of airborne hyperspectral remote sensing technology and would sponsor UPM's research through AIRFOR+. These two oil palm giant companies already have cooperative agreements and contracts with UPM-Aeroscan Precision (M) Sdn Bhd to fund cutting-edge agronomic, geospatial database development technology, and precision agricultural engineering research.

\subsection{The Function of the laboratory}

The focus of AIRFOR + is toward applied research as opposed to basic research. The function of AIRFOR + should be to engage Malaysian agribusinesses in airborne hyperspectral applied remote sensing research, designed to investigate potential business opportunities and to develop new product ideas and application prototypes for Malaysian companies. Emphasis should be placed on working with these businesses to facilitate commercializing the technology by focusing university research capabilities on industry requirements. AIRFOR + can take advantage of the existing relationship between FELDA Agriculture Services and TH Group of Plantations' Commercial Precision Sustainable Oil Palm Management Program. The laboratory should introduce Malaysian companies to spatial information and expose them to the most promising advanced airborne hyperspectral sensing technologies. This will be accomplished by integrating university research activities with industry requirements to take advantage of advanced airborne hyperspectral sensing technologies and applications. Finally the laboratory will expose University students to real-world problem-solving situations through partnership projects with Malaysian or even ASEAN and Asia Pacific rim companies.

\section{Business development and growth opportunities of airborne hyperspectral sensing projects in Malaysia}

Extensive research and development conducted by The Forest Geospatial Information \& Survey Laboratory (FGISL) in collaboration with Aeroscan Precision (M) Sdn Bhd's Project Office based in Lebuh Silikon, UPM, have provided possible breakthroughs in the agricultural, forestry and natural resources fields. A new near- real-time airborne sensing program, UPM-APSB's AISA, will provide its subscribers such as the oil palm giant companies with airborne hyperspectral images and associated information to alert them of their individual oil palm trees and areas that are in possible danger, say pest and diseases or waterlogged, respectively (Figure 2). This early detection could serve as a warning system for crop stress caused by insufficient water, plant disease, insect infestation and other factors. The information retrieved from the airborne sensor has to have its reliability assessed, so that an uncertainty estimate can be considered in any of the models to be developed. This is something that has to be worked on in general - not just for flood models, for instance but agricultural yield forecast models, carbon models, and it is the same across many different EO applications. This geospatial information can save agriculture businesses millions of Malaysian Ringgits (RM) and aid in environmentally responsible decision making.

The goal of the UPM-APSB's AISA program is to develop a company that will utilize communications, airborne sensing and geographic information systems to provide state-of-the-art products and services. UPM-APSB's AISA aims to operate, launch and operationalize an airborne hyperspectral sensor that, unlike its competitors airborne LiDAR, satellite-based IKONOS, QuickBird, and SPOT Image, will provide images covering the entire Malaysia every hour, and relay the information to customers within 24 hours. It currently takes QuickBird or IKONOS a week or two to 
deliver images to its customers, while it takes SPOT three or more weeks. As a near real-time pointable airborne sensor system, UPM-APSB's AISA can provide hourly and/or daily coverage for specific targets upon demand, but it cannot canvas the entire Malaysia in a day, which is one of the major attributes of UPM-APSB's AISA.

\section{(see Figure 2)}

An aircraft prototype has been used in Kemubu Agriculture Development Authority (KADA)'s rice paddies Merdeka estate in Bachok, Kelantan, FELDA Sahabat's oil palm plantations in Lahad Datu, Sabah, and UPM's matured oil palm plantations in Serdang where it has proven to be successful. Several companies, including FELDA Sahabat, KADA and Global Talent Sdn Bhd along with large and medium size individual growers have purchased the geospatial data information (eg. A map of individual counting of oil palms) indicating real usability of the product (Figure 3). Plants meanwhile need water very urgently. They transpire it through their leaves. By using airborne hyperspectral sensing data we can tell the water content and health of plant leaves, based on their spectral characteristics, and on the other hand we can measure soil moisture to help estimate the capacity of the soil to absorb rainfall or whether there will be surface run-off. In 2007, about 50 percent of the money needed for the Oil Palm Sustainable Precision Management Project, for example, will be appropriated by the INNOFUND Research Grant from the Ministry of Science, Technology and Innovation (MOSTI), while the other portion came from Aeroscan Precision (M) Sdn Bhd sources. The FGISL/UPM-APSB/AIRFOR+ is currently looking for partners in agricultural business and information services to begin commercializing and expanding UPM-APSB's AISA in January 2008 fiscal year.

\section{Airborne hyperspectral imaging partnerships and project outcome}

Businesses use remote sensing data to help make decisions. It is therefore important that if you want to make a business out of airborne hyperspectral data you have to keep contact with science and make some new developments - not just relying on the same tools that are available to everyone. For example, a plan is to install a LiDAR in the Cessna 402B aircraft of the Royal Malaysian Air Force (RMAF). This allows us to provide UPM-APSB's customers with low cost hyperspectral data. Bringing the latest airborne hyperspectral sensing techniques from the laboratory to the marketplace is necessary to ensure the business side of airborne hyperspectral sensing in Malaysia. A new algorithm or method for processing (Figure 3)

Airborne hyperspectral sensing observation data with commercial application need to be developed. The airborne hyperspectral remote sensing business must keep up to date with the latest techniques and applications emerging from the scientific and research community. Airborne hyperspectral sensing has a unique and increasing role to play in environmental science, governance and policy making, particularly in respect of deforestation, climate change and carbon stocking. It is already delivering services in areas such as meteorology and agricultural monitoring, and new opportunities are continuously arising as a result of developments in geospatial science and remote sensing technologies. Transforming research-level applications into viable services suitable for use by the wider audience interested in these issues requires practical business know how and is not always a straightforward process. To reflect the diverse needs of both the Earth observation research community and the industrial sector in forming a knowledge transfer partnership is required.

Even though the research is still underway, several products related to the work have already come to market. Aeroscan Precision (M) Sdn Bhd harnessed UPM's geospatial airborne hyperspectral data information to provide innovative geospatial solutions for a variety of industries. It provides tailored solutions for customers' needs and, as a result, has started to make three rather disparate spin-offs: an oil palm crop prescription service for oil palm plantation agencies; an early warning system management tool for oil palm and rice paddies; and an educational service for young Malaysian rice paddies farmers in KADA. Current experimental airborne hyperspectral research produce images in a $1-$ to $2 \mathrm{~m}$ spatial resolution range. With these images one can detect things like roads, bridges, culverst, and small buildings. Within the next few years day-and-night images from UPM-APSB's AISA commercial sensor with sub-meter (0.5 m) resolution or better will be available. At this resolution one can better detect and count individual crop species, buildings and traffic on highways. The service should be available to farmers and those in the agricultural community. FGISL is thinking of commercializing this system through Aeroscan Precision Company providing farmers with automated, digital crop prescriptions within 24 hours of airborne data collection. The service allows customers to generate their own prescriptions and crop scouting maps at any time of the day or night, using Web-based technologies built in collaboration with UPM-Aeroscan that harness over four years of FGISL's precision agriculture algorithms and research. They can print scouting maps showing relative crop health as well as cost reports showing the economics of treating a field with herbicides, insecticides, plant growth regulators, and defoliants. These maps come in electronic formats and as hard copies. Growers can rapidly verify the scouting maps and then download the digital prescription, which is then loaded into an inexpensive Global Positioning System (GPS)-enabled, hand-held computer on the farmer's sprayer equipment. The farmer loads the appropriate fertilizer or crop controller, and then treats the specific area. The ability to focus treatment saves time and money, as manpower and product can be used efficiently. In the case of inorganic pesticides and fertilizers, this approach provides an added environmental benefit, as chemicals with the 
potential of entering groundwater are used sparingly. This represents a jump in commercial applications that many in the business world are not yet aware of.

The UPM-APSB future partnership will probably involve agribusiness. Because agriculture is so important to the Malaysian economy, the second author is currently working with re-known researchers in Yale and Stanford to identify the use of airborne hyperspectral sensing data for precision agriculture and site-specific crop management, especially oil palm, rubber and rice paddies. The commercial firms are not the only ones who benefit from this partnership. The university's role is not to compete with business but to help create more business in areas of rapidly changing technology. This can only be done when we, government, and business are all on the same page.

\section{Application of airborne hyperspectral imaging system technology in agriculture businesses}

Right now in Malaysia there is a big precision agriculture research cum operational program going on in Federal Land Development Authority (FELDA) and probably follow suit with Tabung Haji (TH) Group of Plantations. UPM-APSB is responsible for airborne hyperspectral sensing applications within it, working on one huge test oil palm plantations in Lahad Datu, Sabah. This is a shared cost activity, meaning that $50 \%$ of funding comes from FELDA and $50 \%$ is paid by the company. The authors are participating because it is believe that precision agriculture for sustainable oil palm management will be important in the long-term future for the oil palm industry in Malaysia. The basic idea behind it is to reduce the impact of the oil palm agricultural management on the environment by applying fertilizers, fungicides and pesticides only in the regions it is really needed, on an adaptive basis. This is good for the environment - especially groundwater - and also saves the estate owners money. The accuracy should be sufficient that chemical application can be reduced with no disadvantage for the health of individual plants or the overall yield. The authors are making a strong use of hyperspectral data, UPM-APSB's AISA images for these purposes.

It is important to realize that providing an operational service for customers is different from doing science. The big difference is that the customer just tells us their problem and we have to find a way to solve it. They do not care whether it is with optical or microwave imagery, an airborne sensor or satellite sensor. They just want the final high quality product to provide them the information they need, without wanting to know all the background behind it. Programs like Precision Sustainable Oil Palm Management are very useful for transferring scientific methodologies into practical procedures working on a routine basis. It is important that such procedures get upgraded to provide the best operational information to estate managers and users. It takes good examples and good experiences before a customer feels this really works, airborne hyperspectral data provides relevant information and can be relied on. It can take a long collaboration with a customer before they say this year they want to extend this service from Malaysia to Indonesia or Thailand- it takes time and hard work to gain trust.

\section{The need to develop an airborne hyperspectral agri-business park in UPM's Lebuih Silikon?}

Innovation, dynamic partnerships, accessibility to advanced technologies and facilities: these are some of the critical factors for a sustainable geo-information science agri-business sector to develop. In order to bring these factors together an "Airborne Hyperpectral Agri-Business Park" needs to be established in UPM. This "Airborne Hyperspectral Business Park" constitutes a public private partnership where small and medium sized companies, the national and state government and the National Space Agency ( $A N G K A S A$ in Malay) have to join forces to provide optimal conditions for the Malaysian airborne hyperspectral sensing sector to expand.

Drawing on the experience gained with the execution of MACRES and NSA National Program and building upon traditional Malaysian strengths such as coastal zone management, water management, marine environment and agri-business, the airborne hyperspectral geo-information science sector in Malaysia will start to evolve rapidly. The emphasis of the "Airborne Hyperspectral Business Park" is to boost this growth by exploiting the synergistic effects resulting from clustering the Malaysian geo-information science and airborne hyperspectral imaging industry, one of the largest to be technological research establishments in Malaysia. The participation of several Malaysian Ministries especially Ministry of Science, Technology \& Innovation (MOSTI), Ministry of Agriculture (MOA), Ministry of Defense (MINDEF) and Ministry of Natural Resource \& Environment (MNRE) is of particular importance, because it provides market-driven development of critical technologies and allows for sharing powerful internet connections, airborne hyperspectral sensing Command-and-Control Centers and supercomputing facilities. Another important consideration for clustering this sector in a business park is the ability for end-to-end offering of services, creating new business opportunities in the domestic and international market. By means of a Foundation the "Airborne Hyperspectral Business Park" will be well embedded in the Malaysia's IT knowledge infrastructure with linkages to several other institutions like UPM, MACRES and ANGKASA.

\section{Conclusion}

The business side of hyperspectral data applications and operationalization, especially in the Malaysian sustainable oil palm management is directly related to the accurate and timely determination of individual oil palm problems. Early detection of problems in the field directly affects the cost of treatment as well as oil palm yields in a season. In addition, 
there are enviro-economic implications tied to the targeted use of pesticides, herbicides, and fertilizer in most oil palm plantations. Giant oil palm plantation companies such as FELDA and TH Group of Plantations for instance, will find a great deal of value in the near real-time analysis of UPM-APSB's AISA airborne hyperspectral data, and allow crop management decisions to be made quickly. Oil palm plantation owners will realize greater yields and apply less agricultural chemicals during the growing season. In addition, it is anticipated that agri-business companies and research institutions will make use of the archived spectral libraries developed for oil palm and field analysis. Over time, this data will become more valuable because it will bring to light sustainable oil palm management trends that are currently unknown. The historical airborne hyperspectral data for any plantations will assist estate managers and top management in planning oil palm sustainable production and treatments of problems. Potential users, buyers and sellers of this information may range from the farmer, to the agrochemical producers, to the oil palm companies and industry that collect and analyze these airborne hyperspectral images.

\section{References}

Kamaruzaman Jusoff. \& Malek, Hj. Mohd, Yusoff. (2007). Identification of Leaf Fall Diseases affecting Hevea brasilliensis using a HandHeld Spectroradiometer. Paper Presented at the 2007 Conference on Plantation Commodities "Visionary Agriculture: Malaysian Commodity Crops in 100 Years", 2-4 ${ }^{\text {th }}$. July, 2007. Putra World Trade Center, Kuala Lumpur, Malaysia. 9p.

Kamaruzaman Jusoff. (2004a). From geospatial information technologies to bioinformatics: A Malaysian perspective. Invited plenary paper presented at MSMBB 2004 Scientific Meeting: Advancement of Biotechnology: Consolidating the strength \& resources towards globalization. 19-21 July, 2004. Century Mahkota Hotel, Melaka, Malaysia. 17p.

Kamaruzaman Jusoff. (2004b). Evaluation of spatial variability of soil in an oil palm plantation. Poster Paper presented at the $13^{\text {th }}$ International Soil Conservation Organization (ISCO) Conference, 4-8 July, 2004, Brisbane Convention \& Exhibition center, Queensland, Australia. 4p.

Kamaruzaman Jusoff. (2004c). Pemindahan teknologi maklumat geospatial (TekMaG) kepada komuniti tani: Adakah ia berjaya?" (In Malay). Paper Presented at the 'Seminar Memperkasa Komuniti Tani 2', 25-26 Mei, 2004. Pusat Pendidikan Luar (IDEAL), UPM Serdang, Selangor. Malaysia. 34p.

Kamaruzaman Jusoff. (2005). Market information for cabbage in Cameron Highlands using the IKONOS satellite. Paper accepted for presentation at The International Society For Agricultural Science (ISHS): Improving the performance of supply chains in the transitional economics, July 19-23, 2005. Lotus Pang Suan Kaew, Chiang Mai, Thailand. 7p.

Kamaruzaman Jusoff. (2005a). Airborne hyperpsectral imaging technology for precision oil palm plantation management system (A7). Procs. Agriculture, Biotechnology and Sustainability Conference (Unedited). Technology Breakthroughs and Commercialization-The Way Forward PIPOC 2005. MPOB International Oil Congress, 25-29 September 2005, Sunway Pyramid Convention Center/Sunway Lagoon Resort Hotel, Petaling Jaya, Selangor, Malaysia. Pp. 259-266.

Kamaruzaman Jusoff. (2005b). UPM-Aeroscan's AISA airborne hyperspectral imaging for precision agriculture and forestry. Procs. KUSTEM $4^{\text {th }}$ Annual Seminar 2005 on Sustainability Science and Management: Meeting Challenges in Sustainability Agrotechnology (Sect.8: Sustainable Science \& Technology), 2-5 May, 2005, Primula Beach Resort, Kuala Trengganu, Trengganu, Malaysia. Pp. 869-875.

Kamaruzaman Jusoff. (2006). Precision Management of KADA's Rice Paddies Land Resources in Bachok District, Kelantan Using UPM-APSB's AISA Airborne Hyperspectral Sensor Technology. Abstracts of Papers. Plenary Session. Journal of ISSAAS. Vol. 12, No. 2, December 2006. pp.65-66

Kamaruzaman Jusoff. (2007a). Latest Developments in Research and Applications of Airborne Hyperspectral Imaging. A Public Research Lecture Presentation to The International Institute for Geo-information Science \& Earth Observation, ITC, The Audtorium, $26^{\text {th }}$. January 2007, ITC, Enschede, The Netherlands. 164p.

Kamaruzaman Jusoff. (2007b). Development of Geospatial Database for Sustainable Precision Agriculture with Airborne Hyperspectral Imaging. A Power Point Lecture Presentation to Erasmus Mundus GEM MS Students, Gondwana Room 204, $1^{\text {st }}$. Floor, Geocentrum II, $17^{\text {th }}$. January 2007, Universitet Lund, Sweden. 94p.

Malek Hj. Mohd Yusoff, Kamaruzaman Jusoff and Mohd Hasmadi Ismail. (2007). Soil Nutrient Variability Mapping in UiTM Research Station, Arau, Perlis using Landsat TM7 and Geostatistical Analysis. WSEAS Transactions on Signal Processing. Greece. Issue 1, Vol. 3, January 2007 ISSN 1790-5022:80-87.

Nielson, A. C. (2004). Grocery Shop Directory. ACNielson Checkout Independent Retail News. Top 100 Grocery Brands, March 2004. http://www.acnielson.co.uk/pubs/document/Top 100 brands/pdf 


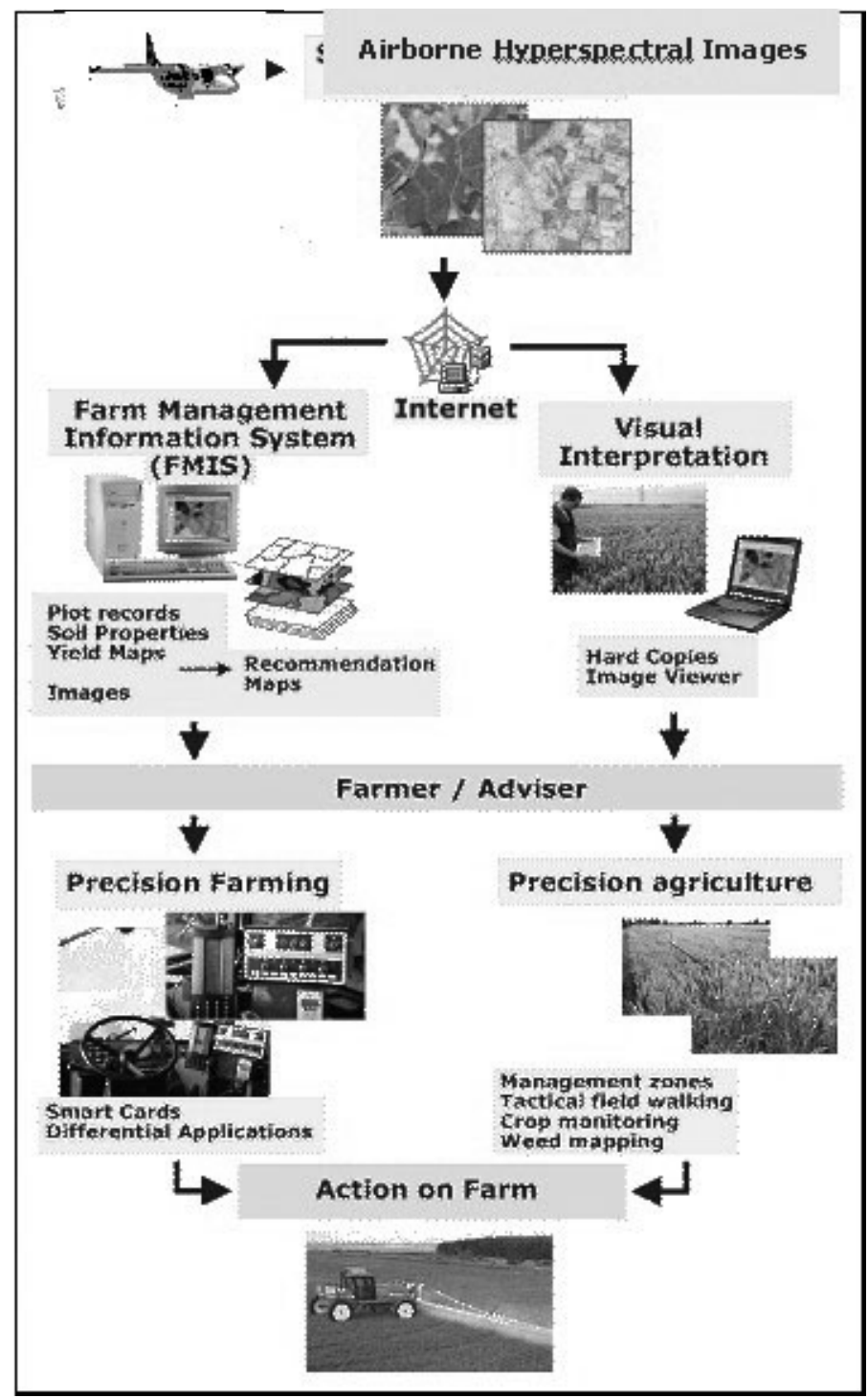

Figure 1. Flow chart of the UPM-APSB's AISA operational and business program 


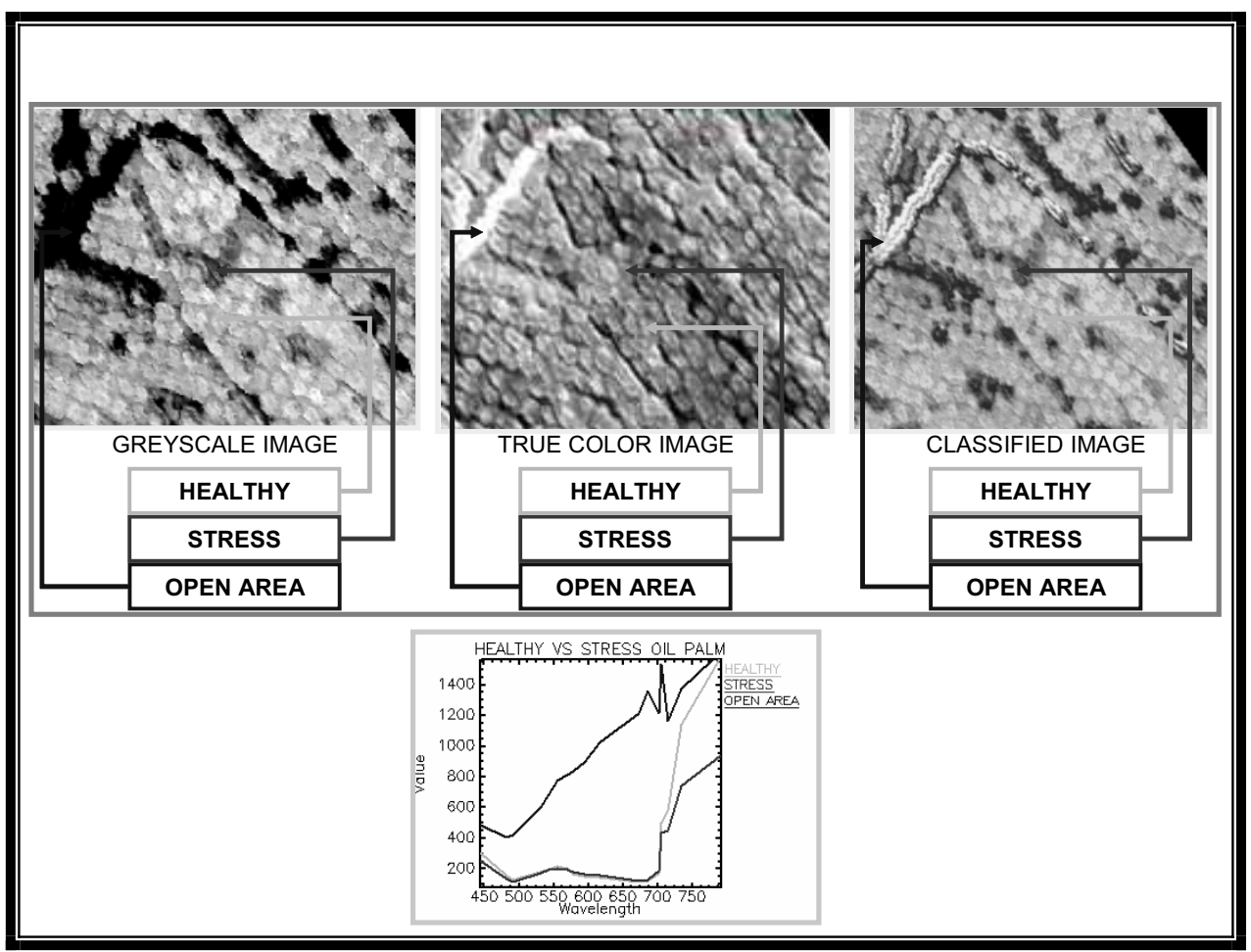

Figure 2. A processed UPM-APSB's AISA airborne hyperspectral image of an oil palm plantation in Sabah, Malaysia showing the healthy, "stressed" palms and open areas

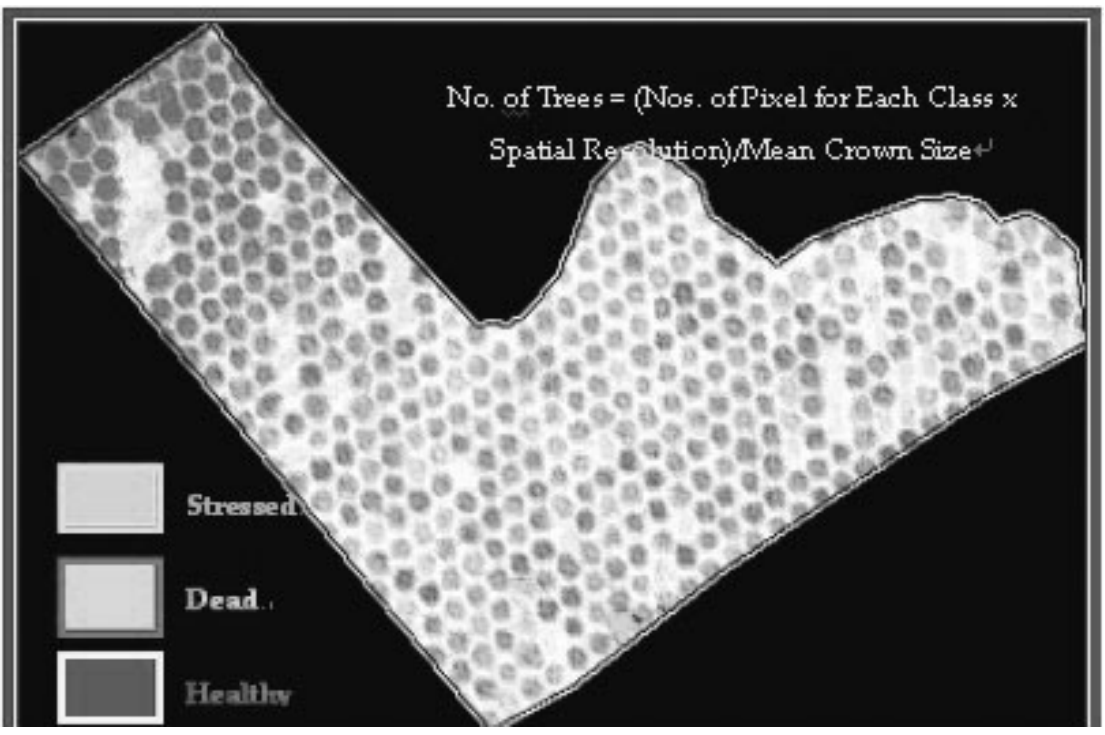

Figure 3. An individual oil palm tree count map showing the healthy (404 trees), "stressed" (199 trees) and dead palms (36 trees) in Pegagau, Sabah 


\title{
A Study on the Business Innovation and the Management Mode of Business Cooperation between Banks and Trust
}

\author{
Xiaoyu Li \\ Business Administration School, North China Electric Power University, Beijing 102206, China
}

\begin{abstract}
Banking is an industry with high intensity and fast update of knowledge, information, and technology. Innovation is a key element for commercial banks' survival and development. In the self-development process, China commercial banks cooperate with trust companies in business and create new financial products, strengthening management and risks control. By this way, banks can find out new profit rising point and the state-owned commercial banks can improve their comprehensive competitive strength. This paper analyzes the present situation and problems of China's banking-and-trust operations, advancing effective business innovation and management mode.
\end{abstract}

Keywords: State-owned commercial bank, Business cooperation between banks and trust, Innovation, Management mode

\section{Introduction}

Along with the gradual perfect of policy and legal platform and the continuous enhancement of social public rational investment idea, China's trust meets its opportunity of development. Trust company, as the only institution that can make fully use of financial market and connect industries and financial market, can provide with all kinds of financial services, from corporate merge and purchase and reengineering to system transformation to financial and renting. As trust company pushes innovation in financial market, it brings about bright prospect for the cooperation between banking and trust. By cooperating with trust companies, China's state-owned commercial banks can achieve multiple income structure and diverse business types, improving the proportion of middle business income, and decreasing costs of operation. State-owned commercial banks should make best use of advantages in capitals, settlement, net, and customers, pay more attentions on and grasp opportunities in financial innovation and business exploration, cooperate with trust companies to make innovation actively, enhance business management and risks control over banks' trust operation, and improve the comprehensive competitive strengths.

\section{The present situation and problems in state-owned commercial banks' business cooperation with trust}

The cooperation between banking and trust has become a new hot in financial cooperation filed. Some state-owned commercial banks have business partnership with domestic trust companies. They cooperate in many aspects by signing business cooperation agreements. In a sense, the cooperation drives relevant business operation's development in state-owned banks. However, there are many problems in the business cooperation between state-owned commercial banks and trust companies at present.

\subsection{The cooperation between banks and trust is in a low level and lack of business innovation.}

In the cooperation between banks and trust, as domestic trust companies make self business innovation, they constantly ask banks in cooperation to make innovations. However, because some branches of state-owned banks fail to analyze customers' needs thoroughly, they are not sensitive to market changes. Products and services cannot achieve timely innovation. All these facts affect the cooperation between banks and trust companies. In specific, less trust companies keep close cooperation with banks. And the cooperation fields become narrower. The business products are unilateral and lack of innovation capability. Market competence is weakened. These results decrease customers' satisfaction to a great degree, affect the maintenance of customer relationship, and restrain the further development of banking-and-trust cooperation in state-owned commercial banks.

\subsection{The approval of business operation is complicated, what affect the marketing efficiency and effect.}

Shortage of innovation in banking-and-trust cooperation will cause the high homogeneity of banks' services at the same time. Banks compete for more market shares. The competition becomes fiercer. Comparing with commercial banks with shareholding systems, state-owned commercial banks' branches have to gain approval in order to cooperate with trust companies, which is complicated and time-consuming. Meanwhile, in contrast with state-owned banks, some trust companies are small, and some at the developing stage in new operation process and market. Therefore, the cooperation is relatively small, which can not win sufficient attentions from the management department of state-owned commercial 
banks. As a result, the approval will consume more time. However, market opportunity does not wait there, plus the branches of state-owned banks can not reply for their customers clearly and timely, what will affect the competence of cooperation business between state-owned commercial banks and trust companies. As a result, trust companies may lose their customers.

\subsection{Lack of specialized marketing team and sufficient talents.}

Banking-and-trust cooperation covers a large scope and needs strong specialization. Therefore, workers of state-owned commercial banks who are engaged in banking-and-trust cooperation should not only possess skilled marketing techniques but also grasp sufficient specialized knowledge concerning banking assets, debts, middle business field, trust industry, trust products, laws and regulations. Because of insufficient training for relevant business operations, knowledge, and techniques, state-owned commercial banks can not find out enough qualified marketing workers for the banking-and-trust cooperation at present. In a short period, specialized talents are in short.

\section{The product innovation for state-owned commercial banks' cooperation with trust}

The key of product innovation for state-owned commercial banks' cooperation with trust lie in banks' complete understanding toward trust and whether banks achieve an optimal organic combination with trust needs. State-owned commercial banks should make full use of self advantages. As state-owned commercial banks advance product integration schemes for trust companies, they should make researches on the products cooperation and innovation and apply them to the cooperation, exploring new financial products that meet the market needs.

\subsection{Trust plan can help state-owned commercial banks to deal with their bad assets properly.}

The high bad assets have troubled state-owned commercial banks for a long time. Trust and market principles provide possibilities of dealing with mortgage assets properly. China's state-owned commercial banks can make best use of trust companies advantages in flexible operation forms, diverse business ways, and rich products and tools to attract market capitals to participate in dealing with bad assets by means of trust. With the banking-and-trust cooperation mode, banks can turn their preferential right to benefit to investors, which can help banks to gain returns from partial assets, improving the effect of asset disposition. Meanwhile, because banks still have the subordinated right to benefit. Therefore, they can enjoy complete right even though they have already realized their preferential right to benefit

3.2 Make best use of advantages in scale and net and enlarge the middle business cooperation field between banks and trust.

In contrast with small- and medium-sized commercial banks, state-owned commercial banks possess evident advantages in settlement net, operation network, and electronic level. By enhancing middle business operation cooperation with trust companies, state-owned commercial banks can effectively enlarge income resources from middle business operation. The cooperation concerns three aspects, namely settlement, agent, and card. In the aspect of settlement, banks can provide with agent services for trust companies in self-owned capitals' settlement and transfer. Besides, banks can use cash management products to help trust companies achieve the effective setting of accounts and the unified management of capitals. In the aspect of agent, banks can provide with agent service for trust plan's capital payment operations and trust loans' interest payment operations. At the same time, banks can rely on trust companies' wide customer resources to develop credit card business.

\subsection{Develop cooperation in credit assets' transfer business and improve the liquidity of banks'credit assets.}

Many problems exist in the credit assets transfer between banks. The most important one is the bargainer's loss of customers. The participation of trust companies in the credit assets' transfer market can rightly satisfy banks' strong desire for sustaining customer sources. In specific, it includes "buy-out operation" and "repurchase operation". In the buy-out operation, banks transfer the credit right to trust companies. As loans are terminated, borrowers will return principals and interests to trust companies. In the repurchase operation, banks take credit assets as mortgage to realize a short-term transaction of capital. By cooperating with trust companies in credit asset transfer, banks can improve their asset structure, adjust the assets-liabilities ratio, avoid capitals' liquidity risks, and create new profit rising point. For trust companies, loans transferred by banks are mostly better assets that can generate expected profits.

\subsection{Enhance trust cooperation in accounts receivable and decrease loan risks.}

The trust of accounts receivable is a kind of new-developed banking-and-trust cooperation product that benefit the bank, the trust company, and the enterprise at the same time. In detail, the enterprise is the trust settler, the trust company the trustee, and the bank the trust beneficiary. The three sides sign trust contract. The enterprise grants accounts receivable to the trust company. The trust company is responsible for supervising the enterprise to take accounts receivable back. The return to accounts receivable belongs to the bank. At the same time, the bank signs a loan contract with the enterprise and provides with loans for the enterprise. For the bank, this banking-and-trust cooperation mode can improve the loan safety. The independent character of trust assets separates accounts receivable from cooperate assets. No matter what problems the enterprise will have, the bank still possess the return to the accounts receivable, which 
guarantees the safety of bank's loans.

\subsection{Enhance the share of customer sources and project sources and realize the advantage complement}

Because of local elements and government background, trust companies can easily obtain better projects and have powerful customers. State-owned commercial banks can emphasize on sharing customer resources and project resources with trust companies, by which they can realize the advantage complement and the mutual development.

\section{The development strategy and management mode for state-owned commercial banks developing banking- and-trust business}

The general development strategy for state-owned commercial banks include: take detailed researches on characters of trust, insist on principle of emphasizing both business exploration and risks defense, exert the general advantages of state-owned banks completely, grasp market opportunities fully, develop long-term and strategic cooperation with trust companies that have strong comprehensive powers, high management levels, and great market influences, take the share of customer resources as the way, and product innovation the motive, work hard to explore banking-and-trust business market. In persisting in the general strategy, state- owned commercial banks should combine it with relevant flexible mechanism together to ensure that the innovation mechanism can stay in a best state under numerous uncertainties.

4.1 Emphasize on the communication and relation with industrial supervision department and make researches on relevant policies and laws.

At present, the law of trust is on the way of gradual perfection. State-owned commercial banks must especially pay more attentions on communicating with industrial supervision department and make researches on policies in advance. And the researches should have a sense of prediction, flexibility, and sensitivity. Besides, the state-owned commercial banks should regulate their product operation mode continuously and adjust their product design ideas and marketing strategy. Meanwhile, they must transfer the trends of trust, the statistical data, and the self-restrained supervision measures to the branches in time.

4.2 The top management level should provide with timely and proper directions for the banking-and-trust cooperation in order to perfect the three-level associated marketing system.

Base on researches and analyses on trust policies and market changes, the top management level of the state-owned commercial bank should study the grave problems emerged in the cooperation with trust companies carefully and make up a proper marketing scheme for the whole bank, guiding the exploration of banking-and-trust cooperation. For the core customers, the bank can adopt the three-level (namely the head offices, the local banks, and the branches) associated marketing, applying a dynamic management. Set up customer manager teams and implement the chief customer manager system. Perfect the business coordination mechanism. Construct a rule of business coordination conference in which the marketing sector serves as the leader and other relevant sectors participate. For customers' needs, they should give timely response and solve them properly. Exert state-owned commercial banks' comprehensive advantages and effectively improve market competence and business response capability.

\subsection{Segment the market and implement the differentiated marketing strategy.}

Commercial banks should insist on the principle of taking customers as the core. Segment the customer market further. Design personalized marketing strategy and implement differentiated marketing strategy. According to trust companies' capital strengths, operations, management, business innovation, market exploration, corporate image, and other indicators, the banks can classify the trust companies into strategic cooperation type, the core cooperation type, the common cooperation type, and the prudent cooperation type. Implement a core marketing for the trust company that has strong capital strengths, nice operations, effective management, powerful production innovation, better corporate image, and excellent market exploration ability, and meet its needs overall. At the same time, pay more attentions on banking-and-trust product innovation and development. Integrate trust companies' research and development resources with commercial banks' comprehensive advantages together. Master the market changes. Produce new products constantly. Develop the banking-and-trust cooperation to a deeper and larger degree.

4.4 Constitute a perfect regulation system, emphasize on empowerment management, and make efforts to defend risks.

Because trust companies have relatively powerful innovation capability, they demand for more banking-and- trust cooperation products, what increases difficulties for empowerment. Therefore, state-owned commercial banks should set up relevant credit assessment system to defend risks. In special, a pre-warning system is necessary to response to diverse needs that may bring about risks because of informal and abnormal behaviors.

\subsection{Perfect the internal evaluation and encouragement mechanism, and implement the banking-and-trust business'} customer manager system.

State-owned commercial banks should popularize the banking-and-trust business' customer manager system in the whole country. For the qualified trust company, they should arrange the chief customer manager and construct a 
"communication system" with it, enhancing mutual understanding and communication. Meanwhile, state-owned commercial banks should perfect the internal evaluation and encouragement system constantly and construct a set of indicator system to assess the banking-and-trust business. The head office can make scientific and reasonable evaluation on customer managers' performance based on a series of qualitative and quantitative indicators, and motivate customer managers' enthusiasm in work by encouragement mechanism.

4.6 Stress on professional training and improve banking-and-trust business customer managers 'integrated quality.

Highly qualified customer managers are the foundation of commercial banks' banking-and-trust business. In order to realize the close meeting of banking-and-trust products and market needs, banks must possess a batch of marketing talents and elites who have advanced marketing methods and rich business knowledge. Correspondingly, a systematic training system is necessary. In order to achieve a rational talents combination and optimal arrangement, banks should insist on the principle of customer first. By a professional training program, all employees can possess industrial sensitivity and relatively higher marketing capability. As a result, the state-owned commercial bank will possess a marketing team that can help the bank to cultivate a close relation with trust companies and gain market competence.

4.7 Construct a decision-support and information management system for banking-and-trust business' new products and drive the experience communication among banks.

For commercial banks, the new products' decision procedure must be simple and effective. Because the new product extremely depends on right time and right opportunity and can be easily copied, the banks' decision system must emphasize on time. Therefore, the decision system has to rely on other special support systems. At the same time, make best use of present business platform and construct a banking-and-trust business information management system, by which the bank can achieve a comprehensive management on trust companies' information, realizing electric information retrieving, statistics, and empowerment. All customer managers in the bank can communicate easily and report for their performance. The electric technology helps to improve work efficiency and realize the share of information resources.

\section{Conclusion}

Because there are still many problems in the banking-and-trust business, it is urgent to enhance the business cooperation between state-owned commercial banks and trust companies, and the product innovation. China's state-owned commercial banks should make full use of self advantages, grasp opportunities of financial innovation and business exploration, implement the product cooperation and innovation with trust companies, achieve multiple income structure and diverse business types, improve middle business income, decrease operation costs, enhance banking-and-trust business management and risks defense, and improve their comprehensive competence.

\section{References}

Da, Xiaoqi. (2003). Probe into the trust cooperation in banks. Friends of Accounting. No.6.

Lan, Yuling. (2007). Analyze on the trust service in private banking service. Seeker. No.2.

Li, Xiaofang. \& Tong, Changfeng. (2007). Cooperating with trust and house rent: the banking industry has a bright prospect. Western Forum. No.4. 


\title{
Examining the Determinants and Outcomes of Superior Downward Influence Tactics: The Mediating Impact of Role Ambiguity and Subordinates' Competence Level
}

\author{
Kim Lian Lee (Corresponding author) \\ Faculty of Management \& Information Technology, University College Sedaya International \\ No 1, Jalan Menara Gading, UCSI Heights, 56000 Kuala Lumpur, Malaysia \\ E-mail: kllee@ucsi.edu.my \\ Abdul Latif Hj. Salleh \\ Department of Business Policy \& Strategy, Faculty of Business \& Accountancy, \\ University of Malaya, Malaysia \\ E-mail: abdul_latif@um.edu.my
}

\begin{abstract}
This paper examines the antecedents and consequences of superior downward influence tactics in Malaysian companies. The literature review revealed that downward influence tactics are useful but practically challenging. Researchers have identified downward influence tactics such as inspirational appeal, consultation, exchange, pressure, ingratiation, and rational persuasion as commonly used influence tactics by superior to change the behavior of subordinates. The purpose of this paper is to develop a conceptual framework for relating different outcomes of downward influence tactics and the determinants under which such influences are exercised. The outcomes are measured in terms of differences in subordinates' satisfaction with supervision and organizational citizenship behavior when subjected to supervisory downward influence tactics. Understanding different influence tactics affect the outcomes which can provide guidelines for superior in using the suitable influence tactics to increase the organizational citizenship behavior and satisfaction in organizations. Leadership styles, organizational context and mediating variables of role ambiguity and subordinates' competency level were also investigated.
\end{abstract}

Keywords: Downward Influence Tactics, Leadership, Organizational Contexts, Role Ambiguity, Competence, Satisfaction with Supervision, Organizational Citizenship Behavior

\section{Introduction and Objective of the Study}

Influence occurred when an influence leader behavior designed to change a member behavior or attitudes. Although in many occasions the term "influence" is used interchangeably with power and influence tactics, Podsakoff, MacKenzie, Morrman \& Fetter (1990) demonstrated that power alone is not sufficient in explaining a leader's effectiveness in influencing people. Effective leaders must have the skill to recognize when to use different tactics of influence as well as the skill necessary to effectively carry out these influence attempts (Kipnis, Schmidt \& Wilkinson, 1980; Yukl \& Falbe, 1990; Yukl, 1998; Bolino \& Turnley, 2003). A number of researchers have identified categories of proactive behaviors called influence tactics used by superior with different target and objectives (Kipnis, Schmidt \& Wilkinson, 1980; Schriesheim \& Hinkin, 1990; Yukl \& Falbe, 1990; Yukl, Falbe \& Youn, 1993; Yukl \& Tracey, 1992; Ansari \& Kapoor, 1987; Erez \& Rim, 1982; Erez, Rim \& Keider, 1986; Schmidt \& Kipnis, 1984). More recently, there have been several researchers suggested that leadership research needs to focus more on "fundamental" issues, such as influence processes that characterize leader-follower interaction (Bass, 1990; Hollander \& Offermann, 1990; Yukl, 1989). Research has shown that leaders' effectiveness with subordinates depends heavily on their abilities to accomplish things through subordinates (Uyterhoeven 1972; Ruello, 1973). Consequently, the more the leader enters into a set of reciprocal relationships, the more the leader becomes skillful in influencing the subordinates. Moreover, in terms of using downward influence tactics effectively, several empirical studies offer strong support for the idea that the most effective leaders in organizations understand the nature of influence, "what" influence tactics are available to them, and "how" and "when" to use those tactics (Case, Dosier, Murkison \& Keys. 1988; Kaplan, 1986; Kipnis \& Schmidt, 
1988; Mowday, 1978; Schilit \& Locke, 1982; Yukl \& Falbe, 1990). These works seems to infer that influence is important in all human relationships.

There have been few studies done to investigate the superior downward influence tactics in Malaysian work settings with relates to organizational context and leadership as key independent variables and outcomes such as satisfaction with supervision and organizational citizenship behavior. There are also few studies that investigate role ambiguity and subordinates' competence level as mediators. Thus, this research is conducted with the aim of achieving greater understanding of adopting the appropriate influence tactics to enable the superiors to better achieve their objectives in maintaining organizational harmony and unity. Secondly, this research is conducted in Malaysian cultural setting with diverse social and organizational culture. It will be interesting to look at how Malaysian workforce responds to different influence tactics as social behavior is normally implanted and entrenched in the given society. The research is important to address question confronting our industrial society concerned with the issue on how can the skills of managers be enriched so as to make it possible for them to act with greater proficiency when their contributions are from dealing with and through people especially their subordinates. One way of looking into this issue is from the "influence" perspectives of the interpersonal interactions that occur across organizational levels characterized by the phrase "superior-subordinate relationships".

In fact, there is a significant focus of interpersonal relationship researches due to our belief that sound superior-subordinate relationships are important and consistent with humanistic and cooperative work environment sought by contemporary managers. It is also believed that positive interpersonal relationship at workplace is able to increase subordinates' satisfaction with supervision and organization citizenship behavior (OCB). The subordinates with high levels of satisfaction and OCB are more likely to be committed to the organization (William \& Anderson, 1991; Smith, Organ \& Near, 1983). It is worthwhile for the superior to be aware of the existence of multiple sources of influence in work situations and how it promote subordinates' satisfaction with supervision and OCB since negative outcome itself could lead to many organizational dysfunctions such as decline in work performances, absenteeism and high turnover (Lamude, 1994; Motowidlo, 2003). According to Williams and Anderson (1991) superior's tactics of influence with subordinates and subordinates' satisfaction with supervision and OCB are inter-related. Different approach of influence styles can trigger negative consequences, which further increases sensitivity and susceptibility to misunderstanding, which in turn increases dissatisfaction. Thus, prevention of subordinates' negative outcome is important when deals with different influence tactics. This becomes a vicious cycle that many organization leaders need to address downward influence tactics and its consequences more systematically.

On the other hand, there was a substantial amount of the research attention in the context of upward influence directional. Little attention has been given in linking the types of downward influence styles. Knowing how downward influence tactics related to the organizational structure, transformational or transactional leadership, role ambiguity and competence level and its consequences will enable the superior to change or maintain his/her influence tactics to achieve the desirable outcomes. Thus, this study seeks to find out the correlates and outcome of downward influence that would ultimately contribute to the knowledge of organizational management and behavior in this area.

\subsection{Research Questions}

The delineation of research question is to find out the downward influence method employed by superior in the Malaysian companies, what are the correlates and consequences of influence tactics and how it affects subordinates. This research also provides information about the appropriateness and effectiveness of each style as it pertains to specific outcomes (Yukl, Kim \& Falbe, 1996). The key advantage to examine the antecedents and consequences of influence tactics is the maximization of organizational outcomes. This study also sought to answer the following research questions.

Are there any significant differences in subordinates' satisfaction with supervision and organizational citizenship behaviour when subjected to downward influence tactics?

Are there any predictable relationships between organizational variables and downward influence tactics and subordinates' satisfaction with supervision and organizational citizenship behaviour?

Can leadership styles be predictors of the exercise of downward influence tactics and subordinates' satisfaction with supervision and organizational citizenship behaviour?

What is the distribution of the use of influence tactics in Malaysian companies?

Can subordinates' competence level and role ambiguity mediate the relationship between the leadership style and downward influence tactics?

Can subordinates' competence level and role ambiguity mediate the relationship between the organizational context and downward influence tactics? 


\section{Theoretical Framework and Literature Review}

The following sections provide the theoretical foundation and review of the relevant constructs and variables as well as their interactions as shown in Figure 1. The main part discusses the constructs and variables, known relationships between them, theoretical perspective that link downward Influence tactics and those that contribute in explaining the determinants and outcomes of downward influence tactics such as leadership styles and organizational contextual variables (key independent variables), satisfaction with supervision, and organizational citizenship behaviour (key dependent variables) and mediator variables such as role ambiguity and subordinates' competence level.

\subsection{Influence and Influence Tactics}

Kipnis et al. (1980) labels of assertiveness, coalitions, exchange, ingratiation, rationality, and upward appeal represent a broad segment of the influence tactic literature. Schriesheim and Hinkin (1990) replicated the study of Kipnis et al. (1980) and developed new items to measure the same subscales. Yukl and colleagues (Yukl \& Falbe, 1990; Yukl \& Tracey, 1992; Yukl, Falbe \& Youn, 1993; Yukl, Kim \& Falbe, 1996) examined influence tactics from the perspectives of both agent and target, and also extended the work of Kipnis et al. by identifying the additional tactics of inspirational appeal, consultation, legitimating, pressure, and personal appeal. Yukl and Falbe (1990) determined that inspirational appeal and consultation were the most frequently used in downward influence tactics. This conclusion coincides with the research results of Hinkin and Schriesheim (1990), who found that consultation and inspirational appeal has significant positive relationships with the bases of power such as expert and referent.

For the purpose of this study, the researchers have chosen Yukl and his colleagues (Yukl \& Falbe, 1990; Yukl \& Tracey, 1992) downward influence tactics. It is among the most popular downward influence used in research. In fact, Yukl and his colleagues model was based on Kipnis et al. (1980) influence styles. This work leads them to identify the primary tactics leaders used in downward direction is defined in Table 1.

\subsection{Leadership Styles}

Past researchers have studied on transactional leadership as the core component of effective leadership behavior in organizations prior to the introduction of transformational leadership theory into the literature (Bass, 1985; Burns, 1978; House, 1977). Transactional leadership is based on exchange relationship where subordinates agreed with, accepted, or complied with the superior in exchange for rewards, resources or the avoidance of disciplinary action (Podsakoff, Todor \& Skov, 1982; Podsakoff, MacKenzie, Moorman \& Fetter, 1990). Previous research has shown transactional contingent reward style leadership to be positively related to followers' commitment, satisfaction, organizational citizenship behavior and performance (Bycio, Hackett \& Allen, 1995; Hunt \& Schuler, 1976; Podsakoff, Todor, Grover \& Huber, 1984; Goodwin, Wofford \& Whittington, 2001).

More recently, there are many empirical work on transformational leadership focused on the extent to which transformational leadership augments the effect of transactional leadership in explaining various outcomes. For example, leader effectiveness (Hater \& Bass, 1988), subordinate satisfaction (Seltzer \& Bass, 1990) and subordinate effort (Bass, 1985), and little is known about the transformational-transactional leadership and the influence tactics although there are several writers highlighted the important of studying power and influence processes (Bass, 1990; Hollander \& Offermann, 1990; Yukl, 1989). These recommendations seem particularly relevant for transformational leadership research as the literature suggests that (1) the pursuit of visionary influence objectives is a distinguishing feature of transformational leadership, (2) transactional and transformational leaders employ different kinds of influence strategies or tactics to obtain follower conformity, and (3) transactional and transformational leaders elicit different patterns of follower conformity (Kelman, 1958; Howell, 1988; Tichy \& Devanna, 1986). This new genre of leadership advocates that transformational leaders can motivate followers to perform beyond the normal call of duty. There is also considerable empirical support that such leaders produce leadership effects such as high follower motivation, satisfaction, and commitment.

\subsection{Organizational Contextual Variables}

Several researchers have attributed the influence tactics to various factors e.g. span of control (Morris, Steers \& Roch, 1979) and organizational structure (Weber, 1946; Crozier, 1964).

\subsubsection{Span of Control}

Span of control is the number of subordinates reporting to a superior. If the span is narrow, manager will have few underlings. Narrow span will provide closer supervision and tighter "boss-oriented" controls; thus resulting in tall, hierarchical structure (Likert \& Likert 1976; Tannenbaum 1968). On the other hand, wider spans will generally entail more responsibility be given to subordinates, thereby making the job more fulfilling. Thus, span of control can be an important variable in the superior-subordinate exchange relation. Moreover, studies by Morris, Steers and Roch (1979) shows that superior span of control contributes to the explained variance in influence styles. Extending this argument, it is also presupposed that supervisory span will have influence to the way manager exercising influence tactics. 


\subsubsection{Organizational Structure}

The study of organizational structure relies on the differentiation of position, formulation of rules and procedures, and prescriptions of authority (Weber, 1946). In this study, structure is conceptualized on a mechanistic-organic continuum. Crozier (1964) suggests that an organization stresses rules, policies, and procedures will lead to rigidity and inflexibility develops an elaborate control system backed by a centralized staff, this is called "mechanistic" or "bureaucratic". Crozier (1964) called the opposite type "organic". Organic structure is to be seen as the dominant form of structural design in the near future. Studies by Wells (1990) and Ferris, Duleboun, Flink, George-Falry, Mitchell and Matthew (1997) stated that structure might affect the influence styles. Their findings show that superior tends to favor inspirational appeal and consultation approach when the structure is organic.

\subsection{Subordinates' Competency Level}

Superior exercises of influence styles can be affected by subordinates' competence level. If subordinate competence level is high, superior may use soft tactics such as inspirational appeal and consultation (Snyder \& Bruning, 1985). On the other hand, assuming subordinates' competency is low, superior may be expected to use hard tactics like pressure (Salam, 1998). This could be due to superior who lack confidence in their own capabilities may feel threatened by highly competent subordinates.

\subsection{Role Ambiguity}

Role ambiguity occurs when employees are not certain of how to go about to perform a given roles or tasks. This could due to the management have not clearly identified the responsibilities of the job (Thomas, 1976). Uncertainty regarding one's job responsibilities creates an environment that fosters influence attempts because of the unclear connections among effort, performance, and desired outcomes (Madison, Allen, Porter, Renwick \& Mayes, 1980; Parker, Dipboye \& Kackson, 1995). Similarly, when employees experience task ambiguity due to their uncertainty of task responsibilities, a favourable situation for influence attempts is created (Hickson, Hinings, Lee, Schneck \& Pennings, 1971). Thus, superior should use inspirational and consultation method to convince subordinates to perform their roles constructively, despite the lack of clarity in their roles.

\subsection{Satisfaction with Supervision}

Satisfaction with supervision has received extensive attention in organizational research (Locke, 1976). Work satisfaction is an important workplace construct and one that is of concern for effective management. Thus, numerous research findings suggest that influence management style is related to various aspects of employee satisfaction are of interest and represent an important extension to the job satisfaction literature. The amount of supervision and direction given to the subordinates will increase their satisfaction with supervision. Conversely, many studies recorded that supervision to the extent that the superior exercises pressure tactics is found to have a negative impact on the subordinates' satisfaction (Kahn, Wolfe, Quinn, Snoeck \& Rosenthal, 1964; Likert \& Likert, 1967).

\subsection{Organizational Citizenship Behaviour (OCB)}

Bateman and Organ (1983) introduced the construct of OCB, drawing upon concepts of super role behaviors presented by Katz and Kahn (1966). Examples of employees OCB include, accepting extra duties and responsibilities at work, work overtime when needed, and helping subordinates with their work (Masterson, Lewis, Goldman \& Taylor, 1996; Organ, 1988). Determining why individuals engage in OCB has occupied a substantial amount of research attention in both organizational behavior and social psychology (Brief \& Motowidlo, 1986; McNeely \& Meglino, 1994). Most research on OCB as focused on individual antecedents. For example, researchers have suggested that there is a relationship between OCB and satisfaction (Bateman \& Organ, 1983) commitment (O'Reilly \& Chatman, 1986), perceptions of fairness (Folger, 1993; Martin \& Bies, 1991; Moorman et al., 1993; Tepper \& Taylor, 2003), perceptions of pay equity (Organ, 1998).

\section{Hypothesized Relationship}

\subsection{Organizational Structure and Downward Influence Tactics}

Except for the perceptual study by Madison, Allen, Porter, Renwick and Mayes (1980), there was no major empirical studies been done to investigate the effects of organizational context on the use of downward influence tactics in organizations. Thus, this study was designed in an attempt to examine the exercise of downward influence in work settings on the contextual effects of organizations on superior's use of influence tactics in dealing with subordinates. Burns and Stalker (1961) define organic structure as horizontal specialization and there are few rules being emphasized in the organization. If the organizational structure is such that organic is prevalent, then superior will have a greater tendency to employ inspirational appeal, consultation, ingratiation and rational persuasion in their downward influence attempts. It can be expected that superior's choice of influence tactics will be a function of the organizational context in which the influence attempt occurs. Consistent with the contextual approach to organizational behavior research (Bass, 1981; Herman \& Hulin, 1972; Rousseau, 1978), this study hope to find the link between organizational 
characteristics to individual responses. Subordinate competence level i.e. the extent to which subordinates is effective in doing their work is suspected to mediate the relationship between organizational structure and downward influence tactics. Past research has shown that these variables tend to be correlated (Payne \& Pugh, 1976). Accordingly, the following hypotheses are advanced:

Hypothesis 1a: Organic structure is positively associated with inspirational appeal, consultation, ingratiation and rational persuasion and negatively associated with pressure and exchange tactics.

Hypothesis 1b: Organic structure is negatively associated with pressure and exchange tactics. Role ambiguity will mediate this relationship such that the negative relationship between organic structure and pressure and exchange tactics will be weaker among employees experiencing high levels of role ambiguity compared with those reporting low levels of role ambiguity.

Hypothesis 1c: $\quad$ Organic structure is positively associated with inspirational appeal, consultation, ingratiation and rational persuasion. This relationship is mediated by the subordinate's competence level.

\subsection{Span of Control and Downward Influence Tactics}

On the other hand, superiors who possess wider span of control are more likely to influence subordinates in a more formalized, impersonal manner, using warnings and punishments (Kipnis \& Cosentino 1969; Kipnis \& Lane 1962). In addition, as spans of control increase, managers are found to more autocratic (Heller \& Yukl, 1969). As such, the following hypotheses are predicted:

Hypothesis 1d: $\quad$ Wider span of control is positively associated with exchange and pressure tactics but negatively associated with inspirational appeal, consultation, and rational persuasion.

\subsection{Leadership Styles and Downward Influence Tactics}

Burns (1978) and Bass (1985) have conceptualized the transactional and transformational leadership. Burns (1978) viewed transformational leadership as a process of activating followers' higher level needs by inspiring higher ideals and raising moral consciousness. Burns contrasted the heroic, agent of transformational leadership with the transactional leader, who invokes exchange processes in order to satisfy followers' self-interests (i.e., exchanging pay and other benefits for follower effort). According to Bass (1985), transactional leadership enhances the likelihood that followers will display expected levels of performance (by providing desired rewards contingent on acceptable performance and by clarifying role expectations when followers do not met performance standards). Transformational leadership involves heightening follower motivation to accomplish goals that exceed expectations by instilling pride and confidence, communicating personal respect, facilitating creative and critical thinking, and providing inspiration. However, transformational leaders frequently employ transactional behaviors to accomplish routine tasks (Avolio \& Bass, 1988).

It may be predicted that transactional leaders frequently exert influence by offering to reciprocate or exchange favours (i.e., exchange tactics). However, it may be expected that transformational leaders employ more personally involving influence tactics (e.g., personal appeals, inspirational appeals, consultation, and rationality) than their transactional counterparts (Falbe \& Yukl, 1992; Yukl, 1998). There are several reasons for suspecting an association between influence tactics and transformational leadership. Leaders' behaviours that inspire others to change their beliefs and values (Bass, 1997) reminiscent of inspirational appeal. Inspirational appeals refer to the use of values and ideals to arouse an emotional response in the subordinates (Yukl, 2002; Yukl \& Seifert, 2002). The request is presented in such a way that it resonates with the subordinate's needs, values, and ideals. Inspirational appeals are known to be an effective tool to raise the subordinate's enthusiasm towards the request (Yukl et al., 1996). Transformational leader inspires and challenge subordinates to achieve beyond their self-expectations by raising their self-confidence (Bass, 1997, 1998). Thus, inspirational appeals tactic is expected to be associated with transformational leadership who often communicate with vivid imagery and symbols in a way that generates enthusiasm (Yukl, 2002).

In addition, transformational leader should be more likely to influence subordinates by getting them personally involved and committed to a project through consultation tactics, including participate them to contribute and suggest ways to improve a proposal or help plan an activity (Yukl, 2002; Yukl e al., 1996; Yukl \& Seifert, 2002; Yukl \& Tracey, 1992). Furthermore, the use of rational persuasion is associated with transformational leadership (Caldwell \& Burger, 1997; Bass, 1997, 1998). Rational persuasion aims at encouraging subordinates to think critically, rationally or creatively and to express their ideas. When using rational persuasion tactic, transformational leaders create an environment that encourages the reframing of problems through the use of explanations, factual evidence, and logical arguments (Yukl, 2002; Yukl \& Seifert, 2002). Rational persuasion is widely used (Aguinis et al., 1994; Yukl \& Falbe, 1990; Yukl \& Seifert, 2002) by transformational leader to obtain subordinate's commitment to a request (Yukl et al., 1996; Yukl \& Tracey, 1992; Kelloway \& Barling, 2000) regardless of whether the target is a subordinate, peer, or superior.

Moreover, transformational leader who take into account individual subordinate's accomplishment by praising and 
flattery to make them feel liked by the superior can show a positive effects on work outcomes (Higgins et al., 2003). Ingratiation involves flattery and favour doing enhancing managerial liking of the subordinate. In addition, superior reacts differently to different subordinates' competence level. Lowin and Craig (1968) have documented in their field experiment that supervisors reacted more warmly, permissively, and collegially to a subordinate when the latter worked efficiently. Greene (1975) in a longitudinal study concluded that managers initiated more structure and showed less consideration for sub-part performers. Therefore, it was hypothesized that;

Hypothesis 2a: Transformational leadership is positively associated with inspirational appeal, consultation, rational persuasion and ingratiation. This relationship is mediated by the subordinate's competence level.

Hypothesis 2b: Transformational leadership is negatively associated with pressure and exchange tactics. This relationship is mediated by the subordinate's competence level.

\subsection{Leadership styles and Organizational Citizenship Behavior}

We tested a hypothesis about the relationships between both transformational and transactional leadership and organizational citizenship behavior (Podsakoff et al., 1990). Transformational leadership has been consistently linked to followers' higher level of OCB (Geyer \& Steyrer, 1998; Howell \& Avolio, 1993; Lowe, Kroeck \& Sivasubramaniam, 1996; Onnen, 1987). On the other hand, transactional leadership has been negatively link to follower low level of OBC (Bass \& Avolio, 1990).

Graham (1988) has suggested that the most important effects of transformational leadership behavior should be on extra-role behaviors that exceed the requirements of in-role expectations. These extra role behaviors are best articulated by the OCB construct developed by Organ (1988); Deluga, (1995), Organ and Konovsky (1989), Podsakof et al. (1990). OCB refers to the behavior of an employee that is discretionary, not rewarded or recognized in an explicit way the organization, and tends to promote efficient and effective functioning of the organization (Organ, 1988). Results of research show transformational leadership behavior to have a positive relationship with OCB (Graham, 1988; Podsakoff et al., 1990; Whittington, 1997). Although the relationship between transactional leadership and OCB has not been empirically examined, Graham (1988) suggests that the instrumental compliance to obtain rewards required by transactional leadership may suggest a reduction in OCB when working for a transactional leader.

OCB is behavior, largely discretionary, and seldom included in formal job description. Transformational leaders motivate followers by getting them to internalize and prioritize a larger collective cause over individual interests. Individuals who are intrinsically motivated to fulfill a collective vision without expecting immediate personal and tangible gains may be inclined to contribute toward achieving the shared workplace goal in ways that their roles do not prescribe. These individuals make these contributions because their senses of self-worth and self-concepts are enhanced in making these contributions. Individuals for whom this link between the interests of self and others has not been established are less likely to make largely discretionary, non-tangibly rewarded contributions. A positive association between transformational leadership and OCB is expected and has been supported empirically (e.g., Podsakoff et al., 1990). Thus, the hypothesis is stated as follows:

Hypothesis 2c: Transformational leadership style is positively correlated with OCB whereby, transactional leadership style is negatively correlated with OCB

\subsection{Leadership Styles and Satisfaction with Supervision}

Among determinants of job satisfaction, leadership is viewed as an important predictor and plays a central role. Leadership is a management function, which is mostly directed towards people and social interaction, as well as the process of influencing people so that they will achieve the goals of the organization (Skansi, 2000). Numerous studies carried out in several countries showed that there is a positive correlation between leadership and the job satisfaction (Seo, et al. 2004; Vance \& Larson, 2002; Chiok Foong Loke, 2001; Martin, 1990; Dunham \& Klafehn, 1990; Stordeur et al., 2000; Hespanhol et al., 1999; Lowe et al., 1996; Berson \& Linton, 2005; Morrison, 1994; Mosaderghrad, 2003a). As such the following hypothesis is predicted.

Hypothesis 2d: Transformational leadership style is positively correlated with satisfaction with supervision, whereas transactional style is negatively correlated with satisfaction with supervision.

\subsection{Structure and Outcomes}

In relation to organizational context, research by Meadows (1980) concluded that organic structure is positively related to satisfaction of higher order needs, but mechanistic structure is associated with their frustration. This statement is also supported by Rahman and Zanzi (1995) in their study which confirms organic structure is associated with greater job satisfaction with supervision and OCB. Considering these past findings, the following hypotheses are suggested as follows:

Hypothesis 3a: $\quad$ Organic structure has direct and positive effect on the satisfaction with supervision. 
Hypothesis 3b: Mechanistic structure has direct and negative effect on the satisfaction with supervision.

Hypothesis 3c: Organic structure has direct and positive effect on the organization citizenship behaviour.

\subsection{Downward Influence Tactics and Outcomes}

Organizational influence researchers (e.g. Kipnis, Schmidt \& Wilkinson, 1980; Kipnis \& Schmidt, 1988; Yukl \& Falbe, 1990; Yukl, Lepsinger \& Lucia, 1993; Yukl \& Tracey, 1992; Hinkin \& Schriesheim, 1990; Pfeffer 1981) generally assert that superior who exhibits inspirational appeal, consultation, ingratiation and rational persuasion tactics are more prone to foster a cordial dyadic relationships among superiors and subordinates. These tactics are related to an effective influence management.

Conceptual and empirical research on influence tactics and OCB have flourished concurrently but only recently have their conceptual overlaps in behavioural and motive content been pointed out (e.g., Bolino, 1999; Eastman, 1994; Ferris, Bhawuk, Fedor \& Judge, 1995). Because of the past investigation of influence tactics and OCB separately, little is known about their level of distinctiveness. This omission represents a research need because both of these categories of behaviour are common within organizations and both have been found to be associated with supervisor-subordinate relationship quality and important organizational outcomes.

The current study was designed to address this gap in the literature by evaluating whether or not supervisor downward influence tactics and OCB are distinct constructs and whether they have a differential impact on superior-subordinate relations. Researchers have found that influence tactics are often used by superiors as a means of obtaining personal goals, promoting their own self interest, exercising social control, and changing the behaviour of others (Ferris \& Judge, 1991; Ferris, Russ \& Fandt, 1989; Kipnis et al., 1980; Barry \& Watson, 1996). The successful used of these tactics tend to be able to reduce resistance by the subordinates' (Pfeffer, 1981; Tedeschi \& Melburg, 1984). Initial conceptual and theoretical work in influence tactics research suggested that ingratiation by superior would enhance supervisor-subordinate relationship (Jones, 1964; Tedeschi \& Melburg, 1984). Ingratiation tactics used by superior to impress their employees with the objective of being better liked (Kipnis, Schmidt \& Wilkinson, 1980; Tedeschi \& Melburg, 1984; Wayne \& Liden, 1995). These tactics include flattery, favour-doing, emphasizing what they have in common with their subordinates and de-emphasizing their differences (Krone, 1992). Research has demonstrated that these tactics are effective in gaining positive outcomes from the subordinates.

On the other hand, researchers have generally maintained that OCB demonstrated by employee arises from a sense of obligation and from personality traits (Bolino, 1999). Social exchange theory is the basis for arguing this behavior (Niehoff, 2000). According to Blau (1964) and Organ (1988) the employment relationship engenders feelings of personal obligation when subordinates are treated well by superiors feel obligated to discharge their obligation by engaging in extra-role behaviours directed at helping others and the organization. Several studies on the inspirational appeal and consultation and rational persuasion tactics show consistent results in subordinates' satisfaction with supervision and OCB (Kipnis \& Schmidt, 1988; Schriesheim \& Hinkin 1990). Likewise, other studies recorded that superior uses pressure and exchange tactics are linked to negative effect on subordinates' satisfaction with supervision and OCB (Yulk \& Falbe, 1990; Yukl \& Tracey, 1992).

Thus, it can be hypothesized that:

Hypothesis 4a: Superior's use of inspirational appeal, consultation, ingratiation and rational persuasion has direct and positive effect on the subordinates' satisfaction with supervision.

Hypothesis 4b: Superior's pressure tactic and exchange tactic have negative effect on the subordinates' satisfaction with supervision.

Hypothesis 4c: $\quad$ Superior's inspirational appeal, consultation, ingratiation and rational persuasion have direct and positive effect on organization citizenship behavior.

Hypothesis 4d: Superior's pressure tactic and exchange tactic have negative effect on organization citizenship behavior

\section{Methodology and Research Design}

\subsection{Sampling Design}

The sampling population is generated from the master list of factories registered with the Federation of Malaysian Manufacturers (FMM). We include manufacturing companies with the number of employees greater than 30 as our sample because this number chosen can reflect a more formalized structure and system of supervision that likely to exist and functioning. The sample size would be 350 respondents from executives, managers and professionals in Malaysian manufacturing companies to answer the survey questionnaires as they represent a group of more educated people who are more aware of the types of influence tactics used by their superiors. The stratified random sampling procedure will be used in selecting samples from the large database. 


\subsection{Research Instruments}

Each of the measurements of relevant constructs was discussed here.

4.2.1 Downward Influence Tactics

Yukl's 44-item Influence Behaviour Questionnaire-2000 (IBQ-2000)

\subsubsection{Organization Structure}

Organization structure was represented a 7 item scale which measures organicity, i.e. the extent to which organizations are structured as organic versus mechanistic entities. This seven-point Likert-type scale was also developed by Khandwalla (1977) and later used by Covin and Slevin (1989) and Low (2005).

\subsubsection{Leadership}

Transformational and transactional leadership were measured by using the German translation of the (MLQ Form 5X Short; Bass \& Avolio, 1995) by Felfe (2006). As the four single components of transformational leadership usually show high intercorrelation $(r=.83$ on average; Bass \& Avolio, 2000). We measured leadership as unidimensional concept (see Hambley, Kline, \& O’Neill, 2005; Walumba et al., 2004). The participants were asked to rate their superior's leadership behavior on a seven-point Liker scale (ranging from "never" to "almost always"). Since the leaders themselves were asked to assess their leadership style, we used a version for self-evaluation that had already been used in previous studies (Felfe, 2003; Goihl, Tartler \& Kroger, 2001; Liepmann \& Goihl, 2001). Cronbach's alphas for this scale were .78 for transformational leadership and .62 for transactional leadership.

\subsubsection{Span of Control}

Span of control is a measure of the total number of person being supervised by a superior.

\subsubsection{Satisfaction with Supervision}

The instrument used to measure satisfaction with supervision is the updated version of the original Job Descriptive Index (JDI; Smith at el., 1969) which was later revised by Roznowski (1989).

\subsubsection{OCB}

OCB scale was measured using a 6-item scale for altruism and an 8-item scale for compliance developed by Smith, Organ and Near (1983). The scale measures high and low of OCB. Respondents indicated the frequency in which they had engaged in the various citizenship behaviours. Responses were made on a 7-point scale. The coefficient alpha was .76 for altruism and .66 for compliance.

\subsubsection{Role Ambiguity}

The six-item scale developed by Rizzo, House and Lirtzman (1970) was used to measure role ambiguity. This scale was selected because it is the most commonly used to measure role ambiguity in management literatures (Jackson \& Schuler, 1985). Individual scale items were evaluated on a 7-point Likert-type scale. The scale was reverse coded such that higher number responses reflect greater level of role ambiguity.

\subsubsection{Subordinates' Competence Level}

Wagner and Morse's (1975) self-report measure of individual sense of competence was used to measure employee task competence in lieu of a more direct measure of competence level. Thirteen items were extracted from their larger pool of items for used based upon their factor loadings as reported in Wagner and Morse (1975). A sample item stated, "I honestly believe I have all the skills necessary to perform this task well." All items were scaled on 7-point agree-disagree rating scales. Evidence pertaining to the reliability and predictive validity of this measure is located in several sources (Morse, 1976; Tharenou \& Harker, 1984; Wagner \& Morse, 1975).

\subsection{Data Analysis Procedure}

The main statistical techniques used will be the Path Analysis. Other statistical analysis to be employed is correlational analysis, moderated regression analysis, and analysis of variance (ANOVA).

\section{Benefit and Implications of the Proposed Research}

There are several specific implications expected from the present study. First, the research suggests that when the superior has a choice in the influence styles he/she emphasizes to achieve greater satisfaction with his/her supervision. For example influence attempt such as inspirational appeal, consultation, rational persuasion, ingratiation tactics are expected to be more favourable than exchange and pressure tactic. Second, in the selection of superior to lead a division of work, especially when the work group is highly experience and skilled, it is expected that certain characteristics or ability will assist in the management of such work group effectively. It may affect the influence style and the outcomes in a direct or indirect way.

Interaction or mediation effect of role ambiguity and subordinates' competence level are investigated and expected to 
shed light on how the variable provide direct and indirect effects on downward influence tactics and the outcomes. In an attempt to solicit subordinate super-ordinate effort in the organization, both satisfaction and OCB are included in the outcome variables of the study. Relationships must exist to highlight the relevant contextual and influence tactics that promotes such behaviour in the organization and this will have great practical significance.

\section{References}

Ansari, M. A. \& Kapoor, A. (1987). Organizational context and upward influence tactics. Organizational Behaviour and Human Decision Processes, 40, 39-49.

Bass, B. M. \& Avolio, B. J. (1990). Transformational leadership: A response to critiques. In Chimers, M. M. \& R. Ayman, (Eds.), Leadership Theory and Research: Perspectives and Directives (pp 49-80). New York: Academic Press.

Bass, B. M. \& Avolio, B. J. (1995). Multifactor leadership questionnaire for research. Pa Alto, CA: Mind Garden, Inc.

Bass, B. M. (1981). Stogdill's handbook of leadership $\left(2^{\text {nd }} E d\right)$. New York: Free Press.

Bass, B. M. (1985). Leadership and performance beyond expectations. Free Press, New York.

Bass, B. M. (1990). From transactional to transformational leadership: Learning to share the vision. Organizational Dynamics, 18(3), 19-6.

Bass, B. M. (1997). Does the transactional-transformational leadership paradigm transcend organizational and national boudaries? American Psychologist, 52.

Bass, B. M. (1998). Transformational leadership: Industry, military, and educational impact. Mahwah, NJ: Erlbaum.

Bateman, T. S. \& Organ, D. W. (1983). Job satisfaction and the good soldier: The relationship between affect and employee "citizenship". Academy of Management Journal, 26, 587-595.

Berson, Y. \& Linton, J. D. (2005). An examination of the relationships between leadership style, quality, and employee satisfaction in R\&D versus administrative environments. $R \& D$ Management, 35(1), 51-60.

Bolino, M. C. \& Turnley, W. H. (2003). "Going the extra mile: Cultivating and managing employee citizenship behavior". Academy of Management Executive, 17(4), 60-71.

Brief, A. P. \& Motowidlo, S. J. (1986). Prosocial organizational behaviours. Academy of Management Review, 11, 710-725.

Burns, J. M. (1978). Leadership. Harper and Row, New York, NY.

Burns, T. \& Stalker, G. M. (1961). The management of innovation. London: Tavistock.

Bycio, P., Hackett, R. D. \& Allen, J. S. (1995). Further assessments of Bass's (1985) conceptualization of transactional and transformational leadership. Journal of Applied Psychology, 80, 468-478.

Case, T., Dosier, L., Murkison, C. \& Keys, B. (1988). How managers influence superiors: A study of upward influence tactics. Leadership and Organizational Development Journal, 19(4), 25-31.

Chiok, Foong, Loke. (2001). Leadership behaviours: effects on job satisfaction, productivity and organizational commitment. Journal of Nursing Management, 9(4), 191-204.

Deluga, R. J. (1995). The relationship between trust in the supervisor and subordinate organizational citizenship behavior. Military Psychology, 7, 1-16.

Dunham, J. \& Klafehn, K.A. (1990). Transformational leadership and the nurse executive. Journal of Nursing Administration, 20(4), 28-34.

Erez, M. \& Rim, Y. (1982). The relationship between goals, influence tactics, and personal and organizational variables. Human Relations, 35, 871-878.

Erez, M., Rim, Y. \& Keider, I. (1986). The two sides of the tactics of influence. Agent vs. Target. Journal of Occupational Psychology, 59, 25-39.

Falbe, C. M. \& Yukl, G. (1992). Consequences for managers of using single influence tactics and combinations of tactics. Academy of Management Journal, 35, 638-652.

Ferris, G. R., Dulebohn, J. H., Frink, D. D., George-Falvy, J., Mitchell, T. R. \& Matthews, L. M. (1997). Job and organizational characteristics, accountability, and employee influence. Journal of Managerial Issues, 20(2), 59-71.

Ferris, G. R., Russ, G. S. \& Fandt, P. M. (1989). Politics in organizations. In R. A. Giacalone \& P. Rosenfeld (Eds.), Impression management in organization (pp. 143-170). Hillsdale, NJ: Erlbaum.

Folger, G. (1993). Justice, motivation, and performance beyond role requirements. Employee Responsibilities and 
Rights Journal, 6(3), 239-248.

Frone, M. R. (1990). Intolerance of ambiguity as a moderator of the occupational role stress-strain relationship: A meta-analysis. Journal of Organizational Behaviour, 3(4), 309.

Geyer, L. \& Steyrer, J. M. (1998). Transformational leadership and objective performance in banks. Applied Psychology: An International Review, 47, 97-420.

Goodwin, V. L., Wofford, J. C. \& Whittington, (2001). A theoretical and empirical extension to the transformational leadership construct. Journal of Organizational Behaviour, 22, 759-774.

Graham, J. (1988). Transformational leadership: Fostering follower autonomy, not automatic followership. In J. Hunt, B. Baglia, H. Dachler, C. Schriesheim (Eds.), Emerging Leadership Vistas. Lexington Books: Lexington, MA; pp 73-79.

Greene, C. N. (1975). The reciprocal nature of influence between leader and subordinate". Journal of Applied Psychology, 60, 187-193.

Hater, J. J. \& Bass, B. M. (1988). Superiors' evaluations and subordinates' perceptions of transformational and transactional leadership. Journal of Applied Psychology, 73, 695-702.

Heller, F. \& Yukl, G. (1969). Participation, Managerial Decision-Making and Situational Variables. Organization Behavior and Human Performance. 4, 227-241.

Herman, J. B. \& Hulin, C. L. (1972). Studying organizational attitudes from individual and organizational frames of reference. Organizational Behavior and Human Performance, 8, 84-108.

Hickson, D. J., Hinings, C. R., Lee, C. A., Schoeck, R. E., \& Pennings, J. M. (1971). A strategic contingency theory of intraorganizational power. Administrative Science Quarterly, 6, 216-229.

Hollander, E. \& Offermann, L. R. (1990). Power and leadership in organizations: Relationship in transition. American Psychologist, 45, 179-189.

House, R. (1977). A 1976 theory of charismatic leadership. In J.G. Hunt \& L.L. Larson (Eds.), Leadership on the cutting edge (pp. 189-207). Carbondale, IL: Southern Illinois University Press.

Howell, J. M. \& Avolio, B. J. (1993). Transformational leadership, transactional leadership, locus of control, and support for innovation: Key predictors of consolidated-business-unit performance. Journal of Applied Psychology, 78, 891-902.

Hunt. J. G. \& Schuler, R. S. (1976). Leader reward and sanctions behavior in a public utility: What difference does it make? Working paper, Southern Illinois University.

Kahn, R. L., Wolfe, D. M., Quinn, R. P., Snoeck, J. D. \& Rosenthal, R. A. (1964). Organizational stress. Studies in role conflict and ambiguity, New York: Wiley.

Kaplan, R. E. (1986). Trade routes: “The manager's network of relationship. Organizational Dynamics, 37-52.

Katz, D. \& Kahn, R. L. (1966). The social psychology of organizations. New York: Wiley.

Kelman, H. C. (1958). Compliance, identification and internalization: Three processes of opinion change. Journal of Conflict Resolution, 2, 51-60.

Kipnis, D. \& Cosentino, J. (1969). Use of leadership powers in industry. Journal of Applied Psychology, 53, $460-466$.

Kipnis, D. \& Lane, W.P. (1962). Self confidence and leadership. Journal of Applied Psychology, 46, 291-295.

Kipnis, D. \& Schmidt, S.M. (1988). Upward influence styles: Relationship with performance evaluations salary and stress. Administrative Science Quarterly, 33, 528-542.

Kipnis, D., Schmidt, S. M. \& Wilkinson, I. (1980). Intraorganizational influence tactics: Explorations in getting one's way. Journal of Applied Psychology, 65, 440-452.

Krone, K. J. (1992). A comparison of organizational, structural and relationship effects on subordinates' upward influence choice. Communication Quarterly, 40, 1-15.

Lamude, K. G. (1994). Supervisors' influence tactics for handling managers' resistance. Psychological Reports, 75, 371-374.

Likert, R. \& Likert, J. G. (1976). New ways of managing conflict. New York: McGraw-Hill.

Locke, E. A. (1976). The nature and causes of job satisfaction. In M. Dunnette (Ed.), Handbook of Industrial and Organizational Psychology, Chicago, IL, pp 1297-1350.

Lowe, K. B., Kroeck, K. G. \& Sivasubramaniam, N. (1996). Effectiveness correlates of transformational and transactional leadership: A meta-analytic review of the MLQ literature. Leadership Quarterly, 1 7, 385-42. 
Lowin, K. B. \& Craig, J. (1968). The influence of level of performance on managerial style: An experimental object-lesson in the ambiguity of correlational data. Organizational Behaviour and Human Performance, 3, 440-458.

Madison, D. L., Allen, R. W., Porter, L. W., Renwick, P. A. \& Mayes, B. T. (1980). Organizational politics: An exploration of angers' perception. Human Relations, 33, 79-100.

Martin, C. L. \& Bies, R. J. (1991). Just laid off, but still a good citizen? Only if the process is fair”. Annual Meeting of the Academy of Management, 6(3), 227-238.

Masterson, S. S., Lewis, K., Goldman, B. \& Taylor, M. S. (1996). Integrating justice and social exchange: The differing effects of fair procedures and treatment on work relationships. Academy of Management Journal, 43, 738-748.

Moorman, C., Rohit, D. \& Zaltman, G. (1993). Factors affecting trust in marketing research relationships. Journal of Marketing, 57, 81-101.

Morrison, E. W. (1994). Role definitions and organizational citizenship behavior: The importance of the employee's perspective. Academy of Management Journal, 37, 1543-1567.

Motowidlo, S. M. (2003). Job performance, in W. C. Borman, D. R. Ilgen \& R. Klimoski, (Eds.), Comprehensive Handbook of Psychology, Vol. 12: Industrial and Organizational Psychology. New York: Wiley.

Mowday, R. T. (1978). The exercise of upward influence in organizations". Administrative Science Quarterly, 23, 137-156.

Niehoff, B. P. (2000). A motive-based view of organizational citizenship behaviours: Applying an old les to a new class or organizational behaviours. Proceedings, Midwest Academy of Management.

Organ, D. W. \& Konovsky, M. (1989). Cognitive versus affective determinants of organizational citizenship behavior. Journal of Applied Psychology, 74, 157-164.

Organ, D. W. (1988). Organizational citizenship behavior: The good soldier syndrome. Lexington, MA: Lexington Books.

Pfeffer, J. (1981). Power in organizations. Boston: Pitman.

Podsakoff, P. M., MacKenzie, S. B. Morrman, R. H. \& Fetter, R. (1990). Transformational Leader Behaviors and their Effects on Follower's Trust in Leader Satisfaction, and Organizational Citizenship Behaviors. Leadership Quarterly, 1, 107-142.

Podsakoff, P. M., Todor, W. D. \& Skov, R. (1982). Effects of Leader Contingent and Non Contingent Reward and Punishment Behaviours on Subordinate Performance and Satisfaction. Academy of Management Journal, 22 , 810-821.

Podsakoff, P. M., Todor, W. D., Grover, R. A. \& Huber, V.L. (1984). Situational moderators of leader reward and punishment behaviors: Fact or fiction? Organizational Behavior and Human Performance, 34(1), 1-63.

Rahman, M. \& Zanzi, A. (1995). A Comparison of Organizational Structure, Job Stress, and Satisfaction in Audit and Management Advisory Services in CPA Firms. Journal of Managerial Issues, 17(3), 290.

Rizzo, A. \& Mendez, C. (1988). Making things happen in organization: Does gender make a difference? Public Personnel Management, 1, 9-22.

Rousseau, D. M. (1978). Characteristics of departments, positions, and individuals: Contexts for attitudes and behavior. Administrative Science Quarterly, 23, 521-540

Ruello, S. H. (1973). Transferring managerial concepts and techniques to operating management. Advanced Management Journal.

Schilit, W. K. \& Locke, B. (1982). A study of upward influence in organizations. Administrative Science Quarterly, 27, 304-316.

Schmidt, S. M. \& Kipnis, D. (1984). Manager's Pursuit of Individual and Organizational Goals. Human Relations, 37, 781-794.

Schriesheim, C. A., \& Hinkin, T. R. (1990). Influence tactics used by subordinates: A theoretical and empirical analysis and refinement of the Kipnis, Schmidt, and Wilkinson Subscales. Journal of Applied Psychology, 759, $246-257$.

Seltzer, J. \& Bass, B. M. (1990). Transformational leadership: Beyond initiation and consideration. Journal of Management, 16(4), 693-703.

Skansi, D. (2000). Relation of managerial efficiency and leadership styles - Empirical study in Hrvatska Elektroprivreda D.D. Management, 5(2), 51-67.

Smith, C. A., Organ, D. W., \& Near, J. P. (1983). Organizational citizenship behavior: Its nature and antecedents. 
Journal of Applied Psychology, 68, 653-663.

Snyder, R. A. \& Bruning, N. S. (1985). Quality of vertical dyad linkages: Congruence of supervisor and subordinate competence and role stress as explanatory variables. Group \& Organization Studies, 10(1), 81.

Stordeur, S., Vandenberghe, C. \& D'hoore, W. (2000). "Leadership styles across hierarchical levels in nursing department". Nursing Research, 49(1), 37-43.

Tadepalli, R. (1991). An empirical investigation of the impact of task conflict and task ambiguity on buyers' role perceptions Journal of Business, 27(3), 251.

Tannenbaum, A. (1968). Control in organizations. McGraw-Hill, New York.

Tedeschi, J. T. \& Melburg, V. (1984). Impression management and influence in the organization. In S.B. Bacharach \& E.J. Lawler (Eds.), Research in the sociology of organizations (Vol. 3, pp. 31-58). Greenwich, CT: JAI Press.

Tepper, B. J. \& Taylor, E. C. (2003). Relationships among supervisors' and subordinates' procedural justice perceptions and organizational citizenship behaviors. Academy of Management Journal. 46(1), 97-05.

Thomas, K. W. (1976). Conflict and Conflict Management. In M.D. Dunnette (Ed.), Handbook of Industrial and Organizational Psychology (pp. 889-935). Chicago: Rand McNally.

Tichy, N. M. \& Devanna, M. A. (1986). The transformational leader. New York: Wiley.

Uyterhoeven, H. (1972). General managers in the middle. Harvard Business Review, 50(92), 75-85

Wayne, S. J. \& Liden, R. C. (1995). Effects of impression management on performance ratings: A longitudinal study. Academy of Management Journal, 38, 232-260.

Weber, M. (1946). From Max Weber: Essays in sociology, in H. H. Gerth and C. W. Mills (Eds.). New York: Oxford University Press.

Wells, G. T. (1990). Influence of organizational structure on nurse manager job satisfaction. Nursing Administration Quarterly, 14, 1-8.

Williams, L. J. \& Anderson, S. E. (1991). Job satisfaction and organizational commitment as predictors of organizational citizenship and in-role behavior. Journal of Management, 17, 601-617.

Yukl, G. (1989). Managerial leadership. A review of theory and research. Yearly Review of Management, 15, 251-289.

Yukl, G. A. \& Falbe, C. M. (1990). Influence tactics in upward, downward, and lateral influence attempts. Journal of Applied Psychology, 75, 132-140.

Yukl, G. A. \& Tracey, B. (1992). Consequences of influence tactics used with subordinates, peers, and the boss. Journal of Applied Psychology, 77, 525-535.

Yukl, G. A. (1998). Leadership in organizations. Englewood Cliffs, NJ: Prentice hall.

Yukl, G. A., Falbe, C. M. \& Youn, J. Y. (1993). Patterns of influence behavior for managers. Group and Organizational Management, 18, 5-28.

Yukl, G., Lepsinger, R. \& Lucia, T. (1993). Preliminary Report on the Development and Validation of the Influence Behavior Questionnaire. In K.E. Clark \& B. Clark (Eds.), The impact leadership (pp. 417-427). Greensboro, NC: Center for creative leadership.

\section{Notes}

Note 1. Proposed Model of Downward Influence Tactics and Interaction

Note 2. Definition of Influence Tactics 
Table 1. Definition of Influence Tactics

\begin{tabular}{|l|l|}
\hline Inspirational Appeals & $\begin{array}{l}\text { The agent makes a request or proposal that arouses target enthusiasm } \\
\text { by appealing to target values, ideals, and aspiration, or by increasing } \\
\text { target self-confidence. }\end{array}$ \\
\hline Consultation & $\begin{array}{l}\text { The agent seeks target participation in planning a strategy, activity, or } \\
\text { change for which target support and assistance are desired, or the agent } \\
\text { is willing to modify a proposal to deal with target concerns and } \\
\text { suggestions. }\end{array}$ \\
\hline Ingratiation & $\begin{array}{l}\text { The agent uses praise, flattery, friendly behaviour, or helpful behaviour } \\
\text { to get the target in a good mood or to think favourably of him or her } \\
\text { before asking for something. }\end{array}$ \\
\hline Rational Persuasion & $\begin{array}{l}\text { The agent offers an exchange of favours, indicates willingness to } \\
\text { reciprocate at a later time, or promises a share of the benefits if the } \\
\text { target helps accomplish a task. }\end{array}$ \\
\hline Pressure & $\begin{array}{l}\text { The agent uses logical arguments and factual evidence to persuade the } \\
\text { target that a proposal or request is viable and likely to result in the } \\
\text { attainment of task objectives. }\end{array}$ \\
\hline
\end{tabular}

Adapted from Yukl \& Falbe (1990) and Yukl \& Tracey (1992)

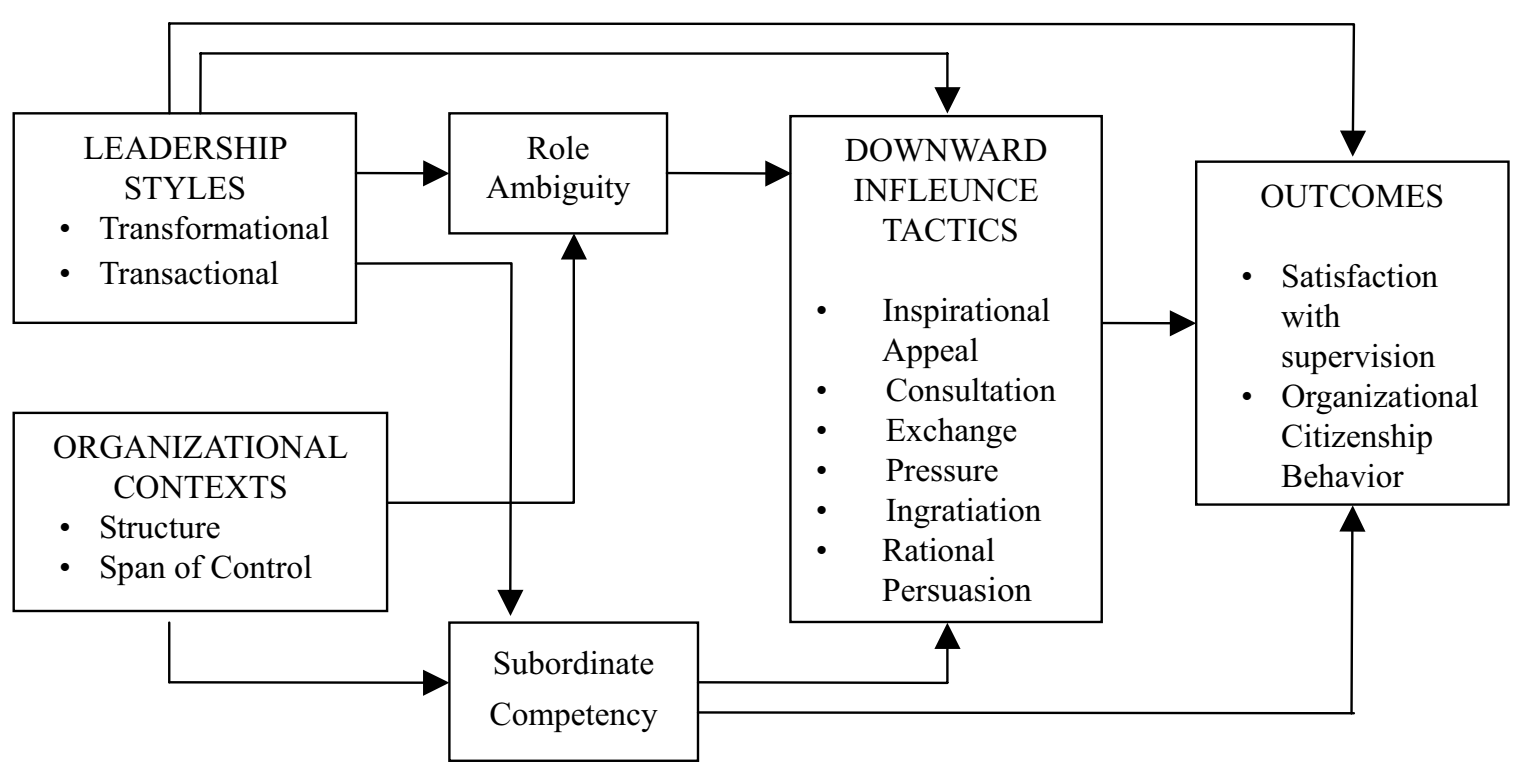

Figure 1. Proposed Model of Downward Influence Tactics and Interactions 


\title{
The Scheme of Rizhao City Brand
}

\author{
Qingjun $\mathrm{Wu}$ \\ Operation and Management College, Qufu Normal University, Rizhao 276826, China \\ E-mail: wuqingjun@yahoo.com.cn
}

\begin{abstract}
Nowadays, the competition of cities essentially is a competition for city brands. In fact, it is necessary for each city to implement a city brand strategy on their developing road.Rizhao, a seaside city in China, has many fine resources such as the coastal deep harbor, the seashore sand beach and the University City, which, however, still are separated rather than combined together.By developing the nationwide theme, the following article associates resources fully in an attempt to build up the Rizhao city brand.
\end{abstract}

Keywords: City Brand, Sand-Beach Bathing Place, University City, Brand Scheme

\section{Introduction}

The city brand is gradually becoming the most precious and valuable intangible assets of the city. And its value lies not only in the fact that it can help city to set up a good image and high prestige for the city, but also that it can unceasingly create new values. A successful city brand will produce enormous cohesive, attractive and radiating power and can cause all kinds of productive elements to accumulate or spread, through which government's financial revenues will be so greatly increased and its economic growth can be greatly accelerated. On the contrary, the city which doesn't own its brand will lack charm and consequently will be in weak side in competitions.

The Rizhao city of China has successfully hosted the world sail match and the national aquatic meeting, with which the city's reputation accordingly has been getting around. However, the world sail match and the aquatic meeting are only aquatic projects and mainly for specialists while the majority of Chinese areas are inlands. Therefore, not so many ordinary people would have paid much attention to them and moreover these games are not the ones that the common people can easily participate. So there was not a strong public basis. As a result, up to now the city of Rizhao still has a long way to go in terms of its popularity.

Rizhao's tourist resources are rich, but scattered and lack of the overall planning and brand strategy. The conformity and optimization of resources needs a platform and medium. If the platform has a nationwide theme, then the according city brand will be nationwide. It is also true of the worldwide theme whose city brand certainly will be worldwide.

China's sports are becoming more and more prosperous, but the male soccer, the most important game, in China is the biggest inferiority. So there is no wonder that one of the wishes for most Chinese is that one day the Chinese soccer can dominate the world like other sports games. This provides an exceedingly good nationwide theme for Rizhao to set up its nationwide brand.

We can organize mass soccer competition mainly for the elementary and middle schools so as to expand the mass base of the Chinese soccer by taking the Rizhao university city as the base, combining rich Rizhao seashore tourist resources and the university city resources that lay idle in summer vacation, taking advantage of the striking contrast between the prosperity of Chinese sports and the sag of Chinese man-soccer and making use of the great expectation held by the whole nation people of hoping Chinese soccer get great-leap-forward development. Rizhao 's well-known city brand can be finally established by organizing national soccer summer camping activities for pupils of elementary and middle schools and holding the national teenagers extra-curricular soccer competition while enjoying the seashore scenery, taking vacation and enjoying the leisure .

\section{Problems concerning the scheme of creating the Rizhao city brand}

\subsection{Only having a single city brand}

At present the major brand of Rizhao is 'A city of aquatic sports '. Actually, Rizhao's rich resources can enable it to create far more than one city brand.

\subsection{Exploring the cities' culture to mould a core city brand}

One of the most urgent problems for Rizhao to conquer on its way of creating a city brand is to repack the entire city resources and reestablish the whole city image. 


\subsection{Utilizing various methods to market the city.}

The city can be marketed through all kinds of media or other traveling advertising way to propagandize the city brand.

2.4 The city must have a unique localization, and its city brand must have the individuality which cannot be substituted, too.

The city brand represents a city's unique charm and its typical cultural characteristics, whose value lies in the unique localization and the irreplaceable individuality.

\section{The specific ideas and Schemes on designing new Rizhao city brands}

The good brand is not innate or a simple summary and induction, but a kind of overall plan for all resources via standing on the strategic height of the sustainable development. The key is how to mould the brand idea.Along with the fast development of Chinese economy in the latest 30 years, for the great majority, material demands have already been satisfied and now more and more demands are turning to a higher level. The pure sightseeing traveling is transforming to the fitness traveling.Rizhao has many advantages like the good deep coastal harbor, the fine clean seashore bathing place, the excellent human resources and convenient infrastructure in University City.Therefore, Rizhao certainly will be able to become a nationwide even worldwide well-known brand city, as long as we can seize this nationwide subject of contrast between the Chinese soccer's depression and other sports' prosperity, expand the mass base of the Chinese soccer by holding 'the national gold-sand-beach soccer- summer-camp for teenagers' which can later be made a yearly event even in the future become 'the permanent national young soccer base' and 'the worldwide golden-sand-beach soccer base'.

The concrete plans are as follows:

(1) Establishing a committee which is responsible for preparation and organization.

(2) Signing related agreements with the correlative interest body to obtain the law protection.

(3) Putting necessary investment on essential places, for instance, constructing the sand- beach- soccer fields near the seashore and building symbolic constructions in the University City and so on.

(4) Seeking for the support of influential media to expand propagandizing influence.

(5) Taking travel agencies as the link and elementary and middle schools as the unit to organize the soccer- competition tourist group for elementary and middle schools graduate in summer vacation.

(6) In summer vacation accommodating tourist groups of elementary and middle schools graduate in idle student dorms of the University City.

(7) Organizing tourist groups of elementary and middle schools graduate to experience university life by visiting the environment and the facilities of the University City.

(8) Holding competitions of various ranks between various elementary and middle schools teams in the University City's stadiums.

(9) Holding sand-beach entertainment soccer competition on the beach and letting people enjoy the seashore scenery, take vacation and enjoy the leisure.

Therefore, the project is a new traveling product which combines the sports fitness and the traveling leisure and offers a precious chance for Rizhao to set up the city brand.

\section{Anticipated effect of Rizhao city new brand}

As far as Rizhao city is concerned, the activity can enhance Rizhao's popularity, accelerate its tourism development and create the city brand. The city brand can be a magnet which displays such formidable attraction as to attract huge funds, information flow, commodities and talented persons. And it can also lead to the development of other correlative industries such as the estate industry, the food and beverage industry, the trade and so on by which the city will realize its development in one leap. Besides that, it can create numerous employment posts and make the local farmers even richer by adding their financial revenues significantly.

Seen from the angle of the national physical commission and the Chinese Soccer association, it will raise interests of adolescents in soccer as hobby, who can do exercises for leisure and amusement, thus it will expand mass base of Chinese soccer and build a solid foundation of the Chinese soccer for long-term development,

Seen from the angle of the universities in the University City, it can enhance their popularity and their enrollment's quality and stability.As to elementary and middle schools, it can enhance their popularity and raise students' patriotism and collective spirit.

In terms of their parents, it can increase family emotion and enhance the familial harmony by providing a precious chance for parents and their children to travel together while enjoying the seashore scenery. 
Considering students themselves, in the summer vacation it can relax their constrained nerves resulting from heavy study tasks, refresh their body as well as mind, develop their hobbies, improve their health and cultivate sentiments, meanwhile raise student's patriotism, collectivism, the team spirit as well as the spirit of striving for success.

Therefore, the city new brand created via the above mentioned ways holds rather high social value and achieves win-win situation for every involved sides.

\section{References}

Liu, Hantai. (2004). Making the City Influence, Marketing Cities(4).

Chen, Jingxin.(2005). the strategy ponder of making the city brand ,Industrial technology economy(6).

Tian, Xizhou. (2002). Innovation of Tourist Market, Productive Forces Research (3). 


\title{
Foreign Direct Investment and Manufacturing Growth:
}

\section{The Malaysian Experience}

\author{
V G R Chandran (Corresponding author) \\ Department of Economics \\ Faculty of Business and Administration \\ University Technology MARA \\ KM 12 Jalan Muar, 85009 Segamat, Johor, Malaysia \\ Department of Economics \\ Faculty of Economics and Administration \\ University of Malaya \\ 50603 Kuala Lumpur, Malaysia
}

Tel: 60-17-684-3705 E-mail: vgrchan@perdana.um.edu.my

\author{
Gopi Krishnan \\ Department of Economics \\ Faculty of Economics and Administration \\ University of Malaya \\ 50603 Kuala Lumpur, Malaysia \\ Tel: 60-16-314-1770 E-mail: gkv1812@yahoo.com.sg
}

\begin{abstract}
This paper examines the short and long run dynamics of Foreign Direct Investment (FDI) over the manufacturing growth in a developing country - Malaysia for the period of 1970-2003. Due to the small sample size, we used a fairly new cointegration method known as "bounds test" and the autoregressive distributed lag (ARDL) approach to estimate the short and long run production elasticity of FDI. Estimated FDI elasticity in the short and long run were found to be statistically significant. In the long run, a $1 \%$ increase in FDI contributes to $0.115 \%$ increase in manufacturing value added output in Malaysia. The model extracts the influence of FDI and technological progress towards manufacturing output. As a consequence of the results, strategies to enhance the competitiveness of Malaysian manufacturing sectors in the world of intense competition for FDI especially among the Asian economies like China and other ASEAN members is further recommended.
\end{abstract}

Keywords: Foreign Direct Investment, Manufacturing Growth, Autoregressive distributed lag

\section{Introduction}

Malaysian gross domestic product (GDP) grew at an average rate of 6.7\% during 1971-1990 (Malaysia, 1971 \& 1990) while during 1990-1999 Malaysia had the highest growth rate averaging 8.1\% per annum outperforming other ASEAN economies (Azmat, 2002) One of the notable strategies of the government to spur its growth is by attracting foreign direct investment (FDI). Malaysia was one of the most active among the ASEAN countries in liberalizing its investment regime in the manufacturing sector during the 1980s and 1990s. Significant progress was seen during the 1980s under the administration of the former Prime Minister Dr. Mahathir Mohammad, where new joint venture projects (especially with Japanese and Korean) with the state owned enterprise were launched. In addition, with the promotion of the Investment Act in 1986, Malaysia experienced a huge influx of FDI in the manufacturing sector. This policy offered many incentives including pioneers status tax holidays, expanded investment tax allowances for expansion projects, tax deduction for export promotions, the establishment of Free Trade Zones and other types of incentives to draw FDI. In fact, Malaysia further improved trade liberalization by relaxing the restrictions over capital ownership of foreign companies hence improving the FDI flows into Malaysia in the late 1980s. Similarly tariff rates in Malaysia have declined considerably over the years (Urata, 1994). 
It has been noted that Malaysia has emerged as one of the new dynamic Asian economies, which has become more competitive across a broad range of manufactured goods and managed to switch to higher value-added manufacturing products (Wilson, 2000). The outward oriented strategies have somehow progressed well in establishing the manufacturing sectors namely the electronic and electrical sectors. Hence, the success of the Malaysian manufacturing sectors can be partly attributed to its trade and FDI liberalization. Since the late 1970s the manufacturing sector has contributed significantly to the growth of the Malaysian economy. Its contribution to the export earnings accounted for $79 \%$ of the total export earning and nearly 33.4\% of Malaysia's GDP in 2000 (Ministry of Finance, 2001).

Despite considerable number of studies examining the relationship between FDI and economic growth, it is found that studies emphasizing the impact of FDI on manufacturing sector growth is rather lacking specifically in the Malaysian context. Furthermore, it is more lucid to examine the impact of FDI on manufacturing sectors since huge influx of FDI inflows in Malaysia are directed towards the manufacturing sectors.

This paper further contributes in the following ways. First, we used a more recent time series data to quantify the link between FDI and manufacturing growth by examining the short and long run production elasticity of FDI on manufacturing sector. Second, we used a more robust method known as the "bounds test" to examine the cointegration between the dependent variable namely manufacturing value added output and its determinants. This method has the advantage of dealing with a small number of observations and does not require the regressors to be in the same order of integration. Therefore, serious questions concerning the robustness of the cointegration tests could be limited compared to other studies that used small observation (less than 100), which is extremely sensitive for Johansen's method.

In addition, few of the model specification problems mentioned by Carkovic \& Levine (2002), which would lead to inaccurate estimation, were solved by adapting the ARDL model. For instance, this method controls the deficiency of other studies by considering the inclusion of lagged dependent variables in examining the short run dynamics of FDI. On the other hand, specifying the model specifically for the manufacturing sectors of Malaysia would avoid the biasness of the use of cross sectional data which normally leads to the failure to capture the country or firm specific effects (Carkovic \& Levine ${ }^{1}, 2002$; Dimelis, 2005). Moreover, the analysis proposed in this paper also makes it possible to explain the long-term dynamics.

Consequently, Malaysia was chosen as the country of choice in our analysis for two reasons. First, Malaysia has successfully moved into the second tier of newly industrialized economies owing to its manufacturing growth via FDI. Likewise, Malaysia has also relied heavily on FDI compared to long-term borrowings (Kiong and Jomo, 2005). Second, significant FDI inflows were evident in the manufacturing sectors especially from Japan, South Korea, US, Singapore and other European countries.

As a whole, this paper contributes to the existing literature by providing new empirical evidence concerning the FDI-led growth hypothesis within the manufacturing sectors. From a policy perspective, the results of this paper may serve as a useful platform to formulate series of new agenda for FDI policies. The rest of the paper is organized as follows. The next section examines the existing literature on FDI, section 3 presents the model specification and preliminary tests while in Section 4 and 5, the data source and empirical results are presented. Finally, section 6 contributes in terms of policy implications and followed by the conclusion.

\section{Literature Review}

A wide range of literatures is available on the issue of the impact of FDI on economic growth. By employing the production function, these studies use a range of methodologies; e.g. Granger causality test, panel data estimation and error correction model. In this section, we review the most recent studies linking FDI and economic growth.

Marwah and Tavakoli (2004) examined the effect of FDI and imports on economic growth in four ASEAN countries. The elasticity of the estimated production function of FDI was found to be significant in explaining the economic growth of all the four countries. Estimated foreign capital elasticity was found to be 0.086 while import contributed 0.443 to growth in the case of Malaysia. Clearly, they conclude that both FDI and imports had a significant impact on growth.

Recent study by Li and Liu (2005), on the other hand, uses the panel data of 84 countries to investigate the influence of FDI on economic growth. The study found a significant relationship between FDI and economic growth. Additionally, a stronger relationship was extracted when FDI is interacted with human capital. The reason being that stronger human capital poses better absorptive capacities due to the complementary nature of the FDI and human capital, most importantly for the developing countries. Kiong and Jomo (2005), on the other hand, examined the influences of FDI on Malaysian economy. The same conclusion emerged in their study. However, while positive effects of FDI on growth were found, the study cautioned that the net effect of FDI could be limited when FDI affects the domestic saving rate negatively.

In contrast, there have been several studies indicating a negative or no relationship between FDI and growth. Study by Akinlo (2004) that investigated the impact of FDI on economic growth in Nigeria using the ECM showed an 
insignificant negative influence of FDI on growth. The author further argued that extractive FDI might not extract significant impact on growth compared to the manufacturing FDI. Additionally, FDI may influence growth negatively once there is an evidence of the foreign investors transferring profits, or other investment gains to their home country. Other noteworthy studies examining the influences of FDI employs the Granger causality test (Kholdy, 1995; NairReichert and Weinhold, 2001) but the results vary according to country, method used and time frame under study.

The mixed results concerning the linkages may have been the consequence of using different sample size, methodologies and partly due to the degree of aggregation where most of the studies were relating FDI to total economy activities e.g. to the growth of the nation measured by GDP. Given these limitations, our aim in this paper is to test the FDI led growth hypothesis within the manufacturing sectors, which deem to be more appropriate in the case of Malaysia. Due to the over reliance on FDI in propelling the Malaysian manufacturing sectors, it is expected that FDI would contribute significantly in a positive way.

\section{Model Specification}

In this section, we describe the empirical method used to examine the relationship between FDI and the growth of manufacturing sector for Malaysia from 1970 to 2003. We characterized the production function for the manufacturing sector as follows:

$V A_{t}=f\left(\mathrm{Cap}_{t}, \mathrm{Lab}_{t}, \mathrm{Fdi}, t\right)$

where $V A_{t}$ is the manufacturing value added output at period $t$. Cap, Lab, and Fdi, represent fixed capital stocks and labour inputs, and manufacturing foreign direct investments, respectively. The variable $t$ in (1) is the linear trend representing the Hicks neutral technical progress. Although, analyzing the influence of other factors such as human capital, and research and development would be interesting, quality and reliable data for manufacturing prove to be the main constraint.

Hence, in writing the above specification, we used the unrestricted intercept and with trend (Case V in Pesaran et al. , 2001) and it can be written as an Autoregressive Distributed Lagged, ARDL[p, q, r, s] model such as:

$$
\begin{aligned}
& \Delta I n V A_{t}=a_{0}+a_{1} t+\sum_{i=1}^{p} b_{1 i} \Delta \operatorname{InV} A_{t-i}+\sum_{i=0}^{q} b_{2 i} \Delta \operatorname{In} L_{t-i}+\sum_{i=0}^{r} b_{3 i} \Delta \operatorname{In} K_{t-i}+\sum_{i=0}^{s} b_{4 i} \Delta I n F D I_{t-i}+ \\
& c_{1} \operatorname{InVA}_{t-1}+c_{2} \operatorname{InL}_{t-1}+c_{3} \operatorname{InK}_{t-1}+c_{4} \operatorname{InFDI}_{t-1}+\varepsilon_{t}
\end{aligned}
$$

where, $\Delta$ is the first difference operator and In for the natural logarithm of the respective variables.

Using the specification in (2), we can test if InVA is co-moving with the regressors. The test is called the 'bounds test' proposed in Pesaran et al. (2001). Mah (2000) indicated that this cointegration test is more reliable compared to Johansen and Juselius (1990), which usually requires larger sample size. Indeed "bound test" to cointegration does not pose a strict classification of regressors to be in the same order. To test the absence of a long run relationship between InVA and its determinants we restrict the coefficient of $c_{1}, c_{2}, c_{3}$ and $c_{4}$ to be zero against the alternative by conducting a restricted F-test (or Wald test). Hence, the null and alternative hypotheses are as follows:

$$
\begin{aligned}
& \text { Ho: } \mathrm{c}_{1}=c_{2}=c_{3}=c_{4}=0 \text { (no long run relationship between InVA and its determinants) } \\
& \mathrm{H}_{1}: \mathrm{c}_{1} \neq 0 ; c_{2} \neq 0 ; c_{3} \neq 0 ; c_{4} \neq 0 \quad \text { (there is long run relationship between InVA and its determinants) }
\end{aligned}
$$

The asymptotic distribution of the test statistics are non-standard regardless of whether the variables are $I(0)$ or $I(1)$. For this purpose Pesaran et al. (2001) computed two sets of asymptotic critical values where the first set assumes variables to be $I(0)$ and the other as $I(1)$ which is known as lower bounds(LCB) and upper bounds (UCB) critical values respectively. Decisions on whether cointegration exists between InVA and its regressors are then made based on the following criteria;

$$
\begin{aligned}
& \text { Computed F statistics > UCB: Reject the null hypothesis } \\
& \text { Computed F statistics < LCB: Fail to reject the null hypothesis } \\
& \text { Computed F statistics value between LCB and UCB: Results are inconclusive }
\end{aligned}
$$

Once there is evidence of cointegration it implies that InVA and its determinants have a stable long-run relationship. Consequently, in the next step we used the two-step strategy of the ARDL method proposed in Pesaran and Shin (1997) to estimate the long run and short run coefficients (elasticities) for our model. The long run estimation follows the following $\operatorname{ARDL}[p, q, r, s]^{\text {model: }}$ 


$$
\begin{aligned}
& \operatorname{InVA_{t}}=a_{0}+a_{1} t+\sum_{i=1}^{p} b_{1 i} \operatorname{InVA}_{t-i}+\sum_{i=0}^{q} b_{2 i} \operatorname{InL}_{t-i}+\sum_{i=0}^{r} b_{3 i} \operatorname{InK}_{t-i}+\sum_{i=0}^{s} b_{4 i} \operatorname{InFDI}_{t-i}+ \\
& +\vartheta_{t}
\end{aligned}
$$

Constructing an error correction model of the following form derives the short-run elasticities:

$$
\begin{aligned}
& \Delta I n V A_{t}=a_{0}+a_{1} \Delta t+\sum_{i=1}^{p} b_{1 i} \Delta I n V A_{t-i}+\sum_{i=0}^{q} b_{2 i} \Delta I n L_{t-i}+\sum_{i=0}^{r} b_{3 i} \Delta I n K_{t-i}+\sum_{i=0}^{s} b_{4 i} \Delta I n F D I_{t-i}+ \\
& +\psi E C M_{t-1}+\omega_{t}
\end{aligned}
$$

Here the $b$ 's are the coefficients relating to the short run dynamics of the convergence to equilibrium and $\psi$ measures the speed of adjustment. To estimate the model we used different lag length. To avoid the loss of degree of freedom the maximum selection of lag does not exceed 3. We used the Akaike Information Criterion (AIC) to choose the appropriate lag length for the ARDL model.

\section{Data Sources}

In this paper, we used annual data from 1970 to 2003 and the data on manufacturing value added output, fixed capital stocks and number of worker for the manufacturing sector was obtained from various issues of Yearbook of Statistics and Malaysian Economic Statistics-Time Series published by Department of Statistics, Malaysia. Data on FDI was obtained from Malaysian Industrial Development Authority. For capital stocks, we used fixed capital stocks due to data limitation on capital expenditure. For the labor (L) due to limited data series on man-hours, we used number of workers. Value added output, fixed capital stocks and FDI was deflated with manufacturing commodity producer price index respectively. All the data was expressed in logarithm indicating that each of the estimated coefficients represents the elasticity. Past literatures suggested that all the regressors to have a positive relationship with InVA. We also examined the order of integration of the variables using both the Augmented Dicky Fuller (ADF) and the Phillip-Perron (PP) unit root test (only PP is reported to conserve space).

\section{Empirical Results}

Based on the results in Table 1, it is found that all the variables were to be random walk, which was indicated by the non-stationarity of the variables at their levels. The series becomes stationary after the first differences signifying that all series are integrated of order one $I(1)$.

Based on bounds test (Table 2), the computed F-statistics exceeds the upper critical values indicating a rejection of the null hypothesis of no cointegration between InVA and its determinants. Hence, there is a strong indication that fixed capital stock, labor and FDI serves as the long run forcing variables in explaining the growth of the manufacturing value added output in Malaysia.

Table 3 shows the estimated long-run coefficients for the ARDL model. All the determinants are found to have correct signs. In the long run, fixed capital was found to have a positive impact on the manufacturing value added output, however was not statistically significant. Owing to the data limitation on investment, the use of fixed capital to proxy investment and not capital per se may have contributed to the insignificant results.

On the other hand, labor has a positive and significant impact on manufacturing value added output (significant at the $1 \%$ significant level). Manufacturing value added output increase by $0.90 \%$ as results of $1 \%$ increase in labor. The higher contribution of labor is not surprising given that many of the manufacturing sectors in Malaysia are still labor intensive.

The contribution of FDI towards manufacturing value added output was positive and statistical significant at $1 \%$ level. The elasticity is 0.084 indicating that $1 \%$ increase in FDI contributed to a $0.084 \%$ increase in manufacturing value added output. In terms of technical progress, its contribution was significant but very much lower (only increases manufacturing value added output by $0.046 \%$ ) that the other determinants. This is acceptable since although Malaysian manufacturing sectors has managed to accumulate capital stocks, over the years it is found that mastery of these technologies are still low among the manufacturing sectors. This may due to the low absorptive capabilities in the manufacturing sectors. Mahadevan $(2001,2002)$ and Tham $(1996,1997)$ have also showed the low level of productivity in manufacturing sector using the total factor productivity (TFP) approach.

Table 4 shows the short run dynamics and the adjustment towards the long run equilibrium. The specification suggest a good fit with $\mathrm{R}^{2}$ of 0.938 suggesting that $94 \%$ of variation in manufacturing value added output is explained by the determinants. As a whole the fixed capital, technical progress and FDI have a positive and significant (at $10 \%$ and $1 \%$ respectively) impact on manufacturing value added output. On the other hand, labor is found to have significant positive effect on manufacturing value added output.

The lagged terms of fixed capital and labor shows a significant negative impact on manufacturing value added. This 
means, in the short run, additional capital and workers are not enhancing the manufacturing growth. This may due to the nature of diminishing returns facing the sectors in the short run. Alternatively, lack of skills, lack of mastery of operation as well as management knowledge, low productivity and the like may have contributed to the negative outcomes.

The statistically significance of the error-correction term (ECM) confirms the presence of long run equilibrium between the manufacturing value added output and the regressors namely fixed capital, labor and FDI (also confirms our previous cointegration analysis). It is found that the ECM is between 0 and -1 and is statistically significant at the $1 \%$ significance level. This implies that, the error correction process converges monotonically to the equilibrium path relatively quickly $(0.908 \%)$.

\section{Policy Implications}

On the basis of the empirical analysis (the ARDL approach) it is found that FDI plays an important role in determining the progress of the Malaysian manufacturing firms. Hence, the mobility of FDI could ultimately alter the progress of the manufacturing sectors. Given the increasing trend of modular production systems, the mobility of multinationals operations has increased. For instance, China's cost advantage cum with huge domestic demand had increased the potential of shifting among foreign investors ${ }^{2}$. Indeed, in recent years it was evident that few of the contract manufacturers have shifted their operation from Malaysia to China. Although, the Chinese and Indian markets provide much catalyst for growth, the foreign investors strategies to tap the fast growing Asia Pacific region namely regions near to Malaysia would inevitably bring FDI into Malaysia. With the ready availability of good infrastructure, political stability and moderate overall cost, Malaysia is still attractive for FDI provided that the other potential areas are further developed.

Until now, it is notable that policy concerning FDI liberalization in Malaysia is still tailored towards providing incentives and other forms of aids for the foreign investors. We suggest that the next viable policy direction of Malaysia should focus on providing the needed complementary assets realizing the importance of FDI and labor force in the long run. On the other hand, strategies to enhance the lack of technical progress are further recommended. Hence, the policy recommendation in this section is solely tailored towards enhancing complementary assets in which Malaysia is relatively weak. Three core strategic thrusts in developing the complementary assets is our emphasis.

First, strategic trust should focus on improving productivity and innovative capabilities ${ }^{3}$ of the manufacturing sectors. The contribution of technical progress in this paper showed only a marginal significant impact towards the manufacturing sectors. In addition, quality FDI can only be attracted if the host country has the ability to improve the manufacturing outputs through productivity gain rather than depending on the traditional factor of production. Thus, creation of technical and management support centers for the manufacturing sectors especially for the small medium enterprise (SMEs) could provide a catalyst for productivity improvement. These centers can play a key role in assisting manufacturers to develop strategic partnership, product development, accounting and marketing supports.

Although most often, innovation literature follows the neo classical arguments, in a developing country, building innovative capabilities requires the government's intervention. This is due to the lack of private participation in R\&D. Owing to the lack of techno-entrepreneurship culture (unlike Singapore) incentives in a form of tax reduction, research grants, sharing R\&D facilities between government agencies and the private firms, linking public institutions and manufacturing firms, and strengthening the abilities of science parks and technology incubators is vital. With these strong innovative infrastructures, chances to attract FDI would improve. There is also an urgent need to revise the research grants awarded to the public institutions - Intensification of Research in Priority Areas (IRPA) research grants, industrial grants and university capabilities in supporting the national innovation systems. Due to the low return on investment $^{4}$ of IRPA grants, efforts also should be focused on providing seed and commercialization funding. Indeed, venture capitalist activities (e.g. technology brokers) should be further fostered. On the other hand, more efforts should be given in establishing better monitoring systems and selection of grant recipients especially in relation to the industrial grants given to the SMEs. In terms of building universities capabilities, universities need to identify their own nice R\&D areas and divert more R\&D efforts in developing pool of expertise in those areas. Reluctance of foreign investors to invest is also due to lack of intellectual property right concern. Government's role in increasing awareness in IPR could create confidence among foreign investors to invest in R\&D in Malaysia.

Secondly, the heavy reliance on labor among manufacturers as shown by our estimation and to attract more FDI will require the development of strong human capital stocks. To build better human capital stocks, the level of education and skill should be further improved. For instance, due to the development of high tech human capital ${ }^{5}$, many information, communication and technology (ICT) and pharmaceutical transnational corporations (TNCs) were attracted to diversify their R\&D activities in India (UNTAD, 2005). On the other hand, with weak science and technology platform (e.g. scientist and engineers, low level of enrollments in S\&T fields) compared to China and Singapore would also mean that Malaysia would find itself too difficult to attract quality FDIs. Furthermore, the mismatch between the industrial requirements and the skill level provided by the education institutions need to be further improved. Although, the 
government has granted the establishment of many private colleges and universities in an effort to improve the knowledge content of its workers, still it is found that many of these mushrooming institutions are still skewed towards offering business (rather the science and technology which is scared) related programs. In fact, strengthening the education institutions is greatly needed. These supporting institutions would have the potential to further boost the comparative advantage of the manufacturing sectors.

As a whole, we suggest that strategies be focused on improving the coordination efforts between the education institutions and the industrial needs, enhancing the number of available scientist and engineers and provide more science and technology based programs with sufficient practical and industrial training components. Just establishing education institution does not grantee success thus recruiting quality teaching staff and placing right students in the right program is paramount important. Improving the establishment of network of foreign universities affiliation with local institutions is vital.

Third, the capability of local supplier especially those who serve the foreign investors need to be strengthened via network cohesion. Efficiency improvement through network of linkages is important for many manufacturing firms ${ }^{6}$. This strategy is indeed in support with the clustering development approach which emphasized inter-firm and intra firm linkages. Indeed the failure of Proton's supplier in upgrading technology capabilities was due to their under developed inter firm sub-contracting networks. Establishing a strong supply chain via horizontal and vertical integration would mean limiting foreign investors from moving out and encouraging more local content indirectly. Hence, the government needs to emphasize on developing well-built regional cluster areas apart from Penang ${ }^{7}$ and Klang Valley. However, this strong linkages can only be established when the foreign investors realize that local suppliers are capable of delivering and fulfilling their needs. A strong social capital e.g. trust should be fostered between foreign investors and the local suppliers. For example, the role of government and trust have enhanced the learning and innovation capabilities among the information hardware industries in Taiwan (Rasiah \& Lin, 2005)

\section{Conclusion}

The contribution of FDI towards the progress of manufacturing sectors has been examined. The empirical investigation found that FDI has played an important role in stimulating the growth of the manufacturing sectors in Malaysia. In addition, the results showed that labor and technological progress has positively contributed to the growth. As a whole, since FDI have become increasingly important, the policy direction focusing on human capital, improving productivity and innovative capabilities of the manufacturing sectors and strengthening the supporting industries and institutions are proposed. This is turn will promote and make Malaysia as an attractive destination for FDI.

\section{References}

Akinlo, A. E. (2004). Foreign Direct Investment and Growth in Nigeria: An Empirical Investigation, Journal of Policy Modeling, 26, 627-39.

Azmat, G. \& Michael, D. C. (2002) Services and Economic Growth in ASEAN economics, ASEAN Economic Bulletin, $19,155-169$.

Brown, R. L., Durbin J. \& Evans J. M. (1975). Techniques for testing the constancy of regression relations over time, Journal of the Royal Statistics Society B 37, 149-192.

Carkovic, M. \& Levine, R. (2002). Does Foreign Direct Investment Accelerate Economic Growth? [Online] Available: www.worldbank.org/research/conferences/ financial_globalization/fdi.pdf, (April 5, 2006).

Dimelis, S. P. (2005). Spillover from FDI and Firm Growth: Technological, Financial and Market Structure Effects, International Journal of the Economics of Business, 12, 85-104.

International Institute of Management Development (2006) IMD World Competitiveness Yearbook 2006, Switzerland.

Johansen, S. \& Juselius, K. (1990). Maximum likelihood estimation and inference on cointegration with application to the demand for money, Oxford Bulletin of Economics and Statistics, 52, 169-210.

Kiong W. H. \& Jomo, K. S. (2005). Before The Storm: The Impact of Foreign Capital Inflows on The Malaysia Economy, 1966-1996, Journal of the Asia Pacific Economy, 10, 56-69.

Knoldy, S. (1995). Causality Between Foreign Direct Investment and Spillover Efficiency, Applied Economics, 27, 745-49.

Li X. \& Liu, X. (2005). Foreign Direct Investment and Economic Growth: An Increasingly Endogenous Relationship, World Development, 33, 393-407.

Mah, J. S. (2000). An Empirical Examination of the Disaggregate Import Demand of Korea - the case information technology products, Journal of Asian Economics, 11, 237-44.

Mahadevan, R. (2001). Assessing the output and productivity growth of Malaysia's manufacturing sector, Journal of 
Asian Economics, 12, 587-97.

Mahadevan, R. (2002). A DEA approach to understanding the productivity growth of Malaysia's manufacturing industries, Asia Pacific Journal of Management, 19, 587-600.

Malaysia. (1971). The First Outline Perspective Plan 1971-1990. Kuala Lumpur: Government Printer.

Malaysia. (1990). The Second Outline Perspective Plan 1991-2000. Kuala Lumpur: Government Printer.

Marwah, K. \& Tavakoli, A. (2004). The Effect of Foreign Capital and Imports on Economic Growth Further Evidence From Four Asian Countries (1970-1998), Journal of Asian Economics, 15, 399-413.

Ministry of Finance. (2001). Economic Report 2001/2002, Percetakan Nasional Malaysia Berhad, Kuala Lumpur.

Nair-Reichert, U. \& Weinhold, D. (2001). Causality Tests For Cross-country Panels: A New Look at FDI and Economic Growth in Developing Countries, Oxford Bulletin of Economic and Statistics, 363 (2), 153-71.

Pesaran, H. M., Shin, Y. \& Smith, R. J. (2001) Bounds Testing Approach to The Analysis of Level Relationship, Journal of Applied Econometrics, 16, 289-326.

Pesaran, M.H. \& Pesaran B. (1997). Microfit 4.0: Interactive Econometric Analysis, Oxford: Oxford University Press.

Rasiah R. \& Lin, Y. (2005). Learning and innovation: the role of market, government and trust in the information hardware industry in Taiwan, International Journal of Technology and Globalisation, 1, 400-32.

Tham, S. Y. (1996). Productivity and competitiveness of Malaysian manufacturing sector. Paper presented at the national convention of the $7^{\text {th }}$ Malaysian plan, Kuala Lumpur Malaysia.

Tham, S. Y. (1997). Determinants of productivity growth in the Malaysian manufacturing sector. ASEAN Economic Bulletin, 13, 333-43.

UNCTAD. (2005). World Investment Report 2005: Transnational Corporations and the Internationalization of R\&D, New York and Geneva, United Nations

Urata, S. (1994). Trade Liberalization and Productivity Growth in Asia: Introduction and Major Findings, The Developing Economics XXXXII (4 December), 363-72.

Wilson, P. (2000). The Export Competitiveness of Dynamic Asian Economies 1983-1995, Journal of Economic Studies, 27, 541-65.

\section{Notes}

Note 1. See Carkovic \& Levine, 2002 for more details.

Note 2. China and India have leapt up the competitiveness ranking from 31 to 19 and 39 to 29, respectively (IMD, 2006).

Note 3. In 2001, innovation capability index of Malaysia (0.467) is still far below that of Singapore (0.748) and Thailand (0.488) (UNTAD, 2005).

Note 4. Level of technological commercialization is still low (5.1\%) given the high R\&D investment through IRPA grants.

Note 5. It is also true in the case of Singapore, where although cost of operation is relatively high compared to Malaysia, strong presence of knowledge workforce and high innovation capabilities managed to attract FDI.

Note 6. Strong local capabilities can also foster R\&D centers to be located in Malaysia. Many of the products were exported to Singapore and re-imported into Malaysia due to lack of local supplier capabilities.

Note 7. Strong intermediary role of Penang Development Corporation has contributed to the synergies created in this cluster.

\section{Acknowledgement}

The authors would like to thank Kamala Nathan for his comments and Rahimah for expert research assistantship. 
Table 1. Phillip-Perron Tests

\begin{tabular}{|l|l|l|l|l|}
\hline & \multicolumn{2}{|l|}{ Log Levels } & Log differences \\
\hline & without trend & with trend & without trend & with trend \\
\hline InVA & -1.6988 & -1.7274 & $-4.7572^{*}$ & $-5.1634^{*}$ \\
\hline InK & -2.5697 & -0.7762 & $-3.5856^{* *}$ & $-4.5580^{*}$ \\
\hline InL & -1.7632 & -2.2808 & $-6.0138^{*}$ & $-6.2306^{*}$ \\
\hline InFDI & -2.0305 & -2.4633 & $-7.0446^{*}$ & $-7.2347^{*}$ \\
\hline
\end{tabular}

* and ** denotes significant level at $1 \%$ and $5 \%$ respectively. The optimal lag was chosen using the Newey-West automatic truncation lag (Newey and West (1994))

Table 2. Cointegration Test based on bounds test 4

\begin{tabular}{|l|l|}
\hline Computed F Statistic (lag =2) & 12.742 \\
\hline Upper Bound & 4.329 \\
Lower Bound & 3.189 \\
\hline
\end{tabular}

$5 \%$ critical value for upper (UCB) and lower bound (LCB) are based on Pesaran and Pesaran using unrestricted intercept and trend in the model

Table 3. Estimated Long Run Coefficients using the ARDL Approach

\begin{tabular}{|l|l|l|}
\hline Regressor & Coefficient & T-Ratio \\
\hline InK & 0.11902 & 1.512 \\
\hline InL & 0.90167 & $11.082^{*}$ \\
\hline InFDI & 0.08360 & $4.4968^{*}$ \\
\hline T & 0.04627 & $3.957^{*}$ \\
\hline
\end{tabular}

* significant at $1 \%$ level.

Table 4. Error Correction Representation for the Selected ARDL Model

\begin{tabular}{|c|c|c|c|}
\hline Regressor & Coefficient & & T-Ratio \\
\hline$\Delta \mathrm{InVA}_{\mathrm{t}-1}$ & 0.18225 & & 1.698 \\
\hline$\Delta \mathrm{InK}$ & 0.23415 & & $1.839 * * *$ \\
\hline$\Delta \mathrm{InK}_{\mathrm{t}-1}$ & -0.33418 & & $-3.209 *$ \\
\hline$\Delta \mathrm{InK}_{\mathrm{t}-2}$ & -0.56231 & & $-4.515^{*}$ \\
\hline$\Delta \mathrm{InL}$ & 0.24874 & & $2.9303 *$ \\
\hline$\Delta \mathrm{InL}_{\mathrm{t}-1}$ & -0.50971 & & $-4.4097^{*}$ \\
\hline$\Delta \mathrm{InL}_{\mathrm{t}-2}$ & -0.22989 & & $-2.8166^{* *}$ \\
\hline$\Delta$ InFDI & 0.075919 & & $4.7811^{*}$ \\
\hline$\Delta \mathrm{T}$ & 0.042017 & & $3.8191 *$ \\
\hline $\mathrm{Ecm}_{\mathrm{t}-1}$ & -0.90810 & & $-8.0746^{*}$ \\
\hline R-Squared & 0.93834 & & \\
\hline R-Bar-Squared & 89724 & & \\
\hline $\mathrm{ecm}=\mathrm{InVa} \quad-.111902 * \operatorname{InK}$ & $-.90167 * \operatorname{InL}$ & $-.08360 *$ InFDI + & $4.7499 * \mathrm{C} \quad-.046269^{*} \mathrm{~T}$ \\
\hline
\end{tabular}

We followed Pesaran and Pesaran (1997) and applied the CUSUM and CUSUMSQ proposed by Brown et al (1975) to inspect the stability of the long run and short run coefficient. The line was within the $5 \%$ significant level, indicating no evidence of any structural instability. Plot of CUSUM and CUSUMSQ can be obtained from the author upon request. 


\title{
Effect of Technical Barriers to Trade on Chinese
}

\author{
Textile Product Trade
}

\author{
Ningchuan Jiang \\ Visiting Professor. FedEx Global Education Center. UNC. Chapel Hill. NC 27599, USA \\ Depart. Economics and Management, Chengdu Textile College, Chengdu 611731, China
}

\begin{abstract}
It has been more than five years for China's entry into WTO. With the decrease of regulations of tariff barrier and non-tariff barrier, the export market of Chinese textile products has been expanded and the market shares have been increased, which arouses great attention of many countries in the world. Some countries increase the limit of import. What should be noticed is the more covert and more agile trade barrier, which becomes the biggest barrier of export of our country's textile products.

This article reviews the concept and content of technical barriers to trade, concludes the condition of technical barriers to trade in the textile product field of America, Europe and Japan, analyzes the reasons of technical barriers to trade combining with Chinese textile product export condition and the effect from technical barriers to trade and finally discusses the measures of dealing with technical barriers to trade and existing problems of Chinese textile product export.
\end{abstract}

Keywords: Technical Barriers to Trade, China, Textile Product Trade, Effect

China is the biggest country producing and exporting textile products. The textile industry is China's traditional predominant industry and pillar industry to gain export profit for the country. Since the reform and opening to the outside of the world, especially after entry into WTO, facing quickly increasing domestic and foreign demand and medium \& low level product market, Chinese textile industry has developed greatly. The textile industry is an important industry of Chinese national economy, which plays a very important role in solving employment and expanding export. According to the data of National Development and Reform Commission, in 2007, the export volume of Chinese textile products reached $\$ 171.2$ billion, which increased by $18.9 \%$ than last year and occupied $8.9 \%$ of Chinese import-export volume; in 2007, the trade surplus of Chinese textile products occupied $6 \%$ of the total national trade surplus.

However, Chinese textile product export always faces the widest and the most strict quota limitation and more rigorous trade barriers. With the arising of new trade protectionism, the new trade barriers with the core of technical barriers to trade appear constantly, which results in more and more new trade disputations. Here the author propose a question: what is Technical Barriers to Trade?

\section{Concept and Development of Technical Barriers to Trade}

Technical Barriers to Trade (for short TBT) means that in order to maintain national security, guarantee human beings' health and safety, protect ecological environment, prevent trick and ensure product quality, one country adopts various compulsory or non-compulsory technical limited measures, such as technical regulations, standards and eligible evaluation procedure to authenticate import products on their technology, sanitation quarantine, product packing and label, which can improve products' technical demand, increase importing difficulty and limit import finally. These measures become the barriers for other countries' products to enter this country's market freely.

Here are the types of TBT:

\subsection{Rigorous and complex technical standard.}

Developed countries have stipulated rigorous technical standard for many finished products. There are product standard, test method standard and safety \& sanitation standard; there are industrial product standard and agricultural product standard. These standards are not the same in various countries, that is, the products can accord with one country's technical standard but not accord with another country's standard. Let me take clothing woolens as an example. France stipulates that the lowest woolen-contained amount is $85 \%$, Belgium's standard is $97 \%$, while German's standard is $99 \%$. Technical standards can not only limit the rendition of foreign products but also set barriers for foreign products.

\subsection{Technical laws and regulations.}

The documents with legal sanction include law, decree or administrative regulations, which are issued and implemented 
by power organs. Some countries issue more and more complex technical regulations to limit importing products. Export of one product is related with various compulsory regulations of import countries. For example, when exporting textile products to America, Japan, France, Britain and Canada, one country should consider some relevant regulations such as demand of burning behavior standard, otherwise exporting products may meet with barriers.

\subsection{Management regulations of product packing and label.}

Some countries make rigorous regulations on packing's and labels of import products. The products must accord with these regulations, otherwise they are prohibited from being imported or sold in the import country's market. The regulations include material, specification, word, figure or code of the product packing. Some packing materials should be testified by the exporter providing with disinfection documents, otherwise products cannot be used or importer. For example, in Jan. 1999 Canada proposed the quarantine demand for wooden packing's of Chinese import products. However, in June of 1999, European Union proposed new demand for wooden pickings' of Chinese import products, that is, wooden pickings' should not contain barks and wormhole with the diameter more than 3mm, wooden pickings' should be dried and should not contain water amount for more than $20 \%$. Other countries also propose some relevant demand for Chinese products.

Labels are extremely important for exporting apparel. For example, European Union countries stick ecological labels on import textile products. The ecological label "OKO-TexStandard 100" is the passport for textile products enter the textile products market of EU; Australia stipulates that on the labels of import apparel, there must be components of raw-materials, age and stature explanation, washing method and production country; Canada stipulates that lobes of import apparel must be printed in English and French.

\subsection{Inspection procedure.}

With the severe competition in the international market, in order to implement trade protectionism policy many developed countries adopt various covert protection methods, among which inspection procedure is one important trade barrier. The forms of inspection procedure are: increasing inspection items, making inspection technology more complex, increasing demand of parameter veracity, inspection instruments, inspection methods, inspection environment and inspection technicians. For example, European Union demands to inspect whether import textile products own heavy metal, pesticide and pentachlorophenol, which becomes a trade barrier difficulty for developing countries to overcome.

\subsection{Environmental and ecological standard.}

In 1996, International Standard Organization (ISO) issued ISO 14000 Environment Management System international standard, but many countries stipulate their own standards according to local condition, which brings severe barriers to international trade. In the name of protecting environment, developed countries stipulate rigorous technical regulations through legal method to form a green technical barrier to prevent foreign products from entering the domestic market.

\section{Technical Barriers to Trade in Textile Product Industry of America, EU and Japan}

The textile industry in China always produces much profit. One fifth of Chinese foreign trade export volume comes from the textile industry. The main target markets of Chinese export textile products are America, European Union and Japan. And these three places feel the great threat coming from Chinese textile industry. Combining with other elements such as politics, economy and environment protection, these three places stipulate various technical barriers to trade especially aiming at Chinese textile products. These technical barriers to trade are listed as following:

\subsection{America.}

There are compulsory acts, demand for packing and labels, evaluation procedure for testing eligibility's and green barriers, among which green barriers have two types. One type of barriers is set in the progress from designing and producing textile products to reject and reuse products; another type of barriers is to demand that textile products should not exert bad influence on the consumers' health during the process of using and wearing textile products.

\subsection{European Union.}

EU is the first group which realizes the technical barriers to trade in the international trade. TBT in the textile product industry are: eco label, health and safety regulations, green barriers, EU new policies for chemical products, social accountability standard(SA8000)GS. mark,etc.Eco labels: among these marks, Oeko Tex Standard 100 and Eco Label are most popular. Oeko Tex Standard 100, about product quality, is stipulated and issued in 1992 by International Environment Protection Textile Association on the basis of doing research on product ecology, which is used for testing the harmful substances of textile products. Comparing with Chinese current textile product standard, Oeko Tex Standard 100 gives definite and quantitative regulation on ecological harmful substances in textile products.

Green barriers: with the excuse of protecting ecological environment and consumers' health, EU stipulated the ban of Chinese textile products export to establish "green barriers" to prevent Chinese textile apparels from entering their markets. For example, on Jan. 6 of 2003, EU passed the instruction of 2003/03/EC to prohibit the manufactures from 
using the blue colorant in textile leather products.

\subsection{Japan.}

except for some regulations similar with TBT, in order to enter Japanese market, the textile products must satisfy various compulsory technical standards, such as national specification, group specification, random quality standard.

\section{Reasons for China Encountering TBT}

\subsection{Trade protectionism re-arising and foreign countries protecting domestic textile apparel market}

TBT is gradually replacing tariff and non-tariff barriers. In future, the trade disputes caused by TBT will be more. Especially after the textile quota was cancelled, European countries and America were stricken greatly. New protectionism re-arose. Many countries made use of TBT to suppress some competitive countries such as China to protect their domestic market, decrease unfavorable balance of trade and win some chips on politics.

3.2 Developed countries strengthening the consciousness of environment protection, safety and health. With the popularity of consciousness of sustainable development and environment protection as well as the increase of people's living standard, developed countries develop their standard of environment protection, safety and health on textile apparels. However, because there is great gap between Chinese textile products and the developed countries' standard, Chinese textile products are always limited by TBT such as green barriers, eco labels, safety demand, eligible evaluation procedure, SPS, pickings and labels.

\subsection{Developed countries decreasing trade favorable balance to protect domestic market}

Because the labor cost is high in developed countries, their competition ability to sell medium \& low level textile products is lower than that of developing countries. Their domestic market shares are also impacted by the same foreign products with low cost. Therefore, setting TBT is a kind of method to protect domestic market. After entry into WTO, the export trade volume of Chinese textile products gradually increase. American, Japan and EU are the main markets for Chinese exporting textile products. There exists mint trade favorable balance in importing \& exporting textile products and this trade favorable balance is increased from 2000 to 2003 intensely. Because of the severe existence crisis in the textile industry, America, Japan and EU have to adopt measures. Therefore, they set various TBT to abate domestic employment pressure, decrease impact of import products and reduce trade favorable balance.

3.4 China lagging behind the western countries in technology and manufacturing equipment as well as having not strong competition ability Chinese textile products export is comparatively not competitive.

Even though Chinese textile products export has been developed for the recent years, but because of the slow technical level, most of export products are featured with low technology, low quality and unadvanced manufacturing equipment. Comparing with the foreign products' improving production technology, product quality and standard, the weakness of Chinese export products is obvious. According to some relevant materials, $70 \%$ of industrial standards are lower that that of international standard. Therefore, even if the developed countries do not stipulate complex and rigorous technical standards, most Chinese products will be refused.

\subsection{China having unadvanced technology and inspection equipment as well as low standard.}

For a long time, Chinese textile apparel has been inspected in some traditional items. The inspection equipment is simple without high precision. Lacking technical communication and cooperation with foreign competitors, Chinese textile inspection technology lags begin that of developed countries. Until now, there are almost 90 items of national standard which are relevant with safety of textile products. Even though these standards adopt ISO standard, but there is still a gap with international standard, which causes big difference in the inspection results and forms technical barriers to trade.

\subsection{Exporting enterprises lacking authentication consciousness, quick-respondence mechanism and early warning mechanism.}

Because most Chinese export enterprises' information channels are hindered, they lack standard consciousness, regulation consciousness, authentication consciousness and information of foreign TBT, which make themselves passive when facing foreign TBT. Therefore, most export products cannot reach international technical standard including manufacturing condition, craftwork and method. Even if some products have quality inspection, but without authentication, these products still cannot enter the main markets of foreign countries, which causes the loss of profit of the enterprise.

\section{Effect of TBT on Chinese Textile Products}

The developed countries such as America, EU and Japan limit the export of textile apparel through stipulating relevant technical regulations and standards, which exert more and more influence on Chinese textile product export. From the nature, TBT is a double-edged sword, which has positive influence on international economy and Chinese economic development as well as the negative influence. 


\subsection{Positive influence.}

Currently, foreign rigorous TBT is greatly affecting Chinese textile product export. However, from a long-term view, it will extort positive influence on the development of Chinese textile product industry.

\subsubsection{Driving technical advancement.}

Foreign TBT becomes the challenge to Chinese textile product export, meanwhile, it provides strong momentum for Chinese textile industry to realize technical advancement.

\subsubsection{Promoting adjustment of products' structure.}

With the purpose of protecting environment and human beings' health, the proper technical index is stipulated to decrease harmful textile products trade, which also can promote Chinese textile industry to adjust products' structure, develop further processing products of environment protection and regard "green textile apparel" as a new growth point for export. Thus Chinese textile products can break foreign TBT and enlarge the international market occupancy rate.

\subsubsection{Promoting the change of conception.}

From some certain point of view, Chinese textile products export encountering foreign TBT may make the operators and manufacturers of Chinese textile industry change their wrong conception: from only focusing on products' outside quality to focusing on products' outside and inside quality; from only emphasizing on products' quality to emphasizing on product's quality and manufacturing process; from taking economic profit as primacy to emphasizing on economic profit and consumers' profit.

\subsubsection{Perfecting construction of system.}

Currently, China has more than 10 centers of inspecting prohibited dye in the textile products exporting bases such as Shanghai and Suzhou. And more than 20 inspection organizations in China have gained authentication qualification to issue inspection report of prohibited dye. At present, there have been more than 200 enterprises getting authentication certificate of Oeko-TexStandard 100. This will be good for fair competition in domestic market and for leading consumers to choose satisfactory products. And it's meaningful for China to expand textile product export volume and break developed countries' green barriers.

\subsection{Negative influence.}

Statistics of UN Trade Developing Conference shows that Chinese textile export products suffers great loss for $\$ 7.4$ billion because of TBT. Some experts think that TBT's influence on Chinese textile product export is more than that of anti-dumping case. Therefore, TBT's negative influence on China is more than positive influence. In 2002, 67.2\% of textile apparel enterprises were influenced by TBT. A huge mount of products had to retreat from foreign market and suffered the loss for $\$ 1.17$ billion. In $2003,74.4 \%$ of enterprises were influenced by TBT with the loss of more than $\$ 1$ billion. The loss extent is larger than that before China's entry into WTO. 15\% of Chinese textile products could not accord with American "green” demand, thus exporting products for $\$ 8$ billion were influenced. EU's Instructing of Prohibiting Nitrogen Dye has influenced more than 70\% apparel enterprises. German "green angel", Canadian "environment choice", Japanese "eco standard" have made the barrier for Chinese textile products export. And various bad influences appear.

\subsubsection{Entry requirement for Chinese textile products is high and international shares are challenged.}

Chinese textile products are always exported to markets of Chinese Hong Kong, Japan, America and EU, in which the export shares occupy over $75 \%$ of Chinese total export volume. However, green barriers are severe in these places which pay more attention to environment protection and safety. Their green trade barrier system becomes more and more complete and the standards are rigorous than before. TBT especially green barriers have become a very important barrier in textile products trade. These stipulations not only strictly limit the usage of harmful chemicals in textile products but also give definite environment protection demand in various stages of textile product lifecycle, including manufacturing fiber, planting \& disposing cotton, processing \& manufacturing products and consumption, etc. These stipulations include chlorinated organic carrier, formaldehyde residues, antiseptic, soluble heavy metal residues, acid \& basicity extent of fabric, coloration extent \& special odor; prohibiting usage of elements destroying ozonosphere; controlling or perishing some harmful germina; the released waste in manufacturing process cannot exceed the standard. If Chinese textile products cannot reach the standards stipulated by these countries, the market shares will be shrunken. And America, Japan and European countries are important members of "Trade and Environment Committee" in WTO. Their activity always result in Domino Effect so that some emerging industrialized countries also simulate them to make TBT, thus Chinese textile products export may encounter more severe situation.

\subsubsection{Export cost is increased and competition is weakened.}

The implement of green barriers demands that the principles of environment science and eco science should be applied into the process of products' manufacturing, processing, storage and transportation, which forms a complete and 
non-pollutant environment management system and influence every link of process from manufacturing, selling to handling abandonment. Therefore, in order to reach the environment standard of importing countries, Chinese textile products exporters have to increase investment of equipment and labors as well as do environment authentication. The improvement of inspection machines and authentification \& inspection fee in the designated foreign inspection organizations will increase the export cost of enterprises. However, Chinese textile enterprises' competition advantages focus on low-cost labors,. The products' technical content is low, which weakens Chinese textile industry's competition in the international market. As a developing country, China has to acclimatize the "green tide". There's no way for China to exclude and reject it. In order to acclimatize the "green tide" and break the TBT, the fee of every link of process from manufacturing, selling to handling abandonment will be increased, thus the total cost also will be augmented. The original price advantage is comparatively weakened, the enterprise's profit is influenced and the international competition of enterprise's export will be bated.

\subsubsection{Complex procedure and high expense will increase the cost.}

The application of EU's textile products'eco label is handled in European countries and the procedures are complex. These complex procedures and demands increase the application difficulty and export cost of Chinese enterprise. After EU's REACH code was implemented, according to the estimate of EU, the inspection fee of every chemical element is 85,000 Euro and the inspection fee of every new element is 570,000 Euro, which will result in great trade barriers for Chinese textile industry.

4.2.4 The affected scope is vast and some relevant industries are influenced.

TBT not only influence Chinese textile apparel industry but also affect printing \& dyeing industry, chemical agents industry, fiber \& raw material industry, transportation industry and decrease the business and income of these industries.

4.2.5 TBT not only affects the market occupancy rate and income of Chinese export enterprises but also influences Chinese employment.

According to survey, when Chinese textile products export is decreased for $1 \%$, the domestic production will be decreased for $0.5 \%$. The number of unemployment population will be 36,000 , which will cause great social pressure. The extremely high dependence on international trade will make Chinese textile industry face great international market risk.

\section{Measures to Cope with TBT for Chinese Textile Products Export}

With the trend of integrative international economy and trade liberalization, and when traditional and non-traditional tariff barriers are dismantled, Western developed countries adopt more covert, less transparent, not easily to be supervised and predicted protective measures---- Technical Barriers to Trade to prevent products of developing countries from entering domestic markets. Therefore, doing research on measures to cope with TBT of developed countries is meaningful for Chinese export trade and production.

\subsection{Main methods adopted by the government}

\subsubsection{Strengthening cross-national communication and negotiation to reduce TBT.}

Chinese government should positively participate in international bilateral and multi-lateral negotiation and strengthen communication with developed countries' governments to reach understanding and memo among countries and reduce TBT as much as possible. The government should develop diplomacy in textile industry to strengthen competition in Chinese textile industry. Through reinforcing the communication, intercourse and mutual trust with the international rivals, cooperators, relevant industries, consumers, social groups, economic \& political organization and individuals, the government should try to banish and avoid the collision and gulf due to misunderstanding, which can enhance Chinese international image, establish the status of powerful country, create Chinese textile national brand, improve the general good reputation of Chinese textile industry, construct industrial system in order to ensure that Chinese textile industry can stabile, healthily and quickly develop in the era of economic and trade globalization.

\subsubsection{Strengthening macro-regulation, standardizing and guiding industry to develop healthily.}

The government should strengthen macro-regulation, encourage establishing high technology and environmental protection textile enterprises and encourage powerful enterprises to invest and establish enterprises outside of China. The government also should standardize and guide the textile industry to develop healthily, which can promote industry to upgrade.

\subsubsection{Pushing international standard.}

According to statistics, $70-80 \%$ of Chinese current industrial technology standard is lower than international standard or foreign advanced standard and technical equipment lags behind the developed countries for 10 to 20 years. The government should increase propaganda, extend international standard such as ISO 9000 quality management and 
quality guarantee standard and ISO 14000 environment management standard. Even though ISO standard is not compel lent standards but it is authoritative in the world. Promoting ISO standard is the passport for products entering international market.

\subsubsection{Stipulating various technical rules and standards suitable for international market.}

Facing more rigorous technical demand of foreign TBT, China should stipulate and perfect technical regulations about textile products, health and environment protection. China should supplement and perfect current methods of inspecting textile products, enhance accuracy and reliability of inspection methods, strengthen compulsory standard and relevant technical regulations with key limitation index and promote the system of "environment protection mark". For the current problems of disobeying stipulating, implementing and supervising regulations, the government should connect enterprise manufacturing, people's demand with form of supervising inspection level.

\subsubsection{Establishing special institution and doing serious research on TBT agreement.}

Chinese relevant departments should establish special institutions, organize experts to participate in stipulating international standards and reflect some opinions and demands of Chinese textile apparel export enterprises on international standards. The government should establish and perfect quick-response and early warning mechanism by consulting EU's early warning mechanism, which is divided into four grades from low level to high level including green, yellow, orange and red grades. When the export is increased sharply, the government can adjust the export of domestic enterprises to avoid TBT; when the foreign countries set the higher level TBT for some certain textile apparel, the government can adjust early warning grade to remind domestic enterprises of noticing the change. Therefore, the early warning mechanism can create good conditions for Chinese textile products entering international market.

\subsubsection{Strengthening cultivating talents.}

To some extent, market competition is the talents competition. The government should increase the investment on inspection technology, methods of inspecting products' quality, collocation of inspection equipment, technical laws and regulations to cultivate the technical talents.

\subsection{Measures to Cope with TBT for Chinese textile enterprises}

The textile industry is one of pillar industries of Chinese national economy. The output and production ability of Chinese chemical fiber, yarn, cloth, silk and apparel ranks No. 1 in the world. China has become the biggest country manufacturing textile products in the world, but just the biggest not the most powerful.

The change of all countries' economic development level and industrial structure has the direct influence on the transit of textile trade mode. Analyzing from international competition, the decisive elements are labor cost and technical level. China is featured in huge population and low cost labor. Therefore, Chinese products always cost-effective in the international market. However, this advantage is challenged by other countries such as India, Pakistan, Bengal. Comparing with these countries, Chinese coast areas have lost the advantage of low labor cost. Therefore, Chinese textile industry should improve competition advantage by making use of labor cost advantage. The government should do the following things:

\subsubsection{Improving export products' quality and ameliorating structure of export products.}

The product quality is the key for existence and development of enterprise. Chinese enterprises have to invest more on science and technology, improve products' technical content, promote new products in international market or realize technical innovation to make structure of export products satisfy demand of various consumers, especially the consumers of developed countries. For TBT in EU, American and Japanese markets, we should readjust products' structure according to the changed technical standards in order to make our products enter the international main markets.

5.2.2 Establishing Chinese own brands and increasing products' additional value. Brand is created through long-term anneal in the market. A well-known international brand symbolizes high-quality products, reliable and honest consumers and continuous profit of enterprise. At preset, in Chinese export textile apparel, there's no any brand or just appointed brand by the buyer or processing trade for buyer. The brand and profit is occupied by the buyer. How can Chinese textile products establish their own brand and form the reliable products conception? Therefore, Chinese textile apparel export enterprises should emphasize on brand establishment of products to make more consumers know Chinese products and enterprises.

\subsubsection{Cultivating China's own technical talents.}

One hand, Chinese government should cultivate talents. On the other hand, Chinese enterprises should improve scientific and technical level. The government should cultivate export specialist and talents in enterprises' quality supervision department and financial management department. These talents should learn in the practice and practice to learn to change old conception, renovate knowledge, improve their own quality to face the fierce international competition. 


\subsubsection{Cultivating the specialists familiar with relevant laws and regulations about TBT.}

If Chinese textile apparel export enterprises want to overcome TBT, they need support and assistance of government, especially macro-regulation on collection of TBT information, technical codes, standard and evaluation procedure. On the other hand, the enterprises should improve their own international competition and develop the core competition products to stride TBT with high-quality products.

\subsubsection{Exploring new markets to stride TBT.}

One reason for Chinese textile apparel encountering TBT is that Chinese export markets are centralized in Japan, America and EU. According to statistics, the export volume in these three markets occupies $75 \%$ of Chinese textile export volume. Markets' extreme concentration arouses dissatisfaction of relevant enterprises of import countries and trade friction between exporter and importer and even makes the importing countries stipulate higher technical standards to limit importing products. In order to avoid unnecessary trade friction, Chinese enterprises should go on the way of market diversifying, that is, Chinese enterprises can explore wider markets outside of the main markets, which can avoid unnecessary trade friction and develop the trade relationship with other countries to find new development space for textile apparel export.

5.2.6 Abiding by the laws and regulations and managing the business with credit.

International trade emphasizes on efficiency and credit. No matter who breaks the international trade laws, he/she will be punished by the regulations. The social responsibility standard and eco environment standard have become the main TBT for Chinese textile products export. Therefore, in the international trade, first, Chinese textile industry should implement labor regulations strictly, stick to people-oriented idea and maintain workers' rights; second, Chinese enterprises should establish quick-response mechanism; third, Chinese enterprises should establish strict quality-supervision mechanism, enhance "green" environment protection consciousness. In the raw materials adoption, manufacturing, designing, packing and disposal after using products of textile products, Chinese enterprises should implement according to environment protection regulations, promote eco environment protection authentication, stick to international standard and adapt to the internationalization trend; fourth, Chinese enterprises should establish credit service mechanism. Only doing business with efficiency, regulations and credit can Chinese enterprises win the competition in the international market.

\section{References}

Wang, Zhonghui, Strding Technical Barriers to Trade-- Influence of Technical Barriers to Trade on Chinese Textile Products Trade, China Social and Scientific Publishing House, 2005.

$\mathrm{Wu}$, Guanrong, Zhang, Shouming, Influence and Countermeasures of Technical Barriers to Trade on Chinese Textile Products Trade, Economic Issues, Feb. 2003.

Yin, Zhengping, Technical Barriers to Trade and Chinese Textile Products Export, Jan. 2007.

Zhang, Liang, Yan, Jun, Research on Technical Barriers to Trade Encountered by Chinese Textile Products Trade and Countermeasures, International Trade Issue, April 2005. 


\title{
The Interest Prohibition and Financial Performance of
}

\author{
Islamic Banks: Indonesian Evidence
}

\author{
Ari Kuncara Widagdo (Corresponding Author) \\ Accounting Department Sebelas Maret University \\ 36A Sutami Street, Surakarta 57126, Indonesia \\ Tel: 62-27-166-8609Ｅ-mail: Widagdo2002@yahoo.com
}

\author{
Siti Rochmah Ika \\ Accounting Department Janabadra University \\ 56 Tentara Rakyat Mataram Street, Yogyakarta 55231, Indonesia \\ Tel: 62-27-455-2209Ｅ-mail: Ika_manis@yahoo.com
}

\begin{abstract}
In the beginning 2004, Majelis Ulama Indonesia (Indonesia Ulema Council) released fatwa that definitely mentioned the proscribing of interest. In the period after fatwa, the main indicators of Islamic banks indicated a significant growth. Thus, the objective of this study is to investigate whether the financial performance of Islamic banks in the period before fatwa is different from that in the period after fatwa. Furthermore, this study intends to examine the comparative financial performance of Islamic banks and conventional banks in the period both before fatwa and after fatwa. In evaluating banks' performance, this study used various financial ratios categorized as profitability, liquidity, risk and solvency, and efficiency. To determine the difference, this study used t-test. The result of this study indicates that, in general, comparison of financial performance of Islamic banks in the period before fatwa and after fatwa does not show statistically difference. Likewise, the result of inter-bank analysis also indicates that there is no major difference in performance between Islamic banks and conventional banks in the period both before fatwa and after fatwa,
\end{abstract}

Keywords: Islamic bank, Fatwa, Interest prohibition, Financial performance

\section{Introduction}

Islamic banks have several characteristics that are different from conventional banks. Interest-free is main characteristic of Islamic banks. As explicitly appear in the Holy Qur'an (2:278-279), interest is prohibited in Islam. The conventional banking system is organized on the basis of a fixed payment called interest. That is why the practices of the modern banking system are in conflict with the principles of Islam which strictly prohibit interest on any type transaction. Islam is opposed to exploitation in every form and stands for fair and equitable dealings among all men. To charge interest from someone who is constrained to borrow to meet his essential consumption requirement is considered an exploitative practice in Islam. Moreover, charging of interest on loans taken for productive purposes is also prohibited because it is not an equitable form of transaction. Besides interest-free, other distinguishing feature of Islamic banks are profit and loss sharing, zakat (the compulsory Islamic tax) implementation, avoiding gharar (speculation in doing transaction or activities), and not involve in the production or consumption of goods and services that are illegal from the point view of Islam (Samad, 2004, p. 3). In short, Islamic banks is emphasized on fulfill the teaching of the Holy Qur'an rather than maximum returns (Kader, et al.2007, p. 38)

Fatwa (religious instruction) that definitely mentioned the proscribing of interest was issued by Majelis Ulama Indonesia (Indonesia Ulema Council, hereinafter MUI). MUI was an independent non governmental organization established on July 26, 1975, at Jakarta. The members of MUI consisted of ulama and other Muslim scholars from various Muslim organizations in Indonesia, including two largest, Nahdlatul Ulama (NU) and Muhammadiyah. On December 16, 2003, fatwa commission, special commission under MUI, based on ijtima, agreed that interest was forbidden (haram). Afterward, on January 24, 2004, MUI issued fatwa number 1/2004 that was valid since on that date. This fatwa stated that interest charged by conventional banks and other financial institutions for loan was categorized as riba al nasi'ah and forbidden (haram). In the end of this fatwa, Muslims in Indonesia were urged to use Islamic financial institution service. In addition, if there was no Islamic financial institution in their area, based on emergency 
principle, Muslims could get service from the conventional financial institution (MUI, 2004). Like other MUI's fatwa, this fatwa was not legally binding society; however, it provided a clear guidance for Indonesian Muslim in dealing with conventional banks services.

The issuance of this fatwa leaded pro and contra in Muslim society in Indonesia (BNI Syariah, 2005). This fatwa was gladly accepted particularly by Muslims that wanted a formal statement from MUI with regard to the prohibition of interest in the transaction for borrowing money (al-qardh) or lending money (al-dayn). For Islamic banks, this fatwa was additional power that provided moral advantage. On the other hand, other party questioned the effectiveness of this fatwa. This fatwa was issued without any coordination with Indonesia Central Bank. Moreover, they were worried that this fatwa would make a rush in conventional banks. People would take out their money from conventional banks and saved it in Islamic banks. The deposit fund of Islamic banks would increase, whereas Islamic banks might not have capability to distribute its fund to the real sector. As result, according this party, the increasing of deposit fund was likely to influence the liquidity of Islamic banks.

Regardless the debate of the fatwa, in fact, the growth of Islamic banks indicated significant growth in year 2004, a year after fatwa. As can be seen in the Table 1, in the end of 2004, main indicators of Islamic banks, such as assets, financing, and deposit of fund, are higher than those in year 2003. More over, in the end 2004, Non Performing Loan (NPL) also shows value below than 5 percent that indicate high quality of financing of Islamic banks.

The objectives of this paper are to investigate whether the financial performance of Islamic banks in the period before fatwa is different from that in the period after fatwa and to examine the comparative financial performance of Islamic banks and conventional banks in the period both before fatwa and after fatwa. The financial performance of banks is measured based on criteria such as profitability, liquidity, risk and solvency, and efficiency. This study is useful in providing valuable information to relevant parties: Muslim society, Islamic bank management, regulators, and MUI as well.

This paper is organized into six sections. Following introduction in this section, Section 2 describes briefly Islamic banking development in Indonesia along with view of Muslim in Indonesia toward interest and factors considered important to select Islamic bank. Section 3 provides a literature review. Section 4 provides research method that includes financial performance measures, data used in this study, and data analysis. Next section is Section 5 that presents empirical results and discussion. Conclusion, including limitation of the study, is presented in Section 6 .

\section{Islamic Banking Development in Indonesia}

\subsection{The growth of Islamic banks 1992-2005}

The development of Islamic institution in Indonesia during 1992-2005 achieved remarkable growth. The history of Islamic banking was started in 1992 with the establishment of Act No. 1/1992 that gave a chance for opening a profit sharing bank. In 1992, MUI held workshop on Islamic economic followed by establishment of the first Islamic bank, namely Bank Muamalat Indonesia (BMI). In period 1992-1998, there were 1 Islamic bank and 78 Islamic rural banks. In 1998, Indonesia government issued Act No. 10/1998, as replacement of old Act (No. 7/1992), affirmed that Indonesia started entering era of dual banking system in which Islamic banks operated side by side with conventional banks. This Act provided legal basis for development of Islamic bank. Moreover, Act No. 23/1999 about Central Bank stated that Indonesia Central Bank, as monetary authority in Indonesia, must provide regulation and facilities for the operation of Islamic banks. After implementation of these Acts, formation of Islamic banks increased significantly. Bank Syariah Mandiri (BSM), as a second Islamic bank, was opened in 1999 followed by some conventional banks that opened Islamic banking units. The next significant event, in 2002, Indonesia Central Bank issued "Blueprint of Islamic Banking Development in Indonesia". The objective of this blueprint was to identify major challenges of development Islamic bank in the future. In addition, this blueprint also provided vision, mission, and goal for development of Islamic bank, so that Islamic bank stakeholders had clear guidance to synchronize their vision and aspiration (Indonesia Central Bank, 2002). Moreover, on January 24, 2004, MUI issued fatwa that clearly mentioned about prohibition of interest and riba. Hopefully, this fatwa could provide additional stimulation to the growth of Islamic institutions in Indonesia. The complete figure of Islamic financial institution development during period 1992-2005 can be seen in the Table 2 .

\subsection{A View toward Interest and Factors Affecting to Select Islamic Bank}

In year 2000, Indonesia Central Bank conducted a study about potency, preference, and attitude of people in Java Island toward Islamic bank. The objectives of that study were to provide a map of development Islamic bank potency and to study characteristic and view of potential consumers toward Islamic banking services (Indonesia Central Bank, $2000, \mathrm{p}$. 1). Indonesia Central Bank carried out this study in partnership with three established universities in Java, namely Bogor Agriculture Institute, Diponegoro University, and Brawijaya University. This study covered provinces in Java Island such as West Java Province, Central Java Province, Yogyakarta Province, and East Java Province. With regard to view toward Islamic bank, in general, most people argued that Islamic bank was an identical to profit sharing bank and a bank that followed Islamic law (shari'ah). More interesting result was their view toward interest. The percentage of 
people that viewed interest was forbidden by Islam was slightly lower than percentage of those who had opposite view. As shown in Table 3, the percentage of people who viewed interest was prohibited by Islam reached 45 percent, whereas percentage of people who thought that interest was not prohibited by Islam and did not have a clear understanding was 55 percent. Furthermore, factors considered important in selecting Islamic bank indicated mixed result. For people living in West Java Province and East Java Province, the dominant factors were quality of services and location of Islamic bank. In those provinces, religion motive was not an important factor in selecting Islamic bank. On the other hand, people in Central Java Province considered that religion was dominant factor.

In conclusion, this study provided initial data about level of understanding people toward interest. Therefore, by issuance of the fatwa, this paper argues that Muslims in Indonesia would clearly understand legal status of interest from point view of Islam. As result, they would fully support the Islamic banks development in Indonesia.

\section{Literature Review}

In general, method analysis of prior studies on examining of financial performance of Islamic banks with ratios analysis can be categorized into two categories. First, studies examine the performance of Islamic banks during certain period (e.g. Sarker, 1999; Arief, 1989; Wibowo and Saptutyningsih, 2004). Studies under this category generally examine performance Islamic banks during several years and make inter-temporal comparison. Second, studies examine the performance of Islamic Banks and compare that with conventional banks' performance (e.g. Samad, 1999; Samad and Hassan, 2000; Rosly and Bakar, 2003).

In terms of studies that examine the financial performance of Islamic banks during certain period, Sarker (1999) analyzed efficiency of Islamic banks under conventional banking framework in Bangladesh. The result revealed that Islamic banks could not operate with its full efficiency level if it operated under a conventional banking framework. He argued further that Islamic product had different risk characteristic, so that different prudential regulation should be established. In Malaysia situation, Arief (1989) examined the financial performance of Bank Islam Malaysia Berhad (BIMB). He found that, during the first six years of its establishment, BIMB indicated imposing progress. In Indonesia environment, Wibowo and Saptutyningsih (2004) examined the financial performance of two main Islamic banks: BMI and BSM, during period 2000-2003 with tool called CAMEL-modified. The result revealed that performance of BMI was superior to performance of BSM. In more recent study, Utami, et al. (2006) tried to define profile of Baitul Maal Wat Tamwil (BMT) in Banyumas Regency based on its financial performance. The result showed that, in most BMTs being surveyed, the level of financial ratio, which included liquidity, solvability, business risk, and productivity of the employee's ratio, increased from the year 2000 until 2002. In global level, Zaman and Movassaghi (2001) reviewed the growth of the Islamic banks on a global basis and assessed its financial performance. This study covered Islamic banks located in some regions such as South Asia, Africa, Southeast Asia, Middle Asia, Europe and America. They ranked performance of Islamic banks around these regions based on some figures extracted from financial statement ended in year 1996. The result showed that Islamic banks located in Middle East and South Asia dominated the rank.

In the context of comparative financial performance of Islamic Banks and conventional banks, some studies have been done in Malaysia (Samad, 1999; Samad and Hassan, 2000; Rosly and Bakar, 2003). Samad (1999) evaluated efficiency of BIMB during 1992-1996 and compared to that of conventional banks. The result indicated that BIMB had relatively higher managerial efficiency than conventional banks. In further study, Samad and Hassan (2000) examined the financial performance of BIMB over the period 1984-1997 and compared that with performance of conventional banks. They employed inter-temporal and inter-bank approach. The finding revealed that financial performance of BIMB was different from conventional banks with respect to liquidity and risk management. In recent study, Rosly and Bakar (2003) examined the financial performance of Islamic banking scheme and made comparative analysis with their mainstream banks' performance. The result showed that mainstream banks were more efficient than Islamic banking scheme. In Bangladesh environment, Hassan (1999) examined performance of Islamic Bank Bangladesh Limited and compared that with other private banks in Bangladesh. The result revealed that, in terms of deposit growth and investment growth, performance of Islamic Bank Bangladesh Limited was better than performance of private banks during period 1993-1994. However, due to the lack of statistical technique, this study is unsatisfactory (Samad and Hassan, 2000). With using banks in Pakistan as case study, Mahmood (2005) compared the financial performance of Islamic bank with that of conventional bank. He found that, almost in all ratios, Islamic bank was superior to conventional bank during 2000-2004. In Bahrain situation, Samad (2004) examined comparative financial performance of Islamic banks and the conventional banks during 1991-2001. The result indicated that there was no significant difference between Islamic banks and conventional banks with respect profitability and liquidity. Similar study in other Middle East country, Kader, et al. (2007) also examined comparative financial performance of Islamic banks and conventional banks in UAE. The finding indicated that there was no major difference between Islamic banks and conventional banks with respect to profitability and liquidity. 


\section{Research Method}

\subsection{Financial Performance Measures}

In evaluating banks' performance, this study used accounting ratios. The use of accounting ratios is common in the literature (Samad and Hassan, 2000; Samad, 2004). Furthermore, accounting ratios could minimize disparity of bank's size and make them at average (Samad, 2004, p.6). In this study, to measure financial performance of bank, this study employed 13 financial ratios. These ratios could be grouped under four broad categories as follows.

\subsubsection{Profitability Ratios}

The profitability ratios are used to asses the capability of company to generate earnings as compared to its expenses and other relevant costs incurred during certain period of time. This study used following ratios for measuring profitability of bank.

a. Return on Asset $(\mathrm{ROA})=$ profit after tax/total asset. It shows how a bank can convert its asset into net earnings. The higher value of this ratio indicates higher capability of firm. This ratio provides indicator for evaluating the managerial efficiency (Samad, 1999; Samad and Hassan, 2000; Samad, 2004; Kader, et al., 2007)

b. Return on Equity $(\mathrm{ROE})=$ profit after tax/equity capital. This ratio indicates how bank can generate profit with the money shareholders have invested. The higher value of this ratio shows higher financial performance. Like ROA, this ratio is also indicator for managerial efficiency.

c. Profit to Total Expenses (PER) = profit after tax/total expense. This ratio indicates profitability of the firm with regard to its total expenses. A high value of this ratio indicates that bank could make high profit with a given expenses.

d. Return on Deposit $($ ROD $)=$ profit after tax/total deposit. This ratio shows percentage return on each dollar of customers' deposit. In the other words, it indicates the effectiveness of bank in converting deposit into net earnings (Rosly and Bakar, 2003, p. 1257).

\subsubsection{Liquidity Ratios}

The liquidity ratios measure the capability of bank to meet its short-term obligations. Generally, the higher value of this ratio indicates that firm has larger margin safety to cover its short-term obligations. Among the various liquidity measures, this study used ratios as follows.

a. Cash deposit ratio $(\mathrm{CDR})=\mathrm{cash} /$ deposit. The higher value of this ratio shows that a firm is more liquid.

b. Loan deposit ratio $(\mathrm{LDR})=$ loan/deposit. The low value of this ratio indicates that bank has excess liquidity. This ratio also indicates effectiveness of mediation function of bank. In the Islamic bank context, this ratio is well known also as Financing Deposit Ratio (FDR).

c. Current ratio $(\mathrm{CR})=$ current asset/current liability. This ratio indicates the capability of firm to meet the current liability with the current asset. The high value of this ratio indicates that firm is more liquid.

d. Current asset ratio $(\mathrm{CAR})=$ current asset/total asset. This ratio shows composition of firm's asset. The high value of this ratio indicates that firm has more liquid asset than long term asset.

\subsubsection{Risk and Solvency Ratios.}

The following ratios measure for risk and solvency.

a. Debt equity ratio $($ DER $)=$ debt/equity capital. This ratio shows how firm finances its operation with debt relative to the use of equity.

b. Debt to total assets ratio $(\mathrm{DTAR})=$ debt/total asset. This ratio indicates the proportion of assets financed with debt. A high value of this ratio provides indication that firm involves in more risky business.

c. Equity multiplier ratio $(\mathrm{EM})=$ total asset/share capital. This ratio shows how many dollars of assets must be supported by each dollars of equity capital. The higher value of this ratio indicates signal for risk failure.

d. Loan to deposit ratio $(\mathrm{LDR})=$ loan/deposit. Besides measuring liquidity, this ratio also indicates credit risk for a firm. High value of this ratio indicates possibility insolvency.

\subsubsection{Efficiency Ratios}

Two ratios were used for measuring efficiency of a bank.

a. Asset utilization ratio $(\mathrm{AU})=$ total operating income/total asset. This ratio measures capability of firm to generate revenue with its asset. The high value of this ratio indicates the high productivity of firm's asset.

b. Operating efficiency ratio $(\mathrm{OE})=$ total operating expense/total operating income. This ratio indicates how efficiently firm uses its assets, revenues and minimizing the expenses. In other words, it shows how well firm 
could reduce the expenses and improves productivity.

\subsection{Data and Sample}

This study used BMI and BSM as a representative of Islamic banks with the reason that these banks have been operating more than 5 years and served as pioneer in Islamic banking in Indonesia. With regard to conventional bank, sample consisted of eight mainstream private banks with the following criteria.

a. The private banks do not have any loss during 2000-2005.

b. Like BSM and BMI, based on Indonesia Central Bank directory, these private banks are categorized as foreign exchange bank.

The complete list of banks could be seen in Table 4. Furthermore, this study used a micro bank level panel data on financial statements of both conventional banks and Islamic banks during period 2002-2005. The financial statements of banks were collected from its website and also Indonesia Central bank database. The various ratios were calculated based on these financial statements.

\subsection{Data Analysis}

To examine the difference of banks' performance, this study employed inter-temporal comparison and inter-bank approach. The used of these methods is quite common in literature (Samad, 2004; Samad and Hassan, 2005). In addition, a statistical technique was performed in this study in order to determine the difference. The following sections are discussion of these methods.

\subsubsection{Inter-Temporal Comparison}

In order to examine difference of Islamic banks' performance in the period before fatwa and after fatwa, this study employed inter-temporal analysis. It means that this study made comparison of performance of Islamic banks between two periods: before fatwa and after fatwa. The window period of this study was two years before fatwa and after fatwa. Because the fatwa was issued on January 24, 2004, this study assumed that it would not affect the financial statements ended year 2003. Thus, period before fatwa included 2002 and 2003, whereas period after fatwa included 2004 and 2005. Thus, Islamic banks' performance in the period 2002-2003 was compared to that in the period 2004-2005. Statistic technique performed in this stage was equality of mean test. The equality of mean test was used to compare means from two samples. Samad (2004, p. 6-7) stated that performance studies widely used this test. To determine whether the difference in means were significant, $\rho$-value must be less than the 0.05 . If the $\rho$-value is less than 0.05 the null hypothesis would be rejected, or it is no difference among the groups mean.

\subsubsection{Inter-Bank Comparison}

By this method, financial performance of Islamic banks was compared with financial performance of conventional banks in the period before fatwa. Similar comparison method was done for the period after fatwa. Statistic technique performed in this stage was also equality of mean test (independent t-test).

\section{Empirical Results and Discussion}

This section presents the finding based on the objectives identified earlier in this study. The findings of the study are also presented in figures and tables. The significant results are further discussed and analyzed in detail in this section.

\subsection{Profitability Analysis}

In terms of inter-temporal analysis of profitability, all measures of profitability of Islamic banks other than ROD show that there is no significant difference in financial performance between period before fatwa and after fatwa. As shown in Table 5, ROD is only ratio that indicates statistically difference. The average ROD of Islamic Banks before fatwa is 0.01050 compared to 0.01800 in the period after fatwa. It indicates that, in the period after fatwa, the growth of profit of Islamic banks is relatively higher than deposit fund growth. The growth of this profit in year 2004 and 2005 are 289.41 percent and 92.93 percent respectively, whereas growth of deposit fund of Islamic banks are 117.8 percent and 14.26 percent respectively. Nevertheless, the significant increase of profit does not make other profitability ratios, such as ROA and ROE, showing significant differences between two periods. The reason for this might be that increasing of profit is also followed by increasing of other accounts, such as asset, and equity. It can bee seen in Table 2, total assets Islamic banks in year 2004 and 2005 dramatically increased. This fact might indicate that Islamic banks are in expansion stage during 2004-2005.

In terms of inter- bank analysis, as shown in Table 6 and Table 7, all measures of profitability do not show any statistically difference between Islamic banks and conventional banks in the period both before fatwa and after fatwa. This result is consistent with finding of the other studies that found no significant difference in profitability between Islamic banks and conventional banks (Samad, 2004; Kader, et al. 2007). This result might be explained by the fact that revenues of Islamic banks were mainly obtained from financing activities that steadily increased during period 2000-2005. The increasing of financing activities in this period was supported by the low of Non Performing Loan 
(NPL) (see Figure 2). As result, profitability of Islamic banks did not lag behind the profitability conventional banks that also increased steadily in that period due to, particularly, the increasing interest rate.

\subsection{Liquidity Analysis}

In terms of inter-temporal analysis of liquidity, as shown in Table 5, all ratios of Islamic banks, except CAR of Islamic Banks, indicate that there is no significant difference between period before fatwa and after fatwa. However, with regard to CAR of Islamic banks, the difference is statistically significant. The mean CAR in the period before fatwa is 0.252 compared to 0.438 in the period after fatwa. In the period after fatwa, it seems that Islamic banks are more liquid and exposed to less liquidity risk than conventional banks. A macro economy condition Indonesia, particularly in year 2005 , could be used for explanation this result. In year 2005, the macro Indonesian economic undertook a rapid downturn triggered mainly by increasing of domestic fuel prices and depreciation of Indonesia currency. The fuel prices increased around of 126.6 percent in average, whereas rupiah, Indonesian currency, experienced significant depreciation around 8.6 percent. In turn, inflation rate soared, causing downward pressure on public consumption levels. In that time, inflation reached 17.11percent that was much higher than target (Indonesia Central Bank, 2006, p. 19). Then, for stabilization of economy condition, Indonesia Central Bank implemented some policies, such as increasing gradually interest rate, open market operation, and increasing minimum reserve requirement. In January 2005, interest rate was 7.42 percent and increased to level of 12.7 percent in November, 2005. In this condition, conventional banks might offer higher return than Islamic banks. In that year, conventional banks promised annual return around 13-15 percent, whereas monthly profit sharing of Islamic banks was around 7-9 percent. Meanwhile, sources of Islamic bank fund are dominated by mudharabah investment that is long term account. For example, based on the position in December, 2005, source of fund Islamic banks consisted of 13 percent of wadiah current account, 28 percent of mudharabah saving account, 58 percent of mudharabah investment account, and 1 percent of received financing (Indonesia Central Bank, 2005 , p. 8). This fact implies that profit oriented is dominant motives of Islamic banks' consumer. Consequently, if conventional banks offer high return, Islamic banks will experience displacement risk. This risk means that consumers take out their money from Islamic banks and save it in the conventional banks (Indonesia Central Bank, 2006, p. 21). To anticipate this risk, therefore, Islamic banks seem maintaining higher liquidity in the period after fatwa than before fatwa. Islamic bank should provide the guarantee of depositors' deposits and trust because Islamic banks are not only a firm, but also moral trustee of the depositors where deposits are trust given to the banking system (Samad and Hassan, 2000, p. 11).

In terms of inter bank comparison as shown in Table 6 and Table 7, some ratios indicate significant difference between Islamic banks and conventional banks. In the period before fatwa, CR ratio shows statistically difference. The mean average of Islamic banks is 2.68800 , compared to 1.00812 of conventional banks. It seems that capability of Islamic banks to meet current liability with the current asset is better to that of conventional banks. The reason for this might be related to dominant form of Islamic banks financing that is short term nature. Like other countries, financing of Islamic banks in Indonesia have been dominated by Murabahah receivables (Indonesia Central Bank, 2006, p. 19). By this form of financing, the Islamic bank purchases for a customer certain product based on his request. The customer will buy the good from the bank on pre-agreed profit basis that does not seem significantly different from interest charged by conventional banks (Brown, 1994). This type of financing is more popular because it is a short term and low risk investment for bank (Samad, 2004, p. 12). Thus, Islamic banks seems need to maintain high liquidity to cover their short term financing.

In the period after fatwa, LDR ratio indicates significant difference. As shown in Table 7, means average of LDR of Islamic bank is 0.87700 , whereas means average for conventional banks is 0.60063 . As shown in Table 2, in terms of financing, comparing to all banks, share of Islamic banks steadily increase since 2003. The percentages of that share in year 2003 until 2005 are 0.16 percent, 1.93 percent, and 2.19 percent respectively (Indonesia Central Bank, 2006). In addition, the high of LDR is supported also by the low of NPL of Islamic banks. During period 2002-2005, NPL of Islamic banks was constantly below than 5 percent that indicated outstanding performance of Islamic Banks (see Figure 2). Thus, those facts indicate that Islamic banks serve intermediation function relatively better than conventional banks. Islamic banks might allocate their funds to real sector such as small medium enterprises (Indonesia Central Bank, 2006, p. 20). It seems that, in the era of post East Asian financial crisis, Islamic banks could recover quicker than conventional banks.

\subsection{Risk and Solvency Analysis}

The comparison of ratios of Islamic banks in the period before fatwa with period after fatwa does not indicate statistically difference. Based on data in Table 5, in the period after fatwa, means average of all risk and solvency ratios (DER, DTAR, EM, and LDR) are higher than that in the period before fatwa. It indicates that Islamic banks involve in more risky business. However, it seems that Islamic banks could manage their business properly, while business risk increases. It could be seen from the low of NPL of Islamic banks (see Figure 2).

In terms of inter-bank analysis, based on data in Table 6 and Table 7, it can be seen that all measures of risk and 
solvency also show that there is not significant difference in performance between Islamic banks and conventional banks in period both before fatwa and after fatwa. This present finding does not support the prior study (Samad and Hassan, 2000) that reveal risk and solvency difference between Islamic banks and conventional banks.

\subsection{Efficiency Analysis}

In terms of inter-temporal analysis, all efficiency ratios show no significant difference. As shown in Table 5, mean average of ratios are relatively equal between two periods. Likewise, inter-bank comparison also indicates that all efficiency measures indicate no significant differences between Islamic banks and conventional banks (see Table. 6 and Table. 7).

\section{Conclusion}

This study examined the financial performance of Islamic banks in Indonesia. Financial performance measures were expressed in terms of various financial ratios categorized as profitability, liquidity, risk and solvency, and efficiency. As mentioned earlier in the introduction, this study attempted to examine whether financial performance of Islamic banks in the period before fatwa was different from that in the period after fatwa. Furthermore, comparative financial performance of Islamic banks and conventional banks during period before fatwa and after fatwa was also examined.

The result of this study has shown that, in general, financial performance comparison of Islamic banks in the period before fatwa and after fatwa was not statistically different. Likewise, inter-bank analysis, in the period both before fatwa and after fatwa, have indicated that there was no major difference in performance between Islamic banks and conventional banks.

The result of this study implies that financial performance of Islamic banks in Indonesia might not associate with fatwa issued by MUI. It seems that macro economy indicator, such as interest rate, might affect the performance of Islamic banks in Indonesia. It is supported by finding of previous studies (Gerard and Cunningham, 1997; Metawa and Almossawi, 1998; Haron and Ahmad, 2000; Ghafur, 2003) that indicate motivation of depositors of Islamic banks is the return of the money (welfare maximization premise).

This present study has limitations that should be considered carefully when interpreting the results. In this study, sample of conventional banks included a conventional bank that opened Islamic banking units in year 2005. This Islamic banking unit might affect the performance of conventional bank as parent company. For further study, it is needed to exclude this bank from sample of conventional bank. Another limitation, sample of Islamic banks in study was represented by BMI and BSM. Meanwhile, prior study (Rachmawati and Syamsulhakim, 2004) indicated that number of branch office might also affect the performance of Islamic bank in Indonesia. Thus, sample of further study needs to include other type of Islamic bank institutions, for example Islamic rural banks that have grown significantly

\section{References}

Arief, M. (1989). Islamic Banking in Malaysia: Framework, Performance and Lesson. Journal of Islamic Economics, 2 (2), 67-78.

BNI Syariah. (2005). Prospect of Shari'ah Bank after Fatwa of MUI. Yogyakarta: Suara Muhammadiyah.

Brown, K. (1994). Islamic Banking: Faith and Creativity. Los Angeles Times, 8 April.

Gerard, P. \& J. Barton Cunningham. (1997). Islamic Banking: A Study in Singapore. The International Journal of Bank Marketing, 15 (6), 204-216.

Ghafur, M. (2003). The Effect of Profit Sharing, Interest Rate, and Income on Mudaraba Deposits: Case Study of Bank Muamalat Indonesia. Journal of Islamic Economics Muamalah, 1 (1), 7.

Haron, S., \& Norafifah Ahmad. (2000). The Effects of Conventional Interest Rates and Rate of Profit on Funds Deposited with Islamic Banking System in Malaysia. Journal of Islamic Financial Services, 1 (4).

Hassan, M. K. (1999). Islamic Banking in Theory and Practice: The Experience of Bangladesh. Managerial Finance, 25 (5), 60-113.

Indonesia Central Bank. (2000). Potency, Preference, and Perception Society toward Islamic Bank at Java Island. Jakarta: Indonesia Central Bank.

Indonesia Central Bank. (2002). Blueprint of Development Shari'ah Banking Indonesia. Jakarta: Indonesia Central Bank, 6-7.

Indonesia Central Bank. (2005). Islamic Banking Statistic 2005. Jakarta: Indonesia Central Bank.

Indonesia Central Bank. (2006). Shari'ah Banking Development Report 2005. Jakarta: Indonesia Central Bank.

Kader, J. M., Asarpota, A. J. \& Al-Maghaireh, A. (2007). Comparative Financial Performance of Islamic Banks vis-à-vis Conventional Banks in the UAE. Proceeding on Annual Student Research Symposium and the Chancellor's 
Undergraduate Research Award. (Online) Available: http://sra.uaeu.ac.ae/CURA/Proceedings (May 31, 2007).

Mahmood, Z. (2005). Islamic Banking: A Performance Comparison of Islamic Bank versus Conventional Bank in Pakistan. Unpublished Master Thesis, Bradford University. (Online) Available: http://virtualscholars.brad.ac.uk:8080/handle/10004/4341 (October, 15, 2007).

Majelis, Ulama, Indonesia. (2004). Fatwa Decree of Majelis Ulama Indonesia No. 1/2004. Jakarta.

Metawa, S.A. \& Mohammed Almossawi. (1998). Banking Behavior of Islamic Bank Customers: Perspectives and Implications. The International Journal of Bank Marketing, 16 (7), 299-313.

Rachmawati, E. \& Syamsulhakim, E. (2004). Factors Affecting Mudaraba Deposits in Indonesia. Working paper in Economics and Development Studies, Padjadjaran University. (Online) Available: http://www.equitablepolicy.org/wpaper/200404.pdf (November, 7, 2007).

Rosly, S. A. \& Bakar, M. A. A. (2003). Performance of Islamic and Mainstream Banks in Malaysia. International Journal of Social Economics, 30 (12), 1249-1265.

Samad, A. \& Hassan, M. K. (2000). The performance of Malaysian Islamic Bank During 1984 -1997: An Explanatory Study. Thoughts on Economics, 10 (1\&2), 7-26.

Samad, A. (1999). Comparative Efficiency of the Islamic Bank Malaysia vis-à-vis Conventional Banks. IIUM Journal of Economics and Management, 7 (1), 1-25.

Samad, A. (2004). Performance of Interest Free Islamic Banks vis-à-vis Interest-Based Conventional Banks of Bahrain. IIUM Journal of Economics and Management, 12 (2), 1-25.

Sarker, M. A. A. (1999). Islamic Banking in Bangladesh: Performance, Problems and Prospects. International Journal of Islamic Financial Services. (Oct-Des), 1(3).

Utami, E. Datien. \& Setiawan, A. I. (2006). Analysis of Financial Performance and Internal Management BMT: Survey BMTs Banyumas Regency. Accounting and Finance Journal, 5 (1), 97-114.

Wibowo, E. \& Saptutyningsih, E. 2004. Analysis of Performance of Bank Muamalat Indonesia and Bank Syariah Mandiri. Journal of Economic Study, 5 (1), 20-25.

Zaman, M. R. \& Movassaghi, H. (2001). Islamic Banking: A Performance Analysis. Journal of Global Business, 12 (22), 31-38.

Table 1. Main Indicators of Islamic Banking 2003-2004

(In billion IDRs)

\begin{tabular}{|l|l|l|l|l|}
\hline Items & $3^{\text {rd }}$ Quarter 2003 & $4^{\text {th }}$ Quarter 2003 & $3^{\text {rd }}$ Quarter 2004 & $4^{\text {th }}$ Quarter 2004 \\
\hline Assets & $6,559.3$ & $7,858.9$ & $12,719.6$ & 15,352 \\
\hline Deposit Fund & $4,646.1$ & $5,724.9$ & $9,675.7$ & 11.862 \\
\hline Financing & 4.832 .3 & 5.530 .2 & $10,131.1$ & 11.489 \\
\hline FDR & $112.44 \%$ & $96.6 \%$ & $104.7 \%$ & $96.86 \%$ \\
\hline NPL & $3.67 \%$ & $2.3 \%$ & $2.8 \%$ & $2.8 \%$ \\
\hline
\end{tabular}

Source: Indonesia Central Bank (2005) 
Table 2. The Development of Islamic Financial Institution in Indonesia 1999-2005

\begin{tabular}{|c|c|c|c|c|c|c|c|c|}
\hline $\begin{array}{l}\text { Bank } \\
\text { Type }\end{array}$ & 1992 & 1999 & 2000 & 2001 & 2002 & 2003 & 2004 & 2005 \\
\hline $\begin{array}{l}\text { Islamic } \\
\text { bank }\end{array}$ & 1 & 2 & 2 & 2 & 2 & 2 & 3 & 3 \\
\hline $\begin{array}{c}\text { Islamic } \\
\text { Banking } \\
\text { Unit }\end{array}$ & - & 1 & 3 & 3 & 6 & 8 & 15 & 19 \\
\hline $\begin{array}{l}\text { Branch } \\
\text { Offices }\end{array}$ & 1 & 40 & 62 & 96 & 127 & 299 & 401 & 504 \\
\hline $\begin{array}{c}\text { Islamic } \\
\text { Rural } \\
\text { Bank }\end{array}$ & 9 & 78 & 78 & 81 & 83 & 84 & 86 & 92 \\
\hline $\begin{array}{c}\text { Total } \\
\text { Assets* }\end{array}$ & NA & NA & 1790168 & 2718770 & 4045235 & 7858918 & 15325997 & 20879874 \\
\hline $\begin{array}{l}\text { Share of } \\
\text { Total } \\
\text { Banking }\end{array}$ & NA & NA & $0.17 \%$ & $0.25 \%$ & $0.36 \%$ & $0.74 \%$ & $1.20 \%$ & $1.42 \%$ \\
\hline $\begin{array}{c}\text { Financing } \\
*\end{array}$ & NA & NA & 1271162 & 2049793 & 3276650 & 5530167 & 11489933 & 15231942 \\
\hline $\begin{array}{l}\text { Share of } \\
\text { Total } \\
\text { Banking }\end{array}$ & NA & NA & $0.40 \%$ & $0.57 \%$ & $0.80 \%$ & $0.16 \%$ & $1.93 \%$ & $2.19 \%$ \\
\hline Deposit* & NA & NA & 1028923 & 1806366 & 2917726 & 5724909 & 11862117 & 15582329 \\
\hline $\begin{array}{l}\text { Share of } \\
\text { Total } \\
\text { Banking }\end{array}$ & NA & NA & $0.15 \%$ & $0.23 \%$ & $0.35 \%$ & $0.64 \%$ & $1.23 \%$ & $1.38 \%$ \\
\hline
\end{tabular}

Source: Indonesia Central bank (2006)

* In million IDRs $\quad \mathrm{NA}=$ Not Available Data

Table 3. View of Muslim in Indonesia toward Interest

\begin{tabular}{|l|l|l|l|}
\hline & Prohibited by Islam & Not prohibited by Islam & $\begin{array}{l}\text { Not Understand/ } \\
\text { Not Sure }\end{array}$ \\
\hline West Java Province & $62 \%$ & $22 \%$ & $16 \%$ \\
\hline $\begin{array}{l}\text { Central Java Province, and } \\
\text { Yogyakarta Province }\end{array}$ & $48 \%$ & $21 \%$ & $31 \%$ \\
\hline East Java Province. & $31 \%$ & $69 \%$ & \\
\hline Total & $45 \%$ & $55 \%$ & \\
\hline
\end{tabular}

Source: Indonesia Central Bank (2000) 
Table 4. List of Selected Banks

\begin{tabular}{|l|l|}
\hline Type of Bank & Bank Name \\
\hline \multirow{4}{*}{ Islamic Bank } & 1. Bank Muamalat Indonesia \\
\cline { 2 - 3 } & 2. Bank Syariah Mandiri \\
\hline \multirow{5}{*}{ Conventional Bank } & 1. Bank Bumi Putra \\
\cline { 2 - 3 } & 2. Bank Buana \\
\cline { 2 - 2 } & 3. Bank Central Asia \\
\cline { 2 - 2 } & 4. Bank Internasional Indonesia \\
\cline { 2 - 2 } & 5. Bank Lippo \\
\cline { 2 - 2 } & 6. Bank Niaga \\
\cline { 2 - 2 } & 7. Bank NISP \\
\cline { 2 - 2 } & 8. Bank Pan Indonesia \\
\hline
\end{tabular}

Table 5. Financial Performance of Islamic Banks Before and After Issuing of Fatwa

\begin{tabular}{|l|l|l|l|l|l|l|}
\hline \multirow{2}{*}{ No } & \multirow{2}{*}{ Ratios } & \multicolumn{2}{|l|}{$\begin{array}{l}\text { Before Fatwa } \\
(2002-2003)\end{array}$} & $\begin{array}{l}\text { After Fatwa } \\
(2004-2005)\end{array}$ & $\begin{array}{l}\text { Sign. 2 Tailed } \\
\rho \text {-value }\end{array}$ \\
\cline { 3 - 7 } & & Mean & $\begin{array}{l}\text { Std. } \\
\text { Deviation }\end{array}$ & Mean & $\begin{array}{l}\text { Std. } \\
\text { Deviation }\end{array}$ & \\
\hline 1 & ROA & 0.19500 & 0.00495 & 0.02250 & 0.00071 & 0.500 \\
\hline 2 & ROE & 0.09100 & 0.05091 & 0.17500 & 0.01273 & 0.313 \\
\hline 3 & PER & 0.13900 & 0.02970 & 0.08950 & 0.03606 & 0.480 \\
\hline 4 & ROD & 0.01050 & 0.00212 & 0.01800 & 0.00141 & 0.042 \\
\hline 5 & CDR & 0.26000 & 0.01414 & 0.20450 & 0.02192 & 0.274 \\
\hline 6 & LDR & 0.75400 & 0.07213 & 0.87700 & 0.00141 & 0.255 \\
\hline 7 & CR & 2.04800 & 0.76933 & 1.71550 & 0.80540 & 0.815 \\
\hline 8 & CAR & 0.25200 & 0.06364 & 0.43800 & 0.06930 & 0.014 \\
\hline 9 & DER & 7.49600 & 4.02061 & 11.67200 & 0.17819 & 0.393 \\
\hline 10 & DTAR & 0.85950 & 0.08556 & 0.91900 & 0.00425 & 0.521 \\
\hline 11 & EM & 9.79700 & 3.90182 & 19.16050 & 2.78105 & 0.298 \\
\hline 12 & AU & 0.01500 & 0.00141 & 0.01850 & 0.00071 & 0.090 \\
\hline 13 & OE & 0.87850 & 0.00636 & 0.80650 & 0.04455 & 0.295 \\
\hline
\end{tabular}


Table 6. Financial Performance Comparison before Fatwa (2002-2003)

\begin{tabular}{|c|c|c|c|c|c|c|c|}
\hline & & Islamic & & Conventic & Bank & & \\
\hline No. & Ratios & Mean & $\begin{array}{l}\text { Std. } \\
\text { Deviation }\end{array}$ & Mean & $\begin{array}{l}\text { Std. } \\
\text { Deviation }\end{array}$ & t-value & Tailed \\
\hline 1 & ROA & 0.01950 & 0.004950 & 0.01358 & 0.012809 & -0.619 & 0.553 \\
\hline 2 & $\mathrm{ROE}$ & 0.09100 & 0.050912 & 0.08814 & 0.224722 & -0.017 & 0.987 \\
\hline 3 & PER & 0.13900 & 0.029698 & 0.08590 & 0.131828 & -0.543 & 0.602 \\
\hline 4 & ROD & 0.01050 & 0.002121 & 0.01121 & 0.014612 & 0.066 & 0.949 \\
\hline 5 & CDR & 0.26000 & 0.014142 & 0.22249 & 0.166820 & -0.627 & 0.550 \\
\hline 6 & LDR & 0.75400 & 0.072125 & 0.52700 & 0.285893 & -2.005 & 0.082 \\
\hline 7 & CR & 2.68800 & 0.500632 & 1.00812 & 0.624952 & -3.479 & 0.008 \\
\hline 8 & CAR & 0.25200 & 0.063640 & 0.31782 & 0.150793 & 0.583 & 0.576 \\
\hline 9 & DER & 7.49600 & 4.020609 & 10.25879 & 3.159859 & 1.066 & 0.318 \\
\hline 10 & DTAR & 0.85950 & 0.085560 & 0.90928 & 0.052893 & 1.086 & 0.309 \\
\hline 11 & EM & 9.79700 & 3.901815 & 26.40441 & 24.730288 & 0.906 & 0.391 \\
\hline 12 & $\mathrm{AU}$ & 0.01500 & 0.001414 & 0.01265 & 0.010690 & -0.297 & 0.774 \\
\hline 13 & $\mathrm{OE}$ & 0.87850 & 0.006364 & 0.90335 & 0.090141 & 0.373 & 0.719 \\
\hline
\end{tabular}

Table 7. Financial Performance Comparison after Fatwa (2004-2005)

\begin{tabular}{|l|l|l|l|l|l|l|l|}
\hline & \multicolumn{3}{|l|}{ Islamic Bank } & \multicolumn{2}{l}{ Conventional Bank } & Stg. \\
No. & Ratios & Mean & $\begin{array}{l}\text { Std. } \\
\text { Deviation }\end{array}$ & Mean & $\begin{array}{l}\text { Std. } \\
\text { Deviation } \\
\text { Tailed }\end{array}$ & & \\
\hline 1 & ROA & 0.02250 & 0.000707 & 0.02025 & 0.009161 & -0.332 & 0.748 \\
\hline 2 & ROE & 0.17500 & 0.012728 & 0.25288 & 0.190618 & 0.552 & 0.596 \\
\hline 3 & PER & 0.08950 & 0.036062 & 0.25313 & 0.114554 & 1.918 & 0.091 \\
\hline 4 & ROD & 0.01800 & 0.001414 & 0.02200 & 0.011988 & 0.451 & 0.664 \\
\hline 5 & CDR & 0.20450 & 0.021920 & 0.21588 & 0.091381 & 0.317 & 0.759 \\
\hline 6 & LDR & 0.87700 & 0.001414 & 0.60063 & 0.216542 & -3.610 & 0.009 \\
\hline 7 & CR & 1.7155 & 0.8053 & 1.0815 & 0.67039 & -1.164 & 0.278 \\
\hline 8 & CAR & 0.43800 & 0.069296 & 0.25200 & 0.098785 & -2.461 & 0.039 \\
\hline 9 & DER & 11.67200 & 0.178191 & 8.24463 & 2.953099 & -1.569 & 0.155 \\
\hline 10 & DTAR & 0.91900 & 0.004243 & 0.79138 & 0.190851 & -.904 & 0.392 \\
\hline 11 & EM & 19.16050 & 2.781051 & 33.91500 & 27.753091 & 0.718 & 0.493 \\
\hline 12 & AU & 19.16050 & 0.000707 & 0.02100 & 0.011735 & 0.288 & 0.781 \\
\hline 13 & OE & 0.80650 & 0.044548 & 0.80463 & 0.105503 & -0.024 & 0.982 \\
\hline
\end{tabular}




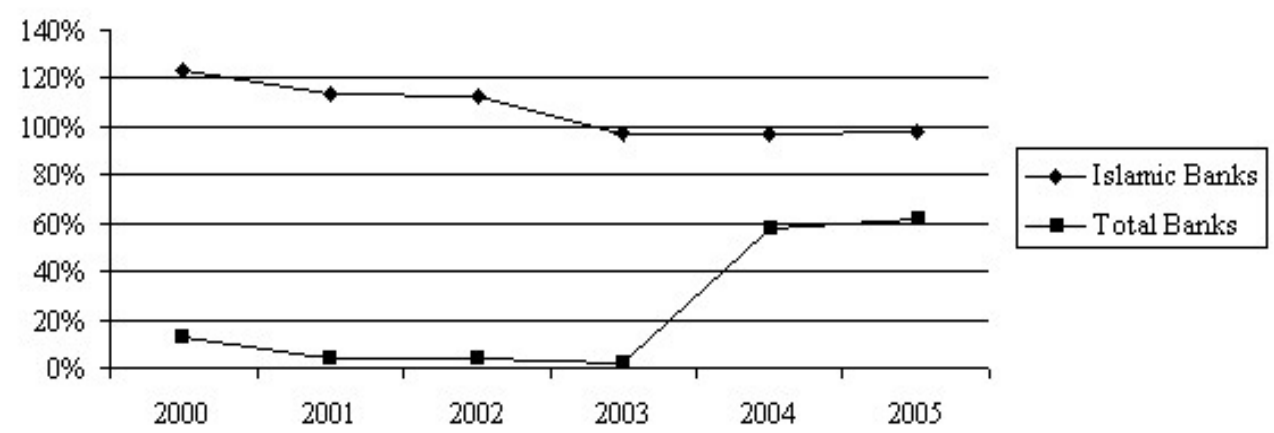

Figure 1. The Growth of LDR 2000-2005

Source: Indonesia Central Bank (2006)

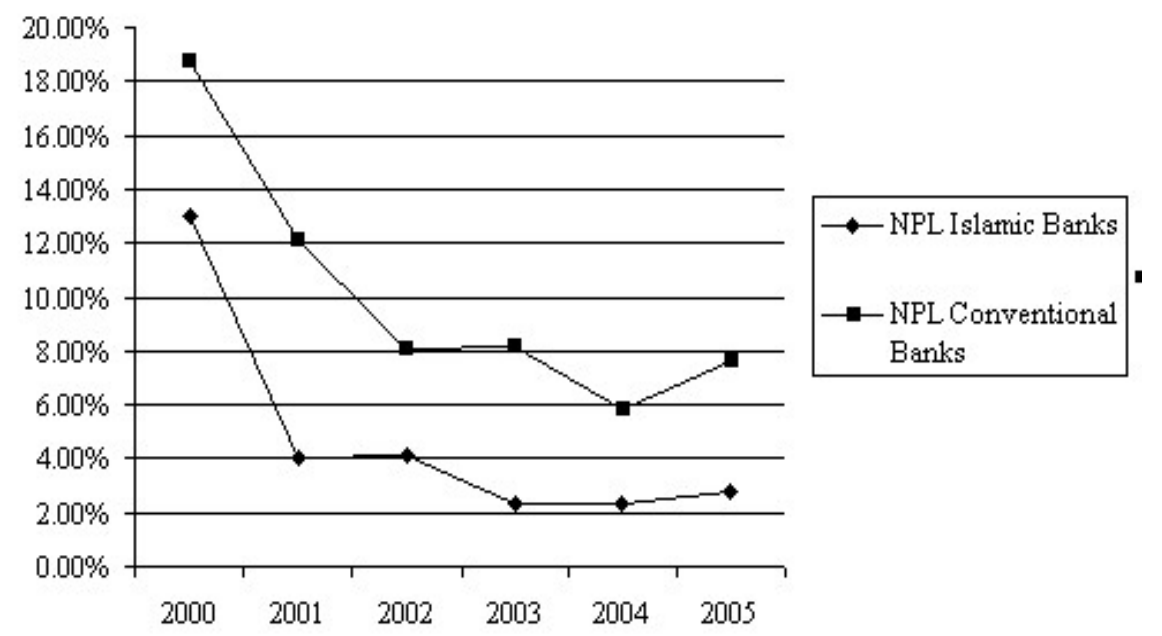

Figure 2. NPL 2000-2005

Source: Indonesia Central Bank (2006) 


\title{
Research on Evolving of Green Products' Attribute
}

\author{
for Manufacturing Industry
}

\author{
Xin Wen (Corresponding author) \\ School of Business Administration, Northeastern University, Shenyang 110004, China \\ School of Management, Shenyang University of Technology, Shenyang 110023, China \\ Tel: 86-24-8367-4510 E-mail: wenxin9901@126.com \\ Jian Xu \& Qingshan Zhang \\ School of Management, Shenyang University of Technology, Shenyang 110023, China
}

\begin{abstract}
Green manufacturing is a key technology to realize eco-industry and sustainable development, it is causing people's great attention. The implementation of green manufacturing has produced revolutionary influence on the products of the manufacturing industry and manufacturing industry. Through analyzing and researching historical evolvement of product attribute, this thesis summarizes the evolving law of product attribute, and indicates developing trends of manufacturing industry green products.
\end{abstract}

Keywords: Green manufacturing, Green products, Product attribute, Evolvement

\section{Introduction}

Manufacturing industry, on one hand, it is the main industry to create the mankind wealth, on the other hand it brings very serious problems on the resource waste and the effect to the environment. In 1992, the environment of United Nations and the development meeting (UNCED) makes a worldwide plan on realizing the development of the mankind society economic and the resource environment, and proposes a new method of continuing development. In order to adapt to the demand of the continuing development of the mankind society, how to use the resource as much as possible and produce waste as little as possible will become the problem that is concerned by the government, manufacturing enterprise and the academe. Thus, a complete new concept - Green Manufacturing,GM generates. And it will soon be researched around the world, especially in some developed countries.

The influence to the product exploitation in the manufacturing enterprise by implementing the Green Manufacturing is essential and evolutionary, it demands the enterprise to consider not only the economic profit, but the profit to the society (including the environmental profit, the continuing developmental profit, etc). While the product in the manufacturing industry appears the friendship to the environment, and generates the active effect, we calls it green products. The attribute of the product changes a lot from the traditional industrial product to the green product in the manufacturing industry. The attribute of the product in different periods can reflect the characteristic and the function of the product in the manufacturing industry, find out the different regulate during the evolutionary process of the product attribute, it is meaningful to the evaluation of the green product. This paper mainly does some research on the evolvement process of the green product attribute, finds out the evolutionary regulate of the product attribute, and makes the prediction on the evolutionary trend of the product attribute.

\section{Historical Evolvement of Product Attribute}

Product attribute is a characteristic that product can satisfy buyers' requirement. The good and bad of a product attribute is a key factors of attracting buyer and occupying market. Product attribute mainly incarnate on the requirement and the interrelated outside environment of products, the change of requirement and environment will lead to the change of product characteristic, the product characteristic direct correlation to main competition factors of markets, and the change of the main competition factors will lead to the change of manufacturing methods. Therefore, this thesis mainly does some research on the evolvement of product attribute by the time order and on the clue of changing of requirement and environment, product characteristic, typical manufacturing mode and main competition factors.

Product attribute begins to changing about the entrance of twenty century, and its evolvement process mainly includes six stages, see Table 1 . 
From Tab.1, we can conclude that the products' typical manufacturing mode is mass production before the fifties of the20th century, at the time, products' demanding exceeds supplying, the market belongs to sellers', products incarnate economy attribute. From the fifties of the20th century, the products' typical manufacturing mode has experienced the first transition, until the mid-term of nineties, it has experienced Lean Production, Agile Manufacturing and Mass Customization. In this stage, products' supplying exceeds demanding, the market belongs to buyers', products incarnate economy and technology attribute. From the mid-term of nineties of the20th century, the products' typical manufacturing mode is experiencing the second transition, this is a new overfly, in this stage, the requirement of the buyers are more rational, and demand that the products' manufacturing, using and recycling obtain harmonious developing of human and nature.

Green manufacturing demands green products. Green products of manufacturing industry are differ from traditional products, see table.2. From sustainable development, environmental ethic, environmental consciousness design and technology mode, the exploiture of green products should bring environmental protection and 'environmental problem' into all aspects of products and their exploiture manufacturing, then make them into interior and core, in other words, products not only demand anciently stressed the attribute of economy and technology, but green nature(Table2).

\section{The Evolving Law of Product Attribute}

\subsection{From the chronological order, the change of the product attribute in the manufacturing industry becomes faster and} faster.

The 1 st evolution takes about 50 years, the 2 nd takes about 20 years, while the 4 th and the 5 th take only about $4-5$ years. The speed of evolution of the product attribute accelerates mainly because the development of the science improvement, the complex of the producing process, and the information technology becomes an important factor of the productivity.

3.2 From the production mode, the production of the manufacturing industry mainly trend to the production based on the technology.

From handwork to mass production, there are the division the work of physical work and brainwork during the labourers. In the LP, the labourer require many skills.In the CIM, there are come forth the sciential workers, the workers mainly depend on knowledge and handle skills, their physical force is subordination. In the AM, Mass Customization and GM, the sciential workers gradually increasing and become main body, the division gradually disappearing, every people will deal with brainwork, let roboticized machine to deal with physical work.

3.3 From the main competitive factor, at different times, the extent of influence that they demand the product and service is different, and changes with the increasing of the consumer's consumption level.

From the Fig.1, we can get the idea: at first, the price is the main competitive factor, and then to the quality, kinds, time, credit, environmental protection in the end, and we can get from Tab.1 and Fig.1, under different competitive factor, the product's attribute is different, from the economic attribute to both economic attribute and technologic attribute, and even more, including the environmental attribute, resource attribute, energy attribute and social attribute.

3.4 From the product characteristic, products first are from singleness, reiteration to diversification, then trend to individuation, their parts' modularization.

From no serving to beginning to emphasize serving, then trend to Characteristic serving including no-used and treated. Therefore, now manufacturing enterprise not only pay attention to the course of products' manufacture, but to the course of products' rejection, recycling, disposing and reuse, this is also nowadays what we called 'product life-cycle' and 'product multi-life-cycle'.

3.5 From the requirement of products, the consumers' requirement is from the basic 'have' to 'have', then to various requirement, in time and exact and cleanness, low pollution.

This show the consumers' requirement more sense, and products' manufacturing and use not only satisfy consumer and enterprise, but society, environment and sustainable development.

In a word, the development and evolvement of manufacturing and its products attribute have strong disciplinarian, the content of products attribute are also gradually enrichment and plenary. On the base of above, we can conclude that the evolving trend of green product attribute.

\section{Developing Trends of Green Products Attribute}

The evolving of products attribute is more close relation to the change of manufacturing mode. The mode experienced a series of development and change, become GM. GM is differ from traditional mode, it is a sustainable development mode of modern manufacturing, and it is a modern manufacturing mode considering synthetically the effect to the environment and the efficiency of the resource, and its goal is to make the smallest bad effect to the environment, the highest efficiency of the resource. GM is more important to intending manufacturing, many scholars at home and abroad have researched on GM in recent years, summarizing current researching, we can conclude the developing 
trends of GM, it is globalization, socialization, integration, parallelization, intelligence, informatization.

To sum up the historical evolvement and evolving law of products attribute, and the development trend of GM, we can conclude the development trend of products attribute:

\subsection{The manufacturing technology of products will become more advanced.}

Green products emphasize on analyzing problem from entire life circulation, therefore, its advanced technology mainly incarnate on the progress of every technology, the progress of function and using nature, the technology's progress of recycling and reusing.

\subsection{The range of green will become more extensive.}

The green is the base of carrying out correspond sustainable development of economy, environment and society. Therefore, the green nature of intending product not only incarnate on the last product, but every stage of manufacturing course, use, recycling and reusing.

\subsection{The range of economy will become more wide.}

From the view of life circulation, the economy not only can reflect all characteristic of product life circulation, it mainly include the cost of product life circulation, benefit from life circulation. The cost of green products is charged with enterprise, user and society, its benefits is also shared by this three aspects.

\subsection{The life-cycle and multi-life-cycle nature of product will gradually become strengthen.}

Because the 'green' of green products incarnate on every stage of life-cycle, green products life-cycle is differ from anciently descriptive, it is refer to all time from requirement identifying, exploitation design to recycling. But products multi-life-cycle include the time of current life-cycle, and also include the time of its parts' disusing and rebirth using after current product discarding or no-using. Therefore, green products demand synthesize considering environmental effect, synthesize utilizing resource, product life-cycle and recycling time.

\section{Conclusion}

The view of continuing development and green manufacturing mode has been accepted by many governments and the society widely, and the research and the implementation appears the trend of more and more international and law, it has formed a irreversible social power which challenges to the traditional manufacturing industry, it now affects and change the trend of the market. Currently, a coherent prospect at home and abroad is that the manufacturing industry in the future should be the one that could protect the environment; green manufacturing is the choice to implement the manufacturing mold of continuing development, the development and design of the green product should be the regulation in the enterprise, the coming product should all come into the green series.

\section{References}

Chen Rongqiu, Zhou Shuiyin. The theoretic and practice of manufacture management[M]. Beijing: Renmin university of China press, 2002.

David F, Criambrone, Boca R. Environment life cycle analysis[M]. New York: Lewis Publishers, 1997.

F Liu, X H Chen, J Liang. The Materials and Energy Flowing Model of Manufacturing Systems[J]. China Mechanical Engineering, 1997, 8(4): 78-80.

F Liu, Z J Xu, B Dan, etal. The Implement and Characteristics of the Energy in Manufacturing Systems[M]. Beijing: China Machine Press, 1995.

Henrik W, Micheal H, Leo A. Environment assessment of products[M]. London: Chapman Hall, 1998.

Lars Hvam. A procedure for building product models[J]. Robotics and Computer-Integrated Manufacturing 1999(15): 77-87.

Melnyk S A, Smith R T. Green Manufacturing. Society of Manufacturing Engineers[R], USA, 1996:1-25.

Veikko J., Pohjola, Paivi Rousou. Using holistic product models to describe industrial production[J]. Resources. Conservation and Recycling, 2002(35): 31-43.

X.Y. Xu, Y.Y. Wang. Multi-model technology and its application in the integration of CAD/CAM/CAE J]. Journal of Materials Processing Technology, 2002(129): 563-567. 
Table 1. Historical Evolvement of Product Attribute

\begin{tabular}{|c|c|c|c|c|c|}
\hline No & Time & $\begin{array}{l}\text { Requirement and } \\
\text { Environment }\end{array}$ & $\begin{array}{l}\text { Product } \\
\text { Characteristic }\end{array}$ & $\begin{array}{l}\text { Typical } \\
\text { Manufacturing } \\
\text { Mode }\end{array}$ & $\begin{array}{l}\text { Main } \\
\text { Competition } \\
\text { Factors }\end{array}$ \\
\hline 1 & $\begin{array}{l}\text { From the } \\
\text { beginning of the } \\
20^{\text {th }} \text { century }\end{array}$ & $\begin{array}{l}\text { Mass Requirement, } \\
\text { Solving the } \\
\text { problem of 'have' }\end{array}$ & $\begin{array}{l}\text { Singleness, } \\
\text { reiteration }\end{array}$ & Mass Production & Price \\
\hline 2 & $\begin{array}{l}\text { From the fifties of } \\
\text { the } 20^{\text {th }} \text { century }\end{array}$ & $\begin{array}{l}\text { Solving the } \\
\text { problem of 'good' }\end{array}$ & $\begin{array}{l}\text { Many models } \\
\text { Standard, } \\
\text { beginning to stress } \\
\text { serving }\end{array}$ & $\begin{array}{l}\text { Lean } \\
\text { Production(LP) }\end{array}$ & Quality \\
\hline 3 & $\begin{array}{l}\text { Fromthe seventies } \\
\text { of the } 20^{\text {th }} \text { century }\end{array}$ & $\begin{array}{l}\text { Various } \\
\text { requirement }\end{array}$ & $\begin{array}{l}\text { Many varieties } \\
\text { small batch } \\
\text { products and } \\
\text { serving, low } \\
\text { repetition }\end{array}$ & $\begin{array}{l}\text { Computer } \\
\text { Integrated } \\
\text { Manufacturing(CI } \\
\text { M) }\end{array}$ & Variety \\
\hline 4 & $\begin{array}{l}\text { From the mid-term } \\
\text { of eighties of } \\
\text { the } 20^{\text {th }} \text { century }\end{array}$ & $\begin{array}{l}\text { The requirement of } \\
\text { in time, nicety }\end{array}$ & $\begin{array}{l}\text { Manufacturing } \\
\text { each model, no } \\
\text { repetition }\end{array}$ & $\begin{array}{l}\text { Agile } \\
\text { Manufacturing(A } \\
\text { M) }\end{array}$ & Time \\
\hline 5 & $\begin{array}{l}\text { From the } \\
\text { beginning of the } \\
\text { nineties of the } 20^{\text {th }} \\
\text { century }\end{array}$ & $\begin{array}{l}\text { Characteristic } \\
\text { requirement }\end{array}$ & $\begin{array}{l}\text { Characteristic } \\
\text { manufacturing and } \\
\text { serving, standard } \\
\text { module }\end{array}$ & $\begin{array}{l}\text { Mass } \\
\text { Customization }\end{array}$ & Credit \\
\hline 6 & $\begin{array}{l}\text { From the mid-term } \\
\text { of nineties of } \\
\text { the } 20^{\text {th }} \text { century }\end{array}$ & $\begin{array}{l}\text { Cleanness, low } \\
\text { pollution }\end{array}$ & $\begin{array}{l}\text { Characteristic } \\
\text { manufacturing and } \\
\text { serving including } \\
\text { rejection and } \\
\text { treated }\end{array}$ & $\begin{array}{l}\text { Green } \\
\text { Manufacturing }(\mathrm{G} \\
\text { M) }\end{array}$ & $\begin{array}{l}\text { Environmental } \\
\text { protection }\end{array}$ \\
\hline
\end{tabular}

Table 2. The Difference of Traditional and Green Products

\begin{tabular}{|l|l|}
\hline Traditional Products & Green Products \\
\hline $\begin{array}{l}\text { Possess the attribute of basic and } \\
\text { economy }\end{array}$ & $\begin{array}{l}\text { Possess the attribute of basic, economy, technology, } \\
\text { environment, resource, energy and society }\end{array}$ \\
\hline $\begin{array}{l}\text { Competitive advantage from Time, } \\
\text { Quality, Cost, Serving }\end{array}$ & $\begin{array}{l}\text { Competitive advantage from green nature advantage } \\
\text { on the base of TQCS }\end{array}$ \\
\hline The nature of economy and technology & The nature of economy, technology, green, life-cycle \\
\hline $\begin{array}{l}\text { A 'solution' of including physical } \\
\text { products and serving }\end{array}$ & $\begin{array}{l}\text { An integrated 'solution' of including physical } \\
\text { products, serving and recycling }\end{array}$ \\
\hline Satisfy buyers & Satisfy all aspects of buyers, environment and society \\
\hline Meet current requirement & Meet current and coming requirement \\
\hline
\end{tabular}




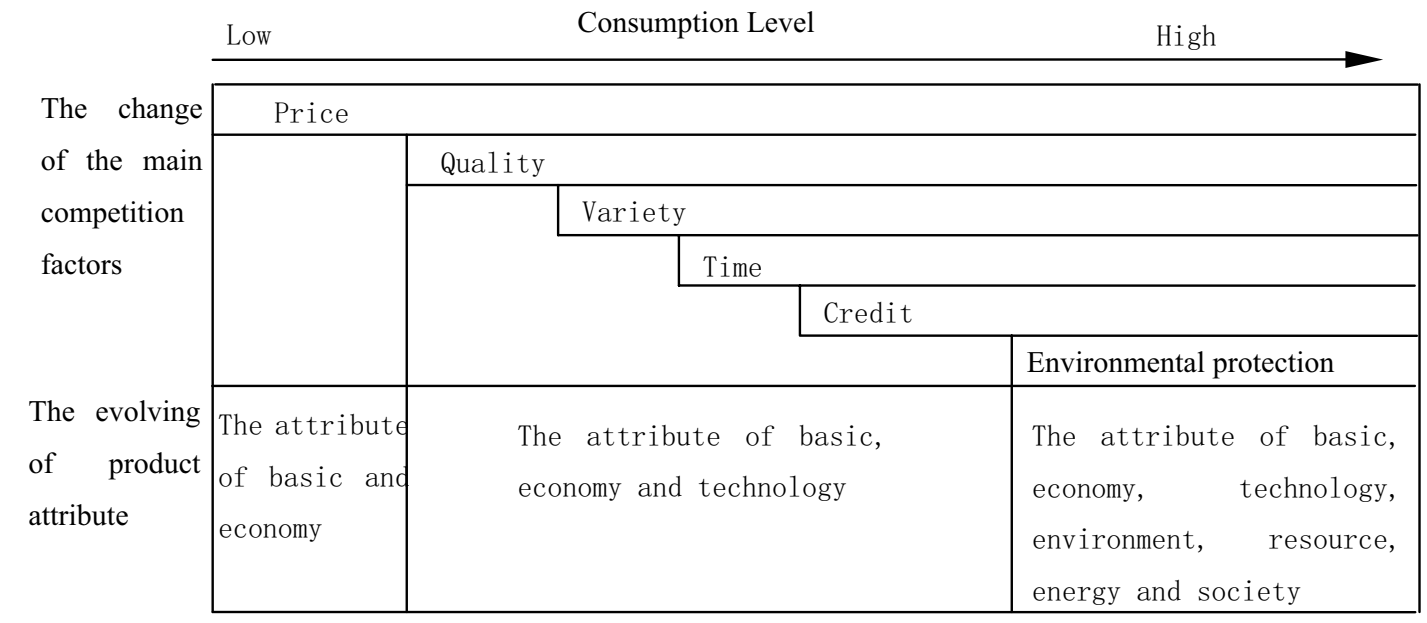

Figure 1. The relation to the change of the main competition factors

and the evolving of product attribute 


\title{
Webs of Culture: Applying InterculturalCommunication Theory to Understand Distributed Decision-Making Processes
}

\author{
Norhayati Zakaria \\ Room 387, Department of International Business, College of Business \\ Universiti Utara Malaysia, Sintok 06010, Kedah, Malaysia \\ Tel: 60-4-928-6540Ｅ-mail: yati@uum.edu.my \\ Derrick Cogburn \\ 232 Hinds Hall, School of Information Studies \\ Syracuse, New York 13104, USA \\ Tel: 1-315-443-5541_E-mail: dcogburn@syr.edu
}

\begin{abstract}
The overarching research question in this paper is: What is the influence of high-versus-low context cultural orientations on effective participation in globally distributed collaboration using email? Two subsidiary research questions follow: (1) What discernable patterns of cultural variation are evident in the email messages, and (2) What is the effect of cultural variation on the contribution of Civil Society during the following stages of the decision-making process: (a) problem identification, (b) proposal making and generation of ideas, (c) response to ideas and deliberation, and (d) solution. To answer these questions, we will apply Edward Hall's (1976) intercultural communication theory as the primary lens. Specifically, we will employ a cultural dimension called "context" which explains the variations in terms of high-context-versus-low context. Other literature in this domain will also be used to explore the various aspects of cultural impacts.

The main objective of this paper is to propose a research design that uses content analysis to look at the World Summit on Information Society (WSIS) public archival email messages. From this source material, we will apply intercultural communication theory in order to provide descriptive statistical analysis and in-depth descriptions for each of the decision-making stages described above, from a cultural stance. At the completion of this study, we hope to be able to demonstrate specific impacts that high context and low context cultural backgrounds have on globally distributed collaboration, and to suggest some fertile areas for future research such as how to minimize the different cultures' drawbacks and maximize their positive advantages to facilitate globally distributed collaboration.
\end{abstract}

Keywords: Cultural values, High context, Low context, Intercultural communication, Distributed decision making, Globally distributed collaboration collaboration

\section{Introduction}

The ability to manage globally distributed collaboration has become crucial as multinational corporations increase their reliance on global virtual teams. Rapid globalization and the advancement of computer mediated communication (CMC) technology entail greater efforts on managing globally distributed collaboration across the world. Virtual collaboration often takes place through CMC technologies, many of which rely heavily on the Internet, and complex information systems (Kanawattanachai \& Yoo, 2002; Solomon, 2001). Computer mediated communication technology (CMC) is defined as the process whereby messages are electronically transmitted from senders to receivers in both asynchronous [e.g. email, discussion forums, etc.] and synchronous settings [e.g. internet relay chat, videoconferencing, etc.] (Elton, 1982; Olaniran, 1994). For example these may be teams in Japan and teams in Germany collaborating on a 12-week software development project with teams in Malaysia, or information communication technology (ICT) policy experts in the USA presenting a proposal and negotiating an alternative solution with experts in Africa and Korea. The advantage of this new form of collaboration is that it provides opportunities for people to work with anyone, anywhere, and any time.

Globally distributed collaboration also demands managing intercultural communication, defined as interaction between people of diverse cultural backgrounds with distinct communication patterns, preferences, and styles (Novinger, 2001; Gudykunst, 1998). On the one hand, CMC allows people to communicate and collaborate unrestricted by barriers of 
time and space. On the other hand, cultural barriers stemming from different managerial aspects and communication styles may adversely affect various elements of collaboration such as negotiations, deliberation of ideas, self-disclosure, conflict resolution, coordination, and so on (Thorne, 2003). Potential culture-related management problem areas include overcoming high anxiety and uncertainty of feelings (Gudykunst, 1997), managing conflicting and frustrating situations (Adler, 2002), saving face in confrontational situations (Ting-Toomey, 1997), making effective group decisions (Oetzel, 2005), using language and non-verbal communication (Lim, 2003; Tayeb, 2002), and adjusting to and acculturating in a new environment (Kim, 1990).

With the range of cultural values, managing this new form of collaboration and communication in a distributed environment using $\mathrm{CMC}$ becomes more challenging and intensified. The use of CMC between people with different cultural values can either facilitate or impede collaboration and communication (Amant, 2002; Olaniran, 2001). Early scholars of CMC suggested that it is ineffective in several areas [e.g. establishing online relationships, producing effective communication, and expressing oneself or receiving feedback] due to the absence of contextual, visual, and aural cues (Daft \& Lengel, 1984; Kiesler, Siegal, \& McGuire, 1984). For example, electronic mail (email) is referred to as a "lean media" because it relies purely on textual elements. For people whose intercultural communication styles rely heavily on non-verbal or paralinguistic cues (tone of voice, facial expressions, body movements, and gestures) to interpret the information they receive, lean media may pose a significant barrier to effective communication.

However, later views of CMC challenged the notion of reduced social cues (Joinson, 2001; Lea \& Spears, 1991; Walther, 1992, 1996). They argued that lean media actually encourage participation by providing anonymity, removing the need for socially accepted responses in expressing opinions and maintaining identity, increasing the ability to control information about oneself, and offering a more liberated self-disclosure. People whose intercultural communication style relies on non-verbal cues to interpret meanings normally dislike confrontation. When expressing their opinions, they prefer a harmonious and friendly atmosphere in order to save face and avoid humiliation or insulting situations (Ting-Toomey, 1997). However, very few studies have investigated whether CMC would provide such individuals a comfortable way to be expressive and opinionated (Olaniran, 2001). On the other end of the spectrum, people whose intercultural communication style values verbal communication feels comfortable using email because it is consistent with their normal patterns of communication. They would readily use words to express their feelings and opinions in this textual-based medium. Again, this perspective has not been adequately addressed in the study of culture and use of CMC (Olaniran, 2001; Shachaf, 2005).

Several empirical studies were conducted to understand the effect of culture on globally distributed collaboration, yet there are still deficiencies and inconsistencies in their findings, which this paper attempts to address (Cogburn \& Levinson, 2003; Jarvenpaa \& Leidner, 1998; Maznevski \& Chudoba, 2002; Shachaf, 2005). The unresolved question therefore is how does culture impacts effective participation when people use CMC technologies to collaborate in a distributed environment? The purpose of this study is to explore the impact of culture on effective participation (in the form of email) of civil society in the United Nation World Summit on Information Society (WSIS). Civil society includes non-governmental and non-profit organizations, networks, and voluntary associations. In this study, individuals who belong to the abovementioned entities are considered members of civil society, and they can participate in WSIS as long as the United Nation accredits the organizations they belong to. Participation hence requires no membership fees.

Therefore, this proposed study takes a "high-versus-low context" theoretical framework (Hall, 1976) as well as other related cultural dimensions useful for understanding cultural differences inherent in managerial issues such as divergent communication styles, conflicts arising from deliberation, and distinct decision-making strategies pertaining to CMC use. Effective participation is defined as when individual(civil society members) are making significant contributions in the following stages of decision-making process - (a) problem identification, (b) proposal making and generation of ideas, (c) response to ideas and deliberation, and (d) solution. The significance of this study is thus to explore and describe the cultural factors that influence the participation of civil society members when they collaborate using email and whether different cultural orientations give rise to different communicative behaviors, and thus impacting an individual's contributions (e.g. whether a person becomes less or more effective in their participation).

In this regard, we will be looking at the cultural variations such as communication styles, individualism vs. collectivism, and task vs. relationship orientation when people engage in the decision-making process. From Hall's theoretical lens and literature support, people that employ high context communication style have different style of making proposal as opposed to people that employ low context communication style. Moreover, the way people present their proposal can also influence the response they generate. Subsequently, the behavior can also influence whether or not the proposal can achieve a consensus that leads to a solution (s) within the participating members.

Substantial empirical research in cross-cultural management and intercultural communication literature has established that numerous challenges arise when people of different cultures collaborate and communicate at an interpersonal level (Adler, 2002; Ting-Toomey, 2005). In a similar vein, CMC literature has also studied the effects and characteristics of technology that facilitate or hinder communication (Daft \& Lengel; 1986, Kiesler \& Sproull, 1986; Walther, 1996). 
However, little empirical research has attempted to bridge these three areas-intercultural communication and cross-cultural management, and CMC (Amant, 2003; Olaniran, 2001).

Several other deficiencies also exist in the empirical studies regarding the impact of culture on communicative behaviors of globally distributed collaboration such as: (1) the few empirical studies that exist have not provided consistent findings or offered definite answers regarding cultural impacts, (2) the effects of different behavioral patterns arising from the presence of diverse cultural values were insufficiently explored or described, and (3) the application of cultural theories to explain the cultural effects on globally distributed collaboration is fairly limited (Cogburn \& Levinson, 2003; Evaristo, 2003; Jarvenpaa \& Leidner, 1999; Massey, Montoya-Weiss, Hung \& Ramesh, 2001; Shachaf, 2005; Thorne, 2003). Yet, the growth of globalization and the increasing use of CMC demand a greater understanding in order to manage globally distributed collaboration, a research gap that will be explored and understood in this study.

Based on the abovementioned literatures, there are some inconsistent results on the impacts of culture when people with different cultural values participate in a globally distributed collaborative environment.

Therefore, the grand tour research question proposed for this study is:

What is the influence of high-context versus low-context cultural orientations on effective participation in distributed collaboration using email?

Specifically:

RQ1. Are there discernable patterns of cultural variations evident in the email messages? If so, what are they and when do they become evident?

RQ2. How do cultural variations appear to impact the contribution of Civil Society members during the following stages of the decision-making process:
a. Problem identification;
b. Proposal making and generation of ideas;
c. Response to ideas and deliberation;
d. Solution.

\section{Cultural Conceptual Framework}

This paper examines a 'globally distributed collaboration' phenomenon (see Figure 1), exemplified in the WSIS event where civil society members from all over the world collaborate on agenda and issues regarding the global information society. Cogburn (2005) established that civil society members used email as their primary means of collaboration when participating in WSIS. Therefore, this study focuses simply on email participation and does not consider other CMC tools such as blogs or wiki webs, or face-to-face meetings. The meetings, however, are important to the direction of civil society. Effective participation in WSIS will be measured by individual's contributions made by a civil society member during the decision-making process. The decision-making process focuses on four stages: (a) problem identification, (b) proposal making and idea generations, (c) response to the ideas or deliberation, and (d) solution. Based on the stages, we will investigate the communicative behaviors from two distinct cultural orientations, high context and low context. For example, an individual may contribute in the four stages differently depending on whether he or she is high context or low context.

The descriptions of the decision-making process can be illustrated in four stages. The first stage involves the identification of problem. It is crucial for members to identify and recognize the issues or problems that they want to solve or bring into attention in WSIS. This is the initial step in decision-making process. The second stage is called proposal making, which centers on the ability of a civil society member to make proposal by giving or generating ideas, and presenting a position on the problems identified or putting across self-interest issues. In public policy making processes, Kingdon (1995) termed this stage as 'agenda setting.' The third stage is called response to ideas or reactions (supportive or contentious), and deliberation. This stage is also known as 'specification of alternatives' where people can choose from range of options (Kingdon, 1995, Adler, 2002). The final stage is called solution (one or many or non-solution), in which the decisions are made either by consensus or by authoritative action. Nonetheless, it is noteworthy to mention that success in one of this stage is not an indicative of success in others. In addition, the stages are not necessarily occurring in a linear fashion. Some or all of the stages are iterative and interdependent and may occur several times before solution is reached and/or agreed upon by members. Likewise, some stages can also be left out. The main outcome for effectiveness is that member can reach a solution that addresses the problem as well as corresponding to the proposal made and responses generated.

On the contrary, there are three instances where participation can be considered ineffective (not the focus of this study):

a) First, when a member fails to identify a problem. Without identification, proposal may not be concrete when in search of a solution. 
b) Second, even though a person may already identify a problem, and then initiate a proposal, if the proposal is not convincing or attractive enough, the proposal may not generate any responses from members. Subsequently, the proposal may just be ideas without further actions.

c) Third, even though the proposal was heard, argued, and deliberated, yet at times it may fail to generate solutions that are in consensus or no solution was achieved at the end.

Phase One of WSIS generated two documents, a Declaration of Principles and Plan of Action. However, this study does not attempt to look at the impact of culture on WSIS outcomes. Rather, this study will focus on the effect of culture on the dynamics of communicative behaviors using email (as pointed out in the circle area of Figure 1.0). The internal dynamics within this collaboration will provide evidence of the two cultural variations (high context and low context). This study is expected to: (1) enumerate implications for civil society effectiveness in this policy formation process, and (2) demonstrate whether or not culture impacts individuals' participation when they use email as their communication mode and how does it impact their participation.

\section{High-Versus-Low Context Theoretical Lens}

Edward Hall's (1976) theory provides the lens through which we will examine intercultural online communication. This theory provides a concrete explanation for communication complexities as well as collaborative behaviors that are based on cultural values. Hall introduces a cultural dimension called context, a continuous spectrum, which illustrates the degree to which a person pays attention to non-verbal cues in a communicative situation. High context culture emphasizes settings or the environment (i.e. context), while low context culture emphasizes words or content.

Hall realized that everyday communication could cause information overload, which he defines as "...a situation in which the system breaks down when it cannot properly handle the huge volume of information to which it is subjected" (p.85). Context plays an important role in minimizing information overload allowing an individual to select what to pay attention to and what to ignore. Contexting involves two completely different but interrelated processes (Hall, 1976). It involves the inside of a person (a person's brain, experience, and structure of the nervous system) or external such as the situation or environment that an event occurs or a person is in. Contexting is thus a process and a strategy by which an individual evaluates the amount and level of information to obtain from or provide to another person when communicating. Understanding the process of "contexting" also aids in overcoming or minimizing cultural differences. Communication problems often arise when individuals define, interpret, understand, and communicate information differently.

This problem is exacerbated between people with different cultural values: what is considered useful, meaningful, and worth communicating among individuals in one culture may not be considered so by people from another culture. Individuals from diverse cultures have different communicative behaviors. Everyday communication decisions such as language use and word choice, why (or whether) a person says what he wants to say, and when and to whom he says it thus become significant aspects to investigate. In short, these decisions illustrate the process of contexting, a strategic behavior in which a person screens out irrelevant information in order to avoid information overload (Hall, 1976).

The process of contexting thus hinges upon an individual's culturally imbued characteristics (Chen \& Starosta, 1998). In his earliest book, Silent Language (1959), Hall argued that the language of behavior is far more important than linguistic code. This silent language is the contextual code, which carries varying meanings. People from different cultures have different ways of interpreting meanings of the messages or information they receive (Chen \& Starosta, 1998; Gudykunst, 1997; Hall, 1976; Ting-Toomey, 1997); therefore, different communication practices and preferences can result in miscommunication, misunderstanding, and misinterpretation among people with conflicting or mismatched cultural values.

Hall's classic theory lays the foundation for many other later cultural theories (for example, Hofstede, 1980; Glenn, 1981; Trompenaars, 1994; Gudykunst et al., 1997). It is useful to note that Hall's theory provides one explanatory perspective for understanding communicative behaviors in globally distributed collaboration - that is a cultural perspective. There are other alternative ways of explaining online communicative behaviors (e.g. leadership, technology, trust, coordination, etc.), all of which provide potential areas for future research though they are not the focus of this study.

\section{Methodology: Content Analysis of Archival E-mail Messages}

We propose to use content analysis as the primary research methodology. Content analysis is recognized as an effective research tool for studying recorded human communications (Krippendorf, 2004, Babbie, 2004). Through content analysis, this study attempts to decode information like “... who says what, to whom, why, how, and with what effect?" (Babbie, 2004, p.314). Content analysis is an unobtrusive research technique and well suited for understanding human intercultural communication because the data is used as it occurs in its most naturalistic setting, thus facilitating external validity. This study uses a deductive analytic framework to analyze the data. 


\subsection{Research Context: Civil Society Participation in WSIS}

World Summit on Information Society (WSIS) is an international conference sponsored by the United Nations (UN) and organized by International Telecommunication Union (ITU) with two-phase events-WSIS I in Geneva, 2003, and WSIS II in Tunisia, 2005.WSIS specifically addresses issues relating to information communication technology (ICT) policy-making processes in influencing and shaping global governance outcomes. WSIS may occur in only a few days, but the preparatory and follow-up processes occur over a period of years. Klein (2005) noted that the activities are most intense during the preparatory phase. Between 2001 and 2003, there were two series of meetings: preparatory meetings (prepcoms) and regional meetings. All the three prepcoms were held in Geneva at 6-month intervals. The regional meetings were carried out in various locations around the world but within a shorter time frame. All the meetings were set to gather input from around the world and to prepare the documents to be adopted in WSIS I.

Overall, the goal of WSIS is to develop a global ICT policy framework to deal with challenges posed by an information society (WSIS, 2003a; WSIS, 2003b). WSIS plays an important role as an avenue for global dialogue, discussion, and consensus building in the acceptance of norms, rules, principles, values and decision-making processes among multiple stakeholders (Klein, 2005). WSIS as a process attempts to encourage an inclusive and broad participation that consist of three main actors: government, private sector, and civil society.

In this study, we focus only on the participation of civil society members. Civil society participation in WSIS originates from several organic non-hierarchical structures (see Figure 2) such as (1) civil society plenary (CSP), (2) civil society bureau (CSB), (3) content and themes working group (C\&T), (4) 19 thematic caucuses and working groups, (5) civil society families, and (6) civil society division (CSD) of the secretariat (2005). Civil society members can contribute to and influence the outcome of WSIS (in the form of its two primary documents, the Declaration of Principles and Action Plan) in several ways:

- Developing positions and lobbying at the national level to feed into regional processes;

- Participating in regional conferences to develop regional consensus positions;

- Participating in international preparatory committee meetings (PrepComs) to develop global consensus positions;

- Proposing and influencing the language (content) of draft documents between on-site events via electronic submissions

The structure that we will focus on is the virtual civil society plenary which includes all civil society members that are registered on the email listserv. CSP is seen as the highest and most legitimate component of civil society. CSP approved the creation of virtual space not only to enhance member participation but also to ensure greater awareness and transparency among and between civil society members in the global governance process. This new structure was introduced in April 2003 by CSP after the PrepCom 2 meeting in Geneva. This virtual space is unique because this is the first time the participation of civil society is promoted at a distance. Furthermore, this online participation structure offers an appropriate research context for this study because of its dynamic process of collaboration within civil society members and the presence of strong elements of intercultural communication.

\subsection{Sources of Data}

The primary source of data for this study consists of the public archival email messages of the virtual civil society plenary. The data covers a 32 months period from April 2003 to November 2005. We will first analyze data from WSIS I, covering April 2003 to December 2003. We will then use the results to further analyze WSIS II, covering January 2004 to November 2005. Between these two phases of WSIS, many face-to-face preparatory conferences and regional meetings took place, which impacted member's email participation in the decision-making process. Although data for these interim meetings, such as what transpired in the meeting is available, it will not be included in this study. We will only use the dates of the face-to-face meetings as punctuations whereby to observe the patterns of email participation.

\subsection{Analytic Framework}

The archival email data will be imported into Atlas-TI version 5.0, a commercial computer assisted qualitative data analysis software (CAQDAS) package, used for content analysis. We will use a deductive coding scheme based on Hall's (1976) high-context and low-context theory and other supported cross-cultural literature (i.e Gudykunst et al., 1996; Triandis, 2002) (see Appendix 3). In this study, the unit of analysis is an individual message, and the coding unit is the sentence and paragraph within each individual message.

Beginning with data from WSIS I, several procedures of the content analysis will be carried out. We intend to first code the demographic information for each of the messages. This descriptive analysis will provide overall background information of the participants in terms of number of messages posted on the overall (based on monthly basis as well as based on individuals), name, email address, gender, language used, country, region, and organization name. Then, the member's participation when they contribute to the four-stage decision-making process (as illustrated in Figure 1.0) will 
be coded. We will isolate each member's contributions in four distinct areas - problem identification, proposal making and idea generations, response to ideas and deliberation, and solution. This analysis will further provide information such as the number of proposals made, types of proposals, overall frequency of proposals, sequence of proposals made in conjunction with face-to-face punctuations such as PrepComs, regional meetings, and summit events, and so on. Once the demographic and participation analysis were conducted, we will conduct a cross-tabulation analysis by looking at the correlation between demographic and proposal making activities. This analysis will generate numerical values such as of frequency of occurrence of the different coding categories.

The most critical analysis would be an exploration of the effect of culture on the participation as illustrated in the decision-making process. The cultural analysis will look at two cultural orientations, high context and low context by examining several sub concepts such as communication styles, individualism vs. collectivism, task vs. relationship oriented. We will perform analysis on the four distinct stages cross-sectioned with the two context types. We will then be able to describe the impact of the different cultural orientations on members' contributions to the decision-making process during WSIS. Once the cultural variables are coded, we will also conduct descriptive statistical analysis such as frequency counts or tabulations on the distinct cultural orientation-high context and low context, and do cross tabulations to identify unique relationships among three main categories--demographic, decision-making, and culture. Subsequently, in-depth descriptions of the effects of culture on the shared patterns of behaviors will be presented by providing verbatim quotations from the messages received from civil society members.

\section{Implications and Conclusion}

Effective communication between individuals from different cultures is a prerequisite for international management, cross-cultural management, and effective global policy-making. The goal of this study is to provide insights into the human communicative behaviors that facilitate intercultural online communication, as well as to present the implications for effective globally distributed collaboration for civil society members and organizations.

This study will have important implications for multinational corporations and international organizations by suggesting methods for building more effective cross-cultural training, ensuring higher cultural awareness and sensitivity, teaching appropriate behaviors for overcoming cultural differences in globally distributed collaboration, developing intercultural online communication competencies, and designing culturally-sensitive IT applications for effective electronic communication. All of these contributions serve the end goal of enabling global civil society to collaborate effectively at a distance with use of socio-technical infrastructure (Kling, 1996) that are compatible with their multiple cultural values, as evident within civil society.

Besides the practical implication, this study is expected to offer some insights to cross-cultural management, intercultural communication, information systems, and computer-mediated communication, as well as contributing to a culturally attuned theory of globally distributed collaboration. This study will provide an integrated theoretical framework that encompasses individuals with a range of communication styles and patterns stemming from their cultural values. Although Hall's theory has been widely used to explicate intercultural communication in a face-to-face environment, it has been under-applied in an online environment, a niche that this empirical research attempts to fill.

\section{References}

Adler, N. J. (2002). International Dimensions of Organizational Behavior, 4th Ed. Cincinnati,OH: South-Western.

Amant, K. S. (2002). When cultures and computer collide: Rethinking computer-mediated communication according to international and intercultural communication expectations, Journal of Business and Technical.

Babbie, E. (2004). The Practice of Social Research (10 ${ }^{\text {th }}$ ed.) Belmont.CA: Wadsworth/Thomson Learning.

Chen, G. M. \& Starosta, W. J. (1998). Foundations of intercultural communication. Needham Heights, MA: Allyn \& Bacon.

Cogburn, D. L. \& Levinson, N. S. (2003). US-Africa virtual collaboration in globalization studies: Success factors for complex, cross-national learning teams. International Studies Perspectives, 4, 34-51.

Cogburn, D. L. (2005). Diversity matters, even at a distance: Evaluating the impact of computer-mediated communication on Civil Society participation in the World Summit on the Information Society. Information Technology and International Development, 1(4), 15-40.

Daft, R. L. \& Lengel, R. H. (1984). Information richness: A new approach to managerial behavior and organizational design. In L. L. Cummings \& B. M. Staw (Eds.), Research in Organizational Behavior, 6 (pp. 191-233). Homewood, IL: JAI Press.

Evaristo, R. (2003). The management of distributed projects across cultures. Journal of Global Information

Gudykunst, W. B. \& Ting-Toomey, S. (1988). Culture and Interpersonal Communication, Sage, Newbury Park, CA. 
Gudykunst, W. B. (1997). Cultural variability in communication. Communication Research, 24 (4), 327-348.

Gudykunst, W. B., Matsumoto, Y., Ting-Toomey, S., Nishida, T., Kim, K. \& Heyman, S. (1996). The influence of cultural individualism-collectivism, self-construal, and individual values on communication styles across cultures, Human Communication Research, 22(4), 510-543.

Hall, E. T. (1959). Silent Language. Garden City, NJ: Anchor Books/Doubleday.

Hall, E. T. (1976). Beyond culture. Garden City, NJ: Anchor Books/Doubleday.

Hampden-Turner, C. \& Trompenaars, F. (2000). Building Cross-Cultural Competence: How to Create Wealth from Conflicting Values. Yale University Press.

Hofstede, G. (1980). Culture's Consequences: International Differences in Work Related Values, Beverly Hills, CA: Sage.

Jarvenpaa, S. L. \& Leidner, D. E. (1999). Communication and trust in global virtual teams. Organization Science, 10 (6), 791-815.

Joinson, A. (2001). Self-disclosure in computer-mediated communication: The role of self-awareness and visual anonymity, European Journal of Social Psychology, 31, 177-192.

Kanawattanachai, P. \& Yoo, Y. (2002). The dynamic nature of trust in virtual teams, Journal of Strategic Information Systems, 11 (3-4), 187-213.

Kiesler, S., Siegal, J. \& McGuire, T. W. (1984). Social psychological aspects of computer-mediated communication, American Psychologist, 9, 1123-1134.

Kim, Y. (1990). Intercultural communication competence: A systems-theoretic view. In S. Ting-Toomey \& F. Korzenny (Eds.), Cross-cultural interpersonal communication. Newbury Park, CA: Sage.

Kingdon, J. W. (1995). Agendas, alternatives, and public policies. NY: Addison-Wesley Longman.Klein, H. (2005). Understanding WSIS: An institutional analysis of the UN world summit on the information society. The Massachusetts Institute of Technology Information Technologies and International Development, 1(3-4), 3-13.

Kling, R. (1996). Synergies and competition between life in cyberspace and face-to-face communities. Social science computer review, 14(1)(Spring): 50-54.

Krippendorf, K. (2004). Content Analysis: An Introduction to its Methodology, $2^{\text {nd }}$ ed. Thousand Oaks, CA: Sage.

Lea, M. \& Spears, R. (1991). Computer-mediated communication, de-individuation and group decision-making, International Journal of Man-Machine Studies, 34, 283-301.

Lim, T. S. (2003). Language and verbal communication across cultures. In W. B. Gudykunst (ed.) Cross-cultural and Intercultural Communication, (pp.53-72). Thousand Oaks, CA: Sage.

Management, 11(4), 58-70.

Massey, A., Montoya-Weiss, M., Hung, C. \& Ramesh, V. (2001). When culture and style aren't about clothes: Perceptions of task-technology fit in global virtual teams. In Proceedings of the ACM 2001 Group Conference (pp.207-213). NY:ACM Press.

Maznevski, M. L. \& Chudoba, K. M. (2000). Bridging space over time: Global virtual team dynamics and effectiveness. Organization Science, 11(5), 473-492.

Milhouse, M. K. Asante. \& P.O. Nwosu (eds.) Transcultural Realities: Interdisciplinary Perspectives on Cross-Cultural Relations (pp. 55-70). Thousand Oaks, CA: Sage.

Novinger, T. (2001). Intercultural communication: A practical guide. Austin: Univeristu of Texas Press.

Oetzel, J. G. (2005). Effective intercultural workgroup communication theory. In W. B. Gudykunst (ed.). Theorizing About Intercultural Communication, (pp. 351-372), Thousand Oaks, CA: Sage.

Olaniran, B. A. (1994). Group perfomance in computer-mediated and face-to-face communication media. Management Communication Quarterly, 7, 256-281.

Olaniran, B. A. (2001). The effects of computer-mediated communication on transculturalism. In V. H.

Shachaf, P. (2005). Bridging cultural diversity through email. Journal of Global Information Technology Management, $8(2), 46-60$.

Solomon, C. M. (2001). Managing virtual teams, Workforce, 80 (6), 60-66.

Tayeb, M. (2003). International Management: Theories and Practices. Essex: Pearson Education Limited.

Thorne, S. L. (2003). Artifacts and cultures-of-use in intercultural communication. Language, Learning and Technology, 
7(2), 38-67.

Ting, Toomey, S. (2005). The matrix of face: An updated face-negotiation theory. In W.Gudykunst (Ed.), Theorizing about intercultural communication (pp. 71-92). Thousand Oaks, CA: Sage.

Ting-Toomey, S. (1997). An intercultural journey: The four seasons. In M. Bond (Ed.), Working at the interface of cultures (pp. 202-215). London: Routledge.

Toner, A. (2004). Unzipping the World Summit on the Information Society, In The Public Voice WSIS Sourcebook: Perspectives on the World Summit on the Information Society, pp.182-194.

Triandis, H. C. (2002). Generic individualism and collectivism. In M. J. Gannon \& K. L. Newman (Eds.) The Blackwell Handbook of Cross-Cultural Management (pp. 16-46), Malden, MA: Blackwell Publisher.

Trompenaars, F. \& Hampden-Turner, C. (2000). Building Cross-Cultural Competence: How to Create Wealth from Conflicting Values, New Haven: Yale University Press.

Walter, J. B. (1992). "Interpersonal Effects in computer-Mediated Interaction." Communication Research, 19, (1), 52-90.

Walther, J. B. (1996). Computer-mediated communication: Impersonal, Interpersonal and Hyperpersonal Interaction. Communication Research, 23, 3-43.

World Summit on the Information Society. (2003a). WSIS Declaration of Principles, United Nations, WSIS-03/Geneva/doc/0004. 12 December 2003, pg. 6. Retrieved October 01 , 2005 at: http://www.itu.int/wsis/docs/geneva/official/dop.html.

World Summit on the Information Society. (2003b). WSIS Action Plan, United Nations, WSIS-03/Geneva/doc/0005. Retrieved October 01, 2005 at: http://www.itu.int/wsis/docs/geneva/official/poa.html. 


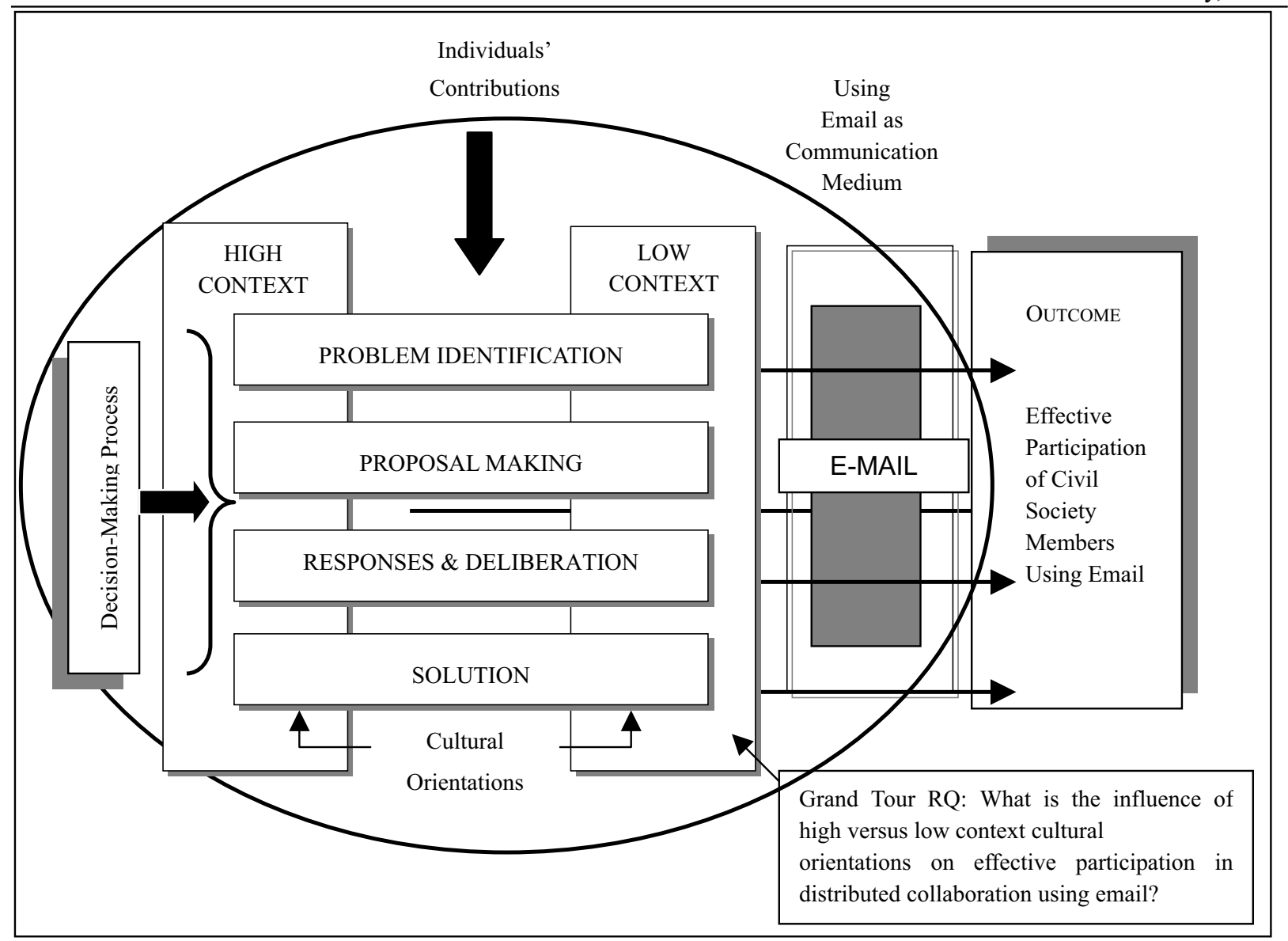

Figure 1. Globally Distributed Collaboration of Civil Society in WSIS using email

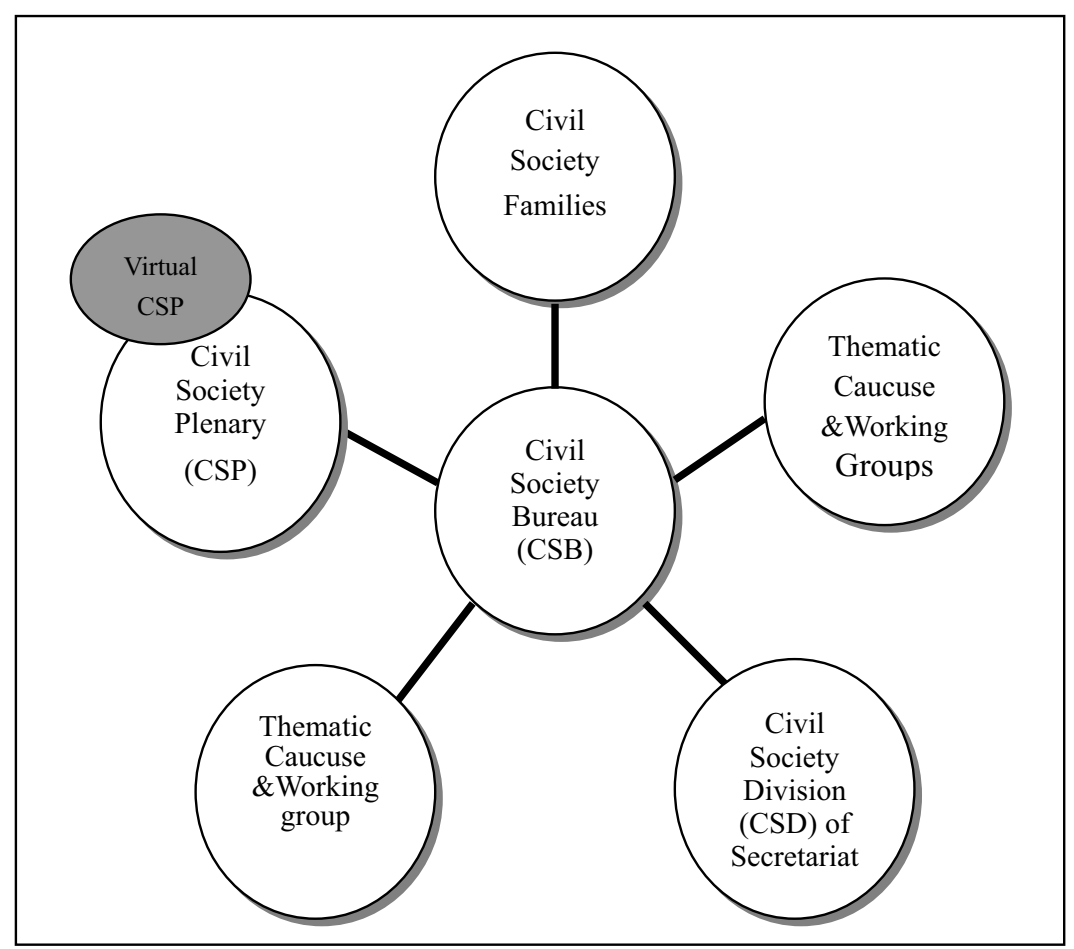

Figure 2. Non-Hierarchical Structure of WSIS Civil Society (Adapted from Cogburn, 2005). 


\title{
A Study on the Development Strategy of China's Clothing
}

\section{Industry at the After-Quota Age}

\author{
Jing $\mathrm{Xu}$ \\ College of Design and Clothing, Tianjin Polytechnic University, Tianjin 300387, China \\ Tel: 86-159-6420-6694Ｅ-mail: xujingmin1982@163.com
}

\begin{abstract}
Textile clothing is an important backbone industry in China. China is the No.1 in the production and export of clothing in the world. Its gross clothing export accounts for one fourth total global clothing trade. After a period of development, the general industrial structure is composed of the fashionable dress industry, the clothing-processing industry, and the clothing industry. In 2005, the quota for textile products was canceled for the first time. The quota system that has restricted the export of textile clothing products for a long period retreated from the history forever. World textile clothing industry enters a brand-new age. The development trend of China's clothing industry will focus on: scale, information, brand, and fashion. Confronting with favorable and unfavorable factors, we should hold five countermeasures: brand development strategy, technique talent strategy, total costs superiority strategy, supply chain advantage strategy, and standard qualification strategy.
\end{abstract}

Keywords: After-quota age, China's clothing enterprise, Development situation, Development trend, Countermeasure

\section{The general introduction for the development of China's clothing industry}

Textile clothing is an important backbone industry in China. China is the No.1 in the production and export of clothing in the world. Its gross clothing export accounts for one fourth total global clothing trade. After a period of development, the general industrial structure is composed of the fashionable dress industry, the clothing-processing industry, and the clothing industry. China's textile clothing has extremely powerful competence in global textile clothing industry because of its cheap labor resources and equipped industrial advantages. In recent years, the development of clothing manufacturing is faster than that of GDP and textile industry. The scale of market realizes a stable increase. China's clothing industry has these features as follow.

\subsection{The business efficiency of domestic clothing enterprises is lower.}

Till May, 2006, we compare the business efficiencies of different enterprises in clothing industry according to the registered type in figure 1.

According to data above, the foreign-funded enterprises have the highest business efficiency, the enterprises funded by Hongkong, Macau, and Taiwan less, and the domestic enterprises poorest. Comparing with data in 2005, the sales and profits of domestic enterprises decrease in 2006. And the decreasing speed is faster than that of total assets. The decreasing proportion of sales and profits is almost shared by foreign-funded enterprises and enterprises funded by Hongkong, Macau, and Taiwan.

1.2 The gross export increases at a higher speed and the quality of exports is better, what is a new feature of China's clothing industry in recent years.

According to new statistical data in China customs, the export price of China's clothing has kept on rising since 2002. And the average price was 2.29 dollars from Jan. to July in 2002. The number reaches 3.09 dollars from Jan. to Junly in 2007. In five years, the number increases 35 percent. Figure 2 reflects the trend of clothing export quantity and sum from Jan. to May between 2001 and 2007.

In the first season of 2005, the foreign exchange gained by export of textile and clothing products in China reached 8.428 billion dollars. The year-on-year growth was $26.78 \%$. Thereof, the foreign exchange gained by common trade accounts for $69 \%$, increasing 3 percent than last year. In the first season, China's export to countries with limits is 2.486 billion dollars, accounting for $29 \%$ of the total export, increasing $15 \%$ than that in same period in last year. The export to countries without limits increases less, merely $7.73 \%$. After canceling the quota for textile exports, the potential of China textile export has been released. But this increase generated by the release is short-term and reasonable. It will finally come back to former level. See figure 3 .

Therefore, confronting with the problems advanced by America and European Union, China's textile industry should 
keep cool, analyzing situations objectively. If we want to achieve higher foreign exchange by exports, we should further adjust the industrial structure and improve the competence of textile products in foreign trade.

\section{The situations confronted by China's textile clothing development at the after-quota age and the} countermeasures.

\subsection{Situations}

Along with the coming of after-quota age, the global textile supply chain faces up with unimaginable changes. New-developing textile countries enter the global supply chain with lower costs. The retail channels in chief consumption countries are gradually controlled by large retail groups. Purchasers have more choices in trade in the world. Supply countries with lowest costs will gain more orders. Although China is regarded as the largest supplier at the after-quota age, developed countries has already warned that: to take China as the only supplier is extremely dangerous.

In the aspect of unfavorable or uncertain factors:

(1) After the cancel of quota for textile trade, Chinese government imposes export taxes by quantities on 148 clothing tax numbers of thirty-three types in six classes, such as skirts, shirts, trousers, pajamas, and underwear. This action will affect the clothing enterprises in these aspects as follow. Firstly, the lower the unit price of relevant products is, the more significant the influence is. At present, the export tax imposed on textile clothing is between 0.2 and 0.3 per piece. The numbers of export taxes are close. And the export taxes are determined by quantities. Therefore, the lower the unit price of relevant products is, the larger the proportion of imposed taxes to total prices. Secondly, export products with low-added values are affected significantly. Products with different added values are affected differently due to different profits. Thirdly, the export to non-quota market will be hurt. The imposed export tax means to improve the added values of export products. But it will exert more negative impacts on the export to non-quota regions. In Shandong province, $60 \%-70 \%$ of clothing is exported to Japan and Korea. The quantity-based taxes increase the costs of export to non-quota regions, reduce enterprises' gross interest rate, and weaken the competence of clothing.

(2) After the cancel of quota, the price of China export to countries with limits has been decreased in a short period. And the amount of export has been increased. The market shares have been enlarged. The international trade environment becomes more severe. Main importing countries set up barriers by special protection terms and anti-dumping measures. The international trade barrier will become an important way for developed countries limiting textile clothing export after canceling quota for textile. Technology barrier, green barrier, anti-dumping measure, and anti-subsidy measure will affect the clothing industry heavily.

(3) Along with the speeded-up globalization of economy, the flow of production factors is more evident. Developed countries dominate the high value-added clothing market by right of their advantages in strong capitals, perfect market net, brands, and high technologies.

(4) The deficiency of coal, electric power, and transportation will harm the enterprises' production and operation.

In the aspect of favorable factors: firstly, the domestic economy in China will keep a stable and fast growth, what will generate a strong demand for clothing and will drive the development of clothing industry. Secondly, the world economy shows a resuming growth, what will benefit China's clothing enterprises in the fields of exploring market and enlarging export. Thirdly, the cotton price in Chinese market decreases further and becomes near to the price in world market, what will generate positive effects on the operation of clothing economy and the improvement of benefit. In prediction, the whole industry's production benefit will increase $20 \%$.

We should notice that the increase of export quantity is normal because of the return from the quota system to the free trade system. The former quota system distorted world textile trade heavily and restrained China's clothing export. World economy will sustain its stable growth. China economy will stay in its stable and fast growing way. The desire for export in China is still strong. Although America and European countries have set up limits for China's export, the products that have been affected merely account for a small proportion of total clothing export. It does not hurt the general export to a great degree. Therefore, China's clothing export will still sustain a stable and faster growth.

\subsection{Countermeasures}

It is an urgent affair to analyze rationally China clothing industry's competitive advantages in the reengineering of global textile supply chain, adjust timely China's textile trade policy and industrial policy, and enhance the implementation. Considering the favorable and unfavorable factors confronted by clothing industry at the after-quota age, we put forward five countermeasures as follow.

\section{(1) Brand development strategy}

Brand competition has already become a main part of market competition. It does not merely mean to improve the famousness of name. Enterprises should endow their brands with rich cultural meanings and develop multiple brand 
strategies. As clothing designers are engaged in their designs, the essential idea is to give prominence to characteristics of local culture and national culture, mining China's humanism resources as much as possible. Only by making best use of the carrier, namely the clothing, and displaying Chinese culture, can we establish the position of "Chinese clothing".

According to the "three-less three-more" feature of China clothing industry, we should take brands as the impetus in development. Integrate the advantage powers and provide with support for a few of head enterprises that can drive the development of surrounding regions. Amounts of small industrial clusters will finally form a national industrial cluster. In the process of supporting a few of head enterprises to form different industrial clusters, we should pay more attention on the conformity of resources and brands. By this way, a group advantage will come into being.

(2) Total costs superiority strategy

In the macro aspect, China's clothing industry possesses a unique position in world clothing trade. It has a bright prospect in the field of export. However, China clothing's competitive advantage chiefly focuses on the price aspect. It does not have a predominant advantage concerning with the production costs. Therefore, Chinese enterprises should make up plans as a whole and choose the operation mode that can help to realize maximum profits at lowest costs. By this way, China's clothing industry will be strong.

Enterprises must try to gain essential advantages in prices of labors, costs of materials, productive efficiency, and countermeasures for sorts of non-tariff barriers in order to enlarge their exports further guarantee their sustainable development. "To decrease costs" is one of lifelong strategies for any enterprise. Under the new world clothing trade situation, it is urgent and important for China's clothing enterprises to apply the total costs superiority strategy.

(3) Technique talent strategy

For any modern enterprise, talent is one of core competences. Technological innovation is the root for enterprises improving their competence. Especially at the knowledge economy times, innovation relates with enterprises' survival and development closely. Enterprises have an increasing demand for talents. They lay more stresses on the exploration and cultivation of talents. On the other hand, talents with potentials have to experience a period of growth and adaptation as they become mature. The most important responsibility of leaders in enterprises is to pick up talents and cultivate them to do what they can do and sustain long-term enthusiasm for work.

(4) Standard qualification strategy

In recent years, a new international trade standard ----- SA8000 social responsibility standard is in front of China's export enterprises. SA8000 is new barrier for some export enterprises. As the first "social moral responsibility attestation standard" in the world, SA8000 requires that enterprises should shoulder social responsibilities as they earn money. It sets up lowest requirements for work environment, employees' health and safety, professional training, wages, rights of labor unions, and other specific issues. It chiefly includes nice factors, namely child labors, compulsory labors, health and safety, freedom of organizing labor unions and collective negotiation rights, punishment measures, work schedule, wages, and management system. More than 40 enterprises have passed the SA8000 attestation in China. And one fourth belongs to the clothing industry. They chiefly locate in the provinces with relatively developed trade along south-east seaside. No clothing enterprise has passed this attestation in Shandong province.

However, in recent years this attestation has become one of requirements listed in multi-national companies' orders more and more. It has already served as a technology barrier for China's export. The up-spring of SA8000 is originated from the imbalanced competitive relation in the world market. It is a kind of adjustment of competition between developing countries and developed countries in the world market. Considering this trend, China's clothing enterprises and Chinese government should take action, escaping from a negative position. In the long run, the SA8000 standard can bring about more values in many aspects for enterprises.

(5) Supply chain advantage strategy

Supply chain management has already gained more and more attentions from enterprises. It has gradually become an option for the development strategy of modern enterprises. In contrast with the traditional vertical management mode, the supply chain management has enormous competitive advantages. As a cooperative strategy for enterprises, the supply chain management can provide with not only a system but also an organizational form in resource allocation.

For China, the key point is to make best use of present opportunity to enlarge the market, build up more marketing channels, and gain certain controlling right in the world supply chain instead of allowing more enterprises to enter the list of international suppliers. It is a long-term and systematic project to construct a complete and effective supply chain for Chinese products. Therefore, it is necessary to motive and use the strengths at the official, industrial, and corporate levels to realize this goal.

\section{Conclusion}

China is an enormous market. Chinese have their unique characteristics in aspects of culture, history, and aesthetics. 
China' enterprises can grasp these characteristics easily. Besides, China is a giant in clothing production field in the world. It has rich industrial resources. These facts serve as preconditions for the birth of world famous brand in a sense. Therefore, as long as Chinese enterprises begin from the features of clothing industry, master the key rings, namely product (design, cloth), market, terminal (channel), production (craft), and brand, make integrated innovation based on national elements and international elements, they can make up changeable market and brand strategies and step into a way to success.

Facing up with opportunities and challenges, clothing enterprises should meet the trend of international economy and the norm of international operation, take immediate and positive action, combine with world-famous enterprises, and explore market together. The combination is an integrating and learning process instead of losing themselves, which can help to gain more spaces and bring about a win-win result. Therefore, persisting in brand strategy and innovation will be the best way for China's clothing enterprises or even all Chinese enterprises to realize the complete prosperity.

\section{References}

(2003-2005). Shandong Clothing Information. No.40-56.

Mao, Lili. \& Wang, Xingjia. (2005). An analysis on the present development of knitted clothing industry of China. Kitting Industries. No.3. p55-59.

Wang, Chunhong. \& Ma, Huiying. (2004). The future winners and losers in textile and clothing industry. Tianjin Textile Science \& Technology. No. 4. P45-47.

Wang, Xi. \& Chen, Yao. (2003). The tendency of garment sales. Journal of Chengdu Textile College. No.1. p20-21.

Yu, Ping. (2005). Effect of SA8000 on China's textile and clothing industry. Wool Textile Journal. No.6. p5-7.

Yu, Weixiang. (2003). How China clothing industry enters WTO. China's Foreign Trade. p80-81.

Zhou, Shaoning. (2005). New tests for wisdom and ability. Textile Information Weekly. No.8. p11.

Zhu, Yuming. (2003). Information technology applications to Chinese garment industry. Journal of Zhejiang Institute of Science and Technology. No.3. p55-59.

$\mathrm{Zu}$, Yidan. \& Li, Xiaoying. (2004). The effects of textile and clothing association on the breakthrough of trade barriers. Shandong Textile Economy. No.5. p3-4. 


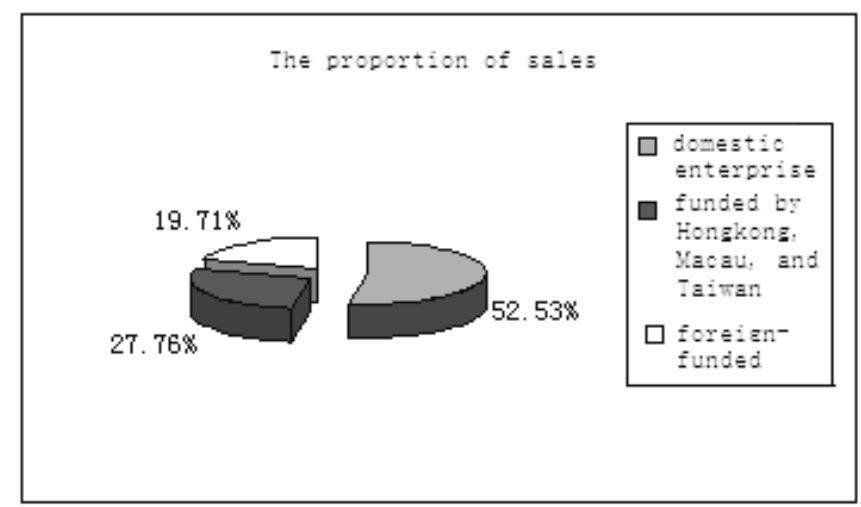

Proportion of total assets
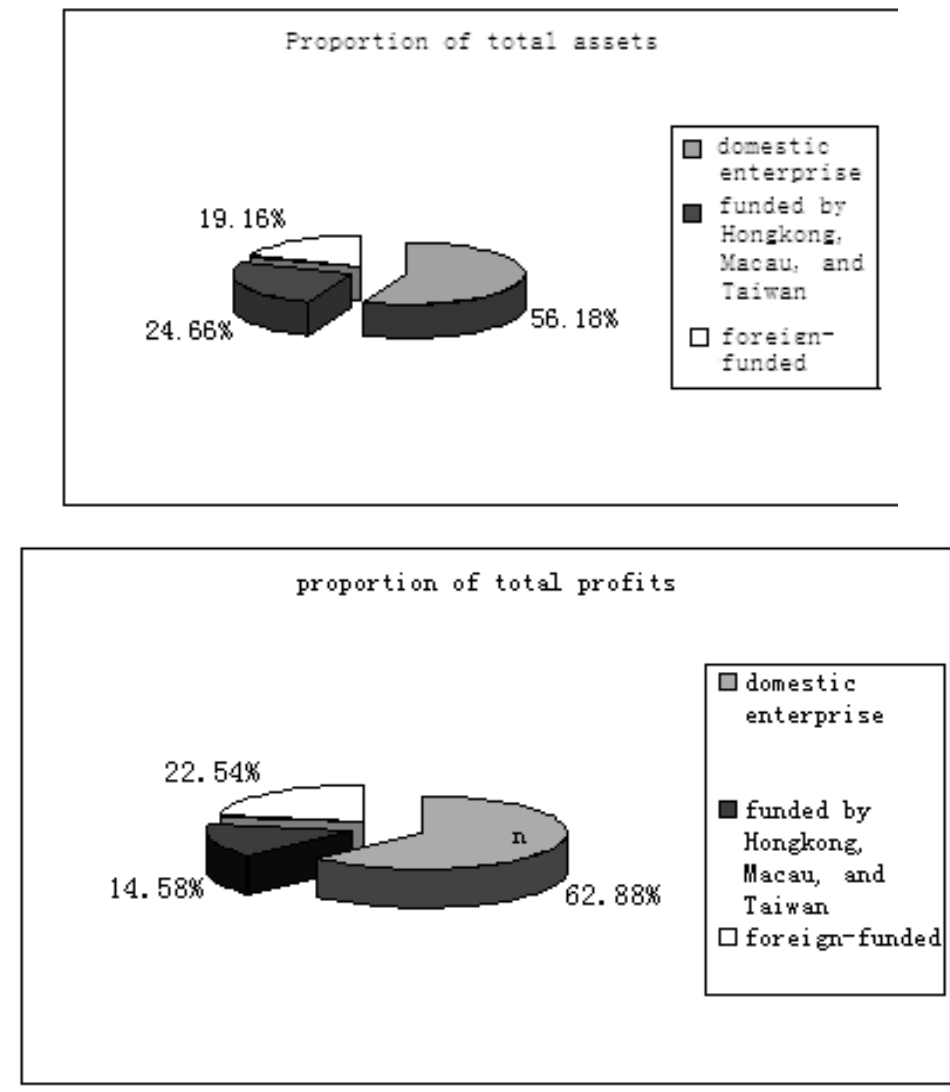

Figure 1. The Comparison of Business Efficiencies in Three kinds of Enterprises 


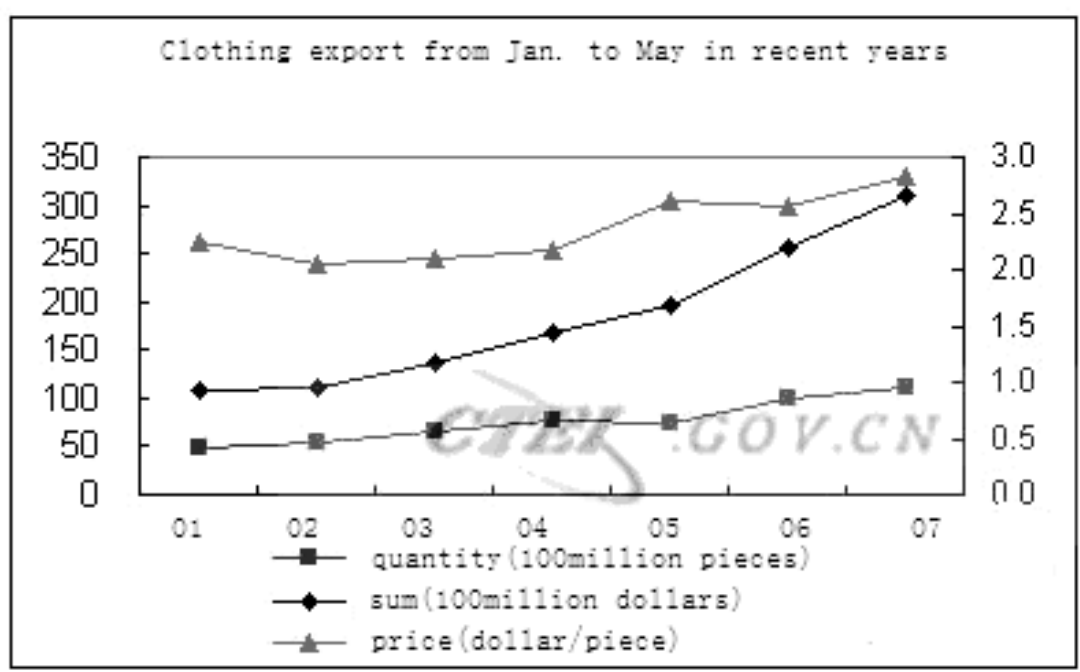

Figure 2. Clothing Export from Jan. to May in Recent Years.

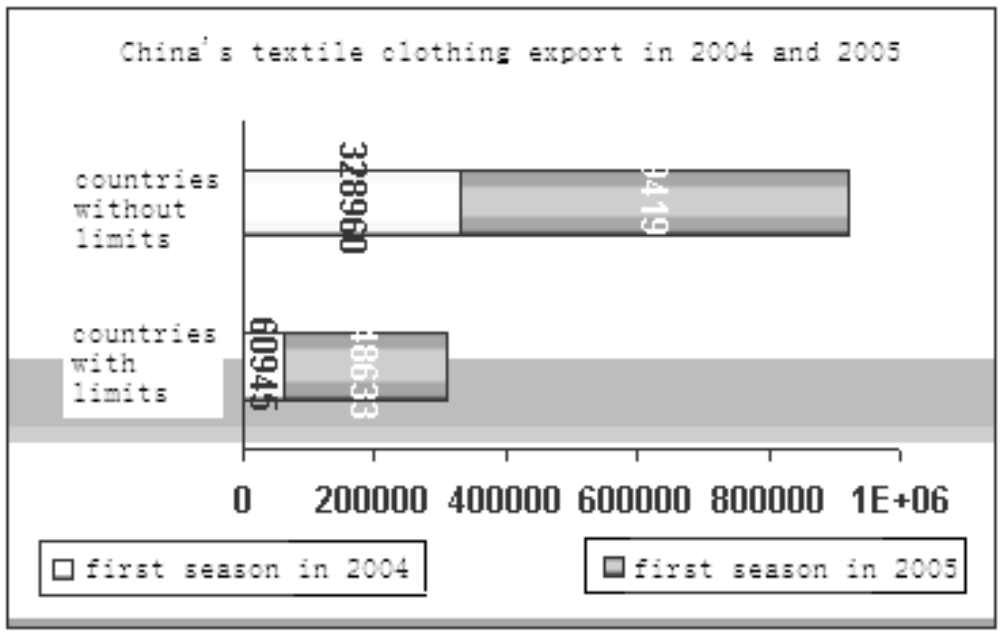

Figure 3. China's Textile Clothing Export in 2004 and 2005. 


\title{
Factors That Influence the Survival of Women-Owned Small
}

\section{Business Start-Ups in the City of Tema, Ghana}

\author{
Ashford C. Chea \\ School of Business, Stillman College \\ $19258^{\text {th }}$ Avenue $\# 12 \mathrm{H}$, Tuscaloosa, AL 35401 USA \\ Tel: 1-205-366-8829Ｅ-mail: achea@ix.netcom.com
}

\begin{abstract}
The one objective of the study was to find out what business practices would be appropriate in helping women in starting and operating their small businesses in Tema, Ghana. Another objective was to find any government policy or law that serves as a barrier to women's entrepreneurship development. The researcher investigated the factors that influenced the survival of women-owned small-scale enterprises in the city of Tema in Ghana. The findings of the study revealed that several major factors were shared among the subjects that affected their businesses survival. These factors included innovation (the most influential), a business plan, a strong family support system, social networks, and professional development. The findings also show that the interviewees had experienced gender discrimination in terms of government economic policies, statutory and customary laws, lack of capital, and administrative hurdles.
\end{abstract}

Keywords: Ghanaian women entrepreneurs, Innovation, Economic development, Small business

\section{Introduction}

\subsection{Background of the City of Tema}

Tema is a port and industrial city about thirty miles east of Accra, the capital of Ghana. There are several rationales for selecting Tema for this study. According to the Ghanaian Times September 201999 issue, Tema is strategically located in terms of economic and business activities. Also, women in Tema are well known for their entrepreneurial spirit. Lastly, women-owned business start-ups' survival rates in Tema are 19\% higher compared to the national average/other cities in the country. The researcher believes that the findings from the study could be used to help potential and current businesswomen in other parts of the country in starting and operating their business successfully.

\subsection{Economic Activity}

Most of Ghana's major manufacturers are located in Tema. This is largely due to its large seaport/harbor and the availability of industrial lands and infrastructure. The major economic activities in the municipality include industrial, agricultural, mining, commercial and service sub-sector, with the industrial sector representing the most in terms of local revenue generation. There are over 250 factories in the city, categorized into eight major areas including chemical, textiles, food-processing, engineering, paints, fish cold storages, printing/arts work and woodworking industries, among others (Courtesy of Tema Development Authority, Tema Municipal Authority, and Tema Tourist Board).

\section{Review of the Literature}

The literature that follows discusses the concepts of entrepreneurship and innovation. It also looks at entrepreneurship in the context of Ghana women entrepreneurs.

\subsection{Entrepreneurship and Innovation}

Entrepreneurial innovation is considered a key factor in business survival and success (Schumpeter, 1934). Innovations are 'the outcome of the innovation process, which can be defined as the combined activities leading to new, marketable products and services and/or new production and delivery system' (Burgelmann and Maidique, 1996, p 2). According to Drucker (1994, p 17), 'innovation is a specific instrument of entrepreneurs, the means by which they exploit change as an opportunity for a different business or a different service'. Successful innovation procedures can be learned and practiced. Thus entrepreneurs need to understand and apply the principles of successful innovation because there are plenty of entrepreneurial opportunities within the areas of change (Drucker, 1994). Entrepreneurs develop new products and services for a market niche, or confront established firms with better quality, additional features or lower prices. These activities are identified with the process of creative destruction and defined as entrepreneurship (Schumpeter, 1947). 
The innovation advantage of large firms tends to be in industries that are capital-intensive, advertising-intensive and highly unionized. On the other hand, industries that are highly innovative, small firms have the advantage (Audretch, 2004). Therefore, innovation in small firms can be more efficient and effective (Vossen, 1998).

The literature stresses several barriers for small firms to innovate successfully. The lack of financial resources, shortfall in marketing and management expertise, and weaknesses in external information and linkages are factors that limit their competitiveness (Freel, 2000; Rothwell, 1994). By contrast, smaller firms have several advantages. Because of their smaller size, they are more flexible and have closer contact and relationships with their customers. This enables them to respond faster to developments in the market, especially to technical changes (Scozzi and Garavelli, 2005). A crucial factor contributing to the occurrence of networking opportunities was based on attendance at social functions such as conferences. Conferences are identified as an effective mechanism in terms of getting to meet potential customers, keeping up to date with the latest developments and analyzing competitors' activities (McAdam and McAdam, 2006).

In the early stages of new firm creation, information networks represent an important resource for the entrepreneurial firm. Effective information networks enrich the entrepreneur's environment, thereby enhancing the other networks and processes in which the entrepreneur engages. The information-seeking behavior undertaken by the entrepreneur is very personal and is primarily a social encounter. The entrepreneur will rely on any informal contacts made throughout his/her personal life as well as business career (Johannisson, 1986).

Access to capital is crucial to the development of small businesses. The uses of capital are multitudinous and range from investments in fixed assets to the adoption and installation of new and better technology for business enhancement. Access to working capital financing is also necessary to smooth out fluctuations in income due to differences in the timing of production and sales. Lack of sufficient capital tends to affect SMEs' ability to develop new products and services or to grow so as to meet demand (Abor and Biekpe, 2006). Heilbrunn (2004) posited that $90 \%$ of business start-ups that failed did so because of the lack of management skills of the owners. Similarly, the lack of financial resources, shortfall in marketing and management expertise, weaknesses in external information and linkages are factors that limit their competitiveness (Freel, 2000).

Another barrier is related to financing the further development of the idea, the manufacturing, and the marketing. With sufficient capital, they would be able to develop the idea and the marketing plan in parallel. Failure to do so would lengthen the time to market and adversely affect income. Also, with sufficient capital they could advertise heavily and build up stock to offer faster delivery and meet larger orders (Larsen and Lewis, 2006). Similarly, there might be a role for government support agencies to develop mechanisms for introducing innovative small and medium-sized enterprises to venture capital (Freel, 2000).

Although the traditional image of the entrepreneur as intrinsically made has been broken to a certain extent, it is still strong enough for some women to find it hard to be taken seriously, which has an adverse impact on applications for funding and finding clients (Brush, 1997). Warren (2004) found that, while this was the case, women were willing to assume the mantle as it pleased others; for example, in order to obtain finance. The study also found the women's experiences of the entrepreneurial identity came secondary to their wish to maintain other aspects of their lives, for example, family, 'yet renegotiate that around the identity of a professional business personal (Warren: 2004, p 33).

This discrimination against women seems to be even worse in Sub-Saharan African countries such as Ghana, where the financial sector is male-dominated $(90 \%$ of staff in most institutions in Ghana are men). Illiteracy or semi-literacy among the majority of women in Ghana creates a further barrier to processing paperwork. Women's lack of control over resources, such as land and labor, also limits their eligibility for loans. Banks' ability to lend is often constrained by inflation-induced de-capitalization, resulting mainly in insufficient funds available to finance loan request. In such cases, it is the women who receive lowest priority (IFAD, 2000).

\subsection{Women Entrepreneurs in Ghana}

Small and medium-sized enterprises (SMEs) in Ghana and elsewhere have a significant impact on the growth of economies through the generation of employment, productivity and innovation (Abor and Biekpe, 2006). However, the low level of women's participation in entrepreneurship and technology has been identified as a problem in terms of economic development and women's personal advancement (Hollowell, Mellors, and Silver, 2006). This discrimination against women seems to be even worse in Sub-Saharan African countries such as Ghana, where the financial sectors in male-dominated $(90 \%$ of staff in most institutions in Ghana are men). Illiteracy or semi-literacy among the majority of women in Ghana creates a further barrier to processing paperwork. Women's lack of control over resources, such as land and labor, also limits their eligibility for loans. Females are mostly involved in sole-proprietorship businesses, which are very small firms, and as such may lack the necessary collateral to qualify for loans (Abor and Biekpe, 2006).

According to the literature, women in Ghana play a vital role in the management of small enterprises and often have a 
strong traditional and contemporary knowledge of their environment. In the rural areas, they perform the bulk of household subsistence work and carry major household responsibilities for farming, food provision, health care, and the utilization and management of enterprises. Women are often the primary users and managers of land, forests, water, and other natural resources. In Ghana, women produce nearly all the food their families consume. Yet for the most part, they still do not have access to land, credit, technology, education, employment and political power (Ardayfio-Schandrof, 1999; Abzug, 2002).

Sarris (2002) states that certain social structures prevent Ghanaian women from having access equal to that of men, particularly to land, credit, education, and extension services, and most of them have their roots in the traditional society. Ardayfio-Schandrof and Wrigley (2001) also reveal that this restricted access to productive resources has clearly undermined the type, level, and extent of women's participation in economic development.

Arhin (2000) reports that the basic problems of Ghanaian women engaged in economic ventures are finance and unfavorable government policies. He points out that traditionally, a woman's debt was held to be the collective responsibility of the family or the husband and therefore a family or husband could prevent a woman from acquiring a loan from the bank or the moneylender. Abzug (2002) endorses this by showing that Ghanaian women engaged in enterprise development could not expand the businesses, as they were not able to obtain financial assistance from the banks. A study by Joekes (1999) in Ghana's Northern Region showed that most women relied on family labor for their small-scale production. About $83.3 \%$ of the women wanted to expand their businesses but were hindered by various problems such as difficulty in borrowing money from banking institutions, obtaining help from extension officers and difficulty in obtaining inputs needed for expanding their productive capacities.

Apart from equity concerns, the economic empowerment of Ghanaian women has been shown to bring direct welfare benefits for the family and national economic development. At the minimum, women's economic progress shifts labor from the subsistence economy to market production, which promotes growth and incomes (Fyle, 2002). Expenditure studies in various parts of Ghana have shown that women consistently spend more of their incomes directly on children and other household supplies, while men tend to concentrate more on capital investment and their own personal needs (Tripp, 2001).

One of the main factors that have shaped the direction of women's economic activities in Ghana has been the male-biased allocation of traditional entitlements and modern assets, a relic of neo-patriarchal ideologies of gender relations found in both patrilineal and matrilineal kinship systems in parts of the country. The same cultural norms, however, embody windows of opportunity for women to acquire wealth, by granting them the right to own their self-acquired property.

In many respects the pattern of men's and women's roles and statuses in Ghanaian society has continued very much as it was in the past, retaining varying degrees of rigidity in a gender-segregated division of labor in non-market production for the home, as well as in market-based production and public office (Yoshikuni, 1999). Over the year, local and international pressure for the increased participation of women in the economy and other affairs of the nation has led to limited efforts on the part of the state to create a more opportunities for girls and women. Nevertheless, despite at least twenty years of such attempts and the evidence of some progress, the gap between women and men in terms of their participation in both the traditional and the modern economy remains wide (Riddell, 2002).

\section{The Theoretical Foundation of the Study}

In a general sense, feminism is a theory that men and women should be equal politically, economically, and socially (Jaggar \& Rothenberg, 1984). Berg (1979) defines feminism as a broad movement embracing numerous phases of women's emancipation. Even though Western perspectives of feminist theory share a commonality with African feminist theory, as regard to women economic empowerment and autonomy, these two orientations of feminist theory are significantly unique in their own ways. According to Mikell (1997), African-feminist theory differs radically from Western forms of feminism that developed in the 1960s. First, the African feminist theory of development owes its origins to different dynamics than those that generated Western feminism. This difference is because African women's resistance to Western domination and its legacy within the African Culture have largely shaped African feminist theory.

Secondly, unlike Western feminist theory, it does not grow out of bourgeois individualism and patriarchal control over women within capitalist, individualizing societies. Thirdly, Western feminism emphasizes individual female autonomy, while African women have been stressing culturally linked forms of public participation. Last, African feminist theorists are concerned about how to reconcile feminism with culture. That is, how to use African culture in assertive and positive ways as they seek solutions to the many problems facing them, their communities, and their states. Similarly, Hooks (2000) note that using Western-oriented feminist theory in investigating African women is not an appropriate reference point. The authors chose to discuss African women's issues and problems from an African experiential base, which, essentially separate from the West's, engages dialogues different from those significant to Western feminist theory. Based on the above, the researcher believes that the most appropriate and useful theoretical 
foundation of this study is the African feminist theory of development. This theory, unlike Western feminist theory, emphasizes the understanding and incorporation of local culture and its impact on African women and development.

\section{Objectives of the Study and Research Question}

The objectives of the study were twofold: To find out if there were government policies, statutory or customary laws that make access to resources difficult for women entrepreneurs in Tema. And To find out the factors that influence the survival of small businesses owned by women in Tema. The research question was as follows: What factor(s) has the most influence on the survival of small businesses owned by women in Tema?

\section{Methodology}

The qualitative method was used in conducting this study. There have been numerous publications on the nature and attributes unique to the qualitative research methodology. For example, Bryan (1988) notes that one underlying attribute of qualitative methodology is its strong adherent to viewing events from the viewpoints of the subjects. Similarly, Hakim(1987) states that the focus on qualitative research is on an individual's own account of his or her attitude, motivation, and behavior. Hakim goes on to say that the qualitative approach allows the researcher to get a descriptive report of the subject's perception, attitude, views and feelings. As Bryan (1988) comments, "the emphasis on description entails attending to mundane detail. The apparent superficial trivia and minutiae of everyday life are worthy of examination because of their capacity to help us to understand what is going on in a particular context and to provide clues and pointers to other layers of reality" (p. 63). Bryan and Burgess (1999) also argue that the data from qualitative research observation consists of detailed descriptions of people activities, behaviors, actions and the full range of interpersonal interactions and organizational processes that are part of observable human experience.

\subsection{Sample Selection Criteria}

The following criteria were used for the purpose of sample selection: The subject had to be a female because of the focus of the study. The subject had to have at least five years of experience in setting up and operating a small business. The subject had to be located in the city of Tema. The subject had to have no more than 30 employees as stated in the definition used for the purpose of the study for a small-business. The subject had to be in the formal sector. That is, registered and licensed by the government. Creswell (1998) notes that using criterion sampling is useful for quality assurance.

\subsection{The Pilot Study}

Prior to introducing the research instrument to the actual studied population in Tema, the researcher carried out a pilot study to pre-test the instrument. Seven women entrepreneurs were interviewed in the city of Accra, Ghana's political capital. They were recruited through a local contact and met the criteria for selection and participation as predetermined by the researcher. The instrument and an introduction letter were sent to the participants of the pilot study a week in advance, explaining the purpose to the study. The participants in the pilot study shared similar characteristics with the subjects that were involved in the actual study. After the pilot study, minor adjustments were made to the research instrument. For example, the researcher learned from the pilot study that the interviewees were not comfortable being called business leaders, as stated in question one of the research instrument, but rather would like to be referred to as simply good businesswomen. Therefore, the words "business leader" were deleted from question one. Another change that was made after the pilot study was that the word "service" was added to question four. The reason was that not all the businesses were selling both services and products. Some were selling products only, while others were offering service only. So, for instance, an entrepreneur who was not selling products would not be able to response to a question as to how she provided high-quality products and vice-versa. Therefore, instead of having question four addressing product quality only, it was adjusted to inquire about service quality provision also, so that the subjects could respond to the nature of the quality of their products or service, accordingly. These were the only adjustments made to the instrument before it was introduced to the actual study population in Tema.

\subsection{Subjects Recruitment}

Various methods were used to identify the interviewees. Initially, the researcher tried to identify women who had been operating small businesses through literature such as the local trade publications. This did not yield much since such information did not exist. Next, the researcher went to the city chamber of commerce and searched the directory of its members. This did not work either. This is because some of the members were not located in the city of Tema, but their businesses were allowed to be listed in the directory for advertisement purposes. Moreover, the majority of the listed businesses did not have their telephone numbers listed in the directory due to the fact that the directory had not been updated for the past seven years. This made it impossible to locate potential interviewees. Finally, the researcher visited three women-oriented organizations and spoke with the officials there. They were told the purpose of the study and how its findings would benefit their organizations and their clients alike. The officials were very receptive and provided current lists of their membership. The lists contained the names of the women, the type of businesses they operated, their phone numbers, business locations, dates of membership, and the dates of their business 
establishment. These lists were used to select and contact the subjects. The organizations also provided limited specialized business advisory services to women entrepreneurs and had more or less the same (overlapping) membership. Each female entrepreneur had to register with each organization in order to be a member and benefit from its specialized services. This facilitated the work since the various lists seemed to have confirmed the same women. Based on the above selection criteria, forty female entrepreneurs were clearly identified and selected. Their enterprises represented a cross-section of businesses that were being run by women in Tema. They included food processing, fashion and design, arts, floral business, pharmacy, cookware, beauty salon, textile, building materials, restaurant, agro-business, crafts, etc.

After the identification, potential interviewees were contacted by phone using the above organizations as references. The phones and fax numbers were given by the above organizations also. A week in advance, the subjects were sent letters through fax, introducing the researcher and explaining the purpose of the research. A copy of the interview questionnaire guide was also provided. Follow-up phone calls and visits were made to the subject business sites to secure the interview sessions. All the subjects agreed that their identities, including their names, addresses, contact phones, voices would be protected as stated in the letters. The Human Subject Forms were signed and submitted to the researcher. Three of the target interviewees turned down the researcher's request to interview them for security and personal reasons. They said they did not want their voices to be audio-taped. So there were thirty-seven potential subjects left for interview. Another potential interviewee cancelled the scheduled interview session. She told the researcher that she was traveling to South Africa to attend a business conference. The researcher was then left with thirty-six subjects for the interview survey.

The researcher then set the interview appointments schedule. He limited the number of interviews to three per day. One was done in the morning hours, while the other two were carried out during the afternoon and evening hours, respectively. The schedule was arranged this way to enable the researcher to have ample time to review interview notes and reflect on the session before going to the next interview in the day. Also, transportation and traffic problems could be avoided since public transportation was the primary mode use to move from one interview to the next. The availability of the interviewees was also taken in account. For this reason scheduling was made flexible enough to accommodate all of the interviewees. The times and sites for each interview were suggested by the interviewees. These were centered on their availabilities, comfort, confidentiality, anonymity, and security.

\subsection{Data Collection and the Research Questionnaire}

The instrument used in this research to collect data was an open-ended questionnaire guide. An in-depth interview strategy and techniques were used. In-depth interviewing entails paying careful attention to the interviewees and recording the answers and then doing follow-up questions as needed. The general interview guide method of conducting in-depth open-ended interviews was utilized. This was appropriate because it provided the researcher with a list of issues that was a basis for exploration during the interview sessions. The subjects were encouraged during the interviews to talk freely about their experiences during the start-up and the operation of their small business enterprises.

\subsection{The Interview Procedure}

The questionnaire was administered by means of face-to-face interviews. The interviews were carried out at locations chosen by the subjects. This was necessary because it allowed for the subject's privacy, convenience, and comfort. Moreover, it allowed for full confidentiality of the interview process. The interviewees were guaranteed that their identities (names, addresses, telephone numbers, and voices) would not be exposed under any circumstance. The interviews conducted sought responses to questions such as: How did you develop into a good businesswoman? What were some of the obstacles you encountered when starting your business? What advice would you provide to an inspiring women entrepreneur in regard to starting and running a successful small business in Tema? Follow-ups probing were made. The follow-ups probing allowed for the collection of more data relevance to the research. Each interview session lasted between 60 to 90 minutes, and was audio-taped and later transcribed. Later, summary notes from the audio-taped interviews were presented to the interviewees for verification and confirmation to avoid errors or misquotes. This editing enabled the researcher to correct any error, and, where necessary, follow-up field checks were carried out. The study was conducted during the months of May, June, and July of 2007.

After completion of all the interview sessions and transcriptions, the verification and confirmation of the transcripts were sought from the subjects to make sure there were no further addition or subtraction needed to be made to the data collected. After that was done, a careful, proper and critical review of the interview transcripts was carried out several times to see if there were some recurring themes from the interviews. The following themes later emerged: Vision and Business Plan, Education and Professional Development, Social Support Network and Trade Association Membership, Community Involvement and Family Support, Flexibility, Human Resources and Relations Management, and Innovation and Quality Control. The participants expressed these recurring themes repeatedly, with strong emphases, during the interview sessions. The themes help explain why small businesses owned by women in Tema survive against all odds. The researcher used textual content analysis and coding, based on the above recurring themes, to analyze the 
data. The analysis of the results is found in the data analysis section of the paper. It shows the type of knowledge and skills relevant to empowering women entrepreneurs, now and in the future, for business survival in Tema in particular and other parts of Ghana in general.

\section{Data Analysis}

The contextual content approach was applied in analyzing the data collected during the study. The analysis starts with the major obstacles that hinder Tema women entrepreneurship. It also looks at other factors that influence their ability to overcome those obstacles.

\subsection{Obstacles Faced by Women Entrepreneurs in Tema}

When asked about the obstacles encountered when starting their businesses an overwhelming and universal 100 percent mentioned lack of access to finance; 27 of the women noted high taxes; 29 stated red tape in government agencies and corruption in obtaining licenses/registrations for start-ups; and 31 mentioned institutional discrimination and sexism/prejudice. Moreover, 25 said that the lack of centralized information centers for business start-up resources was a problem. According to the data collected, when it comes to seeking advice on a critical business decision, two-thirds of the respondents have just one person they turn to, and in more that halve of those cases it is a family member. Husbands top the list as the most frequently consulted in making a critical decision, according to the study. But when the husband is not the confidant, the family choice generally tends toward the male gender. Those whose advice is solicited will often be knowledgeable about the business, and sometimes are helping to run the daily operations. For routine matters, the respondents sought counsel from outside the enterprise, especially when in need of a specialist's advice, and, according to the data, 27 had solicited counsel from consultants in the past 12 months. Outside advisers included specialist such as accountants, lawyers, suppliers, other business owners and consultants. Finally, when asked about their advice/guidance for aspiring women entrepreneurs in Tema, all thirty-six of the respondents noted that strong family support and personal savings are very critical; 30 of the subjects said having a flexible business plan is very helpful; and 26 stated that affiliation with women-oriented business organizations and trade-related association is important. Moreover, 28 of the respondents mentioned that professional development is very crucial; 28 of the subjects also listed having a network of people for advice and support as critical; and 27 emphasized that entrepreneurial innovation is also significant.

\subsection{Professional Development}

Twenty-two of the respondents noted that they had attended business management classes at their local colleges over the course of their business life; 31 stated that they participated in a women-focused entrepreneurship workshops; while 27 of the subjects said they underwent specialized training courses in customer service and quality management. Moreover, 25 of the subjects stated that they do have regular training activities for their workers; while 11 mentioned that they invest in their employees' development once a while.

\subsection{Sources of Finance}

The majority (33) of the interviewees began their businesses with their own personal savings; 31 got some financial help from their families; while 20 mentioned that they also borrowed money from friends. Moreover, 4 received financial assistance from other sources, including financial institutions. Lastly, 15 of the women interviewed said they raised initial funds from susu collection (rotating credit).

\subsection{Community Development}

When it comes to giving back to their communities, 23 of the women said they have been involved with socially responsible initiative unilaterally. 13 noted they do give to their communities through social and trade organizations.

\subsection{Business Plan}

Seventeen of the subjects admitted that they used professionally written business plan for their enterprises; 11 noted that they developed their own business plans; 5 of the respondents said they did not have formal or comprehensive business plans but wrote their thoughts on papers; only 3 mentioned that even though they did not write their business plans on paper, they have them in their heads.

\subsection{Networking}

When it comes to social support all of the respondents listed family support as very critical to their business survival. Women-based organizational support was mentioned by 30 of the subjects. 27 of the respondents mentioned local community support; only 3 interviewees said government support; while 31 emphasized trade associations support. Moreover, the data shows that 30 of the women belong to a trade association, 32 are associated with some form of women-oriented organizations; while 27 noted that they are members of a church-based business organizations. Similarly, 29 of the respondents do have regular strategic network of people for advice and support. The reminding 7 noted they only seek advice once in a while whey they see the need for that. 


\subsection{Business Innovation}

When it comes to entrepreneurial innovation, 27 of the women said they have executed some innovations in their outfits; while 9 noted that they had had thoughts of innovating new ways of doing things in their enterprises. The women in the study said they frequently introduce new products, styles or approaches that are attractive to their customers.

\subsection{Innovation and Business Survival}

One major factor that most influenced the survival of these women-owned enterprises was the sense of innovation. This has been manifested through their business practices in terms of the acquisition of raw materials, product development, production processes, and marketing. Below are selected mini-cases of innovations implemented by four of the women in the study.

\section{Mini-Cases of Entrepreneurial Innovations}

Four cases below exemplify the influence of entrepreneurial innovations in establishment and operations of a variety of businesses owned by woman entrepreneurs in Tema.

\subsection{Mini-Case 1: WVB Food Processing Enterprise}

WVB Food Processing Enterprise is owned by madam WVB; she is the first Ghanaian woman entrepreneur to commercialize pasta (macaroni) production in Ghana, using wheat flour and eggs to produce Egg and Chinese noodles at a time when there was scarcity of all kinds of food items in the country. Although the base input for pasta manufacturing is hard wheat semolina, she was able to produce quality pasta in different shapes and sizes with local ingredients using kontonmire, fresh tomato, eggs, soya beans, and wheat flours to come out with highly nutritious pasta for the local customers. Initially her production was done on a small scale, but after a while she expanded because her company was growing. Madame WVB got her raw materials from farms and suppliers of farm produce and produced about 400 kilograms of pasta a day. Her rationale behind setting up her business was to avert post harvest losses and also to serve as a means of preserving farm produce, and to curtail the drudgery of traditional cooking, which takes a lot of time.

\subsection{Mini-Case 2: UTS Textile Fabrics}

UTS Textile Fabrics is owned by madam UTS. She designs specialized textiles and clothes with an ethnic touch. Madame UTS transcends the fabrics she makes, puts more attention in mixing of colors, and gives each design a certain distinctiveness. She tried textile printing as an additional innovation when her friend encouraged her to get into textile design because of her good sense of color and style. Madame UTS entered into that venture because many people in Ghana wore a lot of foreign clothes made of cotton, so she decided it would be an innovation to design and print with silk, rayon, and other fabrics. At the moment she incorporates African designs into European styles as well as producing home furnishings for which she utilizes unique African, ethnic designs and motifs so as to make exclusive designs for the market. Through color, imagery, and texture, her thoughts and inspiration come alive with ideas that bridge the gap between cultural and contemporary design.

\subsection{Mini-Case 3: SBI Food \& Beverages}

SBI Food \& Beverages is owned by madam SBI; she has developed a system of sustainable crop production in her backyard, and established a six-acre multiple cropping farm to address the problem of seasonality of fruit crops all year round. Madame SBI has experimented with different kinds of fruits to produce jams, wine, and jellies. She produces guava, mango, and pineapple juices. She also produces sour-sop jelly, paw paw, and carambola wines. The production of the sour-sop jelly is something she believes nobody has tried, and she feels proud to be the first person to do so in the country. Madame SBI has also developed her own equipment to keep her business operating. This is because the technology and equipment needed for her business production are not available in the country. She has recently developed another type of juice that is not $100 \%$ fruit juice, which she therefore sells for a slightly cheaper price. This is because customers complained that her other juices are a little expensive compared to other locally produced fruit juices. Initially she would import all of her packaging materials, but the government has increased tariffs on imports, making it very difficult to continue to import packaging materials. In order to deal with this problem, she created her own packaging materials from recycled aluminum, plastic, and paper products.

\subsection{Mini-Case 4: LQY Enterprise}

The last example of small business innovation in this study was exemplified my madam LQY. Since the establishment of her business, she developed innovative strategies to sustain its operations during bad times. For example, in order to overcome production bottleneck, she restructured her production process to include both short and long-term projects. This allows her to operate one flexible and cost effective production line instead of running two separate production lines as she had done initially at a heavy cost since the beginning of her business. The income generated from the short-term project is used to support her long term project. This strategy has helped her business to survive over the years. Today, she sells coconut products, palm oil products, and fish products. Due to the uneven demand for the 
variety of product she sells, madam LQY uses the profit for one product line to cover for the losses from other product lines.

\section{Summary of Findings}

An analysis of existing government policy documents revealed that policies were developed under the assumption that women and men have equal access to resources. Based on this assumption, the criteria for access includes conditions such as detailed project documentation, high and select collateral, long-term customer relationships, business location, advanced degrees and high equity contribution. These requirements are based on the assumption that both women and men: Have resources to hire experts to prepare detailed feasibility studies; are highly educated; owned titled land in Ghana; have been able to establish long-term relationships with banks; have enough resources to contribute the required level of equity (Ghana Ministry of Trade and Industry Document, 2001). These criteria presuppose that women have equal access to land, buildings, education, and possess the freedom, finances, and time to carry out business in Ghana. But in Ghana, women are still less likely to own land and other assets, and they are less educated then men. Fulfilling bank requirements, therefore, is challenging for women. This is despite the reality that women comprise the majority of SMEs operators and SMEs form the bulk of the enterprises in Ghana. Moreover, the analysis of the literature shows that the government credit program's average loan has risen to levels beyond the reach of SMEs. This increase in loan size, combined with the bank's shift in focus from SME sector to tourism and mining, proves increasingly challenging for women who are primarily involved in SMEs.

Also, the macroeconomic environment of structural adjustment has had negative impacts on the input, output, income, savings and investment of micro enterprises owned by women and has restricted new entrants into enterprises ownership. Access to economic resources and appropriate technology remain major obstacles to the survival of women-owned enterprises. And access to international markets has not necessarily been improved for women (Abzug, 2002). Government/customary law bar women from inheriting ancestral land, which is traditionally passed down through male descendents. Registration provides titles in the name of the "head of the family" but once a man dies, his widow's continued access to the land may be threatened by his relative who may want the land. Widow inheritance rights do not exist in principle and land in the hands of widows tends to pass to a male heir of the next generation (Ardayfio-Schandrof, 1999). Women's rights are not specified in this system and they cannot, therefore, treat the land as an economic asset that allows them access to loans. Widespread disinheritance of women places them in a significantly weaker bargaining position within and outside the family (Collier, et al, 2001).

Furthermore, current land reform efforts do not address this problem since registration in the name of the "head of the family" continues to exclude women's ownership. Government document dealing with the land ownership, gives husbands the opportunity to oppose their wives' land ownership and her attempt to use it as a collateral to borrow needed funding for her enterprise. This law remains intact.

Moreover, the findings show that the following obstacles are faced by women entrepreneurs: (a) the tax system is a hindrance not only because the rates are high, but also because the system is complex, changes frequently, and facilitates corruption; (b) frequently changing legislations; (c) lack of access to starting and working capital, high interest rates, and unaffordable collateral; (d) administrative controls and (e) lack of official financing.

Finally, the entrepreneurial innovations of the women in this study, which are manifested in the operations of their businesses, have been a major factor that influenced their survival. Although other factors, such as professional development, social networking, business plan, and family support, contributed partially to their survival as stated in this study, their propensity to innovate, through the acquisition of raw materials, product development, production processes, and marketing stands out as the most significant factor that influences the survival of their businesses.

\section{Recommendation and Policy Implications}

In this section, the author provides some recommendations derived from his findings that can help would-be women entrepreneurs in Tema in particular and in Ghana in general. He also offers recommendations that the government of Ghana can adopt to encourage and assistant women entrepreneurs in the country. Lastly, the author outlines several policy implications for the Ghanaian government.

\subsection{Recommendations for a Tema Woman Entrepreneur}

Several recommendations are made from this study. First, a woman entrepreneur in Tema should be innovative, flexible, and resilient in the operations of her enterprises. Second, it is recommended that she should be a member of at least one trade association where she can learn from and exchange ideas with like-minded people. Third, she should build support systems/social networks for advice and inspiration. Fourth, she should incorporate her families into her business and seek their support. Finally, a woman business owner in Tema should have a vision and business plan to guide her through the operations of her business. 


\subsection{Recommendations for the Ghanaian Government}

First, the government should develop facilities that foster and support entrepreneurial innovations among businesswomen. Second, government, together with other women-focused NGOs in Tema, should foster the expansion of community based financial institutions and networks. Small business development funds need to be available to women entrepreneurs for loans, grants, or guaranteed low interest financial assistance through these institutions. This support should be given high priority for business start-ups. Women-owned small ventures have difficulties obtaining financial resources. Third, the government should integrate women-owned small enterprises into the formal sector. This could proceed along two lines as follows: (i) the inclusion of women entrepreneurs in economic planning by providing new incentives and disseminating information about existing incentives more effectively; (ii) studying and using international experience in increasing women-owned businesses, especially in industrial and urbanized transition countries. Lastly, the government should reduce the tax burden imposed on small businesses.

\subsection{Policy Implications}

There are several public policy implications that are derived from this study. First, the findings of the study mean that the Ghanaian government should drastically reduce the many regulatory hurdles for establishing and operating new private enterprises. Second, the findings also imply that government must ensure that women-owned small enterprises have access to bank credit. Third, the findings entails that government should promote informal lending schemes to women-owned small start-up businesses, such as group lending and special micro-venture schemes. Fourth, the findings imply that government should provide women-owned small and medium access to market and technical information and expertise. Fifth, the findings imply that government strengthens university and continuing education offerings related to business and entrepreneurial skills cater to women. Sixth, there should be a reduction in administrative controls and government corruption. The government and government agencies should also operate with transparent rules to minimize corruption. Two useful new directions for policy worth considering are: (i) eliminating corrupt practices, which should become an explicit feature of government support to women-owned small businesses; (ii) downsizing government agencies at all levels. The above should make it easier to start and run businesses. The maze of bureaucratic paperwork that is often required to start businesses in Tema seriously deters entry into many industries. Moreover, such administrative hassles can be especially bad: in some cases they may punish small, local entrepreneurs who lack the resources to overcome such high hurdles. Having more government agencies that can block a firm's path will lead to more points at which a firm is required to pay bribes to move the process forward. Finally, the development and establishment of clear policies with respect to SMEs and the financial sector will work toward eliminating some of the biases that limit the available credit in this sector. Furthermore, establishing these policies from a gender perspective will ensure that women will be served by the programs. By incorporating gender concerns, programs will reach those most in need and provide them with credit.

\section{Conclusions}

These conclusions are drawn from the researcher's professional involvement with women entrepreneurs in Ghana, analysis of the literature, and the interview data. The study shows a potential for women-owned business development and growth in the city of Tema. Women initiating businesses in Tema will need to understand that: First, Tema women are denied capital when attempting to initiate a business. They are faced with discrimination and sexism from their male counterparts and society at large. Second, outright sexism and discrimination exist among both private and government banks in Tema, but obtaining investment from family members and friends can provide an avenue to capital that may be more beneficial in terms of access and repayment. Third, there is a negative perception and attitude relating to the ability of Tema women-owned businesses to provide quality goods and services. However, this is slowly evolving toward a more positive concept. It will be some time before the negativism is eliminated. Fourth, the economic growth and potential being experienced in the city of Tema will provide business opportunities for the next few years. Tema women entrepreneurs need to study local growth industries and be ready to take advantage of these opportunities. Fifth, Government economic policies discriminate against women entrepreneurs. Sixth, there are very limited, if any, government initiatives in regard to institution capacity building to provide women with the necessary resources they need to start and operate a business successfully. Also there is no government initiative to promote and support innovations among women-owned businesses. Seventh, education, especially business-related training, is crucial to the survival of the interviewees' businesses. Finally, the entrepreneurial innovations of the women in this study, which are manifested in the operations of their businesses, have been a major factor that influenced their survival. Although other factors contributed partially to their survival as stated in this study, their propensity to innovate, through the acquisition of raw materials, product development, production processes, and marketing stands out as the most significant factor that influences the survival of their businesses. Hence, this investigation has answered the following stated research question: What factor has the most influence on the survival of women-owned small businesses in the city of Tema? 


\section{References}

Abor, J. \& Biekpe, N. (2006). A comparison of male-owned and female-owned businesses in Ghana. International Journal of Entrepreneurship and Innovation, 7, 105-112.

Abzug, C. (2002). Impact of SAPs on the female gender in North Ghana. Accra, Ghana: Worldwide Press Ltd.

Ardayfio-Sanchandrof, E. \& Wrigley, C. (2001). Gender-sensitive policies for sustainable livelihood security. Accra, Ghana. University of Ghana Publications.

Ardayfio-Sanchandrof, E. (1999). Poverty assessment profile in rural Ghana. Accra, Ghana: University of Ghana Publications.

Arhin, W. (2000). Profile of women in the informal sector: The case of women in Accra. Accra, Ghana: Grassroots Media.

Audretsch, D. (2004). Sustaining innovation and growth: public policy support for entrepreneurship. Industry and Innovation, 11, 167-191.

Berg, B. (1979). The remembered gate: Origin of African feminism. New York \& London: Oxford University Press.

Brush, C. G. (1997). Women-owned businesses: obstacles and opportunities. Journal of Developmental Entrepreneurship, 2, 1-24.

Bryan, A. \& Burgress, R. (1999). Qualitative research. London, Thousand Oaks, and New Delhi: SAGE Publications. Bryan, A. (1988). Quantity and quality in social research. London, Boston, Sydney, and Wellington. UNWIN HYMAN. Burgelmann, R. A. \& Maidique, M. A. (1996). Strategic Management of Technology and Innovation, Irwin, Chicago, IL.

Collier, M. et al. (2001). Structural adjustment, the informal sector and market women. Accra, Ghana: Friedrich Ebert Foundation.

Creswell, J. W. (1998). Qualitative Inquiry and research design: Choosing among five traditions. Thousand Oaks, London, New Delhi. SAGE Publications.

Drucker, P. F. (1994). Innovation and Entrepreneurship, revised ed, Butterworth-Heinemann, Oxford.

Freel, M. (2000). Barriers to product innovation in small manufacturing firms. International Small Business Journal, 18, 60-80.

Fyle, P. (2002). Socio-cultural obstacles of the participation of women in the democratization process. Cape Coast, Ghana: Odufi Publishing Ltd.

Ghana Ministry of Trade and Industry. (2001). Private sector reinvention and modernization strategy of Ghana: Transforming vision 2020 into reality. Accra, Ghana.

Hakim, C. (1987) Research design: Strategies and choices in the design of social research. London, Boston, and Sydney. ALLEN \& UNWIN.

Heilbrunn, S. (2004). Impact of gender on difficulties faced by entrepreneurs. International Journal of Entrepreneurship and Innovation, 5, 159-165.

Hollowell, C., Mellors, N. \& Silver, J. (2006). Alternative routes: a study on women and technology entrepreneurship in the north-west of England. International Journal of Entrepreneurship and Innovation, 7, 113-120.

Hooks, B. (2000). Feminist theory: From margin to center ( $2^{\text {nd }}$ ed.). Cambridge, MA: South End Press.

IFAD. (2000). Ghana: Women's access to formal financial services, Rural Financial Services Project, IFAD, Rome.

Jaggar, A. \& Rothenberg, P. S. (1984). Feminist frameworks: Alternative theoretical accounts of the relation between women and men $\left(2^{\text {nd }}\right.$ ed.). New York, London \& Paris: McGraw-Hill, Inc.

Joekes, P. (1999). Democracy, governance and economic policy: sub-Saharan Africa in comparative perspective. London, England: Overseas Development Institute.

Johannisson, B. (1986). Network strategies: management technology for entrepreneurship and change. International Small Business Journal, 5, 19-36.

Larsen, P. \& Lewis, A. (2006). Confronting barriers to innovation. International Journal of Entrepreneurship and Innovation, 7,121-126.

McAdam, M. \& McAdam, R. (2006). The role and operation of entrepreneurial networking with the university science park incubator. International Journal of Entrepreneurship and Innovation, 7, 87-97.

Mikell, G. (1997). African feminist: The politics of survival in sub-Saharan Africa. Philadelphia: University of 
Pennsylvania Press.

Osei, B. (1998, September 30). Female and small scaled employment under modernization in Ghana, The Ghanaian Times, pp. E9-E10.

Ridddell, R. (2002). Structural adjustment programs in Ghana: Workshop report. Accra, Ghana.

Rothwell, R. (1994). Industrial innovation: success, strategy, trends, in Dodgson, M., and Rothwell, R., eds, The Handbook of industrial innovation, Edward Elgar, Cheltenham.

Sarris, A. (2002). The demand for insurance by developing countries agricultural producers: Theory and an application to cocoa in Ghana. World Bank Policy Research Working Paper 2887. Washington, D. C.: World Bank Publications.

Schumpeter, J. (1934). The theory of economic development. NY and London: Oxford University Press.

Schumpeter, J. (1947). The creative response in economic history. Journal of Economic History, 7, 149-159.

Scozzi, B. \& Garavelli, C. (2005). Methods for modeling and supporting innovation processes in SMEs. European Journal of Innovation Management, 8, 120-137.

Tripp, S. (2001). Gender, environment, and development in Ghana. Accra, Ghana: Worldwide Press Ltd.

Vossen, R. (1998). Relative strengths and weaknesses of small firms in innovation. International Small Business Journal, 16, 88-94.

Warren, L. (2004). Negotiating entrepreneurial identity: Communities of practice and changing discourses. International Journal of Entrepreneurship and Innovation, 5, 25-35.

Yoshikuni, W. (1999). The regional focus for development strategy in Ghana. Accra, Ghana: Worldwide Press Ltd. 
Table 1. Business Profiles

\begin{tabular}{|c|c|c|c|c|c|}
\hline $\begin{array}{l}\text { Name } \\
\text { Business }\end{array}$ & $\begin{array}{l}\text { Number of } \\
\text { Employees }\end{array}$ & $\begin{array}{l}\text { Owner's } \\
\text { Education }\end{array}$ & $\begin{array}{l}\text { Age of } \\
\text { Owner }\end{array}$ & $\begin{array}{l}\text { Year Firm } \\
\text { Established }\end{array}$ & Type of Business \\
\hline JKL Ent. & 12 & Graduate & 54 & 1986 & Cookware \\
\hline DEF Ent. & 28 & Bachelors & 41 & 1990 & Flowers \\
\hline GHI Ent. & 7 & Bachelors & 56 & 1991 & Arts/Painting \\
\hline PQR Ent. & 26 & Bachelors & 47 & 1983 & Processed Foods \\
\hline STU Ent. & 7 & Certificate & 42 & 1990 & Salon \\
\hline VWX Ent. & 19 & Bachelors & 39 & 1992 & Pd. Foods/Beverages \\
\hline YZO Ent. & 17 & Certificate & 37 & 1993 & Fashions Design \\
\hline CEB Ent. & 10 & Bachelors & 43 & 1995 & Building Materials \\
\hline WBE Ent. & 11 & Certificate & 50 & 1990 & Restaurant \\
\hline MNO Ent. & 5 & Bachelors & 35 & 1994 & Drug Store \\
\hline MAG Ent. & 22 & Bachelors & 43 & 1993 & School \\
\hline FTD Ent. & 12 & Graduate & 46 & 1994 & Textile Fabrics \\
\hline SBI Ent. & 11 & Bachelors & 50 & 1989 & Pd. Foods/Beverages \\
\hline MBB Ent. & 7 & Associate & 38 & 1991 & Restaurant \\
\hline ABC Ent. & 23 & Certificate & 43 & 1988 & Fashions Design \\
\hline UIJ Ent. & 7 & Certificate & 39 & 1995 & Communications \\
\hline IOJ Ent. & 12 & Bachelors & 36 & 1994 & Textile Fabrics \\
\hline PYA Ent. & 6 & Bachelors & 45 & 1995 & Communications \\
\hline UTS Ent. & 13 & Bachelors & 43 & 1992 & Textile Fabrics \\
\hline WVB Ent. & 5 & Associate & 51 & 1989 & Processed Foods \\
\hline IHF Ent. & 12 & Associate & 55 & 1986 & Salon \\
\hline ZAP Ent. & 9 & Bachelors & 39 & 1992 & Clothing Boutique \\
\hline HEZ Ent. & 11 & Graduate & 51 & 1992 & Educational Supplies \\
\hline LQY Ent. & 10 & Associate & 39 & 1993 & Soap Manufacturing \\
\hline DRN Ent. & 10 & Bachelors & 41 & 1993 & Transportation \\
\hline EAK Ent. & 5 & Certificate & 40 & 1994 & Pd. Foods/Beverages \\
\hline SOE Ent. & 20 & Bachelors & 48 & 1991 & Processed Foods \\
\hline AMG Ent. & 8 & Graduate & 44 & 1993 & Structural Design \\
\hline BIG Ent. & 5 & Certificate & 32 & 1994 & Fashions Design \\
\hline TOA Ent. & 7 & Certificate & 46 & 1990 & Fashions Design \\
\hline ZOE Ent. & 16 & Bachelors & 52 & 1988 & School \\
\hline OTD Ent. & 4 & Certificate & 31 & 1996 & Cookware \\
\hline DSM Ent. & 8 & Certificate & 40 & 1990 & Textile Fabrics \\
\hline IMT Ent. & 11 & Certificate & 51 & 1987 & Construction Supplies \\
\hline MKP Ent. & 7 & Certificate & 35 & 1996 & Restaurant \\
\hline UKT Ent. & 4 & Certificate & 41 & 1995 & Salon \\
\hline
\end{tabular}


Table 2. Business Size

\begin{tabular}{|l|l|}
\hline Number of Employees & Number of Businesses \\
\hline $1--------10$ & 19 \\
\hline $11-------20$ & 13 \\
\hline $21-------30$ & 4 \\
\hline
\end{tabular}

Table 3. Business Inception

\begin{tabular}{|l|l|}
\hline Timeline & Number of Businesses \\
\hline $1980-------1990$ & 13 \\
\hline $1991-------2000$ & 23 \\
\hline
\end{tabular}

Table 4. Age Distribution of Interviewees

\begin{tabular}{|l|l|}
\hline Age Groups & Number of Women \\
\hline $30----39$ years & 11 \\
\hline $40----49$ years & 16 \\
\hline $50----60$ years & 9 \\
\hline
\end{tabular}

Table 5. Educational Levels of Interviewees

\begin{tabular}{|l|l|}
\hline Type of Qualifications & Number of Women \\
\hline Certificates & 13 \\
\hline Associate & 4 \\
\hline Bachelors & 15 \\
\hline Graduate & 4 \\
\hline Total & 36 \\
\hline
\end{tabular}

Table 6. Sectoral Composition of Interviewees

\begin{tabular}{|l|l|}
\hline Type of Businesses & Quantity \\
\hline Beauty Salons & 3 \\
\hline Processed Foods & 6 \\
\hline Textile Fabrics & 4 \\
\hline Fashions Design & 4 \\
\hline Education & 3 \\
\hline Restaurants & 3 \\
\hline Cookware & 2 \\
\hline Communications & 2 \\
\hline Construction Supplies & 2 \\
\hline Others & 7 \\
\hline Total & 36 \\
\hline
\end{tabular}


Table 7. Small Business and Professional Development

\begin{tabular}{|l|l|}
\hline Type of Professional Development & Number of Women \\
\hline Attended Business Courses & 22 \\
\hline Attended Entrepreneurship Workshops & 31 \\
\hline Attended Customer Service and Quality Management Training & 27 \\
\hline
\end{tabular}

Table 8. Small Business Finance

\begin{tabular}{|l|l|}
\hline Source of Finance & Number of Women \\
\hline Personal Savings & 33 \\
\hline Family Funding & 31 \\
\hline Friends Lending & 20 \\
\hline Rotating Credit & 15 \\
\hline Other & 4 \\
\hline
\end{tabular}

Table 9. Small Business and Social Responsibility

\begin{tabular}{|l|l|}
\hline Channel of Contribution & Number of Women \\
\hline Unilateral Contribution & 23 \\
\hline Group Contribution & 13 \\
\hline
\end{tabular}

Table 10. Small Business Innovation

\begin{tabular}{|l|l|}
\hline Nature of Innovation & Number of Women \\
\hline Potential Innovation & 9 \\
\hline Actual Innovation & 27 \\
\hline
\end{tabular}

Table 11. Use of Small Business Plan

\begin{tabular}{|l|l|}
\hline Nature of Business Plan & Number of Women \\
\hline Professional Business Plan & 17 \\
\hline Self-Written Business Plan & 11 \\
\hline Wrote Thoughts on Paper only & 5 \\
\hline Have Thoughts in Head & 3 \\
\hline
\end{tabular}

Table 12. Small Business and Social Support System

\begin{tabular}{|l|l|}
\hline Sources of Social Support & Number of Women \\
\hline Strong Family Support & 36 \\
\hline Women Business Organization Support & 30 \\
\hline Local Community Support & 27 \\
\hline Trade Association Support & 31 \\
\hline Government Support & 3 \\
\hline
\end{tabular}


Table 13. Social Group Affiliation

\begin{tabular}{|l|l|}
\hline Type Of Affiliation & Number of Women \\
\hline Trade Association & 30 \\
\hline Women Business Organization & 32 \\
\hline Church-based Business Organization & 27 \\
\hline Regular Social Network & 29 \\
\hline
\end{tabular}

Table 14. Small Business Obstacles

\begin{tabular}{|l|l|}
\hline Type Of Obstacle & Number of Women \\
\hline No Access to Credit & 36 \\
\hline High Taxes & 27 \\
\hline Difficulty Obtaining Business License & 29 \\
\hline Sexism & 31 \\
\hline No Central Business Information Center & 25 \\
\hline Difficulty Obtaining Raw Materials & 5 \\
\hline
\end{tabular}

Appendix A: Research Instrument (Interview Guide)

1. What would you say to an aspiring women entrepreneur about how you developed into a good businesswoman?

2. What would you say to woman who wants to start a small business in Tema in regard to social responsibility and employee relations?

3. How do you ensure you provide excellent customer service?

4. How do you ensure you provide high quality products?

5. What was your vision for the future when you started your business?

6. How did you transform your vision into a business reality?

7. What were some of the obstacles you encountered when starting your business?

8. How did you overcome the obstacles you encountered when starting your business?

9. What advice or guidance would you provide to an aspiring woman entrepreneur in regard to starting a small business and its survival in the city of Tema? 


\title{
Research on the Exit Routes of Chinese Private Equity Funds
}

\author{
Jingjing Yang \\ School of Inter-culture Studies, Jiangxi Normal University \\ 99 Ziyang Road, Nanchang, Jiangxi, China PR, 330022,China \\ E-mail: ysydnc@hotmail.com \\ Lesha Zhang \\ 402, no. 42, jingyuan road, jiading district, shanghai, 201800, China \\ E-mail: zhanglesha@hotmail.com
}

\begin{abstract}
Up to the present, private equity (PE) is a relatively new financial instrument in China. Due to the rapid growth of Chinese economy, a great number of domestic and overseas capitals had participated in PE business in recent years. PE usually claims back the funds from the investment after earning satisfactory profits. The primary exit routes for PE include IPO, write-offs, Management Buyout (MBO), repayment of shares or loans and sold to other venture capitals or financial institutions. Among these strategies, IPO has always been the dominant exit routes for PE. Nonetheless, PE faced a few obstacles withdraw the funds from investment through IPO in China lately, such as the bad performance of domestic stock market and the tight monetary policy. Accordingly, PE should consider further the effectiveness of these routes when reclaiming the funds from the investee companies.
\end{abstract}

Keywords: Research, Exit, PE, IPO, M\&A, MBO, Transfer

\section{Circumstance of current Chinese Private Equity}

Private equity (PE) is an asset class consisting of equity securities in operating companies which are not publicly traded on a stock exchange. PE is a fairly new financial instrument in China and developing extremely rapidly recently. Numerous domestic and overseas capitals have been rushing into the industry in recent years. However, the industry is lack of a systematic legal environment and formal regulations, especially in the aspect of exiting. After the new Partnership Business Law (PBL) was promulgated on $1^{\text {st }}$ June 2007, a number of new limited partnership PE have emerged in Chinese financial market. These limited partnership PE which had existed and been operated effectively in western countries for long are fairly fresh and popular in China presently. Compared with other sorts of privately offered funds (POF) in Chinese financial market, limited partnership PE performed much more actively and flexibly. Most of privately offered funds in China not only invest in secondary market, but also are involved in private placement, strategic allotment, private equity investment, etc. However, nearly all the limited partnership privately equity funds in western countries has a promissory duration of operation. These POF would exit the market on the date of maturity to pay back the limited partners as investment returns. Moreover, as an important form of privately offered funds, PE usually reclaims the funds from the investment after gaining satisfactory profits. Thus, the exit routes of Chinese limited partnership privately offered funds, and especially PE should be researched in advance to prevent a chaotic phenomenon in future.

Chinese POF used to operate primarily in two different models which are account management model and trust plan model before the promulgation of the new Chinese Partnership Business Law. In the account management model, investors usually open an account with a stock broker in the name of themselves firstly. Then the funds managers will act on behalf of the investors to manage their accounts. If the net value of investment has lost more than a certain percentage, say $10 \%$, investors is permitted to end the clientage unilaterally. Oppositely, the profit exceeding $10 \%$ will be distributed at a promissory ratio. Most of petty POF are operating in this model, and main investors are from funds custodians' relative or friends. Because such type of POF is short of legal safeguard, both investors and custodians could not appeal to court if their benefits had been infringed. On the contrary, a great number of POF with huge amount of capital may raise funds and invest collectively in the way of trust plan (Yang Jingjing, 2008). Hence, it is a fairly regular POF model at present. Compared with the circumstance in China, limited partnership PE is the dominant form of PE in developed countries, especially US. A majority of PE in China are running in this way before the new PBL was enacted on $1^{\text {st }}$ June 2007. 
Nowadays, PE is crucial to the capital markets overseas. For instance, according to the statistics of KPMG, the gross monetary amount of M\&A is 1300 billion US dollars from Jan 2006 to November 2006 in US. 35\% of them were supported by PE (Ba Shusong, 2007). As a prosperous financial industry, PE also plays a more and more significant role in current Chinese capital market. 12 domestic PE had established in 2007 compared to the only 6 new PE appeared in 2006. These 12 funds had risen 3.73 billion US dollars which had gone up by 145.9 percent in 2007. Additionally, in all 12.818 billion US dollars had been invested in Chinese mainland by PE in the past year. In terms of industrial distribution, the Broad IT industry continued to lose weight in the total equity investment. Oppositely, the Traditional and Services industries became hot investment sectors in the year 2007.

In 2007, Chinese PE industry had changed quite a lot, especially in the aspect of investment strategy. On the one hand, more and more PE became interested in investing their funds on bridge finance and PIPE (private investment in public equity). In 2007, 22 investments had been taken place in the form of Pre-IPO capital compared with only 11 in 2006. For instance, the investment of 100 million US dollars made by Carlyle Group in New Century international hotel management limited company was accomplished through the way of bridge financing in 2007. Besides that, Merrill Lynch, Deutsche Bank and Temasek Holdings also had invested 400 million US dollars in Heng Da real estate group while Heng Da planed to list in Hong Kong Stock Exchange. In addition, 22 PE had invested their funds in the form of PIPE in 2007 in contrast with only 19 in 2006. On the other hand, few PE had made their investments in the form of Mezzanine Capital and turnaround in 2007. 9 investments of 843 million US dollars which are $6.6 \%$ of total amount of the year occurred in 2007.

\section{Obstacles of claim back the funds through IPO}

From the late 2007, Chinese stock market has been performing much more like a bear market. Shanghai Security Index has felt from the top 6124.04 in 16 October 2007 to 3271.29 in 2 April 2008. Consequently, investing on stock market has not been the merely leading investment strategy of domestic POF at present. Thus, Private equity has become the principal investment channel for domestic POF lately. $94 \mathrm{PE}$ had withdrawn funds from the companies invested in 2007. $84 \%$ of these, which are 79 cases had reclaim the funds through IPO. In addition, some of investors of other 9 PE decreased their shares to exit. Investors of $5 \mathrm{PE}$ sold their shares to other investors to claim back the funds. Besides, only 1 PE quit the market by M\&A in 2007. Take United States for example, American PE usually exits from the market within 5 years at present. The primary exit forms include IPO, management buyout (MBO), write-offs, repayment of shares or loans and sold to other venture capitals or financial institutions. IPO is an extremely popular way for these funds to exit the market. Similarly, IPO is also the most ideal route for PE to claim the money for the moment. On the one hand, one of the best news for PE to exit the investment in domestic enterprises is that the Second Board Market which is also called Growth Enterprises Market in China will open within 2008. According to the current listing requirements of Medium and Small Size Board, to be listed on Shanghai and Shenzhen Stock Exchange, a company is expected to demonstrate earning power of aggregate profit for the last three fiscal years of 300 million Chinese Yuan together with a minimum in the most recent fiscal year of 50 million Chinese Yuan. Additionally, all three years must be profitable. Compared with the main board, the requirement of profitability and other financial factor will certainly be much lower. Based on current media report, the requirement of aggregate profit for enterprises listed on Second Board would be minimum 10 million Chinese Yuan for the last three fiscal years. Besides that, the requirement for stock volume would be not less than 15 million shares before listing. Obviously, the emergence of Second Board would be highly advantageous to PE.

On the other hand, according to the agreement of cooperation on financial service sector concluded after the third China-U.S strategic economic dialogue on December 2007, China Security Regulatory Commission (CSRC) will evaluate the influence of foreign capital holding shares in domestic security companies (Gao Qin, 2008). After the evaluation, CSRC will offer a policy proposal for adjusting the authorized proportion of foreign capital share participation in domestic security companies. Furthermore, qualified foreign investment companies and banks are permitted to issue shares in Chinese Yuan on Shenzhen and Shanghai stock exchange.

Nevertheless, there are still a few barriers for PE to reclaim the funds from the investee companies through IPO. First of all, the exact number of companies permitted to list on Second Board every year is still unknown. Consequently, what is certain is that numerous domestic small and medium size companies with shares held by PE may not make their dream come true in the near future. Additionally, the performances of both Shanghai and Shenzhen stock market will be doubtable under the pressure from the issuing of restricted shares. Based on current data, in all 412 listed companies announced the reduce stake from 2006 to $1^{\text {st }}$ April, 2007. Furthermore, among all these listed companies, 83 companies declared having sold initial offering more than $30 \%$ of total share capital.

Moreover, the reduce stake of restricted shares commence to reach a climax in 2008. As estimated, 118.127 billion, 663.742 billion and 121.321 billion restricted shares will come into the market in year 2008; 2009 and 2010. The market value of Shanghai and Shenzhen stock exchange was approximately 7556.574 billion Chinese Yuan. In term of current price level, the market value of two stock exchanges will be 9314.981 billion Chinese Yuan at the end of 2008. 
In addition, the market value will increase by $66.10 \%$ to 6157.79 billion Chinese Yuan in the end of 2009 . In the end of 2010 , the market value of two stock exchanges will increase by $43.27 \%$ to 22285.494 billion Chinese Yuan. It is almost 3 times than current market value (Chang Yan, 2008).

To make matter worse, tight monetary policy is adopted by Chinese government to attain a soft-landing of domestic economy. Hence, these PE would face the problem of insufficient capital when exiting the investment market by IPO. Furthermore, the whole procedure of IPO usually takes probably 18 months in China. The condition of domestic stock market after 18 months is too unclear to be forecasted. Moreover, it has been more and more difficult for domestic companies to be listed overseas since the Ministry of Commerce had been endowed with the authority of permission for domestic companies offering shares overseas through the documentation of the regulation on merger and acquisition for foreign investors in China issued on $8^{\text {th }}$ September 2006. Numerous early VC (Venture Capital) and PE active in China had oversea background, so that IPO overseas used to be the most ideal way to exit. The first-day return of IPO in Hong Kong is 6.37 which is the highest among all IPO overseas in 2007 (China Venture, 2008). Nevertheless, more and more $\mathrm{PE}$ in China would choose to list the investee companies on domestic stock exchange instead of oversea stock markets.

\section{Advises for PE withdrawing the funds}

Two suggestive arrangements could help PE claim back the funds through IPO more fluently under current circumstance. Firstly, PE should add a few defensive clauses in the investment contract signed with the target companies. For instance, the stock repurchase agreement could be executed to force the company buy back the shares when the performance of the company is not as ideal as predicted. Secondly, domestic PE should hold enough shares to control the target company sufficiently when made the investment decisions. Accordingly, the resolution of listing could be passed by management board more easily. Besides that, PE also could switch to another exit route much conveniently when facing obstacles in IPO.

Additionally, the CSRC (Chinese Securities Regulatory Commission) is working on the integration of all the regional assets and equity exchange markets to promote a multi-level domestic capital market these days. If a united state over the counter (OTC) market could be established in the near future by bring all the regional assets and equity exchange markets into the third board which is also called Particular Transfer Sector. An effective and integrated assets and equity exchange market is beneficial to PE to transfer the shares held in unlisted companies or companies failed to IPO.

Generally, people tend to think that private equity funds will obtain higher returns in exits via IPO, compared with those via trade sale and MBO. Nevertheless, when comparing those returns, they have not taken into account the duration of each deal from investment to exit. When calculating the investment returns of those exits, PE-backed investments with IPO as exiting route are mainly distributed in the late- stage enterprises, a major percentage of which are in the Pre-IPO period. Their investment term is relatively short while the term for investments adopting the other two exit routes generally last more than three years. Therefore, the average overall investment multiples for trade sale and MBO are higher than that for IPO (Leo Liu, 2007). Notwithstanding, both investors and PE are inclined to reclaim the funds within a fairly short period due to the instable global economic situations, Consequently, IPO is still an ideal form for private equity funds to exit in the investment in Chinese enterprises (Leo Liu, 2007). Besides that, the regional economic conditions of investee companies are also significant to the exit decisions. At present, a majority of companies invested by PE centralized in Beijing and southeast coastal areas in China. Because these regions are far more developed than cities in southwest and northwest of China, companies could acquire more resource and support from local government. The predominance in human resource, material resource and technology also could help PE achieve the goal of exiting much fluently after gaining enough profits from the investment.

Hypothetically speaking, the custodians of PE in China should consider other exit routes even if $84 \%$ of domestic PE had quit the market by IPO in 2007. Besides IPO, other 9 PE had exited the market by stock reduction. Another 5 PE sold their shares to other investors to exit from the fund business. Furthermore, 1 fund quit the market by M\&A in 2007. In addition, these exit routes may gain more profit than PO. According to the statistics of Zero2IPO, in all 53 trades of exiting had been happened in PE business in 2006. 23 of these 53 trades had been accomplished by IPO. The analysis on 34 of these 53 trades shows that the arithmetic mean and median of investment return are 2.98 and 2.60. Both of them are lower than data of the return of share transfer and management buyout. Consequently, the adoption of other routes of exiting is duly acceptable when encountering obstacles in IPO. Moreover, a combined way of exiting had emerged in Chinese PE industry recently. For instance, some multinational investment banks had arranged a combined exit route for Taizinai group to claim back their capital before they had made the investment. Actis, Morgan Stanley and Goldman Sachs hold in all 30\% shares of the joint venture company after they had invested 73 million US dollars in Taizinai group on $7^{\text {th }}$ Jan 2007. Taizinai group is the largest producer of yogurt drink in China. It had constantly exceeded $100 \%$ for 11 years in terms of CAGR (Compound Annual Growth Rate). Its domestic sales value in 1997 was only 5million Chinese Yuan, but it reached nearly 3billion Chinese Yuan in 2007. Additionally, this group are running business in 8 different industries, including milk and logistic. Neither Taizinai group nor its subsidiary companies were listed when these PE participated in the group. After these multinational investment banks become the shareholders of 
Taizinai, they intended to separate and restructure the company for a better valuation (Yin Xiankai, 2007). Part of the subsidiary companies can be listed in order to withdraw the funds in secondary market. Besides that, the shares of other non-listed divisions can be transfer to outside parties or repurchased by the company. The model adopted to reclaim the funds in Tainizai group combines IPO with stock transfer and stock repurchase. Such a fresh exit strategy is a greatly efficient and operative route for current Chinese PE to withdraw their funds, especially under the circumstance of poor performance of domestic stock market. Nonetheless, this may not be suitable for reclaiming funds from the investment in companies which concentrate on only one industry.

\section{Conclusion}

To date, IPO is still the leading exit routes for PE to reclaim the funds from the investment. Nevertheless, Chinese stock market has been performing much more like a bear market since the late 2007. Besides, the reduce stake of restricted shares commences to reach a climax in 2008 and will last in future 2 years. The whole market is not well forecasted by analysts. To make matter worse, tight monetary policy is adopted by Chinese government to avoid overheated economy. Consequently, $\mathrm{PE}$ in China should consider more about other exit routes to withdraw the funds when facing obstacles in IPO. Additionally, the combined way of exiting is also a practical strategy for PE. For instance, the model adopted to reclaim the funds in Tainizai group combines IPO with stock transfer and stock repurchase. To sum up, PE industry is short of a systematic legal environment and formal regulation, especially in the aspect of exit. Furthermore, there are also not adequate experience can be adopted for reference. PE in China should consider all the economic and legal factors deliberately when reclaiming the funds from the investee companies.

\section{References}

Ba, Shusong. (2007). PE in Europe and US likes a duck to water. Popular Financing

Chang, Yan. (2008). Chinese VC and PE investment market developed rapidly in 2007. Capital Markets

China Venture. (2008). China Venture Capital Market Annual Report 2007.

Gao, Qin. (2008). Active PE investment Market Domestic IPO becomes the primary channel. Security Daily

Liu, Leo. (2007). Analysis on China PE Performance in 2006: Investment Return Realized via IPO is lower than that via Trade Sale and MBO. Zero2IPO Group.

Yang, Jingjing. (2008). The practical analysis on participators of current Chinese POF. International Journal of Business and Management

Yin, Xiankai. (2007). Combined form of exit-Model of Taizinai appears in PE industry for the first time. The Economic Observer Newspaper 


\title{
The Influences on the Frequency with Which Product Costs
}

\section{Are Used in Decision Making}

\author{
John A. Brierley \\ Management School, University of Sheffield, 9 Mappin Street \\ Sheffield, S1 4DT, United Kingdom \\ Tel: 44-114-222-3431Ｅ-mail: j.a.brierley@sheffield.ac.uk
}

\begin{abstract}
This paper assesses the influence of the level of competition, product customization, importance of product costs in decision making and operating unit size on the frequency with which product costs are used in decision making. As the frequency of use is measured on a three-point ordinal scale of sometimes using, often using or using product costs all the time in decision making, the influence of the four constructs is tested using ordinal regression rather than ordinary least squares regression. Based on the questionnaire responses from 240 British management accountants, the results of the ordinal regressions show that the log odds of operating units sometimes using, or sometimes or often using product costs in decision making is negatively related to the importance of product costs in selling price decisions and operating unit size measured by the number of employees.
\end{abstract}

Keywords: Frequency of use of product costs, Importance of product costs, Ordinal regression, Questionnaire survey

\section{Introduction}

The product costing system should report accurate product costs to make decisions relating, for example, to the pricing, introduction, discontinuation and response to rival products (Cooper \& Kaplan, 1987; Johnson \& Kaplan, 1987). Although there are studies that have examined the extent to which product costs are used in decision making (e.g. Emore \& Ness, 1991; Joshi, 1998), many surveys of product costing practice have not considered the frequency with which product costs are used in decision making (e.g. Joye \& Blayney, 1990; Cohen \& Paquette, 1991; Dean et al. 1991; Kellett \& Sweeting, 1991; Clarke, 1992, 1997; Green \& Amenkhienan, 1992; Drury et al., 1993; Lukka \& Granlund, 1996). Furthermore, to the author's knowledge, prior research has not considered the factors influencing the frequency with which product costs are used in decision making, and hence there is a need to conduct exploratory research in this area. Consequently, this paper uses the results of a research study involving a questionnaire survey of management accountants working in British manufacturing industry to identify the factors influencing how frequently product costs are used in decision making.

In this research product costs were found to be used either sometimes, often or all the time in decision making. Given that it is difficult for a subjectively coded three-point scale to approximate an interval scale, it is not possible to apply ordinary least squares (OLS) regression analysis because OLS regression assumes that the dependent construct is coded on at least an interval scale, with equal intervals between the various points on the scale. Ordinally coded data assumes that there is a ranking between points on a scale, but it does not make any assumption about the distance between the points. Consequently, ordinally coded data, as in this research, should not be used as a dependent construct in OLS regression. This problem can be overcome by using ordinal regression, which does not make any assumption about the size of the intervals between points on ordinally coded data (see e.g., Bender \& Benner, 2000; McCullagh, 1980; McCullagh \& Nelder, 1989; Norusis, 2005). In addition, unlike OLS regression, ordinal regression does not require a constant variance in the residuals.

Unlike binary logistic regression, which considers the log odds of an individual event occurring when the dependent construct is binary coded, ordinal regression considers the log odds of an event occurring and all other events that are ordered before it. Hence, the objective of this paper is to use ordinal regression analysis to develop and test a model of the influences of the level of competition, product customization, importance of product costs in decision making and operating unit size on the frequency with which product costs are used in decision making. The results show that the importance of product costs in decision making and operating unit size, when measured by the number of employees, have a significant influence on the log odds of the frequency of use of product costs in decision making.

The remainder of the paper is structured into a further four sections. Section two proposes four hypotheses relating to the influence of the four factors on the use of product costs. Section three describes the research methods in terms of a 
questionnaire survey of management accountants working in British manufacturing industry and the data analysis using ordinal regression. Section four reports the results of the ordinal regression analysis. Section five concludes the research, and identifies its limitations and opportunities for future research.

\section{Research hypotheses}

Four constructs are examined as possible influences on the frequency with which product costs are used in decision making. The possible influence of each of these constructs is discussed below and because of the exploratory nature of this research. This results in a series of research propositions for each construct, rather than a list of hypotheses.

\subsection{Competition}

Prior research has identified a positive relationship between the level of competition in the marketplace and the use of management accounting systems (Khandwalla, 1972; Mia \& Clarke, 1999). In relation to product costing, it can be argued that as the level of competition increases it is necessary that firms should make greater use of their management information systems to obtain the data necessary to make good quality decisions to compete effectively in competitive markets. To do this, there is a need to rely on a variety of different types of management information, including product cost information. If firms do not do this, then a competitor or competitors may take advantage of errors arising from decision making based on incomplete information. Consequently, it is expected that operating units facing a high level of competition would be likely to make more use of product costs in decision making. Hence:

$\mathrm{P}_{1}$ : As the level of competition increases, the frequency with which product costs are used in decision making increases.

\subsection{Product customization}

Customized products are produced in manufacturing processes that are non-repetitive manufacturing processes for which it is not possible to calculate standard production costs (Drury \& Tayles, 2005)(Note 1). If a company is producing customized products, the variety of products produced will increase and each of these products is likely to have a different product cost, because it will have been produced differently and contain different components to other products. To ensure that appropriate product related decisions are made when a variety of customized products are produced, there is a need to use product cost information frequently in decision making. Hence:

$\mathrm{P}_{2}$ : As the level of product customization increases, the frequency with which product costs are used in decision making increases.

\subsection{Importance of product cost in decision making}

The higher the importance of product costs in decision making it is expected that the more likely they will be used more frequently in decision making. Hence:

$\mathrm{P}_{3}$ : As the level of importance of product costs increases, the frequency with which product costs are used in decision making increases.

\subsection{Operating unit size}

Larger operating units are likely to have access to more resources, have more contacts and communication channels than smaller operating units (Bjørnenak, 1997). In larger operating units, resources could take the form of the quantity and expertise of staff to analyse product cost information, which could lead to them using product cost information more frequently in decision making. Hence:

$\mathrm{P}_{4}$ : As the operating unit size increases, the frequency with which product costs are used in decision making increases.

\section{Research method}

\subsection{Research questionnaire}

Possible questionnaire respondents were obtained from a list of 854 members of the Chartered Institute of Management Accountants who were working in British manufacturing industry and had the job title of cost, management or manufacturing accountant. An introductory letter was posted to all possible respondents explaining the purpose of the research and that they would receive a questionnaire in two weeks time. Accompanying each questionnaire was a covering letter, which assured respondents of the confidentiality of their responses, and a stamped-addressed envelope. Non-respondents to the questionnaire were posted a follow-up letter two weeks later, and a further follow-up letter, questionnaire and stamped-addressed envelope were posted to non-respondents two weeks after that. After identifying possible respondents who worked in the same operating unit, had left their operating unit, operating units which had closed down, and possible respondents whose work did not involve manufacturing or product costing, the total possible respondents employed in independent operating units declined to 673. A total of 280 usable questionnaires were received (effective response rate $=41.6$ percent) and, of these, 274 respondents indicated that they used product costs in decision making (Note 2).

The existence of non-response bias was tested by Mann-Whitney tests comparing respondents who had returned the 
questionnaire before the first reminder had been sent out $(n=131)$ and those who returned the questionnaire after the second reminder had been sent out $(n=51)$. This did not reveal any significant differences between these two types of respondent on any of the research constructs $(\mathrm{p}>0.05)$ (Note 3$)$. Hence, non-response bias may not be a problem.

\subsection{The ordinal regression model}

The ordinal regression model for a dependent construct defined as the frequency with which product costs are used in decision making is:

$\ln \left(\theta_{\mathrm{j}=1,2}\right)=\alpha_{\mathrm{j}=1,2}-\beta_{1}$ COMP $-\beta_{2}$ CUST $-\beta_{3}$ IMPORT $-\beta_{4}$ SIZE $+\mathrm{e}$

Where:

$\ln \left(\theta_{\mathrm{j}=1,2}\right) \quad=\quad$ The link function that connects the independent constructs of the linear model. In this case, it is the natural logarithm of $\theta_{\mathrm{j}=1,2}$, where $\mathrm{j}$ is the number of link functions. In this research there are two link functions (Note 4 ), that is $\mathrm{j}=\mathrm{k}-1$, where:

$\mathrm{k}=$ The number of points on the ordinally coded scale of the dependent construct, in this case a three-point scale.

$\theta_{\mathrm{j}=1,2}=$ The odds of an event occurring, that is $\mathrm{pk} /(1-\mathrm{pk})$, where:

$\mathrm{pk}=$ The cumulative probability of an event or events occurring, and

$1-\mathrm{p}_{\mathrm{k}}=$ the cumulative probability of that event or events not occurring.

In this case:

$\theta_{1}=\mathrm{p}$ (sometimes using product costs) $/ \mathrm{p}$ (often using or using product costs all the time)

$\theta_{2}=\mathrm{p}$ (sometimes or often using product costs) $/ \mathrm{p}$

$\alpha_{\mathrm{j}=1,2} \quad=$ A constant term for each of the link functions.

$\beta_{1-4} \quad=$ The ordinal regression coefficients.

COMP $=$ The level of competition.

CUST $=$ The level of product customization.

IMPORT $=$ The importance of product costs in selling price decisions.

SIZE $=$ The operating unit size, measured by SALES $=$ Annual sales revenue or EMPLOYEES $=$ Number of employees.

e $\quad=$ Residual error term.

The ordinal regression model is a cumulative logit model, because it is based on the cumulative probabilities of an event occurring. Hence, $\theta_{1}$ is the probability of operating units sometimes using product costs, relative to those that are often using or using them all the time, and $\theta_{2}$ is based on the cumulative probability of operating units sometimes or often using product costs relative to those that are using them all the time. As ordinal regression is a form of logistic regression and its parameters are estimated using the maximum likelihood method, each logit has its own different constant term, but the same set of $\beta$ s. Hence, the two ordinal regression equations are assumed to be parallel. This means that the four independent variables in the model have the same effect on the two logit functions. Thus, the two logit functions are:

$\ln \left(\theta_{1}\right)=\alpha_{1}-\beta_{1}$ COMP $-\beta_{2}$ CUST $-\beta_{3}$ IMPORT $-\beta_{4}$ SIZE $+\mathrm{e}$
$\ln \left(\theta_{2}\right)=\alpha_{2}-\beta_{1}$ COMP $-\beta_{2}$ CUST $-\beta_{3}$ IMPORT $-\beta_{4}$ SIZE $+e$

Given that there are two size measures, there are two versions of each logit function depending upon whether size is measured by the annual sales revenue or the number of employees.

The model is written as subtracting the $\beta$ s from the link function because of the form of the ordinal regression model. For example, although the level of competition is assumed to be related positively to the frequency with which product costs are used in decision making, the logit link is calculated so that it considers the log odds of operating units sometimes using product costs (code $=1)$, and operating units sometimes using or often using products costs (codes $=1$ and 2 respectively). As these are the smaller valued codes on the scale measuring the frequency of use, the level of competition would be expected to be related negatively to the log odds of each of these events occurring.

\subsection{Construct measurement}

Respondents were asked to answer the questionnaire from the perspective of the operating unit in which they worked, such as the division of a divisionalized company, factory within a division or a non-divisionalized company. The extent to which operating units' used product costs in decision making (defined as selling price, make-or-buy, product mix, 
output level, cost reduction, product design etc., decisions) was obtained from a single question with responses of $1=$ used all the time, $2=$ often used, $3=$ sometimes used, $4=$ rarely used and $5=$ never used, which were then reverse scored for data analysis.

The level of competition was measured by two questions developed by the researcher. The first question assessed the general level of current competition for the major products of the operating unit with responses on five-point Likert scale ranging from $1=$ Very intense to $5=$ Very slack. The second question asked for information about the level of expected competition over the next two years for the major products of the operating unit, with responses ranging from $1=$ Very high and $5=$ Very low. For data analysis, the scores on the two questions were reverse scored and initially summed and divided by 2 to provide a measure of the general level of competition on a nine-point scale from a low score of 1 to a high score of 5. Product customization was measured by two questions developed by the researcher. From these two questions, respondents identified the range of products produced by their operating unit on a five-point Likert type scale. For the first question responses ranged from $1=$ Virtually all customized products, to $5=$ Virtually all standardized products. For the second question responses ranged from $1=$ At least $95 \%$ of products produced are unique and produced to satisfy individual customer's orders, to $5=$ At least $95 \%$ of products are identical products produced in large quantities. The responses to both questions were initially reverse scored for data analysis and summed and divided by 2 to give a low score of 1 to a high score of 5 (Note 6).

The importance of product costs in decision making was assessed by its importance in selling price decisions, because it is an important decision that most organizations will have to undertake and, in which, product costs are likely have some role (e.g. Cooper \& Kaplan, 1987; Drury et al., 1993). The importance of product costs in selling price decisions was assessed by responses on a six point scale ranging from $1=$ Very important to $5=$ Very unimportant and $6=$ Do not make this type of decision. For the purpose of data analysis, only those operating units making selling price decisions were included, and the importance measure was reverse scored for analysis. Operating unit size was measured by annual sales revenue of and the number of employees employed by the operating unit. Respondents were asked to indicate the approximate annual sales revenue of their operating unit in the last financial year and the approximate number of employees in their operating unit.

\section{Results}

The ordinal regression analysis was applied using listwise deletion, which resulted in a sample of 241 respondents. All of these operating units made some use of product costs in decision making, but because only one operating unit rarely used product costs in decision making this was eliminated from the data analysis and the usable sample declined to 240 respondents. The results of ordinal regression analysis including the raw scored independent constructs revealed that, of the cells between the dependent construct and the independent constructs, 66.5 percent were empty when size was measured by annual sales revenue and 66.2 percent were empty when size was measured by the number of employees. The high level of empty cells meant that the goodness-of-fit statistics for the ordinal regression equations were unreliable (Norusis, 2005). To increase the dependability of these goodness-of-fit statistics it was necessary to reduce the number of empty cells between different values of the dependent construct and different values of the independent constructs, and the number of cells with small expected values on the points on the scales of each independent construct. This was achieved by rescaling the independent constructs, and, by trail and error, this led to the scales of the independent constructs being reduced to three-point ordinal scales.

There was no need to change the coding for the use of product costs measure because operating units either sometimes used ( $\operatorname{code}=1)$, often used $(\operatorname{code}=2)$ or used product costs all the time (code $=3$ ) in decision making. For the competition measure, as no operating units had a score of 1 or 1.5 and only one operating unit had a score of 2, the responses were reduced to a three-point scale with scores of 2, 2.5 and 3 being recoded 1, scores of 3.5 and 4 being recoded 2, and scores of 4.5 and 5 being recoded 3 . The responses to the product customization measure were spread more evenly. Hence, the scale was reduced to a three-point scale with scores of $1,1.5$ and 2 being recoded 1 , scores of $2.5,3$ and 3.5 being recoded 2 , and scores of $4,4.5$ and 5 being recoded 3 . The importance of product costs in decision making was recoded, with scores of 1 and 2 being recoded as 1 , a score of 3 being recoded as 2 , and scores of 4 and 5 being recoded as 3 . The annual sales revenue measure was coded $£ 0 \mathrm{~m}$ to $£ 20 \mathrm{~m}=1$, greater than $£ 20 \mathrm{~m}$ to $£ 100 \mathrm{~m}=2$ and greater than $£ 100 \mathrm{~m}=3$. The number of employees was coded 0 to 100 employees $=1,101$ to 500 employees $=2$ and greater than 500 employees $=3$.

The distribution of responses for all of the constructs in the ordinal regression model is shown in Table 1. This table shows that most operating units use product costs at least often in decision making, face a high level of competition, have varying levels of product customization, regard product costs as being important in selling price decisions and are moderately sized.

Table 2 shows the Spearman Rank correlation coefficients between the six construct measures, and that the only significant correlations with the level of use of product costs was for the importance of product costs and for the number of employees. This indicates that these constructs may be related to the use of product costs in the ordinal regressions. 
Unsurprisingly, the largest correlation was between the two size measures $(r=0.693)$, but this is of no importance because these two constructs do not appear in the same ordinal regression equations. The other significant correlation was between annual sales revenue and the level of competition, but the low correlations between the independent constructs indicates that multicollinearity is unlikely to be a problem in the ordinal regressions.

Table 3 shows the results of the ordinal regressions and reveals that the importance of product costs in selling price decisions and the number of employees were significantly related to the level of use of product costs. Hence, proposition 3 is accepted and proposition 4 is partly accepted, because the size effect for the annual sales revenue was not significant $(\mathrm{p} \geq 0.05)$. In addition, there were non-significant effects for competition and product customization, and, hence, propositions 1 and 2 were rejected. The ordinal regression equations for the frequency of use of product costs were, when size was measured by annual sales revenue were:

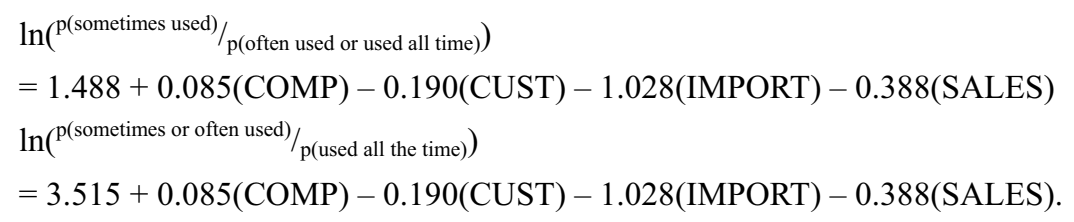

When size was measured by the number of employees the ordinal regression equations were:

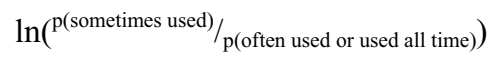

$=2.185+0.053(\mathrm{COMP})-0.187(\mathrm{CUST})-1.022($ IMPORT $)-0.625($ EMPLOYEES $)$

$\ln \left({ }^{\mathrm{p}(\text { sometimes or often used }) / \mathrm{p} \text { (used all the time) })}\right.$

$=4.243+0.053(\mathrm{COMP})-0.187(\mathrm{CUST})-1.022(\mathrm{IMPORT})-0.625($ EMPLOYEES $)$.

This shows that the log odds of an operating unit either sometimes, and sometimes or often using product costs in decision making was related negatively to the importance of product costs in selling price decisions and to the number of employees. Alternatively, the log odds of an operating unit having used product costs all the time in decision making, or often used or used all the time was related positively to importance and the number of employees (Note 7).

It is necessary to test if the two regression lines are parallel, in other words that the relationship between the independent constructs and the two link functions is the same for each of the link functions. This test compares the model assuming that the two lines are parallel with the model assuming separate lines. A non-significant chi-square statistic indicates that the two lines are parallel and that the relationship between the independent constructs is the same for the different link functions of the dependent construct. If the chi-square statistic is significant then different models are required for the different link functions. The test for parallel lines when the ordinal regression model included size measured by annual sales revenue was chi-square $=2.900, \mathrm{p}=0.575$ and when size was measured by the number of employees, chi-square $=2.647, \mathrm{p}=0.619$. The non-significant chi-square indicates that the two lines are parallel.

If the model provides a good fit of the data, the observed and expected cell counts are similar, and there is no significant difference between them. When size was measured by annual sales revenue the goodness-of-fit statistics were:

Pearson: $\quad$ chi-square $=80.104, \mathrm{p}=0.476$ and

Deviance: $\quad$ chi-square $=86.577, \mathrm{p}=0.288$.

When size was measured by the number of employees, the goodness of fit statistics were:

Pearson: $\quad$ chi-square $=88.056, \mathrm{p}=0.204$ and

Deviance: $\quad$ chi-square $=91.659, \mathrm{p}=0.138$.

The non-significant goodness-of-fit statistics indicates that the model provided a good fit of the data, and the observed and expected cell counts were similar. In addition, the model fitting test compares the model with predictors to the model without predictions. A significant chi-square indicates that a model with predictors provides a better fit to the data. When size was measured by the annual sales revenue: chi-square $=16.547, \mathrm{p}=0.002$, and when size was measured by the number of employees: chi-square $=22.097, \mathrm{p}=0.000$. In both cases the models including predictors provided a better fit to the data than if they were not included.

Although the objective of the research was to develop a model of the factors influencing the use of product costs, measures of the strength of the association between the independent constructs and the dependent construct are reported for completeness. When size was measured by annual sales revenue, the strength of the associations were Cox and Snell pseudo $\mathrm{R}^{2}=0.067$, Nagelkerke pseudo $\mathrm{R}^{2}=0.079$ and McFadden pseudo $\mathrm{R}^{2}=0.038$. When size was measured by the number of employees they were Cox and Snell pseudo $\mathrm{R}^{2}=0.088$, Nagelkerke pseudo $\mathrm{R}^{2}=0.105$ and McFadden pseudo $\mathrm{R}^{2}=0.050$. Hence, the explanatory variance was low. 


\section{Conclusion}

This paper has developed and tested an ordinal regression model of the factors influencing operating units' frequency of use of product costs in decision making. The model tested the influence of the level of competition, the level of product customization, the importance of product costs in selling price decisions and operating unit size as independent constructs. The results indicate that the log odds of an operating unit sometimes using, and the log odds of an operating unit sometimes or often using product costs is negatively related to the importance of product costs in selling price decisions and to the number of employees employed in the operating unit, or, alternatively, the importance of product costs and the number of employees is related positively to the frequency of usage, when this is defined as the log odds of an operating unit using product costs all the time, or often or all the time in decision making.

The level of competition, product customization and annual sales revenue do not impact on the frequency of use. Given that this is exploratory research these constructs need to be tested in future research. In particular, given that there is a significant effect for size when measured by the number of employees, the marginally non-significant effect for annual sales revenue needs to be confirmed in future research.

The pseudo $\mathrm{R}^{2}$ in the ordinal regressions are low, which indicates that other constructs affect the level of use that have been omitted from the model. These constructs could include the quantity of staff in the accounting department, the quality of staff, the time available to use product costs in decision making and the level of accounting knowledge of non-accounting staff, senior management support for the use of product costs in decision making and having a person within the accounting department to promote the use product costs in decision making.

The main limitation of the research is the coding of the independent constructs on a three-point ordinal scale. This reduces the amount of data that is included in these constructs, and, hence, the discrimination between different levels of intensity of these constructs. Notwithstanding this limitation, the research illustrates the application of a research method that has been used rarely, namely ordinal regression. The method has the potential of overcoming the limitation of applying an ordinally coded dependent construct in OLS regression analysis. It is hoped that the technique described in this paper will encourage other researchers in this area to apply the ordinal regression method in future research.

\section{References}

Bender, R. \& Benner, A. (2000). Calculating ordinal regression models in SAS and S-Plus. Biometrical Journal, 42, 677-699.

Bjørnenak, T. (1997). Diffusion and accounting: The case of ABC in Norway. Management Accounting Research, 8 , 3-17.

Clarke, P. J. (1992). Management accounting practices in Irish manufacturing businesses: A pilot study, Proceedings of the Annual Conference 1992, The Irish Accounting and Finance Association, 17-34.

Clarke, P. J. (1997). Management accounting practices in large Irish manufacturing firms. Irish Business and Administrative Research, 18, 136-152.

Cohen, J. R. \& Paquette, L. (1991). Management accounting practices: Perceptions of controllers. Journal of Cost Management for the Manufacturing Industry, 5(3), 73-83.

Cooper, R. \& Kaplan, R. S. (1987). How cost accounting systematically distorts product costs. In W. J. Burns, and R. S. Kaplan (Eds.), Accounting and management: Field study perspectives (pp. 204-228). Boston, MA: Harvard Business School Press.

Dean, G. W., Joye, M. P. \& Blayney, P. J. (1991). Strategic management accounting survey: Overhead cost allocation \& performance evaluation practices of Australian manufacturers. (Monograph No. 8). Sydney: Accounting and Finance Foundation, The University of Sydney.

Drury, C. \& Tayles, M. (2005). Explicating the design of overhead absorption procedures in UK organizations. British Accounting Review, 37, 47-84.

Drury, C., Braund, S., Osborne, P. \& Tayles, M. (1993). A survey of management accounting practices in UK manufacturing companies. London: Chartered Association of Certified Accountants.

Emore, J. R. \& Ness, J. A. (1991). The slow pace of meaningful change in cost systems. Journal of Cost Management for the Manufacturing Industry, 4(4), 36-45.

Green, F. B. \& Amenkhienan, F. E. (1992). Accounting innovations: A cross sectional survey of manufacturing firms. Journal of Cost Management for the Manufacturing Industry, 6(1), 58-64.

Johnson, H. T. \& Kaplan, R. S. (1987). Relevance lost: The rise and fall of management accounting. Boston, MA: Harvard Business School Press.

Joshi, P. L. (1998). An exploratory study of activity based costing practices and benefits in large size manufacturing 
companies in India. Accounting and Business Review, 5, 65-93.

Joye, M. P. \& Blayney, P. J. (1990). Cost and management accounting practices in Australian manufacturing companies: Survey results. (Monograph No. 7). Sydney: Accounting and Finance Foundation, The University of Sydney.

Kellett, B. M. \& Sweeting, R. C. (1991). Accounting innovations and adaptations: A UK case. Management Accounting Research, 2, 15-26.

Khandwalla, P. N. (1972). The effects of different types of competition on the use of management controls. Journal of Accounting Research, 10, 275-285.

Lukka, K. \& Granlund, M. (1996). Cost accounting in Finland: Current practice and trends of development. European Accounting Review, 5, 1-28.

McCullagh, P. (1980). Regression models for ordinal data (with discussion). Journal of the Royal Statistical Society B, 42, 109-142.

McCullagh, P. \& Nelder, J. A. (1989). Generalized Linear Models. New York: Chapman and Hall.

Mia, L. \& B. Clarke. (1999). Market competition, management accounting systems and business unit performance. Management Accounting Research, 10, 137-158.

Norusis, M. J. (2005). SPSS 13: Advanced statistical procedures companion. New York: Prentice Hall.

\section{Notes}

Note 1. Product customization is different to product diversity. The latter can be divided between volume diversity and support diversity. Volume diversity is similar to product customization, but support diversity is caused by products consuming resources in production departments in different proportions. As support diversity increases, then production process complexity increases and this can result in the production of customized products.

Note 2. A copy of the questionnaire is available on request.

Note 3. The results of the Mann Whitney tests are available from the author, on request. Unless stated otherwise, all statistical tests are two-tailed tests and all statistical significance levels are at the $\mathrm{p}=0.05$ level.

Note 4. There are various ways of defining the link function depending upon the distribution of the dependent construct. The results of the empirical research revealed that this link function was the best fitting of all the possible link functions. Examples of other forms of the link function are provided in Norusis (2005).

Note 5 . There is no need to include the probability of sometimes using, often using or using product costs all the time because the probability of this event is 1 .

Note 6. A factor analysis with a varimax rotation confirmed that the two, two-item measures of competition and product customization each loaded on to a single factor. The Cronbach's alphas for competition and product customization were 0.842 and 0.804 respectively, which indicated a satisfactory level of reliability.

Note 7 . These results would have been obtained if the dependent construct had been reverse coded. In this case, the sign of the ordinal regression coefficients would reverse. 
Table 1. Distribution of responses for the model constructs ${ }^{\mathrm{a}}$

\begin{tabular}{|c|c|c|c|c|}
\hline & Score 1 & Score 2 & Score 3 & Total \\
\hline & $(\%)^{\text {No. }}$ & (\%) & $\begin{array}{l}\text { No. } \\
(\%)^{\text {Non }}\end{array}$ & $(\%)^{\text {No. }}$ \\
\hline $\begin{array}{l}\text { Frequency of use of product } \\
\text { costs in decision making }\end{array}$ & $\begin{array}{r}24 \\
(10.0)\end{array}$ & $(32.9)^{79}$ & $\begin{array}{l}137 \\
(57.1)\end{array}$ & $\begin{array}{l}240 \\
(100)\end{array}$ \\
\hline Level of competition & $\begin{array}{l}13 \\
(5.4)\end{array}$ & $(39.6)^{95}$ & $\begin{array}{l}132 \\
(55.0)\end{array}$ & $\begin{array}{l}240 \\
(100)\end{array}$ \\
\hline Level of product customization & $\begin{array}{r}88 \\
(36.7)\end{array}$ & $(30.8)^{74}$ & $(32.5)^{78}$ & $\begin{array}{l}240 \\
(100)\end{array}$ \\
\hline Importance of product costs & $(3.8)^{9}$ & $(8.8)^{21}$ & $\begin{array}{l}210 \\
(87.5)\end{array}$ & $\begin{array}{l}240 \\
(100)\end{array}$ \\
\hline Annual sales revenue & $\begin{array}{r}78 \\
(32.5)\end{array}$ & $\begin{array}{l}122 \\
(50.8)\end{array}$ & $(16.7)^{40}$ & $\begin{array}{l}240 \\
(100)\end{array}$ \\
\hline Number of employees & $\begin{array}{r}29 \\
(12.1)\end{array}$ & $\begin{array}{c}127 \\
(52.9)\end{array}$ & $(35.0)^{84}$ & $\begin{array}{r}240 \\
(100)\end{array}$ \\
\hline
\end{tabular}

${ }^{\text {a }}$ Scored on a three-point scale with low score $=1$ and high score $=3$.

Table 2. Spearman rank correlation coefficients ${ }^{\mathrm{a}}$

\begin{tabular}{|l|l|l|l|l|l|l|}
\hline & \multicolumn{1}{|c|}{1} & 2 & 3 & 4 & 5 & 6 \\
\hline 1. Frequency of use & 1.000 & & & & & \\
\hline 2. Level of competition & 0.009 & 1.000 & & & & \\
\hline 3. Level of product customization & 0.100 & 0.015 & 1.000 & & & \\
\hline 4. Importance of product costs & $0.241^{* * *}$ & 0.094 & 0.119 & 1.000 & & \\
\hline 5. Annual sales revenue & 0.073 & $0.160^{*}$ & -0.036 & -0.122 & 1.000 & \\
\hline 6. Number of employees & $0.171^{* *}$ & 0.004 & -0.012 & -0.080 & $0.693^{* * *}$ & 1.000 \\
\hline
\end{tabular}

a $* \mathrm{p}<0.05, * * \mathrm{p}<0.01, * * * \mathrm{p}<0.001$ 
Table 3. Ordinal regression analysis

\begin{tabular}{|c|c|c|c|c|c|}
\hline & $\begin{array}{l}\text { Regression } \\
\text { coefficient }\end{array}$ & $\begin{array}{l}\text { Standard } \\
\text { error }\end{array}$ & $\begin{array}{l}\text { Wald } \\
\text { statistic }\end{array}$ & $\mathrm{df}$ & $\mathrm{p}$ \\
\hline $\begin{array}{l}\text { Panel A: Including annual sales } \\
\text { revenue as the measure of operating } \\
\text { unit size }\end{array}$ & & & & & \\
\hline Constant $\left(\alpha_{1}\right)$ & 1.488 & 1.028 & 2.086 & 1 & 0.148 \\
\hline Constant $\left(\alpha_{2}\right)$ & 3.515 & 1.053 & 11.155 & 1 & 0.001 \\
\hline Level of competition & -0.085 & 0.218 & 0.152 & 1 & 0.696 \\
\hline Level of product customization & 0.190 & 0.157 & 1.462 & 1 & 0.227 \\
\hline Importance of product costs & 1.028 & 0.280 & 13.487 & 1 & 0.000 \\
\hline Annual sales revenue & 0.388 & 0.198 & 3.857 & 1 & 0.050 \\
\hline $\begin{array}{l}\text { Panel B: Including number of } \\
\text { employees as the measure of operating } \\
\text { unit size }\end{array}$ & & & & & \\
\hline Constant $\left(\alpha_{1}\right)$ & 2.185 & 1.081 & 4.088 & 1 & 0.043 \\
\hline Constant $\left(\alpha_{2}\right)$ & 4.243 & 1.110 & 14.621 & 1 & 0.000 \\
\hline Level of competition & -0.053 & 0.216 & 0.060 & 1 & 0.807 \\
\hline Level of product customization & 0.187 & 0.158 & 1.399 & 1 & 0.237 \\
\hline Importance of product costs & 1.022 & 0.278 & 13.568 & 1 & 0.000 \\
\hline Number of employees & 0.625 & 0.206 & 9.240 & 1 & 0.002 \\
\hline
\end{tabular}




\title{
An Analysis on Selection Efficiency of Japanese
}

\section{Internal Supervision System}

\author{
Benxu Zou \\ Department of Management, Shengyang Sport University \\ 36 Jinqiansong East Road, Sujiatun District, Shengyang 110102, China \\ Tel: 86-24-8916-6656 E-mail: zoubenxu@163.net \\ College of Business Adiministration, Liaoning Technical University \\ Fuxin, 123000, China
}

Guoyin Shang

School of Business Administration, Northeastern University

Shenyang 110004, China

\begin{abstract}
This article, aiming at the reality of the appearance of optional governance structure between the supervision of the supervisory board and that of the board of independent directors, firstly applies the model to analyze the efficiency of this oversight pattern, and then on the basis of relative data, analyzes the status quo of internal supervision system implementation. The research shows, although there is still some doubt about whether the board of independent directors could brandish its role after being introduced into Japanese corporate governance environment, primarily it could be affirmative that this kind of introduction is efficient. Moreover, from its future trend, although internal overseeing mode of Japanese corporation could realize optimal choice by developing the superior and weeding out the inferior between the board of supervisors system and the board of independent directors system, which are sure to be co-existing and play a very important role for the time being, and the revelation from which is that no matter how to choose governance system, as a general rule to be obeyed, it should reflect definite policy direction and make spontaneity and self-organization to dominate. However, What kind of governance system to be chosen by the enterprises should be decided by China listed companies themselves during their trial and error process, while the supervising idea that monitoring departments should believe in is "invisible hands".
\end{abstract}

Keywords: The supervisory board, Independent directors, Commercial laws, Corporate governance

Since entering the new millennium, with the appearance of the new governance environment, many countries in the world set off an upsurge of revising commercial laws and company laws. Following the trend, Japan also revised its commercial law in 2002. Under the newly-revised Commercial Law, we can see that the Board of Supervisors based Japanese companies' internal supervisory model has been changed to an optional governance structure between the board of supervisors and board of independent supervisors. What is the impact of this profound change on Japanese companies' governance system and what is the implementing situation after the reform are of great concern to both the theoretical and practical world. This paper will first find out the context of the reform of Japanese commercial law, based on which an efficiency analysis of the optional internal supervisory system will then be carried out, also a current implementing situation analysis of this system based on relative data will also be conducted, in the hope of providing reliable experiential support for the construction of Chinese listed companies' Board of supervisors system and independent supervisors system and the next step of reform of corporate governance.

\section{Reform context of Japanese commercial law and the optional structure of internal supervisory system}

Since the 1990s, along with the promotion of international enterprises, foreign institutional investors have begun to intervene in the Japanese stock market; the traditional corporate mutual holdings began to have a dissolving tendency and the shareholding structure also appeared to have a decentralized trend. Among them, some powerful domestic and foreign institutional investors began to speak as a shareholder, demanding that the Japanese companies improve their governance structure. For example, the California Civil Service Retirement Fund strongly suggested that Japanese companies should set up independent director system. These initiatives and external calls had impinged on the Japanese government and business circles, but because of the resistance from Japan's business circles, as well as some members 
of Congress, the reform had not been put into legislative practice for a long time.

At the same time, along with the reform of the board of supervisors system, all walks of life in Japanese society (such as Japan Corporate Governance Forum, the Economy and Friends, etc.) also put forward suggestions to improve corporate governance, asking to reform the system of the board of directors and strengthen the governance function of stockholders and board of directors. Under the pressure of different interest groups and external appeals, how to absorb and learn the advanced concept and outstanding system from the advanced countries of Europe and the United States, how to change the prior control model to the subsequent monitoring laws, how to fully release the government controls, and increase companies' autonomy space, at the same time, strengthen the company's internal and external controls, to enhance the companies' international competitiveness in the environment of globalization have become urgent issues. Based on these, in the multi-party efforts, in April 2002, "Business Law etc., the draft amendment of some laws" was put forward in the House, asking to introduce committee system in the improvement of corporate governance structure. In May 2002, the final revision of the Japanese Commercial Code marked the formal introduction of the system of board of directors into Japan. And, according to the revised commercial law, if large companies or enterprises considered to be large companies can meet certain conditions, they can choose to set up a board of supervisors governance structure, or a committee of important property structure or committee governance structure, and small companies can only choose to board of supervisors governance system, (See Figure 1). The board of supervisors governance structure follows the original governance structure without any change; Committee of important property refers to appointing the special decision-making powers which formally solely belong to the board of directors to the committee of important property, at the same time there still exists the board of supervisors. The aim of setting up the committee of important property is to overcome the shortcomings of immobile operations due to too many directors, and it usually consists of more than 3 members. Committee governance structure includes 3 special committees, i.e. the nominating committee, the oversight committee and the remuneration committee and one or more executive managers (CEO), meanwhile, the system of the board of supervisors is abolished (Tsutiyakamisyou and Okamotokyoukiti, 2003, pages 321-322). Subsequent amendments of the Commercial Code in 2003 (May 29, July 30, August 1 all together three times) and 2004 (June 2, June 9 (2), December 1, December 3 (2) a total of six times) had no substantive changes, just made some technical level treatments.

\section{Efficiency analysis of the options of Japanese internal supervisory pattern after reformation}

According to the reformed commercial law, we can see that Japan's corporate governance structure reform didn't adopt across-the-board strategy, but a relatively free choice method. Despite still there are some doubts on whether the independent director system can function well or not in the environment of Japanese corporate governance after its introduction, but what can be certain is that this way of introduction is efficient, which can be proved by the following model.

Assuming that under Japan's governance environment, the market enterprises choosing an independent director system (or board system) has experienced three stages: at the initial point in the decision-making, enterprises can choose either the system of independent directors or the board of supervisors system, with the selecting standard being the expected governance cost and proceeds. In this paper the process is called: the initial system-selection stage. After selecting an independent director system, the enterprise will try to make the system play a role through various internal institutional arrangements, but it will still face two results: the independent director system is brought into play and it is not. However,whether the independent system is brought into play or not, the enterprise will bear the cost of selecting the independent director system (it is called governance cost of independent director system in this paper), and this phase is called the stage of trial and error system. When the enterprise went through trial and error after some time, other enterprises will make a comparison of the revenues and costs with and without the introduction of independent director system in the same system environment, and ultimately determine whether the independent director system will be chosen in the next phase, which is called in the paper : System reselecting stage. At this stage, some enterprises that have already introduced the system of independent directors may choose to reestablish their original system, however, this paper assumes that the enterprises that will make a choice are those without the system of independent directors or newly set-up enterprises.

In Figure 2, in the initial system-selection stage, if enterprises do not choose the independent director system, their practical governance revenue is 5, and the governance implementation cost of the system of independent directors is 0 . However, after selecting independent directors, the enterprise will also face with the issue that whether the independent directors can function or not. Thus, at the stage of system trial and error, if an independent director system can effectively play the role, the enterprise's governance performance will become 10 , and the final proceeds is seven ,minusing the governance cost (that is, at this time the proceeds of the independent directors) 3. Conversely, if an independent director system is not functioning, corporate governance revenue will become $5-3=2$, still with governance cost 3. After the enterprise system going through trial and error stage, it will enter the system-reselecting stage; at this stage, other companies make a choice of the future system based on the ratioof the governance revenue to 
cost. Obviously, at this time for a rational enterprise, if the system of independent directors is found not to function well, it would not choose the system of independent directors.(See Figure2)

In Figure 3, a crucial factor - government mandatory is taken into further consideration. Due to the government's intervention in the re-selection phase, the enterprise has to choose the system of independent directors even if it does not work; meanwhile those enterprises already implemented the independent director system can not abolish this system. Thus, the enterprise governance cost must always be 3, and the governance revenue can only be 5-3=2.(See Figure3)

Based on the analysis of Figure 2 and Figure 3, from a cost-benefit point of view, at the system selection stage, there is no doubt that the introducing method of Japanese independent director system has reduced the cost of system trial and error. For example, the lifelong employment and sequence of work formed by the long-term accumulation in Japanese culture have become routine in Japanese enterprises. The objective of working hard for an employee is to get the chance of promotion, however, if the system of independent directors was established, not only the number of directors would decrease, but also part of the original director positions would be taken by independent directors, which will be boycotted by staff members, consequently increasing governance cost. In addition, the companies without independent directors will arrange their own governance system according to the performance of those enterprises with independent director system. Even if in certain phase of the future, judging from the good revenues of enterprises with corporate governance, the supervisory department will require all the listed companies to introduce the system of independent directors throughlaws and regulations, which would be a buffer opportunity for those enterprises without the system of independent directors, and is more contributed to rapid integration after the system is introduced.

\section{Conclusions and revelations}

The above analysis shows that was introduced a major property commission and the Committee set-up system after the 2002 Japanese commercial law reform, and after two years of trial and error, the relevant system arrangement also becamemore and more perfect, which undoubtedly further enriched the contents of Japanese corporate governance. Although the future trend of Japan's mode of supervision will probably make an optimal choice between the board of supervisors system and the independent director system, but in the near future, the two systems will co-exist and will play an important role respectively.

Japan's reform path has also provided valuable experience for the Chinese corporate governance structure reform, which has a similar cultural background. In the reform process of China's state-owned enterprises, in order to establish modern enterprise system, from the system conversion of enterprises to the choices of corporate governance system, the mandatory system conversion is available to everywhere. It can be said that in the transitional period, many mandatory system changes has greatly accelerated the process of reform. But it is found that the system being implemented has serious deficiencies, with the prerequisite of not acknowledging the market's main body status. However, when there is no clear understanding of the effects of the existing system or there is still much room for the existing system to improve, the mandatory system changes will bring the inefficiency of system introduction. As to the introduction of the system of independent directors, in some sense it is a judgment of efficiency of the existing system. However, the foundemental reason for the fmalfunction of existing supervisory system is the existing shareholding structure. Under the same shareholding structure, it is bound to appear the same agent mechanism, and some inevitable problems that will lead to malfunction of the Board of Supervisors will come into being. Trying to solve Chinese listed companies' governance problems in a short time by way of grafting and transplanting the exotic independent director system is unrealistic.

Judging from the current situation, China's future governance structure of listed companies at most has two possible models, one is to fully adopt system of independent directors while abolishing the system of board of supervisors; Another is the two systems co-exist on the basis of further clarifying functions of independent directors and board of supervisors. However, regardless of the governance system chosen, as a general rule to be obeyed, it should reflect definite policy direction and make spontaneity and self-organization to dominate. What kind of system of governance to choose, the listed companies should decide on their own in the process of trial and error; and the supervising concept that monitoring departments should hold is the "invisible hands".

\section{References}

Li, Weian and Wang, Shiquan (2005) Appraisal and Empirical Research about the Governance of Supervisor Board of China's Public Companies. Nankai Business Review, ((1):4 9).

Ootsukaakiko.(1999)Structure Change of Japanese Stock Market [J]. Monthly Newspaper of Post Institute, ( (3): 27 46).

Sisidozenniti and Tsunekijyunn (2004). Law and Economics: Microeconomic Study of Enterprise Association Law. yuhikaku.

Tsutiyakamisyou and Okamotokyoukiti (2003).Corporate Governance Theory: Basic Theory and Practice[M].Tokyo: 
yuhikaku.

Wang, Shi-quan and Liu, Jin-yan. (2007) An Analysis of the Efficiency of Japanese Independent Director System. Contemporary Economy of Japan, ( (2):48 52).

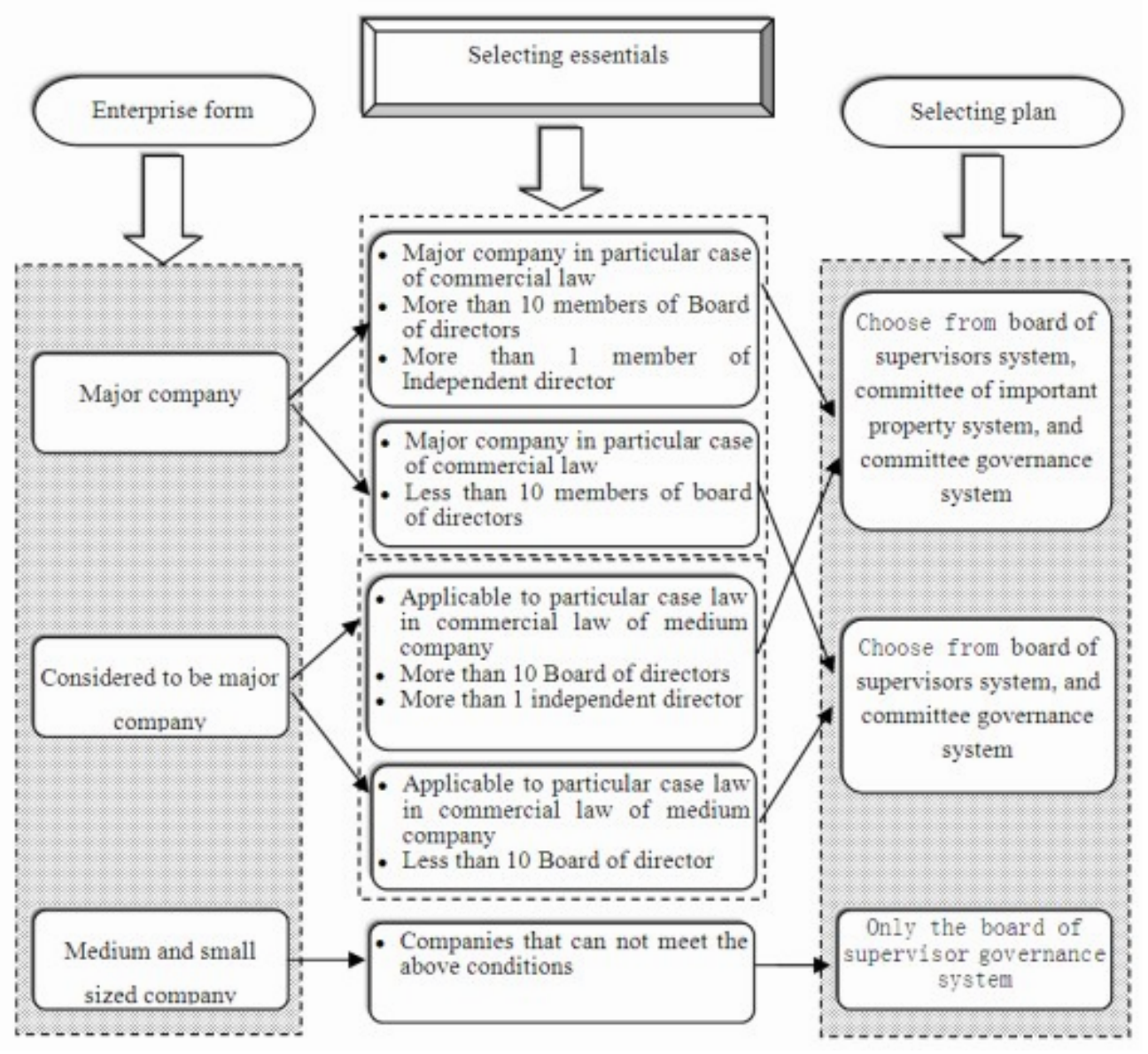

Figure 1. Enterprise Form and the Options of Corporate Governance System Source of data: 2002 Japan Commercial Code and Tsutiyakamisyou and Okamotokyoukiti (2003).Corporate Governance Theory: Basic Theory and Practice[M].Tokyo: yuhikaku, p322 (processed by the writer). 


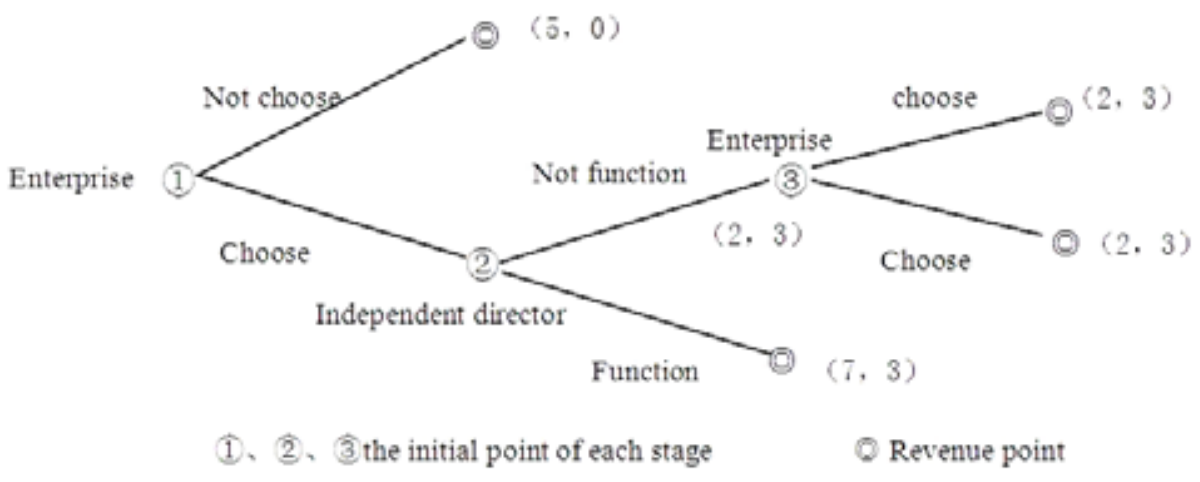

Figure 2. Revenue and Cost of Corporate Governance on the Basis of Government Mandatory System Change

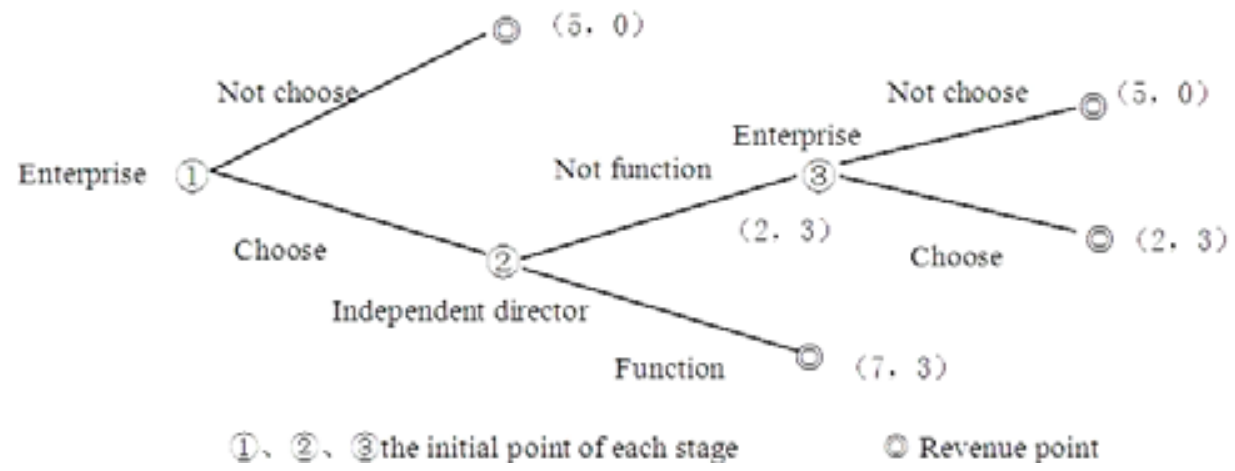

Figure 3. Revenue and Cost of Corporate Governance on the Basis of Government Mandatory System Change 


\title{
Service Quality and Student Satisfaction: A Case Study at \\ Private Higher Education Institutions
}

\author{
Hishamuddin Fitri Abu Hasan \\ Research and Planning Department \\ Public Service Department of Malaysia \\ Federal Government Administrative Centre \\ 62510, F.T Putrajaya, Malaysia \\ Tel: 60-12-500-3429 E-mail: hishamfitri@jpa.gov.my
}

\author{
Azleen Ilias \\ Rahida Abd Rahman \\ Mohd Zulkeflee Abd Razak \\ School of International Business and Finance Labuan \\ Universiti Malaysia Sabah \\ Labuan International Campus \\ 87000, F.T Labuan, Malaysia \\ Tel: 60-87-460-517Ｅ-mail: neelza80@yahoo.co.uk
}

\begin{abstract}
This study attempts to examine the relationship between service quality dimensions and overall service quality (tangibility, responsiveness, reliability, assurance and empathy) and students satisfaction. Furthermore, this study is also examine critical factors in service quality dimensions (tangibility, responsiveness, reliability, assurance and empathy) that contributes most to the satisfaction of the students. This study was conducted using a set of questionnaire to 200 Bachelor Degree students from two private higher education institutions. The study will provide results from empirical test of these relationships. The empirical results of this study can provide support for the Parasuraman's SERVQUAL (1985), which related to the factors contributing to students' satisfaction.
\end{abstract}

Keywords: Service quality, SERVQUAL, Private higher education institutions.

\section{Introduction}

\subsection{Introduction}

In today's competitive academic environment where students have many options available to them, factors that enable educational institutions to attract and retain students should be seriously studied. Higher education institutions, which want to gain competitive edge in the future, may need to begin searching for effective and creative ways to attract, retain and foster stronger relationships with students. As a private organization, it has to depend on the interaction and mechanism of the market. As a result, competition to woo as many students as possible or so-called "potential customer" may become more and more intense. To make the matter harder, as a private institution, it does not have the "privilege" to receive any subsidies or financial assistances from the government (Teo, 2001).

An expectation that cannot be fulfilled on the institutions is the key factors for students' withdrawal (Alridge and Rowley, 2001). According to the study by Kanji, Abdul Malek and Wallace (1999) do give some insights on the real situation of the Higher Education Institutions in Malaysia. Most institutions do give a great deal of importance to meeting customers' expectations which is similar to business organization, but they still lack customer awareness among the staff, and it has become a common drawback for many institutions.

This bring us to an understanding that students will have more opportunity to support their continued enrollment into higher educational institutions and on how well the educational programs and services met students' expectations for services. In this competitive market, satisfaction with services may make the difference (Parasuraman, Zeithaml and 
Berry 1996). This study attempts to explore the aspects of service quality and the level of satisfaction among the students of private higher education institutions.

\subsection{Problem Statement}

Particularly in Malaysia, National Accreditation Body (LAN) once had to reject accreditation applications of 40 programs by private higher learning institutions due to the weaknesses in core course structures. Among factors that contributed toward the problems were the lecturers' lack of skills to handle the task and failure to attain the required curriculum standard set up by LAN (Mohd Feroz Abu Bakar, 2004).

The government for example has for long not compromising on the quality of education offered and hope to see that the private higher education will provide a quality education toward the students ("We won't compromise", 2001). This of course is in-synchronization with the current trend in education industry. Former Education Minister Tan Sri Musa Mohamad, has once made a statement regarding the weakness in the private HEI. According to him, he is aware there is a change of attitude among the present students nowadays as they are getting bolder in exercising their rights to demand for quality. One of his remarks on this issue is,

"Don't be surprised if a student takes one of you to court for not teaching properly."

(Rajah and Nadarajah, 2000).

In fact this is true as an issue on professionalism of an administration and the academic staffs of the private higher institution has been raised in one of the newspaper by the frustrated student due to his/her college misguided concern on issues like college reputation by "forcing" the students to involve in charitable activities that in the end overlook the bigger issue which is their academic performance ("Unprofessional College", 2004). This of course shows that students nowadays are indeed do not wait and see for the changes to be made but will put an effort to find an effective channels to voice their grievances if the management do not demonstrate that they care towards the complaints.

The intention here is obvious and well made but the problem is, comparing to the public higher education learning, it seems the perceptions of the people toward the private higher education tend to be biased in term of quality. It seems that the majority of students and parents especially Bumiputera place their hopes on public higher education institutions. If the students fail to be offered a place there, the perception is that he or she will have a bleak future. This is something that should not happen, as even the Prime Minister himself does not want these institutions to be the "last resort options" or a poorer alternative to public universities (Ling, 2003).

\subsection{Research Question}

RQ1: Determine the relationship between service quality dimensions and satisfaction among the students in two private higher institutions?

RQ2: What are critical factors in service quality that contribute most to the satisfaction of the students?

\subsection{Research Objectives}

Generally, the purpose of this study is to determine the relationship between service quality and student satisfaction in two private higher institutions. Several factors in service quality that will be discussed and analyzed are Tangibility, Assurance, Reliability, Responsiveness and Empathy.

The purpose of this research:

(1) To examine the relationship between service quality dimensions (tangibility, responsiveness, reliability, assurance, empathy and overall service quality) and students satisfaction

(2) To examine critical factors in service quality (tangibility, responsiveness, reliability, assurance and empathy) that contributes most to satisfaction.

\subsection{Significance of the Study}

Enhancing service quality has been demonstrated across numerous industries. The quality of service that can be applied to universities, especially to private universities, differentiates them from their public counterparts. Private HEI while attempting to compete at academic levels with other HEIs should offer an added advantage to champion quality services to their students. Notably, it can even be assumed to be an important road to the competitive excellence for the service oriented organization as by neglecting these aspects of quality services will put such organization at a competitive disadvantage compared to its counterparts because most of its revenues are enrollment related thus affecting its financial health (Zammuto et al., 1996). This study is important because it is going to measure the level of service quality and the level of satisfaction among the students as have been stressed by Iacobucci, Ostrom and Grayson (1995), "Presumably, if quality programs were initiated based on marketing research- that is, the changes were market driven and customer oriented- the quality improvements should lead to customer satisfaction" (p. 296). The result from the study can be used to give valuable information on the elements and the dimensions, which have been given a priority by 
students in assessing the quality of services and satisfaction. In addition to that, this study is going to provide the conclusions and some recommendations, which are hoped that it's going to provide useful information to the private higher education institutions.

\section{Literature}

\subsection{Student Satisfaction}

Kotler and Clarke (1987) define satisfaction as a state felt by a person who has experience performance or an outcome that fulfill his or her expectation. Satisfaction is a function of relative level of expectations and perceives performance. The expectation may go as far as before the students even enter the higher education, suggesting that it is important to the researchers to determine first what the students expect before entering the university (Palacio, Meneses and Perez, 2002). In contrary, Carey, Cambiano and De Vore (2002), believe that satisfaction actually covers issues of students' perception and experiences during the college years.

While most student satisfaction study focus on the perspective of customer, researchers is facing a problem of creating a standard definition for student satisfaction thus providing a need of customer satisfaction theory to be selected and modified so that it can explain the meaning of student satisfaction (Hom, 2002). Even though it is risky to view students as customer, but given the current atmosphere of higher education marketplace, there is a new moral prerogative that student have become "customer" and therefore can, as fee payers, reasonably demand that their views be heard and acted upon (William, 2002).

\subsection{Service Quality}

A definition of quality revolves around the idea that quality has to be judged on the assessment of the user or consumer of the service. The construct of quality as conceptualized in the services literature is based on the perceived quality. Perceived quality is defined as the consumer's judgment about an entity's overall experience or superiority (Zeithaml, 1987; Zammuto et al. 1996). Similarly, Parasuraman, Zeithaml and Berry (1990) also concluded that consumer perceptions of service quality result from comparing expectations prior to receiving the service, and their actual experience of the service. Perceived quality is also seen as a form of attitude, related to, but not the same as satisfaction, and resulting from a comparison of expectations with perceptions of performance (Rowley, 1996).

Therefore, perceived service quality could be the product of the evaluations of a number of service encounters and in this case, of a student, these could range from encounters with office staff, to encounters with tutors, lecturers, the head of departments, etc (Hill, 1995). As a result, if an organization regularly provides service at a level that exceeds customer expectations, the service will be evaluated as high quality. In contrast, if an organization fails to meet customer expectations, the service will be judge as poor quality (Zammuto et al., 1996).

Generally, students have three main criteria that need to be satisfied with services. These has been labeled as Requisite encounters which essentially enable students to fulfill their study obligations; Acceptable encounters which students acknowledge as being desirable but not essential during their course of study and Functional, an encounter of a practical or utilitarian nature (Oldfield and Baron, 2000).

According to Lassar, Manolis and Winsor (2000), two most prevalent and widely accepted perspectives on service quality include the SERVQUAL model and the Technical/Functional Quality framework. Gronroos (1984) held that service quality is made up of three dimensions "the technical quality of the outcome", "the functional quality of the encounter" and "the company corporate image". He argued that in examining the determinants of quality, it is necessary to differentiate between quality associated with the process of service delivery and quality associated with the outcome of service, judged by the consumer after the service is performed.

Parasuraman, Zeithaml and Berry (1985) however listed ten determinants of service quality that can be generalized to any type of service. The ten dimensions include tangibility, reliability, responsiveness, competence, access, courtesy, communication, credibility, security and understanding. In addition, these ten dimensions were then regrouped in the well-known five dimensions in the SERVQUAL model (Parasuraman et al., 1990) which include assurance, empathy, reliability, responsiveness and tangibility.

Previous research also done by Mahiah., S. et al. (2006) also confirmed Parasuraman, Zeithaml and Berry (1985) and they suggest that increasing of sophistication of reliability, empathy, tangibility, responsiveness and assurance can increase customer satisfaction towards services rendered by Human Resource department.

\subsection{Service Quality in Higher Education}

It is interesting to identify here about the applicability of SERVQUAL to education sector, meaning that there is a suitability of applying it in higher education. Numerous studies have adapted this measurement in HEI, such as SQ in business schools (Rigotti and Pitt, 1992) and higher educational institutions (Cuthbert, 1996; Soutar and McNeil, 1996; Saaditul, Samsinar and Wong, 2000). 
In the study by Cuthbert (1996) it has been found that among the dimension in SQ, the score for tangibility (3.34) is the highest, followed by assurance (3.21), reliable (3.11), responsive (3.04) and empathy (2.58). However he added that this does not represent tangibility as a major contributor towards satisfaction of the students as he believes it is the service encounter which is the determinant factor. O'Neill and Palmer (2004) also hold the exact same idea that, although tangibility is ranked as the best in term of overall performance score, but it has been ranked as the least importance by the students compared to process and empathy. Study by Perisau and McDaniel (1997) is best described as, assurance and reliability has been identified as the most important suggesting that students are most concern with the knowledge, courtesy and ability to inspire trust and confidence which is part of the assurance dimension.

Nevertheless, there are studies that have a different opinion on the importance of tangibility dimension in service quality. Smith and Ennew (2001) outlined an interesting aspect in his research toward the SQ in higher education. He highlighted that there is difficult aspect in the choice of satisfaction perception of customer between the affective indignation and the technical functionality. For example, the particular facility consumed by the students could be judged according to how reliable they are (technical functionality) or according to their ages, appearances, courtesy and empathy (affective). The perfect reliable facility, which is not up to date, but are capable of carrying out the task, may still be negatively rated if the users expect the university to provide up to date facility. He also showed that there were specific supportive items known as peripheral aspect and the university facilities, which students consume such as cafeterias and residential accommodation that will directly and indirectly have a significant impact on the evaluation of the university. Based on the study by Umbach and Porter (2002), it also appears that the size or a number of faculties within a department in HEI is important in explaining student satisfaction.

LeBlanc and Nguyen (1997) for example stressed on the reputation as a factor, which is tied closely to management's capacity to foster an organizational climate directed at serving the needs of its customers and to the image of the HEI. It is also process-related in that, it involves an ability to inspire trust and confidence and provide personal attention to students in a professional and caring manner. In term of importance, the study has shown that perceived value is derived mainly from price/quality, a factor that is closely tied to the business school's capacity to offer sufficient services to students and convince them that they are receiving quality services in exchange for what they give by means of their tuition fees.

While Ford, Joseph and Joseph (1999) go a little bit more specific on the services in their study about service quality by comparing the importance score of service quality in higher education for the New Zealand student sample and the United States sample. They found that for the New Zealand sample, academic reputation has been ranked as the first followed by career opportunities, programme issues, cost/time, physical aspects, location and others while for the USA sample, it was found that the first rank is academic reputation, cost/time, programme issues, others, physical aspects and choice influences.

Earlier researches on service quality in higher education also often emphasized academic more than administration, concentrating on effective course delivery mechanisms and the quality of courses and teaching (Atheeyaman, 1997; Cheng and Tam, 1997; Soutar and McNeil, 1996; Griemel-Fuhrmann and Geyer, 2003). However there are also an attempt to look upon the administrative side of higher institution like the study by Kamal and Ramzi (2002), which attempt to measure student perception of registration and academic advising across different faculties and other administrative services to assure positive quality service that compliments the academic.

\subsection{Service Quality and Students'Satisfaction}

Service Quality is commonly noted as a critical prerequisite for establishing and sustaining satisfying relationship with valued customers. In this way, the association between service quality and customer satisfaction has emerged as a topic of significant and strategic concern (Cronin and Taylor, 1992). In general, perceived service quality is an antecedent to satisfaction (Spreng and Mckoy, 1996). Thus, a proper understanding of the antecedents and determinants of customer satisfaction can be seen as to have an extraordinarily high monetary value for service organization in a competitive environment (Lassar, Manolis and Winsor, 2000).

Bigne, Moliner and Sanchez (2003) found that the overall service quality have a significant relationship with satisfaction at $\mathrm{R}=0.66$. Ham and Hayduk (2003) have confirmed that, even in the higher educational settings, there is a positive correlation between perception of service quality and student satisfaction, and analyzing upon the relationship based on each of the dimension of service quality, reliability $(\mathrm{R}=0.547$; sig. $=0.000)$ has the strongest relationship followed by responsiveness and empathy $(\mathrm{R}=0.5431$; sig. $=0.000)$, assurance $(\mathrm{R}=0.492$; sig. $=0.000)$ and tangibility $(\mathrm{R}=0.423$; sig. $=0.000)$.

Elliot and Shin (2002) found that the highly significant variables in the model that appear to directly impact overall customer satisfaction with university performance are: (1) excellence of instruction in major $(0.0522 ; p<0.0002)$, (2) able to get desired classes $(0.0935 ; \mathrm{p}<0.0000)$, (3) knowledgeable advisor $(0.0517 ; \mathrm{p}<0.0000)$, (4) knowledgeable faculty (0.0406; $\mathrm{p}<0.0094)$, (5) overall quality of instruction $(0.0510 ; \mathrm{p}<0.0000)$, (6) tuition paid is a worthwhile 
investment (0.0749; $\mathrm{p}<0.0000)$, (7) approachable advisor (9.0631; $\mathrm{p}<0.0000)$, (8) safe and secure campus (0.0646; $\mathrm{p}<0.0000)$, (9) clear and reasonable requirements for major $(0.0539 ; \mathrm{p}<0.0000),(10)$ availability of advisor $(0.0537$; $\mathrm{p}<0.0000)$, (11) adequate computer labs (0.0631; $<<0.0000)$, (12) fair and unbiased faculty $(0.0443 ; \mathrm{p}<0.0004)$, and (13) access to information $(-0.367 ; \mathrm{p}<0.0021)$.

\section{Methodology}

\subsection{Research Framework}

This study was adopted from Parasuraman's SERVQUAL dimensions. The dependent variable in this study is overall student satisfaction that is measured by the overall satisfaction with the HEIs. The independent variable in this study is service quality in higher education that measures the level of satisfaction with service performance. The dimensions included in this variable are tangibility, assurance, responsiveness, reliability, and empathy.

\subsection{Sample}

The samples in this study were bachelor degree students studying at a Private HEIs. For that purpose, directory from http://www.studymalaysia.com/jps/directori/senarai_ipts.shtml is use to identify the related private higher institutions that may serve as potential respondents. Respondent consists of Bachelor Degree students from Kuala Lumpur Infrastructure University College (KLiUC) and Kolej Universiti Teknologi dan Pengurusan Malaysia (KUTPM). We have distributed 230 questionnaires for every institution. Finally, 200 respondents completed and returned the questionnaires, which represents about $87 \%$ response rate.

\subsection{Instrumentation}

This study used questionnaire as a medium to obtain the data needed. There are three sections in the questionnaire, consisting of Section A: Demographic factor, Section B: Measurement of Service Quality in Higher Education and Section C: Measurement of Student Satisfaction. In this section A, four question covering from the subjects of gender, age, race or ethnicity, and their semester of study. Followed by section B: service quality in higher education and section C: student satisfaction. Instrument used in this research is adapted from Parasuraman et al. (1990) with some of the items used extracted from LeBlanc and Nguyen (1997) using the five dimensions in service quality (tangibility, assurance, reliability, responsiveness and empathy) using the Likert scale from 1 for not satisfied at all to 6 for very satisfied. In measuring student satisfaction, instrument for this variable was adapted from Atheeyaman (1997). In this variable, it has six items with Likert scale ranges from 1 for much worse than expected to 6 for much better than expected.

\subsection{Data Analysis Procedures}

The data analysis for this study conducted through 'Statistical Package for Social Science' software or SPSS version 12. The study also tested reliability of the instrument so that it enables to produce a robust and valid result.

\section{Findings}

\subsection{Profiles of the respondents}

The demographic information includes the following characteristic of participants: gender, age, semester of studies and ethnicity. The demographics information is represented in Table 1.1 based on frequency distributions and percentages.

From the 200 respondents in this study, 95 (47.5\%) are male and $105(52.5 \%)$ are females. The calculated mean age of the respondents is 23 years old with the majority of the students being 22 years old (33\%). Most of the respondents are in the fourth semester of their study $(28 \%)$, followed by fifth semester and above $(27 \%)$, second semester $(20 \%)$, third semester (14.5\%) and first semester (10.5\%). Majority of the respondents are Malay (72\%) followed by Chinese and Indian $(25 \%)$ and other ethnicity contributing about $3 \%$.

\subsection{Descriptive statistics of the variables in the model of the study}

For the dependent variable: student satisfaction contains of six items, while for the independent variable service quality, each of the dimension starting with tangibility contains 16 items, assurance 9 items, while reliability, responsiveness and empathy contains 7 items, totaling 46 items.

In Table 1.2, it shows that mean of student satisfaction was (4.17 on a 6-point scale) followed by service quality with an overall mean of 4.07 (on a 6-point scale). For each dimension, assurance scores the highest (4.44 on a 6-point scale), followed by responsiveness (4.09 on a 6-point scale), reliability (3.98 on a 6-point scale), tangibility and empathy (3.95 on a 6-point scale). The minimum score for student satisfaction is 1.00 indicating that there are students who felt that their satisfaction is much worse than expected and the maximum score is 6.00 indicating that there are some who felt that the satisfaction was much better than expected. As may seen in the Table 1.2 below, the mean for service quality is 4.07 , which can be perceived as students in these higher education institutions are actually somewhat satisfied with overall service quality. 
In Table 1.3, it can be seen that the highest mean score for item under an independent variables was "appearance of lecturers" (mean=4.89; $\mathrm{sd}=0.87$ ), followed by "friendly and courteous lecturers" $(4.76 ; 1.00)$ and "academic credentials of lecturers" $(4.77 ; 0.92)$ while the lowest score were "computers adequacy provided in the lab for students" $(3.27 ; 1.36)$ and "up-to-datedness of computers" $(3.38 ; 1.37)$ which mean that the lowest satisfaction toward the services was related to tangibility of services and the highest was related to assurance. However it can also be seen here tangibility item (appearance of lecturers) had the highest overall score. For the dependent variable (student satisfaction), the item "I am satisfied with my decision to attend this University" $(4.32 ; 0.99)$ score the highest while "If have a choice to do it all over again, I still will enroll in this University" $(3.94 ; 1.17)$ score the lowest.

\subsection{Reliability of the study}

Reliability coefficients of all variables included representing all dimensions for service quality presented in Table 1.4. All alpha coefficients are above 0.75. Previous research done by Mahiah., S. et al. (2006), support this study that seems this instruments quite reliable. For example tangibility dimension for this study (0.908) compared with Mahiah study (0.851), assurance is $0.887(0.917)$, reliability is $0.874(0.889)$, responsiveness is $0.854(0.919)$ and empathy is $0.881(0.886)$

\subsection{Relationship between Service Quality Determinants and Students'Satisfaction}

Table 1.5 indicate that there are significant and positive relationship between tangibility, assurance, reliability, responsiveness, and empathy and overall service quality to students' satisfaction. From the output, empathy has the strongest relationship with satisfaction followed by assurance, tangibility, responsiveness and reliability. The relationship between tangibility and student satisfaction is $\mathrm{r}=0.568$ meaning that tangibility has a moderate relationship toward satisfaction similar with assurance $(\mathrm{r}=0.582)$, reliability $(\mathrm{r}=0.555)$ and responsiveness $(\mathrm{r}=0.556)$. Only empathy show a stronger relationship with satisfaction with $\mathrm{r}=0.640$. The relationship between overall service quality and students' satisfaction is 0.653 meaning that the relationship is stronger than moderate. Furthermore, the results indicate that all the dimensions are highly correlated and very significant with one another. Therefore, the results proven that the service quality dimensions (tangibility, assurance, responsiveness, reliability and empathy) have a significant relationship with students' satisfaction. In fact, Mahiah., S. et al. (2006), shown that tangibility, empathy, reliability, responsiveness and assurance are highly correlated and very significant with one another.

\subsection{Critical factors in Service Quality}

In the Table 1.6, the results show that $\mathrm{R} 2=0.475$ (adjusted $\mathrm{R} 2=0.46$ ), meaning that $47.5 \%$ of the variance in students' satisfaction are explained by the five dimensions provided in the output. The $F$ statistics produced( $\mathrm{F}=29.102)$ is significant at the 0.000. From this result, tangibility (unstandardized coefficients $B$ is 0.175 at sign. $T=0.104$ ), responsiveness (unstandardized coefficients B is -0.004 at sign. $T=0.972$ ), and reliability (unstandardized coefficients B is -0.151 at sign. $\mathrm{T}=0.244$ ) are not significantly related with satisfaction.

From the results, it is apparent that two dimensions (empathy and assurance) are consistently more significant than the other dimensions (age, tangibility, responsiveness and reliability). It mean empathy and assurance are the two critical factors that contribute most to students' satisfaction. For assurance (unstandardized coefficients B is 0.406 at sign. T= 0.001 ) and empathy (unstandardized coefficients $\mathrm{B}$ is 0.498 at sign. $\mathrm{T}=0.000$ ) are significantly related with satisfaction.

\section{Discussion and Conclusion}

In this final section of the study, discussions on the important findings of the study will be reviewed in terms of its significance and support by other researches. This study attempts to examine the relationship between service quality dimensions (tangibility, responsiveness, reliability, assurance, empathy and overall service quality) and students satisfaction, and secondly to examine critical factors in service quality (tangibility, responsiveness, reliability, assurance and empathy) that contributes most to satisfaction.

\subsection{Discussion}

The Research Question 1 (RQ1) indicates five-service quality (tangibility, responsiveness, reliability, assurance and empathy) and overall service quality has strong relationship with students' satisfaction. The result is consistent with the finding by Ham and Hayduk (2003) and Bigne et al. (2003) that found there is a positive relationship between service quality and student satisfaction. In the study, empathy $(\mathrm{r}=0.640)$ has the strongest relationship followed by assurance $(\mathrm{r}=0.582)$, tangibility $(\mathrm{r}=0.568)$, responsiveness $(\mathrm{r}=0.555)$ and reliability $(\mathrm{r}=0.556)$. In addition, the relationship between overall service quality and students' satisfaction is 0.653 meaning that the relationship is stronger than moderate. Seeing that tangibility has a stronger relationship than responsiveness and reliability bring the researcher back to what Umbach and Porter (2002) have been stressing on earlier, seeing it as a compliment to the services provided in higher education in such to enhance satisfaction. Smith and Ennew (2001) also agree and the way they see it, the peripheral aspects and facilities will have a direct and indirect effect on the evaluation of higher institution. It is found that, although the dimensions in service quality are important but assurance is found to be one of the most important (Perisau and 
McDaniel, 1997). Consistent with what has been depicted by Soutar and McNiel (2003) in their research, stating that although all dimensions is service quality are actually useful in explaining student satisfaction, but that does not mean that all dimensions are significant. It proven that assurance is one of the dimensions that are significantly related with satisfaction meaning that students in higher institution are actually concern with the knowledge, courtesy and ability to inspire trust and confidence.

Cuthbert (1996), in his study has mentioned that the most important contributor to satisfaction is actually due to the service encounter. Soutar and McNeil (1997) also conclude the same opinion by seeing it from perspective of communication. This finding corresponds with Danielson (1998) found that when students expressed satisfaction with their college experiences, these situations seem to be centered on involvement and contact with people.

By sharing the same fundamental nature, it confirmed that empathy plays a crucial and an influential role toward satisfaction because referring back to the meaning of empathy; it defined as "being able to communicate care and understanding through the interpersonal skills of the staff and student-friendly policies and procedures". O'Neill and Palmer (2004) said empathy is a dimension that is significant with satisfaction, although the strongest support for this finding is actually from Maushart (2003) as he found that when student show a high satisfaction with their college experience, it is due to the formal and informal contact with their lecturer. It is understandable to the reason why the contact with the lecturers seem to play an important role because according to Clewes (2003) the process of teaching and learning is actually the central part to students' evaluation of service quality. It could have an effect toward students' evaluation on satisfaction. In this study, the Research Question 2 (RQ 2) indicates that assurance (unstandardized coefficients $\mathrm{B}$ is 0.406 at sign. $\mathrm{T}=0.001$ ) and empathy (unstandardized coefficients $\mathrm{B}$ is 0.498 at sign. $\mathrm{T}=0.000$ ) are significantly related with satisfaction are critical factors that contribute most to the satisfaction of the students.

\subsection{Conclusion}

From the results, it is clear that service quality has significant positive relationship with student satisfaction. Thus, it confirms what other literature try to suggest here, which is by improving service quality, it may potentially improve the students' satisfaction as well and that is the priority of the private higher institutions due to the fact that they have to compete to earn interest from the students to study there. It is important to verify here that from the regression analysis, two dimensions in service quality empathy and assurance are the most critical factor in explaining students' satisfaction. Whatever done to increase empathy and assurance in service quality therefore will help students to give better evaluation to their satisfaction.

\subsection{Limitation and Recommendation}

Service quality has been widely accepted as an antecedent of satisfaction and neglecting it may jeopardize the competitiveness of an organizations as satisfaction and competitiveness of a service related organizations are inter-related. For that, denying or neglecting the importance of service quality is the same like risking the continuation and the competitiveness of the institutions because by taking it into consideration service quality can actually explain almost $48 \%$ variance in satisfaction. More than that, by focusing on critical factor in service quality especially empathy and assurance mean that the institution is paving a way toward a better evaluation in satisfaction.

(1) One of the limitation in this study is to the context of respondents is very limited to only two private higher institutions that offered bachelor degree courses. As this private higher institutions do offer courses for the diploma and certificate courses, than it should be reasonable that they too are included in the future research.

(2) Further study is suggest to make a comparative study to investigate whether there are any differences in service quality and student satisfaction between public higher institutions and private higher institutions.

(3) Further study should also take serious consideration in terms of accessibility to the data collection because most of the institutions have been very reluctant in giving good cooperation. A serious preparation towards the unexpected situation is needed thus that it is in the ability researcher to face and in control of the situation.

\section{References}

Alridge, S., \& Rowley, J. (2001).Conducting a withdrawal survey. Quality in Higher Education, 7(1), 55-63.

Atheeyaman, A. (1997) Linking student satisfaction and service quality perceptions: the case of university education. European Journal of Marketing, 31(7), 528-540.

Bigne, E., Moliner, M. A., \& Sanchez, J. (2003). Perceived quality and satisfaction in multi service organizations: The case of Spanish public services. The Journal of Services Marketing, 17 (4), 420-442.

Carey, K., Cambiano, R. L. \& De Vore, J. B. (2002). Student to faculty satisfaction at a Midwestern university in the United States. HERDSA, 93-97. Retrieved August $28^{\text {th }}$ 2004, from www.ecu.edu.au/conferences/herdsa/main/papers/ref/pdf/ Carey.pdf

Cheng, Y. T., \& Tam, W. M. (1997). Multi-models of quality in education. Quality Assurance in Education, 5(1), $22-31$. 
Clewes, D. (2003). A Student-centred Conceptual Model of Service Quality in Higher Education. Quality in Higher Education, 9(1), 69-85.

Cronin, J. J. Jr., \& Taylor, S. A. (1992). Measuring service quality: a re-examination and extension. Journal of Marketing, 56, 55-68.

Cuthbert, P. F. (1996). Managing service quality in HE: is SERVQUAL the answer? Part 2. Managing Service Quality, 6(3), 31-35.

Danielson, C. (1998). Is satisfying college students the same as decreasing their dissatisfaction? AIR 1998 Annual Forum Paper. Paper presented at the Annual Forum of the Association for Institutional Research (38th, Minneapolis, MN, May 17-20, 1998), US Michigan.

Elliot, K. M., \& Shin, D. (2002). Student satisfaction: an alternative approach to assessing this important concept. Journal of Higher Education Policy and Management, 24(2), 197-209.

Ford, J. B., Joseph, M., \& Joseph, B. (1999). Importance-performance analysis as a strategic tool for service marketers: the case of service quality perceptions of business students in New Zealand and the USA. The Journal of Services Marketing, 13(2), 171-186.

Griemel-Fuhrmann, B., \& Geyer, A. (2003). Students' evaluation of teachers and instructional quality-analysis of relevant factors based on empirical evaluation research. Assessment \& Evaluation in Higher Education, 28 (3), $229-238$.

Gronroos, C. (1984). A service quality model and its marketing implications. European Journal of Marketing, 18(4), 36-44.

Ham, L., \& Hayduk, S. (2003). Gaining competitive advantages in higher education: analyzing the gap between expectations and perceptions of service quality. International Journal of Value-Based Management, 16 (3), $223-242$.

Hom, W. (2002). Applying Customer Satisfaction Theory to Community College Planning of of Student Services. IJournal. Retrieved January $7^{\text {th }} 2004$, from http://www.ijournal.us/ issue_02/ij_issue02WillardHom_01.htm

Iacobucci, D., Ostrom, A., \& Grayson, K. (1995).Distinguishing service quality and customer satisfaction: the voice of the consumer. Journal of Consumer Psychology, 4(3), 277-303.

Kamal Abouchedid, \& Ramzi Nasser (2002). Assuring quality service in higher education: registration and advising attitudes in a private university in Lebanon. Quality Assurance in Education, 10(4), 198-206.

Kanji, G. K., Abdul Malek bin A.Tambi, \& Wallace, W. (1999). A comparative study of quality practices in higher education institutions in the US and Malaysia. Total Quality Management, 10(3), 357-371.

Kotler, P., \& Clarke, R. N. (1987). Marketing for health care organizations. Englewood Cliffs, NJ: Prentice-Hall.

Lassar, W. M., Manolis, C., \& Winsor, R. D. (2000). Service quality perspectives and satisfaction in private banking, Journal of Service Marketing, 14 (3), 244-271.

LeBlanc, G., \& Nguyen, N. (1997). Searching for excellence in business education: an exploratory study of customer impressions of service quality. International Journal of Educational Management, 11(2), 72-79.

Ling, C. S. (April 09, 2003). Equal quality education' at private centers. New Strait Time - Management Times.

Mahiah., S., Suhaimi., S., \& Ibrahim., A.(2006). Measuring the level of customer satisfaction among employees of human Resource Division. Advances in Global Business Research 2006. Vol. 3. No.1. ISSN: 1549-9332.

Maushart, J. (December 4, 2003). Study says students are satisfied with college experience. The Daily Aztec, San Diego State U.

Mohd Feroz Abu Bakar (19 ${ }^{\text {th }}$ October 2004). LAN tolak 40 program IPTS. Berita Harian, 3.

O’Neill, M. (2003). The influence of time on student perceptions of service quality: The need for longitudinal measures, Journal of Educational Administration, 41(3), 310-324.

Oldfield, B. M. \& Baron, S. (2000). Students perception of service quality in a UK university business and management faculty. Quality Assurance in Education, 8 (2), 85-95.

O'Neill, M. A., \& Palmer, A. (2004). Importance-performance analysis: a useful tool for directing continuous quality improvement in higher education. Quality Assurance in Education, 12(1), 39-52.

Palacio, A. B., Meneses, G. D. \& Perez, P. J. P. (2002).The configuration of the university image and its relationship with the satisfaction of students. Journal of Educational Administration, 40(5), 486-505.

Parasuraman, A., Zeithaml, V. A., \& Berry, L. L (1996). The behavioral consequences of service quality. Journal of Marketing, 60(2), 31-46.

Parasuraman, A., Zeithaml, V. A. \& Berry, L. L. (1990). Five imperatives for improving service quality. Sloan 
Management Review, 29-38.

Parasuraman, A., Zeithaml, V. A., \& Berry, L. L. (1985). A conceptual model of service quality and its implications for future research. Journal of Marketing, 49, 41-50.

Parasuraman, A., Zeithaml, V., \& Berry, L. (1988). SERVQUAL: a multiple item scale for measuring consumer perceptions of service quality. Journal of Retailing, 6(1), 12-36.

Perisau S. E., \& McDaniel, J. R. (1996). Assessing service quality in schools of business. International Journal of Quality and Reliability Management, 14(3), 204-218.

Rajah, D., \& Nadarajah, V. (August 8th, 2000). Go for quality: Musa suggests methods for varsities to improve, New Strait Time, 1 .

Rowley, J. E. (1996).Customer compatibility management: an alternative perspective on student-to-student support in higher education. International Journal of Educational Management, 10(4), 15-20.

Saaditul Ibrahim, Shamsinar Md SIdin \& Wong Chee Meng (2000). Customer satisfaction towards service quality of higher education in Malaysia. Seminar FEP 2000 Pulau Pinang, 20 - 23 October 2000. Retrieved November $9^{\text {th }}, 2004$, from http://www.econ.upm.edu.my/ repport/mgm11b.html.

Sekaran, U. (1992). Research method for business: A skill building approach. New York: John Wiley \& Sons Inc.

Smith, R. \& Ennew, C. (2001, January). Service quality and its impact on word of mouth communication in higher education. Online: http://www.unim. nottingham.ac.uk/dbm/papers/ 2001-01.pdf. on $15^{\text {th }}$ September 2004.

Solomon, M. R. (1996). Consumer behavior. Englewood Cliffs, NJ: Prentice-Hall.

Soutar, G. \& McNeil, M. (1996). measuring service quality in a tertiary institution. Journal of Educational Administration, 34(1), 72-82.

Spreng, R. A. \& Mackoy, R. D. (1996). An empirical examination of a model of perceived service quality and satisfaction, Journal of Retailing, 72(2), 52-64.

Teo, C. L. (October $21^{\text {st }}$ 2001). Realities of private institution. New Strait Time, 4.

Umbach, P. D. \& Porter, S. R. (2002). How do academic departments impact student satisfaction? Understanding the contextual effects of departments. Research in Higher Education, 43(2), 209 - 234.

Unprofessional College. (2004, November $\left.1^{\text {st }}\right)$. Harian Metro, 11.

We won't compromise on quality of private higher education, says Hon. (April 02 $2^{\text {nd }}, 2001$ ). New Strait Time, 4.

William, J. (2002). The student satisfaction approach: student feedback and its potential role in quality assessment and enhancement. 24 ${ }^{\text {th }}$ EAIR Forum, Prague, 8-11 September.

Zammuto, R. F., Keaveney, S. M. \& O'connor, E. J. (1996). Rethinking student services: assessing and improving service quality. Journal of Marketing in Higher Education, 7(1), 45-69.

Zeithaml, V. (1987). Defining and relating price, perceived quality and perceived value. Cambridge, MA: Marketing Science Institute. 
Table 1.1 Profile of Respondents

\begin{tabular}{|c|c|c|}
\hline Variables & Frequency (n) & Percentage (\%) \\
\hline \multicolumn{3}{|l|}{ Gender } \\
\hline Male & 95 & $47.5 \%$ \\
\hline Female & 105 & $52.5 \%$ \\
\hline \multicolumn{3}{|l|}{ Age } \\
\hline 21 & 40 & $20.0 \%$ \\
\hline 22 & 66 & $33.0 \%$ \\
\hline 23 & 63 & $31.5 \%$ \\
\hline 24 & 20 & $10.0 \%$ \\
\hline 25 & 6 & $3.0 \%$ \\
\hline 26 & 2 & $1.0 \%$ \\
\hline 28 & 2 & $1.0 \%$ \\
\hline 29 & 1 & $0.5 \%$ \\
\hline \multicolumn{3}{|l|}{ Mean age $=22.54$} \\
\hline \multicolumn{3}{|l|}{ Ethnicity } \\
\hline Malay & 144 & $72.0 \%$ \\
\hline Chinese & 25 & $12.5 \%$ \\
\hline Indian & 25 & $12.5 \%$ \\
\hline Others & 6 & $3.0 \%$ \\
\hline \multicolumn{3}{|l|}{ Semester } \\
\hline First Semester & 21 & $10.5 \%$ \\
\hline Second Semester & 40 & $20.0 \%$ \\
\hline Third Semester & 29 & $14.5 \%$ \\
\hline Fourth Semester & 56 & $28.0 \%$ \\
\hline Fifth and Above & 54 & $27.0 \%$ \\
\hline
\end{tabular}

Table 1.2 Descriptive Statistics of Measures

\begin{tabular}{|l|l|l|l|l|l|l|}
\hline Variable Type & Variable Name & N & $\begin{array}{l}\text { No. of } \\
\text { item }\end{array}$ & $\begin{array}{l}\text { Minimum } \\
\text { Score }\end{array}$ & $\begin{array}{l}\text { Maximum } \\
\text { Score }\end{array}$ & $\begin{array}{l}\text { Actual } \\
\text { Means }\end{array}$ \\
\hline Dependent Y & Student Satisfaction & 200 & 6 & 1.00 & 6.00 & 4.17 \\
\hline Independent & & & & & & \\
Service Quality & & & & & & \\
X1 & Tangibility & 200 & 16 & 2.25 & 6.00 & 3.95 \\
X2 & Assurance & 200 & 9 & 1.25 & 6.00 & 4.44 \\
X3 & Reliability & 200 & 7 & 1.43 & 6.00 & 3.98 \\
X4 & Responsiveness & 200 & 7 & 1.43 & 6.00 & 4.09 \\
X5 & Empathy & 200 & 7 & 1.71 & 6.00 & 3.95 \\
\hline
\end{tabular}


Table 1.3 Questionnaire items

\begin{tabular}{|c|c|c|c|}
\hline & Question & Mean & $\begin{array}{l}\text { Standard } \\
\text { Deviation }\end{array}$ \\
\hline & Service Quality (Independent Variable) & & \\
\hline & Tangibility & & \\
\hline 1 & Appearance of Lecturers & 4.8850 & 0.87499 \\
\hline 2 & Layout of classrooms & 4.1300 & 1.13115 \\
\hline 3 & Lighting in classrooms & 4.5450 & 0.93399 \\
\hline 4 & Appearance of building and grounds & 4.0452 & 1.11598 \\
\hline 5 & Overall cleanliness & 3.7186 & 1.17688 \\
\hline 6 & Degree to which classrooms and study rooms are comfortable & 4.0150 & 1.06322 \\
\hline 7 & Decoration and atmosphere & 3.8700 & 1.13558 \\
\hline 8 & Appearance of personnel & 4.2350 & 1.12521 \\
\hline 9 & Available of parking & 3.6566 & 1.38638 \\
\hline 10 & The degree to which curriculum is up to date & 4.1005 & 1.04927 \\
\hline 11 & Number of courses offered & 4.3131 & 0.94677 \\
\hline 12 & Computers adequacy provided in the lab for students & 3.2650 & 1.36163 \\
\hline 13 & 'Up-to-datedness' of computers & 3.3800 & 1.36562 \\
\hline 14 & 'Up-to-datedness' of software used in computers & 3.4824 & 1.26269 \\
\hline 15 & Access to the Internet/e-mail & 3.5550 & 1.23475 \\
\hline \multirow[t]{2}{*}{16} & The organizational culture, belief and value in this university & 4.0408 & 1.03694 \\
\hline & Assurance & & \\
\hline 17 & Friendly and courteous university staffs & 4.1809 & 1.11348 \\
\hline 18 & Friendly and courteous lecturers & 4.7626 & 1.00719 \\
\hline 19 & Lecturers research efficiency/productivity & 4.5900 & 0.88647 \\
\hline 20 & Academic credentials of lecturers & 4.7700 & 0.92269 \\
\hline 21 & Lecturers are innovative and agents of change & 4.5377 & 0.90305 \\
\hline 22 & The degree to which university involve with the community & 4.2727 & 0.90305 \\
\hline 23 & University's staffs knowledge on rules and procedures & 4.3266 & 0.98926 \\
\hline 24 & Security measures at your university & 4.1364 & 1.05993 \\
\hline \multirow[t]{2}{*}{25} & $\begin{array}{l}\text { Communication skills: courses are well taught by the lecturers in this } \\
\text { university }\end{array}$ & 4.4400 & 0.86611 \\
\hline & Reliability & & \\
\hline 26 & Registration is timely and error-free & 3.5228 & 1.27204 \\
\hline 27 & This university keeps its records accurately & 3.8878 & 1.16692 \\
\hline 28 & The general reliability of lecturers ie. keeps time/don't cancel classes & 4.3550 & 1.06991 \\
\hline 29 & Staff sincere interest in solving student's problem & 3.9000 & 1.30326 \\
\hline 30 & This university provides its services at a time it promises to do so & 3.8100 & 1.03889 \\
\hline 31 & Teaching capability of lecturers/proficiency & 4.3150 & 0.96978 \\
\hline \multirow[t]{2}{*}{32} & Lecturers sincere interest in solving student's problem & 4.1106 & 1.09075 \\
\hline & Responsiveness & & \\
\hline 33 & Availability of personnel to assist you & 3.9850 & 1.07730 \\
\hline
\end{tabular}




\begin{tabular}{|l|l|l|l|}
\hline 34 & Availability of lecturers to assist you & 4.5381 & 0.97144 \\
\hline 35 & Lecturers capacity to solve problems when they arise & 4.4600 & 1.07899 \\
\hline 36 & Staffs capacity to solve problems when they arise & 4.0253 & 1.11945 \\
\hline 37 & $\begin{array}{l}\text { I seldom get the 'run-around" when seeking information on this } \\
\text { University }\end{array}$ & 3.9250 & 1.18168 \\
\hline 38 & Channels for expressing student complaints are readily available & 3.8300 & 1.11684 \\
\hline 39 & Queries are dealt with efficiently and promptly & 3.8593 & 1.26742 \\
\hline 40 & Empathy & Administration has students' best interest at heart & \\
\hline 41 & Access to computer facilities is accommodate with students' convenient & 3.7300 & 1.18990 \\
\hline 42 & Access to study rooms is accommodate with students' convenient & 3.9500 & 1.22253 \\
\hline 43 & Staff are willing to give students individual attention & 3.8200 & 1.11075 \\
\hline 44 & $\begin{array}{l}\text { The extent to which lecturers are sympathetic and supportive to the } \\
\text { needs of students }\end{array}$ & 4.4322 & 0.87281 \\
\hline 45 & Opening hour of computer rooms to the students & 3.8550 & 1.25773 \\
\hline 46 & University are fair and unbiased in their treatment of individuals students & 4.0500 & 1.11522 \\
\hline & Student Satisfaction (Dependent Variable) & & \\
\hline 1 & I am satisfied with my decision to attend this University & 4.3166 & 0.99254 \\
\hline 2 & If have a choice to do it all over again, I still will enroll in this University & 3.9397 & 1.17051 \\
\hline 3 & My choice to enroll in this University is a wise one & 4.1350 & 1.04990 \\
\hline 4 & I am happy on my decision to enroll in this University & 4.2400 & 1.03817 \\
\hline 5 & I did the right decision when I decided to enroll in this University & 4.1750 & 1.08641 \\
\hline 6 & I am happy that I enrolled in this University & 4.2100 & 1.09172 \\
\hline
\end{tabular}

Table 1.4 Reliability Results

\begin{tabular}{|l|l|l|l|l|}
\hline Variable Type & Variable Name & No. of item & Actual Test $(\alpha)$ & Mahiah. S. \\
\hline Dependent & Student Satisfaction & 6 & 0.938 & \\
\hline Independent & & & & \\
Service Quality & & & & \\
X1 & Tangibility & 16 & 0.908 & 0.851 \\
X2 & Assurance & 9 & 0.887 & 0.917 \\
X3 & Reliability & 7 & 0.874 & 0.889 \\
X4 & Responsiveness & 7 & 0.854 & 0.919 \\
X5 & Empathy & 7 & 0.881 & 0.886 \\
\hline
\end{tabular}


Table 1.5 Correlation Results

\begin{tabular}{|c|c|c|c|c|c|c|c|}
\hline Variable Type & $\mathrm{Y}$ & $\mathrm{X} 1$ & $\mathrm{X} 2$ & $\mathrm{X} 3$ & $\mathrm{X} 4$ & $\mathrm{X} 5$ & $\mathrm{X} 6$ \\
\hline \multicolumn{8}{|l|}{ Dependent } \\
\hline$Y=$ Satisfaction & 1.00 & & & & & & \\
\hline \multicolumn{8}{|l|}{ Independent } \\
\hline X1-Tangibility & $0.568 * *$ & 1.00 & & & & & \\
\hline X2-Assurance & $0.582 * *$ & $0.699 * *$ & 1.00 & & & & \\
\hline X3-Reliability & $0.555^{* *}$ & $0.728 * *$ & $0.789 * *$ & 1.00 & & & \\
\hline X4-Responsiveness & $0.556^{* *}$ & $0.669 * *$ & $0.776^{* *}$ & $0.847 * *$ & 1.00 & & \\
\hline X5-Empathy & $0.640 * *$ & $0.688 * *$ & $0.623 * *$ & $0.763 * *$ & $0.747 * *$ & 1.00 & \\
\hline X6-Overall Quality & $0.653 * *$ & $0.899 * *$ & $0.867 * *$ & $0.914 * *$ & $0.885 * *$ & $0.849 * *$ & 1.00 \\
\hline
\end{tabular}

Table 1.6 Regression Results

\begin{tabular}{|l|l|l|l|l|l|}
\hline Table & 1.6. & Regression & Results & Table & 1.6. \\
\hline Table & 1.6. & Regression & Results & Table & 1.6. \\
\hline Table & 1.6. & Regression & Results & Table & 1.6. \\
\hline Table & 1.6. & Regression & Results & Table & 1.6. \\
\hline Table & 1.6. & Regression & Results & Table & 1.6. \\
\hline Table & 1.6. & Regression & Results & Table & 1.6. \\
\hline Table & 1.6. & Regression & Results & Table & 1.6. \\
\hline
\end{tabular}

$\mathrm{R}=0.689$

$\mathrm{R} 2=0.475$

Adjusted R2 $=0.459$

F Change $=29.102 \quad$ Sig. $F=0.000 \quad N=200$

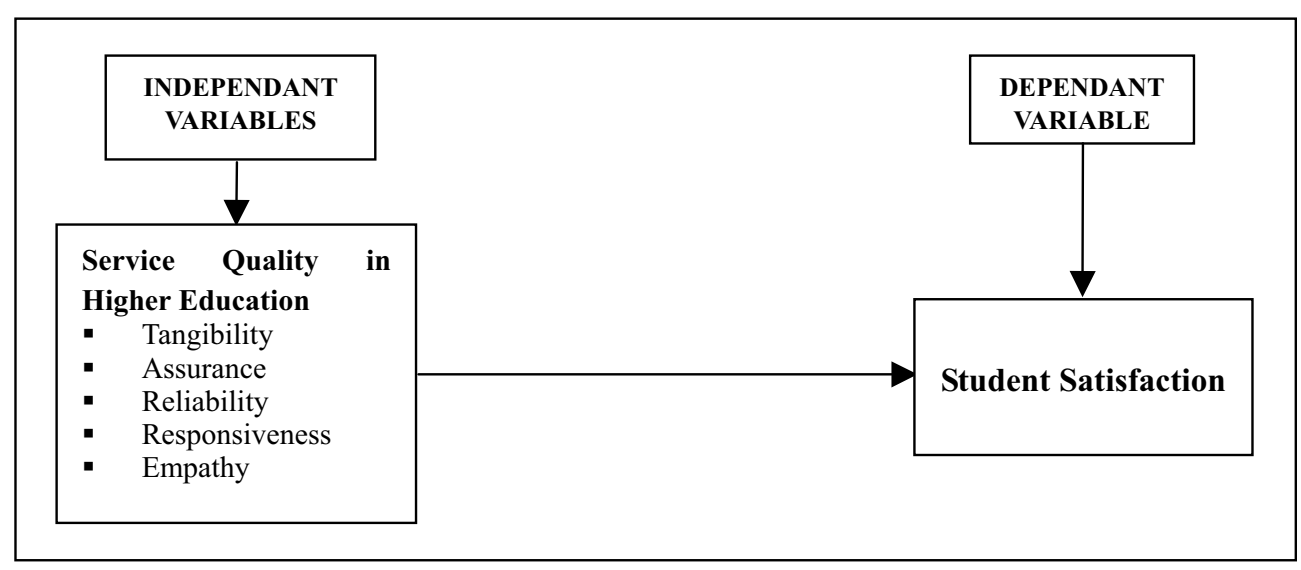

Figure 3.1 Research Framework 


\title{
Mature Cluster's Risk Evaluation
}

\author{
Fei Gao, Kai Li, Yaning Li \\ School of Business Administration, Northeastern University, Shenyang 110004, China \\ Tel: 86-131-4982-3459 E-mail: fgao@mail.neu.edu.cn
}

The research is financed by National Natural Foundation of China.No.70772097.

\begin{abstract}
In view of the adverse effect of declining cluster, a method of analyzing and assessing declining risks of mature cluster is studied. Through analyzing causes of declining risks, an evaluation index system for declining risks is built. According to the index system, the characteristic patterns of different risk levels are described. Owing to the complexity and uncertainty of cluster system, a TOPSIS comprehensive evaluation method based on fuzzy nearness degree is proposed to assess declining risks.
\end{abstract}

Keywords: Cluster, Decline, Risk, Fuzzy nearness degree

\section{Introduction}

Cluster does not always develop forward. Its evolution presents a nonlinear trajectory. Declining cluster's adverse effects attract people's attention to the study of declining risks of cluster. Tichy (1998, p.215) discusses the life cycle and structural risks of cluster. On the basis of Tichy's research, Fritz (1998, p.180) analyzes cyclical risks of cluster. Bent Dalum (2005, p.230) digs out causes of cluster's risks from dimensions of Technological Change and Institutional Change. Harrison (1994, p.5) and Pouder (1996, p.1192) analyze declining risks of cluster with the knowledge of New Economic Sociology. It should be pointed out that clusters at different phases of their life cycle are faced with different risks. Above researches haven't aimed at risks of different phases specifically and lacks qualitative evaluation on risks, which increases the difficulties in risk management of cluster.

In view of mature cluster's importance to the development of regional economy, this paper focuses research on mature cluster's risks and establishes mathematical evaluation model of risk level through analyzing risks' features. Owing to the complexity and uncertainty of cluster system, a TOPSIS comprehensive evaluation method based on fuzzy nearness degree is proposed, so as to avoid subjective arbitrariness in classification and weight assignment of linear aggregation model.

\section{Feature analysis on mature cluster's risks}

\subsection{Causes of mature cluster's risks}

Based on researches of Tichy and Fritz, Cai Ning (2003, p.60) divides the declining risks of cluster into "cyclical risks", "structural risks" and "network risks". Cyclical risks happen suddenly and can not be artificially controlled. It is caused by cyclical fluctuations of external economy and may occur at any phase of cluster's life cycle. Structural risks refer to the risks brought about by cluster's aging. It is primarily influenced by the advanced nature of alternative products, the extent of changes in market demands and cluster's innovation capability. Cai Ning constructs the analysis framework of cluster's "network risks" from three dimensions of network structure, network resource and network activity.

The first kind of network structure risks comes from network structure's effects on cluster's innovation capability. Håkansson (2006, p.256) believes that network structure takes on the functions of organizing firms' innovation activities. Markusen (1996, p.300) points out that the more mature a cluster is, the more likely it becomes a closed network. The closed cluster's product network and knowledge network reduce ties with outside, and actors within cluster can't be aware of external changes timely. As continuous increasing of cluster's network intensity and network density, the high degree of knowledge flowing within cluster makes most firms depend on technology imitation and lost of enthusiasm on technology innovation. The second kind of network structure risks arises from high degree of asset specificity. Taking Tichy's viewpoint as a reference, Hub-and-Spoke Cluster whose center is large leading firm has the biggest risks. When such kind of cluster is at its maturity phase, it is characterized with dependence of small firms on large leading firms, which induces the risks of over-specialization and technology rigidity. Once a central firm fails, the whole cluster will be affected.

Network resources including culture, trust and material resources also give rise to network risks. Burt (2000, p.350) 
points out that over-embedded in a network atmosphere will reduce the inflow of new information and induce rigidity risks. Bennett and Harrison (1994, p.6) points out that the regional embedded network are coordinated and managed by trust mechanism. However, this kind of non-expansion trust based on genetic, blood and geographical relationships may be temporary, because the radius of cooperation between firms in this kind of network are short, which leads to the fierce competition. At the same time, firms embedded in the same network atmosphere are likely to have the same strategy when facing the same situation, which reduces the chances of success and make markets crowded.

Actors' activities are also important factors giving rise to risks of mature cluster. Porter (1998, p.80)points out actors' connection with each other by network activities will lead to additional management cost of network. Cai Ning (2003, p.60) believes that incomplete contract, moral hazard, opportunism and lazy behaviors may increase the costs of network, resulting in the weakening of network's advantages. As network costs increased, firms and intermediary institutions withdrawal from cluster gradually, leading to the breakage of industrial chain and the decrease of service level, which further accelerates cluster's declining.

\subsection{Features of different risk levels}

The above analysis provides theoretical basis for selection of risk indexes as showed in table 1. According to the risks level, this paper divides mature cluster's operation conditions into three kinds: normal operation, risky operation and declining operation. Linguistic variables including "low", "medium", "high", "very high" are used to describe features of different risk levels.(Table 1)

\section{Cluster's risk evaluation based on fuzzy nearness degree}

When evaluating cluster's risks, the first step is to set up an expert panel who value risk indexes on a scale of 0-10 with Delphi method. Cauchy Membership Function is selected in this paper to calculate indexes value's degree of memberships to linguistic variables. Suppose the membership functions of linguistic variables are as follows.

$$
\begin{aligned}
& \mu_{\text {low }}(x)= \begin{cases}1, & x \leq 3 \\
{\left[1+((x-3) / 2)^{2}\right]^{-1}, x>3}\end{cases} \\
& \mu_{\text {medium }}(x)=\left[1+((x-5) / 2)^{2}\right]^{-1} \\
& \mu_{\text {high }}(x)=\left[1+((x-8) / 2)^{2}\right]^{-1} \\
& \mu_{\text {veryhigh }}(x)= \begin{cases}1, & x \geq 9 \\
{\left[1+((x-9) / 2)^{2}\right]^{-1}, x<9}\end{cases}
\end{aligned}
$$

Suppose universe $\mathrm{U}$ is the set of risk indexes value, denoted as $U=\left\{u_{1}, \cdots ; u_{21}\right\} ; \mathrm{V}$ is the linguistic variables set, denoted as $V=\left\{v_{1}, \cdots, v_{4}\right\}=\{$ low, medium, high, very high $\} ; \mathrm{W}$ is the set of cluster's operation conditions, denoted as $W=\left\{w_{1}, w_{2}, w_{3}\right\}=\{$ normal operation, risky operation, declining operation $\}$.

Determine the relationship between risk indexes value and linguistic variables, namely the relationship between $U$ and $\mathrm{V}$ with formula (1)-(4). On this step, the relationship of risk index $u_{i} \in U(1 \leq i \leq 21)$ and linguistic variables set $\mathrm{V}$ is described by a fuzzy subset $\tilde{s}_{i}=\left(s_{1 i}, s_{2 i}, s_{3 i}, s_{4 i}\right)^{T}$, getting the fuzzy matrix $\tilde{S}$.

According to the relationship between linguistic variables and operation conditions showed in table 1 , namely the relationship between $\mathrm{V}$ and $\mathrm{W}$, determine the relationship between $\mathrm{U}$ and $\mathrm{W}$. On this step, the relationship of risk index $u_{i} \in U(1 \leq i \leq 21)$ and operation conditions set $\mathrm{W}$ is described by a fuzzy subset $\tilde{r}_{i}=\left(r_{1 i}, r_{2 i}, r_{3 i}\right)^{T}$, getting the fuzzy matrix $\tilde{R}$.

In order to make a fuzzy evaluation on cluster's risks level, the fuzzy subset corresponding to different level of risks are introduced as $\tilde{D}_{1}=(1,0,0), \tilde{D}_{2}=(0,1,0), \tilde{D}_{3}=(0,0,1)$.

Facts have proved that it is effective to make multi-objective decision with the method of asymmetric nearness degree. The definition of asymmetric nearness degree is 


$$
N(\tilde{A}, \tilde{B})=1-\frac{2}{n(n+1)} \sum_{k=1}^{n}\left|\mu_{A}\left(V_{k}\right)-\mu_{B}\left(V_{k}\right)\right| K
$$

When calculate the nearness degree $N\left(\tilde{r}_{i}, \tilde{D}_{j}\right)$ between $\tilde{r}_{i}(i=1,2, \cdots, 21)$ and $\tilde{D}_{j}(j=1,2,3)$, considering the difference of membership degrees that belong to different grades play different roles, $\tilde{r}_{i}$ needs to be standardized. Put $r_{j i}$ in the front. $\forall j^{\prime}, j^{\prime \prime}$, if $\left|j^{\prime}-j\right|>\left|j^{\prime \prime}-j\right|\left(\right.$ namely $j^{\prime \prime}$ is more far from $j$ ), put $r_{j^{\prime} i}$ before $\underset{j^{\prime \prime} i}{r_{j}}$. Consider another situation when $\left|j^{\prime}-j\right|=\left|j^{\prime \prime}-j\right|$, if $j^{\prime}<j^{\prime \prime}$, put $r_{j^{\prime} i}$ before $r_{j^{\prime \prime} i}$. Then, record standardized $\tilde{r}_{i}$ as $\tilde{r}_{i}^{\prime}$. Standardizing $\tilde{D}_{j}$ accordingly, get $\tilde{D}_{j}^{\prime}$. Therefore, evaluating $N\left(\tilde{r}_{i}, \tilde{D}_{j}\right)$ is equal to evaluating $N\left(\tilde{r}_{i}^{j}, \tilde{D}_{j}^{\prime}\right)$. Asymmetry nearness degree between each risk index and fuzzy subsets corresponding to different level of risks is recorded as follows:

$$
\tilde{Z}_{i}=\left(Z_{1 i}, Z_{2 i}, Z_{3 i}\right)^{T}=\left(N\left(\tilde{r}_{i}, \tilde{D}_{1}\right), N\left(\tilde{r}_{i}, \tilde{D}_{2}\right), N\left(\tilde{r}_{i}, \tilde{D}_{3}\right)\right)^{T}
$$

Ynder the whole risk indexes system, the asymmetry nearness degree between $U=\left\{u_{1}, \cdots, u_{21}\right\}$ and fuzzy subsets is

$$
Z=\left(Z_{i j}\right)_{3 \times>1}=\left(\tilde{Z}_{1}, \tilde{Z}_{2}, \cdots, \tilde{Z}_{21}\right)
$$

According to the method of TOPSIS, define referenced grade $W^{+}$and $W^{-}$as follows.

$$
\begin{aligned}
& \tilde{C}^{+}=\left(C_{1}^{+}, C_{2}^{+}, \cdots, C_{21}^{+}\right)=\left(\max _{j=1,2,3} N\left(\tilde{r}_{1}, \tilde{D}_{j}\right), \max _{j=1,2,3} N\left(\tilde{r}_{2}, \tilde{D}_{j}\right), \cdots, \max _{j=1,2,3} N\left(\tilde{r}_{21}, \tilde{D}_{j}\right)\right) \\
& \tilde{C}=\left(C_{1}, C_{2}, \cdots, C_{21}\right)=\left(\min _{i=1.2,3} N\left(\tilde{r}_{1}, \tilde{D}_{j}\right), \min _{i=1.2,3} N\left(\tilde{r}_{2}, \tilde{D}_{j}\right), \cdots, \min _{i=1.2,3} N\left(\tilde{r}_{21}, \tilde{D}_{j}\right)\right)
\end{aligned}
$$

Grade $W^{+}$is a kind of virtual evaluation grade defined by formula (8), which indicate grade $W^{+}$(ideal grade) is most proper for each risk index ; Likewise, Grade $W^{-}$is a kind of virtual evaluation grade defined by formula (9), which indicates grade $W^{-}$(Negative ideal grade) is most improper for any risk index. In order to get the evaluation result under the whole index system, the nearness degree between operation condition $\mathrm{j}$ and actual risk level of cluster is recorded as follows.

$$
\tilde{C}_{i}=\left(C_{i,}, C_{i 2}, \cdot, C_{L_{i}}\right)=\left(N\left(\tilde{r}_{1}, \tilde{D}_{i}\right), N\left(\tilde{r}_{2}, \tilde{D}_{i}\right), \cdots, N\left(\tilde{r}_{21}, \tilde{D}_{i}\right)\right),(j=1,33)
$$

Calculate the symmetry nearness degree between $\tilde{C}_{j}$ and $\tilde{C}^{+}, \tilde{C}^{-}$.

$$
\begin{gathered}
\delta\left(\tilde{C}^{+}, \tilde{C}_{j}\right)=\frac{\sum_{k=1}^{21} \mu_{C_{j}}\left(u_{k}\right)}{\sum_{k=1}^{21} \mu_{C^{+}}\left(u_{k}\right)} \\
\delta\left(\tilde{C}^{-}, \tilde{C}_{j}\right)=\frac{\sum_{k=1}^{21} \mu_{C^{-}}\left(u_{k}\right)}{\sum_{k=1}^{21} \mu_{C_{j}}\left(u_{k}\right)}
\end{gathered}
$$

Calculate $\delta\left(\tilde{C}^{+}, \tilde{C}_{j}\right) / \delta\left(\tilde{C}^{-}, \tilde{C}_{j}\right)$. If $\delta\left(\tilde{C}^{+}, \tilde{C}_{p}\right) / \delta\left(\tilde{C}^{-}, \tilde{C}_{p}\right)=\max _{j=1} \delta\left(\tilde{C}^{+}, \tilde{C}_{j}\right) / \delta\left(\tilde{C}^{-}, \tilde{C}_{j}\right)$, a conclusion could

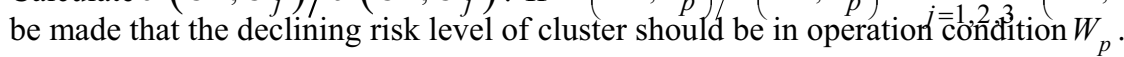

\section{Conclusion}

On the basis of extracting features of mature cluster's declining risks, this paper established a risk indexes system. A TOPSIS comprehensive evaluation method based on fuzzy nearness degree was proposed to evaluate the level of declining risks. Firstly, asymmetry nearness degrees between risk indexes system and operation conditions were calculated. Secondly, according to the method of TOPSIS, the positive and negative ideal grades were defined. Lastly, symmetry nearness degrees between each operation condition and ideal grades were compared to determine the risk level of mature cluster. The method developed in this paper is meaningful to comprehensive management and risk control of clusters. The adopted membership function could be further amended according to actual situation when in application.

\section{References}


Bent D, \&Christian R.(2005). Technological life cycles: lessons from a cluster facing disruption. European Urban and Regional Studies, 3, pp. 229-246.

Burt, \&Ronald S.(2000). The network structure of social capital. Research in Organizational Behavior, 22, pp. $345-423$. Cai Ning, Yang Shuan-zhu, \&Wu Jie-bing(2003). Research on risk of industrial clusters. China Industrial Economy, 181,pp59-64.

Fritz O..(1998) Vhhringer H, \&Valderrama M., A risk-oriented analysis of regional clusters,” In Fritz O. (Eds.), Clusters and Regional Specialization. London: Pion Limited, pp. 180-191.

Harrison, Bennett(1994). The Italian industrial districts and the crisis of the cooperative form: Part I. European Planning Studies, 1.2, pp.3-23.

Håkansson, Håkan; \&Snehota, Ivan(2006). No business is an island: The network concept of business strategy. Scandinavian Journal of Management, 22, pp. 256-270.

Markusen A(1996)..Sticky places in slippery spaces: A typology of industrial districts. Economic Geography, 72, pp. 293-313.

Porter,M.E.(1998). Clusters and the New Economics of Competition. Harvard Business Review, .98, pp. 77-90.

Pouder, Richard, \&John S(1996). Hot spots and blind spots: geographical clusters of firms and innovation . Academy of Management Review, 21, pp. 1192-1225.

Tichy G..(1998). Clusters:less dispensable and more risky than ever. In Fritz O. (Eds.), Clusters and Regional Specialization. London: Pion Limited, pp. 211-225.

Table 1. Features of different risk level

\begin{tabular}{|l|c|c|c|}
\hline \multirow{2}{*}{ Risk indexes } & Mature cluster's operation conditions \\
\cline { 2 - 4 } & $\begin{array}{c}\text { Normal } \\
\text { operation }\end{array}$ & $\begin{array}{c}\text { Risky } \\
\text { operation }\end{array}$ & $\begin{array}{c}\text { Declining } \\
\text { operation }\end{array}$ \\
\hline Regional economic conditions & High & Medium & Low \\
\hline Advanced nature of alternative products & Low & High & Very high \\
\hline Changes of market demands & Low & High & Very high \\
\hline Government support efforts & High & Medium & Low \\
\hline Completeness of scientific personnel & High & High & Low \\
\hline R \& D investment levels & High & Medium & Low \\
\hline Number of patent applications & High & Medium & Low \\
\hline Innovation achievements transformation & High & Medium & Low \\
\hline Regional knowledge flow level & High & Very high & Meidum \\
\hline Technological imitation level & Low & Very high & Very high \\
\hline Product network's openness & High & Medium & Low \\
\hline Knowledge network's openness & High & Medium & Low \\
\hline Assets specificility & Medium & Very high & Low \\
\hline Cluster's culture penetration & High & Very high & Low \\
\hline Trust and cooperation between actors & High & Very high & Low \\
\hline Convergence of strategy & Medium & Very high & Low \\
\hline Congestion in factors market & Medium & High & Very high \\
\hline Congestion in production market & Hedium & High & Very high \\
\hline Completeness of industrial chain & Medium & Low \\
\hline Service level of intermediary institutions & High & Medium & Low \\
\hline
\end{tabular}


A journal archived in Library and Arehives Canada

A journal indexed in CANADIANA(The National Bibliography)

A journal indexed in AMICUS

A leading journal in business and management

\section{International Business Research}

\section{Quarterly}

Publisher Canadian Center of Science and Education

Address 4915 Bathurst St. Unit \#209-309, Toronto, ON. M2R IX9

Telephone 1-416-208-4027

Fax 1-416-208-4028

E-mail Ibr@cesenet.org

Website www.ecsenet.org

Printer William Printing Inc.

Price CAD. $\$ 20.00$

ISSN 1913-9004 